ROY DANIEL AGUIRRE CARVAJAL

AVALIAÇÃO DA EFICIÊNCIA DE COMPENSADORES DE ATRITO IMPLEMENTADOS EM UM SISTEMA DIGITAL DE CONTROLE DISTRIBUIDO

SÃO PAULO

2015 
ROY DANIEL AGUIRRE CARVAJAL

\section{AVALIAÇÃO DA EFICIÊNCIA DE COMPENSADORES DE ATRITO IMPLEMENTADOS EM UM SISTEMA DIGITAL DE CONTROLE DISTRIBUÍDO}

Dissertação apresentada à Escola Politécnica da Universidade de São Paulo para obtenção do título de Mestre em Ciências.

Área de Concentração:

Engenharia de Sistemas

Orientador: Prof. Dr. Claudio Garcia 
Este exemplar foi revisado e corrigido em relação à versão original, sob responsabilidade única do autor e com a anuência de seu orientador.

São Paulo, de de

Assinatura do autor:

Assinatura do orientador:

Catalogação-na-publicação

Carvajal, Roy Daniel

Avaliação da Eficiência de Compensadores de Atrito Implementados em um Sistema Digital de Controle Distribuído / R. D. Carvajal -- versão corr. -- São Paulo, 2015.

p.

Dissertação (Mestrado) - Escola Politécnica da Universidade de São Paulo. Departamento de Engenharia de Telecomunicações e Controle.

1.Atrito estático 2.Compensadores de atrito 3.SDCD I.Universidade de São Paulo. Escola Politécnica. Departamento de Engenharia de Telecomunicações e Controle II.t. 
Dedicado a

minha família 


\section{Agradecimentos}

Meus sinceros agradecimentos ao professor Dr. Claudio Garcia pela grande oportunidade, orientação e apoio constante para a realização deste trabalho.

Agradeço aos meus pais por muito me influenciar com seus exemplos de dedicação, por seus conselhos, por ser o meu grande apoio e meu combustível. Aos meus irmãos por sempre me animarem e darem forças para continuar.

Aos meus amigos e companheiros do caminho Fabián Núñez Larrotta, Marco Jesús León Aldana, Jorge Luis Salazar, Oscar Rodríguez por fazerem parte da minha vida e estiverem ao meu lado sempre.

Aos colegas do grupo de pesquisa pelo conhecimento compartilhado.

Ao LAC - Laboratório de Automação e Controle da Escola Politécnica de USP pela disponibilização dos recursos físicos.

À CAPES pelo apoio financeiro 


\section{Resumo}

O objetivo principal deste trabalho de Mestrado é avaliar compensadores que tentam diminuir o efeito do atrito estático existente em válvulas de controle. Os compensadores de atrito utilizados neste trabalho foram: CR1, CR2 Knocker, Two-move, controle por modos deslizantes e controle por modos deslizantes integrador. Estes compensadores são implementados em um ambiente industrial (SDCD). Devido ao atrito, o sistema tem um comportamento não-linear, o qual pode afetar o bom rendimento de um controlador PID, sendo que o sistema em malha fechada pode ter oscilações. Então, para obter uma diminuição do efeito do atrito, empregam-se compensadores de atrito. Para implementá-los, é necessário conhecer os parâmetros do atrito existente. Portanto, a primeira parte deste trabalho consiste em uma explicação dos diferentes modelos e métodos que se vai usar neste trabalho. Também foram realizadas simulações das estratégias de controle utilizadas. Após estes tópicos, vai se identificar o modelo do sistema que conta com uma malha de controle de vazão, com o objetivo de auxiliar na sintonia do controlador PID. Depois, introduzem-se os compensadores de atrito, os quais tentam minimizar os índices ITAE (Integrated Time Absolute Error) e IAE (Integrated Absolute Error), bem como o desgaste que se produz nos equipamentos, devido ao uso (excessiva movimentação da haste das válvulas). O objetivo assumido é implementar as estratégias de controle em um software industrial. Os resultados mostraram que os compensadores CR1 e CR2 obtiveram os melhores índices de desempenho e conseguiram compensar o atrito na haste da válvula de controle.

Palavras-chave: Atrito, SDCD, Modos Deslizantes, válvulas de controle, compensadores de atrito. 


\section{Abstract}

The main objective of this work is to evaluate compensators that try to decrease the static friction effect existent in control valves. The friction compensaters used in this work were: CR1, CR2, Knocker, Two-move, sliding mode control and sliding mode control with integrator. These compensators are implemented in an industrial environment (DCS). Due to friction, the system has a nonlinear behavior, which may affect the good performance of a PID controller, wherein the closed loop system can have oscillations. So to get a decrease in the effect of friction, friction compensators are employed. To implement them, it is necessary to know the parameters of the friction existent. So the first part of this work consists of an explanation of the different models and methods that will be use in this work. Also, simulations were made of the control strategies used. After these topics, it will be identify the system model which has a flow control loop, in order to help the PID controller tuning. Then it will be introduced friction compensators, which attempt to minimize the ITAE (Integral Time Absolute Error) and IAE (Integrated Absolute Error), and wear that occurs on the equipment due to the use (excessive movement of the valve stem). The assumed objective is to implement control strategies in an industrial software. The results show that the compensators CR1 and CR2 have the best performance indexes and they compensate for the friction in the control valve stem.

Keywords: Friction, DCS, Sliding mode, control valves, friction compensators. 


\section{Lista de Figuras}

1 P\&ID da Planta de Vazão do LCPI. . . . . . . . . . . . . . . . . . . p. 26

2 Válvula de controle da Planta de Vazão. . . . . . . . . . . . . . . . . . p. 27

3 Esquema de uma válvula com atuador pneumático. . . . . . . . . . . p. 28

4 SCADA da Planta de Vazão. . . . . . . . . . . . . . . . . . . . . p. 29

$5 \quad$ Rodas de engrenagem. . . . . . . . . . . . . . . . p. 31

6 Não-linearidades da válvula pneumática. . . . . . . . . . . . . . . . . . $\quad$ p. 32

7 Curva de assinatura de uma válvula com efeito do stiction. . . . . . . . p. 32

8 Diagrama de fluxo do modelo de Kano. . . . . . . . . . . . . . . p. 35

9 Curva de assinatura correspondente ao modelo de Kano. . . . . . . . . p. 36

10 Comparação das funções tangente hiperbólica e sign. . . . . . . . . p. 38

11 Diagrama de blocos do compensador CR1. . . . . . . . . . . p. 40

12 Diagrama de blocos do compensador CR2. . . . . . . . . . . p 40

13 Diagrama de blocos para o compensador Knocker. . . . . . . . . . . . p. p1

14 Pulsos do compensador Knocker. . . . . . . . . . . . . . p. p. 42

15 Diagrama de blocos para o compensador Two-move modificado. . . . . p. 44

16 Efeito Chattering. . . . . . . . . . . . . . p. 50

17 Sistema em malha fechada. . . . . . . . . . . . . . . p. 53

18 Vazão para o modelo da válvula com gaxetas de grafite com controlador PI. . . . . . . . . . . . . . . . . . p. . 55

19 Sinal de controle para o modelo da válvula com gaxetas de grafite com controlador PI. . . . . . . . . . . . . . . . . p. 55

20 Posição da haste do modelo da válvula com gaxetas de grafite com controlador PI.

21 Vazão para o modelo da válvula com gaxetas de grafite com controlador PI $\left(T_{i}\right.$ aumentado para $\left.12 \mathrm{~s}\right) . \ldots \ldots$. . . . . . . . . . . 56

22 Sinal de controle para o modelo da válvula com gaxetas de grafite com controlador PI $\left(T_{i}\right.$ aumentado para $\left.12 \mathrm{~s}\right) \ldots \ldots \ldots$ p. . . . . . . . . 56

23 Posição da haste do modelo da válvula com gaxetas de grafite com controlador PI $\left(T_{i}\right.$ aumentado para $\left.12 \mathrm{~s}\right) . \ldots \ldots$. . . . . . . . 57 
24 Vazão para o modelo da válvula com gaxetas de grafite com controlador PI $\left(T_{i}\right.$ aumentado para $\left.16 \mathrm{~s}\right) \ldots \ldots \ldots$

25 Sinal de controle para o modelo da válvula com gaxetas de grafite com controlador PI $\left(T_{i}\right.$ aumentado para $\left.16 \mathrm{~s}\right) \ldots \ldots \ldots$

26 Posição da haste do modelo da válvula com gaxetas de grafite com controlador PI ( $T_{i}$ aumentado para $\left.16 \mathrm{~s}\right)$.

27 Vazão para o modelo da válvula com gaxetas de grafite com compensador CR1.

28 Sinal de controle para o modelo da válvula com gaxetas de grafite com compensador CR1.

29 Posição da haste para o modelo da válvula com gaxetas de grafite com compensador CR1.

30 Vazão para o modelo da válvula com gaxetas de grafite com compensador CR2.

31 Sinal de controle para o modelo da válvula com gaxetas de grafite com compensador CR2. . . . . . . . . . . . . . . .

32 Posição da haste para o modelo da válvula com gaxetas de grafite com compensador CR2 . . . . . . . . . . . . . . . . . . .

33 Vazão para o modelo da válvula com gaxetas de grafite com compensador Knocker. . . . . . . . . . . . . . . . .

34 Sinal de controle para o modelo da válvula com gaxetas de grafite com compensador Knocker. . . . . . . . . . . . . . . . . .

35 Posição da haste para o modelo da válvula com gaxetas de grafite com compensador Knocker.

36 Vazão para o modelo da válvula com gaxetas de grafite com compensador Two-move. . . . . . . . . . . . . . . . . . . p. 64

37 Sinal de controle para o modelo da válvula com gaxetas de grafite com compensador Two-move. . . . . . . . . . . . . . . . .

38 Posição da haste para o modelo da válvula com gaxetas de grafite com compensador Two-move. . . . . . . . . . . . . .

39 Vazão para o modelo da válvula com gaxetas de grafite para o controlador por modos deslizantes com chattering. . . . . . . . . . . . . . . .

40 Sinal de controle para o modelo da válvula com gaxetas de grafite para o controlador por modos deslizantes com chattering. . . . . . . . . . . .

41 Posição da haste para o modelo da válvula com gaxetas de grafite para o controlador por modos deslizantes com chattering. . . . . . . . . . . .

42 Superfície de escorregamento para o controlador por modos deslizantes com chattering. . . . . . . . . . . . . . . . . 
43 Vazão para o modelo da válvula com gaxetas de grafite para o controlador por modos deslizantes sem chattering. . . . . . . . . . . . . . . .

44 Sinal de controle para o modelo da válvula com gaxetas de grafite para o controlador por modos deslizantes sem chattering. . . . . . . . . . .

45 Posição da haste para o modelo da válvula com gaxetas de grafite para o controlador por modos deslizantes sem chattering. . . . . . . . . . .

46 Superfície de escorregamento para o controlador por modos deslizantes sem chattering. . . . . . . . . . . . . . . . . .

47 Vazão para o modelo da válvula com gaxetas de grafite para o controlador por modos deslizantes integrador com chattering. . . . . . . . . . . .

48 Sinal de controle para o modelo da válvula com gaxetas de grafite para o controlador por modos deslizantes integrador com chattering. . . . . .

49 Posição da haste para o modelo da válvula com gaxetas de grafite para o controlador por modos deslizantes integrador com chattering. . . . . .

50 Superfície de escorregamento para o controlador por modos deslizantes integrador com chattering. . . . . . . . . . . . . . .

51 Vazão para o modelo da válvula com gaxetas de grafite para o controlador por modos deslizantes integrador sem chattering. . . . . . . . . . . .

52 Sinal de controle para o modelo da válvula com gaxetas de grafite para o controlador por modos deslizantes integrador sem chattering. . . . . .

53 Posição da haste para o modelo da válvula com gaxetas de grafite para o controlador por modos deslizantes integrador sem chattering. . . . . .

54 Superfície de escorregamento para o controlador por modos deslizantes integrador sem chattering. . . . . . . . . . . . . p. 70

55 Vazão obtida com o controlador PI $(T=10 \mathrm{~ms}) \ldots \ldots \ldots$. . . . . . . . 73

56 Sinal de controle do controlador PI $(T=10 \mathrm{~ms}) \ldots \ldots \ldots \ldots$ p. 73

57 Posição da haste com controlador PI $(T=10 \mathrm{~ms}) \ldots \ldots \ldots$. . . . . . 74

58 Vazão obtida com o controlador PI com $T_{i}=12 \mathrm{~s}(T=10 \mathrm{~ms}) . \quad \ldots \quad$ p. 74

59 Sinal de controle do controlador PI com $T_{i}=12 \mathrm{~s}(T=10 \mathrm{~ms}) . \quad \ldots \quad$ p. 74

60 Posição da haste com controlador PI com $T_{i}=12 \mathrm{~s}(T=10 \mathrm{~ms}) \ldots$. . . p. 75

61 Vazão obtida com o controlador PI com $T_{i}=16 \mathrm{~s}(T=10 \mathrm{~ms}) . \quad \ldots \quad$ p. 75

62 Sinal de controle do controlador PI $\operatorname{com} T_{i}=16 \mathrm{~s}(T=10 \mathrm{~ms}) . \quad \ldots \quad$ p. 75

63 Posição da haste com controlador PI com $T_{i}=16 \mathrm{~s}(T=10 \mathrm{~ms}) \ldots$. . . p. 76

64 Vazão obtida com o compensador CR1 $(T=10 \mathrm{~ms}) . \quad \ldots \ldots$. . . . . 76

65 Sinal de controle com o compensador CR1 $(T=10 \mathrm{~ms}) . \quad \ldots \ldots$ p. . . 77

66 Posição da haste da válvula com o compensador CR1 $(T=10 \mathrm{~ms})$. . . p. 77 
67 Vazão obtida com o compensador CR2 $(T=10 \mathrm{~ms}) . \quad \ldots \ldots$. . . . . 77

68 Sinal de controle para o compensador CR2 $(T=10 \mathrm{~ms}) \ldots \ldots$. . . . . 78

69 Posição da haste da válvula com o compensador CR2 ( $T=10 \mathrm{~ms})$. . . $\quad$ p. 78

70 Vazão obtida com o compensador Knocker $(T=10 \mathrm{~ms})$. . . . . . . . p. 78

71 Sinal de controle com o compensador Knocker $(T=10 \mathrm{~ms})$. . . . . . $\quad$ p. 79

72 Posição da haste da válvula com o compensador Knocker $(T=10 \mathrm{~ms})$. p. 79

73 Vazão obtida com o compensador Two-move $(T=10 \mathrm{~ms}) . \quad \ldots \ldots$ p. . 79

74 Sinal de controle com o compensador Two-move $(T=10 \mathrm{~ms}) . \ldots$ p. 80

75 Posição da haste da válvula com o compensador Two-move ( $T=10 \mathrm{~ms}$ ). p. 80

76 Vazão para o controlador por modos deslizantes com chattering $(T=10$ $\mathrm{ms}) \ldots \ldots \ldots \ldots \ldots \ldots \ldots$ p. . . . . . . . . . . . . . . . . . . .

77 Sinal de controle para o controlador por modos deslizantes com chattering $(T=10 \mathrm{~ms})$.

78 Posição da haste da válvula para o controlador por modos deslizantes com chattering $(T=10 \mathrm{~ms}) \ldots \ldots \ldots \ldots$

79 Superficie de escorregamento para o controlador por modos deslizantes com chattering $(T=10 \mathrm{~ms}) \ldots \ldots \ldots \ldots \ldots$ p. . . . . . . . . . . . .

80 Vazão para o controlador por modos deslizantes sem chattering $(T=10$ $\mathrm{ms}) . \ldots \ldots \ldots \ldots \ldots \ldots \ldots$

81 Sinal de controle do controlador por modos deslizantes sem chattering

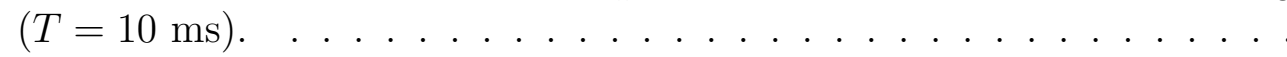

82 Posição da haste da válvula para o controlador por modos deslizantes sem chattering $(T=10 \mathrm{~ms}) \ldots \ldots \ldots \ldots$

83 Superficie de escorregamento para o controlador por modos deslizantes sem chattering $(T=10 \mathrm{~ms}) \ldots \ldots \ldots \ldots$

84 Vazão para o controlador por modos deslizantes integrador com chatte$\operatorname{ring}(T=10 \mathrm{~ms}) \ldots \ldots \ldots \ldots \ldots \ldots$

85 Sinal de controle do controlador por Modos deslizantes integrador com chattering $(T=10 \mathrm{~ms}) . \ldots \ldots \ldots \ldots$

86 Posição da haste da válvula para o controlador por modos deslizantes integrador com chattering $(T=10 \mathrm{~ms}) \ldots \ldots \ldots$. . . . . .

87 Superficie de escorregamento para o controlador por modos deslizantes integrador com chattering $(T=10 \mathrm{~ms}) \ldots \ldots \ldots$ p. . . . . . 86

88 Vazão para o controlador por modos deslizantes integrador sem chatte-

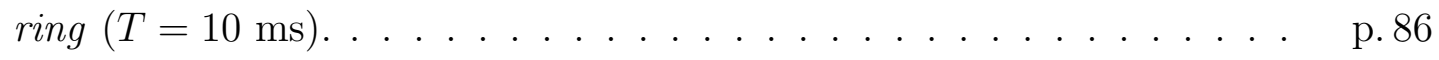

89 Sinal de controle do controlador por modos deslizantes integrador sem chattering $(T=10 \mathrm{~ms})$. 
90 Posição da haste da válvula para o controlador por modos deslizantes integrador sem chattering $(T=10 \mathrm{~ms}) \ldots \ldots \ldots$ p. 87

91 Superficie de escorregamento para o controlador por modos deslizantes integrador sem chattering $(T=10 \mathrm{~ms}) \ldots \ldots \ldots$ p. . . . . . . . 88

92 Vazão obtida com o controlador PI $(T=0,5 \mathrm{~s}) \ldots \ldots \ldots$ p. . . . . 88

93 Sinal de controle do controlador PI $(T=0,5 \mathrm{~s}) \ldots \ldots \ldots$ p. . . . . . . 89

94 Posição da haste com controlador PI $(T=0,5 \mathrm{~s}) \ldots \ldots$. . . . . . . . 89

95 Vazão obtida com o controlador PI $\operatorname{com} T_{i}=12(T=0,5 \mathrm{~s}) \ldots \ldots$ p. 89

96 Sinal de controle do controlador PI com $T_{i}=12(T=0,5 \mathrm{~s}) \ldots \ldots$ p. 90

97 Posição da haste com controlador PI com $T_{i}=12(T=0,5 \mathrm{~s}) \ldots$. . . p. 90

98 Vazão obtida com o controlador PI $\operatorname{com} T_{i}=16(T=0,5 \mathrm{~s}) \ldots \ldots$ p. 90

99 Sinal de controle do controlador PI $\operatorname{com} T_{i}=16(T=0,5 \mathrm{~s}) \ldots \ldots$ p. 91

100 Posição da haste com controlador PI com $T_{i}=16(T=0,5 \mathrm{~s}) \ldots$. . . p. 91

101 Vazão obtida com o compensador CR1 $(T=0,5 \mathrm{~s}) \ldots \ldots$. . . . . . . 92

102 Sinal de controle do compensador CR1 $(T=0,5 \mathrm{~s}) \ldots \ldots$. . . . . . . 92

103 Posição da haste da válvula com o compensador CR1 $(T=0,5$ s) . . . p. 92

104 Vazão obtida com o compensador CR2 $(T=0,5 \mathrm{~s}) \ldots \ldots$. . . . . . 93

105 Sinal de controle do compensador CR2 $(T=0,5 \mathrm{~s}) \ldots \ldots$. . . . . . 93

106 Posição da haste da válvula com o compensador CR2 $(T=0,5$ s $) \ldots$. . p. 93

107 Vazão obtida para o compensador Knocker $(T=0,5 \mathrm{~s}) \ldots \ldots$. . . . . 94

108 Sinal de controle do compensador Knocker $(T=0,5 \mathrm{~s}) \ldots \ldots$. . . . . 94

109 Posição da haste da válvula com o compensador Knocker $(T=0,5$ s). . p.94

110 Vazão obtida com o compensador Two-move $(T=0,5 \mathrm{~s}) \ldots \ldots$. . . . . 95

111 Sinal de controle com compensador Two-move $(T=0,5 \mathrm{~s}) \ldots \ldots$. . . . 95

112 Posição da haste da válvula com o compensador Two-move $(T=0,5$ s). $\quad$ p. 95

113 Vazão para o controlador por modos deslizantes com chattering $(T=0,5$ s). . . . . . . . . . . . . . . . . . p. 96

114 Sinal de controle do controlador por modos deslizantes com chattering $(T=0,5 \mathrm{~s}) \ldots \ldots \ldots \ldots$

115 Posição da haste da válvula para o controlador por modos deslizantes com chattering $(T=0,5 \mathrm{~s}) . \ldots \ldots \ldots$ p. 97

116 Superficie de escorregamento para o controlador por modos deslizantes com chattering $(T=0,5 \mathrm{~s}) \ldots \ldots \ldots \ldots \ldots \ldots$ p. . . . . . . . . . . .

117 Vazão para o controlador por modos deslizantes sem chattering $(T=0,5$ s). . . . . . . . . . . . . . . . . . . . . . . 98 
118 Sinal de controle do controlador por modos deslizantes sem chattering $(T=0,5 \mathrm{~s}) \ldots \ldots \ldots \ldots \ldots \ldots \ldots \ldots \ldots$

119 Posição da haste da válvula para o controlador por modos deslizantes sem chattering $(T=0,5 \mathrm{~s}) . \ldots \ldots \ldots \ldots$

120 Superficie de escorregamento para o controlador por modos deslizantes sem chattering $(T=0,5 \mathrm{~s})$.

121 Vazão para o controlador por modos deslizantes integrador com chatte-

122 Sinal de controle para o controlador por modos deslizantes integrador com chattering $(T=0,5 \mathrm{~s})$

123 Posição da haste da válvula para o controlador por modos deslizantes integrador com chattering $(T=0,5 \mathrm{~s}) \ldots \ldots \ldots$

124 Superficie de escorregamento para o controlador por modos deslizantes integrador com chattering $(T=0,5 \mathrm{~s}) \ldots \ldots \ldots$

125 Vazão para o controlador por modos deslizantes integrador sem chattering $(T=0,5 \mathrm{~s}) \ldots \ldots \ldots \ldots \ldots$

126 Sinal de controle para o controlador por modos deslizantes integrador sem chattering $(T=0,5 \mathrm{~s}) . \ldots \ldots \ldots \ldots$. . . . . . . . . . 102

127 Posição da haste da válvula para o controlador por modos deslizantes integrador sem chattering $(T=0,5 \mathrm{~s}) \ldots \ldots \ldots$. . . . . . . 103

128 Superficie de escorregamento para o controlador por modos deslizantes integrador sem chattering $(T=0,5 \mathrm{~s}) \ldots \ldots \ldots$. . . . . . . 103

129 Vazão obtida com o controlador PI para o modo regulatório. . . . . . . p. 103

130 Sinal de controle do controlador PI para o modo regulatório. . . . . . . p. 104

131 Posição da haste da válvula com o controlador PI para o modo regulatório.p. 104

132 Vazão obtida com o controlador PI para o modo regulatório. . . . . . . p. 105

133 Sinal de controle do controlador PI para o modo regulatório. . . . . . . p. 105

134 Posição da haste da válvula com o controlador PI para o modo regulatório.p. 105

135 Vazão obtida com o controlador PI para o modo regulatório. . . . . . . p. 106

136 Sinal de controle do controlador PI para o modo regulatório. . . . . . . p. 106

137 Posição da haste da válvula com o controlador PI para o modo regulatório.p. 106

138 Vazão obtida com o compensador CR1 para o modo regulatório. . . . . p. 107

139 Sinal de controle do compensador CR1 para o modo regulatório. . . . . p. 107

140 Posição da haste da válvula com o compensador CR1 para o modo regulatório. . . . . . . . . . . . . . . . . . p. 107

141 Vazão obtida com o compensador CR2 para o modo regulatório. . . . . p. 108 
142 Sinal de controle do compensador CR2 para o modo regulatório. . . . . p. p. 108

143 Posição da haste da válvula com o compensador CR2 para o modo regulatório. . . . . . . . . . . . . . . . . . . p. 108

144 Vazão obtida com o compensador Knocker para o modo regulatório. . . p. 109

145 Sinal de controle do compensador Knocker para o modo regulatório. . . p. 109

146 Posição da haste da válvula com o compensador Knocker para o modo regulatório. . . . . . . . . . . . . . . . . p. 109

147 Vazão obtida com o compensador Two-move para o modo regulatório. . p. 110

148 Sinal de controle do compensador Two-move para o modo regulatório. . p. 110

149 Posição da haste da válvula com o compensador Two-move para o modo

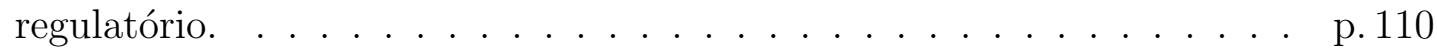

150 Vazão com o controlador por modos deslizantes com chattering para o modo regulatório. . . . . . . . . . . . . . . . . . . .

151 Sinal de controle do controlador por modos deslizantes com chattering para o modo regulatório. . . . . . . . . . . . . . . . . . .

152 Posição da haste da válvula com o controlador por modos deslizantes com chattering para o modo regulatório. . . . . . . . . . . . . . . p.112

153 Superfície de escorregamento do controlador por modos deslizantes com chattering para o modo regulatório. . . . . . . . . . . . . . . p. 112

154 Vazão para o controlador por modos deslizantes sem chattering para o modo regulatório. . . . . . . . . . . . . . . . . . . . p. 112

155 Sinal de controle do controlador por modos deslizantes sem chattering para o modo regulatório. . . . . . . . . . . . . . . . .

156 Posição da haste da válvula com o controlador por modos deslizantes sem chattering para o modo regulatório. . . . . . . . . . . . . p.113

157 Superfície de escorregamento do controlador por modos deslizantes com chattering para o modo regulatório. . . . . . . . . . . . . . . .

158 Vazão com o controlador por modos deslizantes integrador com chattering para o modo regulatório. . . . . . . . . . . . . . . . . p. 114

159 Sinal de controle com o controlador por modos deslizantes integrador com chattering para o modo regulatório. .......................

160 Posição da haste da válvula com o controlador por modos deslizantes integrador com chattering para o modo regulatório. . . . . . . . . . . . p.114

161 Superfície de escorregamento com o controlador por modos deslizantes integrador com chattering para o modo regulatório. . . . . . . . . . . .

162 Vazão com o controlador por modos deslizantes integrador sem chattering para o modo regulatório. . . . . . . . . . . . . . . . . . 
163 Sinal de controle com o controlador por modos deslizantes integrador sem chattering para o modo regulatório. . . . . . . . . . . . . . p. 115

164 Posição da haste da válvula com o controlador por modos deslizantes integrador sem chattering para o modo regulatório. . . . . . . . . . p.116

165 Superfície de escorregamento do controlador por modos deslizantes integrador sem chattering para o modo regulatório. . . . . . . . . p. 116

166 Diagrama de barras para o índice ITAE $(T=10 \mathrm{~ms}) \ldots \ldots \ldots$. . . . 117

167 Diagrama de barras para o índice IAE $(T=10 \mathrm{~ms}) \ldots \ldots \ldots$. . . . . 117

168 Diagrama de barras para o tempo de subida $(T=10 \mathrm{~ms}) . \quad \ldots . . \quad$ p. 117

169 Diagrama de barras para o índice $D_{v}(T=10 \mathrm{~ms}) \ldots \ldots \ldots$. . . . . 118

170 Diagrama de barras para o índice $\operatorname{ITAE}(T=0,5 \mathrm{~s}) \ldots \ldots \ldots$ p. 118

171 Diagrama de barras para o índice IAE $(T=0,5 \mathrm{~s}) \ldots \ldots \ldots$. . . . . 119

172 Diagrama de barras para o tempo de subida $(T=0,5 \mathrm{~s}) \ldots \ldots$. . . . 119

173 Diagrama de barras para o índice $D_{v}(T=0,5 \mathrm{~s}) \ldots \ldots$. . . . . 120 


\section{Lista de Tabelas}

1 Parâmetros estimados da válvula de controle com gaxetas de grafite

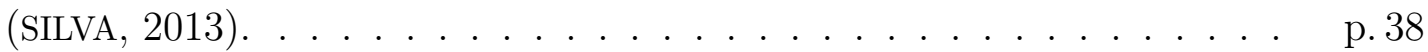

2 Parâmetros do modelo de primeira ordem mais tempo morto do processo. p. 52

3 Parâmetros do controlador PI obtida pelo método da Síntese Direta. . . p.54

4 Índices de desempenho das simulações com diferentes sintonias do controlador PI (válvula com gaxetas de grafite) . . . . . . . . . . . . p.59

5 Parâmetros S e J para o projeto dos compensadores CR1, CR2 Knocker

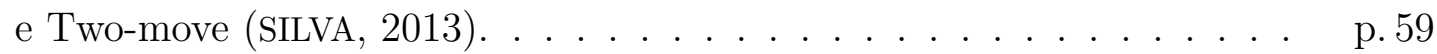

6 Parâmetros para o projeto do compensador Knocker. . . . . . . . . . . p. 59

7 Índices de desempenho das simulações com os compensadores de atrito (válvula com gaxetas de grafite). . . . . . . . . . . p. 60

8 Parâmetros para o projeto do controlador por modos deslizantes. . . . . $\quad$ p. 62

9 Parâmetros para o projeto do controlador por modos deslizantes integrador. p. 62

10 Índices de desempenho das simulaçães dos controladores por modos deslizantes e modos deslizantes integrador. . . . . . . . . . . . . p. 64

11 Índices de desempenho das simulaçães dos compensadores e controladores por modos deslizantes e modos deslizantes integrador. . . . . . . . . p. 71

12 Índices de desempenho dos controladores PI para o período de amostragem de $10 \mathrm{~ms} \ldots \ldots \ldots \ldots$. . . . . . . . . . . . . . . . . . . . . .

13 Índices de desempenho dos compensadores de atrito para o período de amostragem de $10 \mathrm{~ms} . \ldots \ldots \ldots \ldots$ p. . . . . . . . . . . . . . .

14 Índices de desempenho dos controladores por modos deslizantes e modos deslizantes integrador para o período de amostragem de $10 \mathrm{~ms}$. . . . . .

15 Índices de desempenho dos compensadores e controladores para o período de amostragem de $10 \mathrm{~ms} . \ldots \ldots \ldots$ p. . . . . . . . . . . . . . . .

16 Índices de desempenho do controlador PI com diferentes sintonias para o período de amostragem de $0,5 \mathrm{~s} \ldots \ldots \ldots$. . . . . . . . . . . . 91

17 Parâmetros para o projeto do compensador Knocker para o período de amostragem de 0,5 s. . . . . . . . . . . . . . . . p. 91

18 Índices de desempenho dos compensadores de atrito para o período de amostragem de 0,5 s. . . . . . . . . . . . . . . . p. 96 
19 Índices de desempenho dos controladores por modos deslizantes e modos deslizantes integrador para o período de amostragem de 0,5 s. $\quad \ldots \quad$. . 97

20 Índices de desempenho dos controladores e compensadores de atrito para o período de amostragem de 0,5 s. . . . . . . . . . . . . p. 104

21 Índices de desempenho dos compensadores e controladores de atrito para o modo regulatório. . . . . . . . . . . . . . . . . . p. 116 


\section{Sumário}

\section{Lista de Abreviaturas e Siglas}

1 Introdução $\quad$ p. 21

1.1 Motivação . . . . . . . . . . . . . . . . . . . . . p. 21

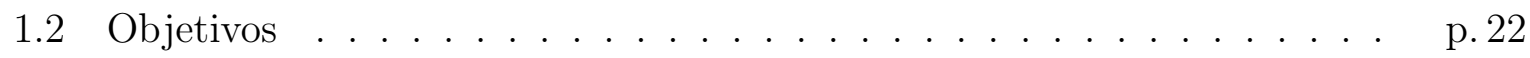

1.3 Revisão Bibliográfica . . . . . . . . . . . . . . . . . p. 22

1.4 Estrutura do texto . . . . . . . . . . . . . . p. 24

2 Planta de Vazão $\quad$ p. 25

2.1 Descrição da Planta Piloto de Vazão . . . . . . . . . . . . . . . p. 25

2.2 Válvula Pneumática . . . . . . . . . . . . . . . p. 27

2.3 Plataforma $800 \mathrm{xA}$ da $\mathrm{ABB} \ldots \ldots \ldots \ldots \ldots$ p. . . . . . . . . . . . . . . .

3 Análise do atrito estático (Stiction) p. 30

3.1 Problemas de uma malha de controle . . . . . . . . . . . . . p. 30

3.1.1 Atrito estático (Stiction) . . . . . . . . . . p. 30

3.1 .2 Banda morta . . . . . . . . . . . . . . p. 31

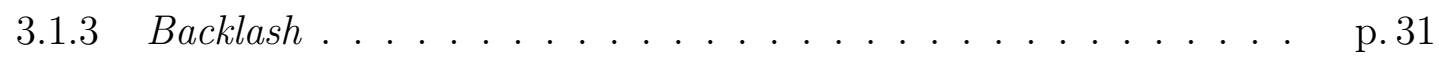

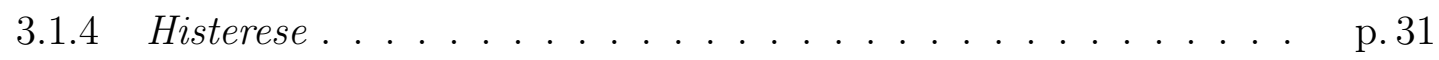

3.2 Modelagem do Stiction . . . . . . . . . . . . . . . . p. 33

3.2 .1 Modelos empíricos . . . . . . . . . . . . p. 33

3.2.1.1 Modelos do stiction de um parâmetro . . . . . . . p. 33

3.2.1.2 Modelo empírico de dois parâmetros . . . . . . . p. 34

3.2.1.3 Modelo de Kano . . . . . . . . . . . . . . . p. 34

3.2 .2 Modelos Físicos . . . . . . . . . . . . . . . p. . 35

4 Compensadores de atrito $\quad$ p. 39

4.1 Métodos para compensar o stiction . . . . . . . . . . . . p. 39

4.1 .1 Compensador CR . . . . . . . . . . . . p. 39 
4.1 .2 Compensador Knocker . . . . . . . . . . . . . . p. 41

4.1.3 Compensador Two-move . . . . . . . . . . . p. 42

4.1.4 Controle não-linear por modos deslizantes . . . . . . . . . . p. p. 45

4.1.4.1 Linearização Exata . . . . . . . . . . . . . p. 45

4.1.4.2 Linearização do sistema dinâmico da válvula de controle p. 47

4.1.4.3 Modos Deslizantes . . . . . . . . . . . . p. 48

4.1.4.4 Camada Limite . . . . . . . . . . . . . . p. 50

4.1.4.5 Modos Deslizantes Integrador . . . . . . . . . . p. 51

5 Simulação dos compensadores de atrito p. 52

5.1 Sintonia do controlador PI para a malha de vazão . . . . . . . . . . p.53

5.2 Simulações apenas com controlador PI para o modelo da válvula com gaxetas de grafite . . . . . . . . . . . . . . . p. 54

5.3 Simulações com compensadores CR1, CR2, Knocker e Two-move para o modelo da válvula com gaxetas de grafite . . . . . . . . . . . . p.59

5.4 Simulações dos controladores por modos deslizantes para o modelo da válvula com gaxetas de grafite . . . . . . . . . . . . . . p. p 61

6 Resultados Experimentais $\quad$ p. 72

6.1 Ensaios no modo servo . . . . . . . . . . . . . p. 72

6.1.1 Resultados para o período de amostragem de $10 \mathrm{~ms} \ldots$. . . . . 72

6.1.1.1 Apenas Controlador PI . . . . . . . . . . . p. 72

6.1.1.2 Compensadores CR1, CR2, Knocker e Two-move . . . p. 75

6.1.1.3 Controlador por modos deslizantes . . . . . . . p. 81

6.1.2 Resultados para o período de amostragem de $0,5 \mathrm{~s} \ldots$. . . . p. 84

6.1.2.1 Apenas Controlador PI . . . . . . . . . . p. 85

6.1.2.2 Compensadores CR1, CR2, Knocker e Two-move . . p. 87

6.1.2.3 Controle por modos deslizantes . . . . . . . . p. 96

6.2 Ensaios no modo Regulatório . . . . . . . . . . . . . p. 100

7 Conclusões $\quad$ p. 121

7.1 Análise dos resultados para o modelo da válvula com gaxetas de grafite p. 121

7.2 Análise dos resultados para os compensadores de atrito . . . . . . . p. 122

7.2.1 Análise dos resultados para os compensadores de atrito para o período de amostragem de $10 \mathrm{~ms} \ldots \ldots$. . . . . . . . . . 122 
7.2.2 Análise dos resultados para os compensadores de atrito para o período de amostragem de $0,5 \mathrm{~s} \ldots$. . . . . . . . . . p. 123

7.2.3 Sugestões para trabalhos futuros . . . . . . . . . . . . . . . . p. 123

$\begin{array}{ll}\text { Referências Bibliográficas } & \text { p. } 125\end{array}$ 


\section{Lista de Abreviaturas e Siglas}

CR Constant Reinforcement

IAE Integrated Absolute Error

IP Corrente para pressão

ITAE Integrated Time Absolute Error

MDC Modos Deslizantes com chattering

MDS Modos Deslizantes sem chattering

MDIC Modos Deslizantes Integrador com chattering

MDIS Modos Deslizantes Integrador sem chattering

PID Proportional Integral Derivativo

SDCD Sistema Digital de Controle Distribuído 


\section{Introdução}

\subsection{Motivação}

Com o passar do tempo, pode-se ver como o controle automático tem desempenhado um papel importante no avanço da engenharia e da ciência. Este é essencial em diversas áreas dos processos industriais e de produção. O controle automático também é importante em operações industriais tais como controle de pressão, nível, pH, temperatura, vazão, entre outros. Neste caso em particular, o trabalho vai-se centrar no controle de uma Planta Piloto de Vazão, a qual contém válvulas industriais de controle, as quais apresentam partes móveis para o seu funcionamento. Estas partes móveis provocam a existência do atrito estático, o qual é um fenômeno muito comum em atuadores que possuem partes móveis. O resultado de trabalhar com instrumentos desta natureza, é que os processos estarão sujeitos a não linearidades, isto significa um pior desempenho da malha de controle. Uma válvula de boa qualidade e que esteja em ótimo estado apresenta um baixo índice de atrito, o que implica que o atrito existente no processo não afeta o controle em malha fechada. No entanto, ao longo do tempo, o índice de atrito tende a aumentar devido ao desgaste do instrumento (desgaste das peças), isto tem como consequência uma diminuição da produtividade, diminuição da qualidade do produto ou aumento do custo de produção. Na literatura, esta não linearidade se denomina stiction (static friction).

Trabalhos publicados (DANESHWAR; NOH, 2014) dizem que 90\% das válvulas de controle são operadas por atuadores pneumáticos. Também indicam que ao longo da década passada, cerca de 20-30\% de todas as malhas de controle tinham oscilações causadas pelo stiction. No trabalho realizado por (CHOUDHURY; THORNHILL; SHAH, 2005), afirma-se que só uma melhora de $1 \%$ tanto na eficiência energética como na manutenção do controlador representa centenas de milhões de dólares em economia para as indústrias de processos.

O ideal para enfrentar estes problemas é uma adequada manutenção dos instrumentos, no entanto, segundo (SRINIVASAN; RENGASWAMY, 2005), os processos industriais têm paradas programadas, as quais se realizam entre um período de seis meses a três anos de operação. Isto significa, que os processos muitas vezes operam com instrumentos que não têm as condições desejadas para realizar o seu trabalho. Isto implica que observar não linearidades na malha de controle de certo processo, as quais geram perdas tanto na qualidade do produto como perdas econômicas.

O anteriormente mencionado justifica o desenvolvimento deste trabalho de Mestrado, 
pois é muito importante a implementação de novas técnicas de controle que permitam obter um melhor desempenho das válvulas de controle com alto atrito.

\section{$1.2 \quad$ Objetivos}

O objetivo deste trabalho é avaliar o desempenho compensadores de atrito, implementados em um ambiente industrial mediante o Sistema Digital de Controle Distribuído da ABB.

O trabalho apresenta simulações do modelo da planta, o que permite obter uma ideia dos resultados esperados na planta, o desenvolvimento dos compensadores implementados no Sistema Digital de Controle Distribuído da ABB e depois são apresentados os resultados obtidos em uma válvula de controle real.

Os resultados obtidos de cada compensador implementados no Sistema Digital de Controle Distribuído da ABB serão comparados com os já existentes na literatura, implementados em Matlab.

\subsection{Revisão Bibliográfica}

Na literatura é muito comum observar trabalhos feitos com o objetivo de analisar e tentar corrigir o atrito presente nas válvulas de controle. O estudo do static friction na engenharia de controle tem recebido uma grande atenção, devido ao impacto no desempenho de controle, como se afirma em (DANESHWAR; NOH, 2014). Nesse trabalho, desenvolveu-se um modelo apropriado de uma válvula com stiction, o qual pode ser usado no controlador implementado visando diminuir o efeito indesejável do atrito estático. A metodologia aplicada para alcançar estes objetivos, através do mapeamento do processo com uma válvula com stiction para um sistema difuso, é obter um modelo difuso dinâmico, através de um algoritmo de agrupamento iterativo, o qual gera parâmetros a partir de um conjunto de medidas que são obtidas a partir da saída do controle e da saída do processo. Para conseguir determinar estes parâmetros, é aplicada a técnica dos mínimos quadrados. Os autores afirmam que os resultados revelam que os dados obtidos podem representar efetivamente um modelo adequado da válvula com stiction para diferentes valores de atrito estático.

Em (XIE; CONG; HORCH, 2013) fez-se um estudo, o qual tinha por objetivo realizar simulações de uma válvula com stiction, baseando-se no ISA standard tests (ISA, 2000, 2006), tomando como ponto de partida o modelo da válvula de Choudhury (CHOUDHURY; THORNHILL; SHAH, 2005). Os autores trabalharam em uma melhora deste modelo e eles afirmam que o modelo proposto passou por todos os testes da ISA e, portanto, fornece uma simulação mais realista de uma válvula real industrial. 
Em (HÄGGLUND, 2011) descreve-se um método para realizar um diagnóstico automático do atrito estático em válvulas de controle. O diagnóstico é realizado através de uma análise da forma das oscilações que aparecem na saída do processo. Este processo é automático, no sentido que nenhuma informação do processo é assumida, exceto aquela que já está disponível nos controladores.

Outro trabalho desenvolvido em um ambiente industrial, é o feito por (KVAM, 2009), para a Siemens Oil and Gas. Este trabalho tem por finalidade desenvolver um algoritmo que detecte o atrito estático. A Siemens Oil and Gas afirma que o stiction presente na válvula é um problema difícil e ao mesmo tempo demorado de detectar em plantas de produção de óleo e gás (offshore). O algoritmo detecta o stiction em dados a partir de processos não integrativos com entradas constantes.

Outro trabalho realizado com o fim de compensar os efeitos do atrito estático de uma válvula de controle, foi o feito em (SILVA, 2013), no qual se testam compensadores que não necessitam de modelos internos, e também se podem implementar em CLPs e SDCDs. Os compensadores foram implementados em uma malha de controle de vazão de água utilizando válvulas de controle. A finalidade é diminuir o ITAE (Integrated Time Absolute Error) e o desgaste dos instrumentos ocasionado pela movimentação da haste da válvula. Os compensadores implementados são o CR, Knocker e Two-move. Estes compensadores são implementados mediante o software acadêmico Matlab enquanto os algoritmos deste trabalho foram implementados por meio de um SDCD.

Na literatura também existem compensadores os quais se baseiam em modelos não lineares, como é o caso de (BAEZA, 2013). Aqui o autor apresenta o estudo de cinco compensadores não lineares, os quais são: controlador rastreador de trajetória, controlador por modos deslizantes, controlador por modos deslizantes integrador, controlador por modelo interno não linear e controlador PI não linear, os quais são testados em uma válvula de controle real. O autor afirma que os resultados obtidos mostram que os compensadores têm um comportamento satisfatório.

Também é possível encontrar livros os quais estudam o fenômeno do atrito, como é o caso de (MOHIEDDINE; HUANG, 2010). Os autores afirmam que a monitoração do desempenho do controle (Control Performance Monitoring, CPM) é uma área a qual cada dia é mais importante no mundo da ciência e da tecnologia. Com o CPM é possível descobrir as diferentes causas de um baixo rendimento em malhas de controle industrial. Este trabalho é uma coleção de contribuições de pesquisas internacionais, as quais estudam métodos para a detecção e diagnóstico do atrito estático em malhas de controle manipuladas por válvulas. É explicado o modelamento do atrito estático e se realizam comparações entre diferentes modelos, metodologias para a detecção de oscilações em malhas de controle e também se encontram vários exemplos de aplicações industriais, nos quais é muito comum ver este fenômeno. 


\subsection{Estrutura do texto}

Este trabalho está organizado em sete capítulos. Neste primeiro capítulo é apresentada a motivação do projeto junto com os objetivos propostos, que conduzem ao desenvolvimento do mesmo.

O Capítulo 2 apresenta a planta piloto onde vão se implementar os algoritmos para compensar o atrito (Laboratório de Controle de Processos Industriais da Escola Politécnica - USP) e o Sistema Digital de Controle Distribuído da ABB para implementá-los.

O Capítulo 3 aborda os conceitos e as características dos tipos de modelos que existem para representar o atrito estático que existe em válvulas pneumáticas, assim como também quais são os problemas gerados pela presença do atrito estático.

O Capítulo 4 explica os diferentes tipos de compensadores que serão implementados. Aborda os compensadores de atrito que não precisam de um modelo da planta e aborda também os compensadores de atrito não-lineares, que necessitam de modelo da planta.

O Capítulo 5 apresenta as simulações dos compensadores de atrito realizadas no modelo da planta de vazão.

O Capítulo 6 apresenta os resultados obtidos neste trabalho de Mestrado.

O Capítulo 7 apresenta as conclusões dos resultados obtidos e algumas sugestões para trabalhos futuros. 


\section{Planta de Vazão}

A primeira parte deste capítulo consiste em uma explicação do funcionamento da Planta Piloto de Vazão do Laboratório de Controle de Processos Industriais (LCPI), na qual vão se realizar os diferentes testes e aplicações. Este laboratório faz parte do Departamento de Engenharia de Telecomunicações e Controle da Escola Politécnica da Universidade de São Paulo.

\subsection{Descrição da Planta Piloto de Vazão}

A planta piloto do LCPI consiste basicamente em um circuito fechado de vazão de água, conforme se pode observar na Figura 1. Para movimentar a água se tem uma bomba, a qual possui um inversor de frequência que permite controlá-la. Desta maneira, se faz circular a água de um tanque mediante uma tubulação (PVC) de 2 polegadas. Neste circuito se encontram duas válvulas de controle em linha, cada uma com gaxetas de materiais diferentes (teflon e grafite). Existe uma terceira válvula a qual é usada para gerar perturbações no processo. Cabe ressaltar que só se pode usar uma das duas válvulas (grafite e teflon) em cada teste, pois em um processo industrial na vida real não é comum ter duas válvulas em linha. Para realizar o controle da planta, pode-se escolher duas diferentes maneiras de implementá-lo. Cada válvula possui um conversor I/P, um posicionador eletropneumático e um posicionador digital. O conversor I/P realiza a pressurização do atuador, ele converte um sinal de 4-20 mA para um sinal de 6-30 psi. Para selecionar entre os posicionadores ou o conversor, a planta tem duas chaves seletoras, as quais podem ser vistas na Figura 2. Cada válvula tem um medidor de pressão relativa no atuador e um medidor de posição da haste.

Para realizar o controle na válvula, pode-se operar de duas formas: a primeira forma de trabalho é mediante uma placa de aquisição de dados, a qual realiza a interface entre um computador e os diferentes instrumentos que compõem a Planta de Vazão. O software com o qual se pode acessar todas as variáveis de entrada e saída é o Simulink do Matlab. A segunda forma, que também vai ser o modo de operação neste trabalho, é através de um SDCD da ABB e um computador que tem um software SCADA. O Sistema Digital de Controle Distribuído da ABB representa um modo de trabalho industrial, enquanto o Simulink do Matlab, é um ambiente acadêmico. 
Figura 1: P\&ID da Planta de Vazão do LCPI.

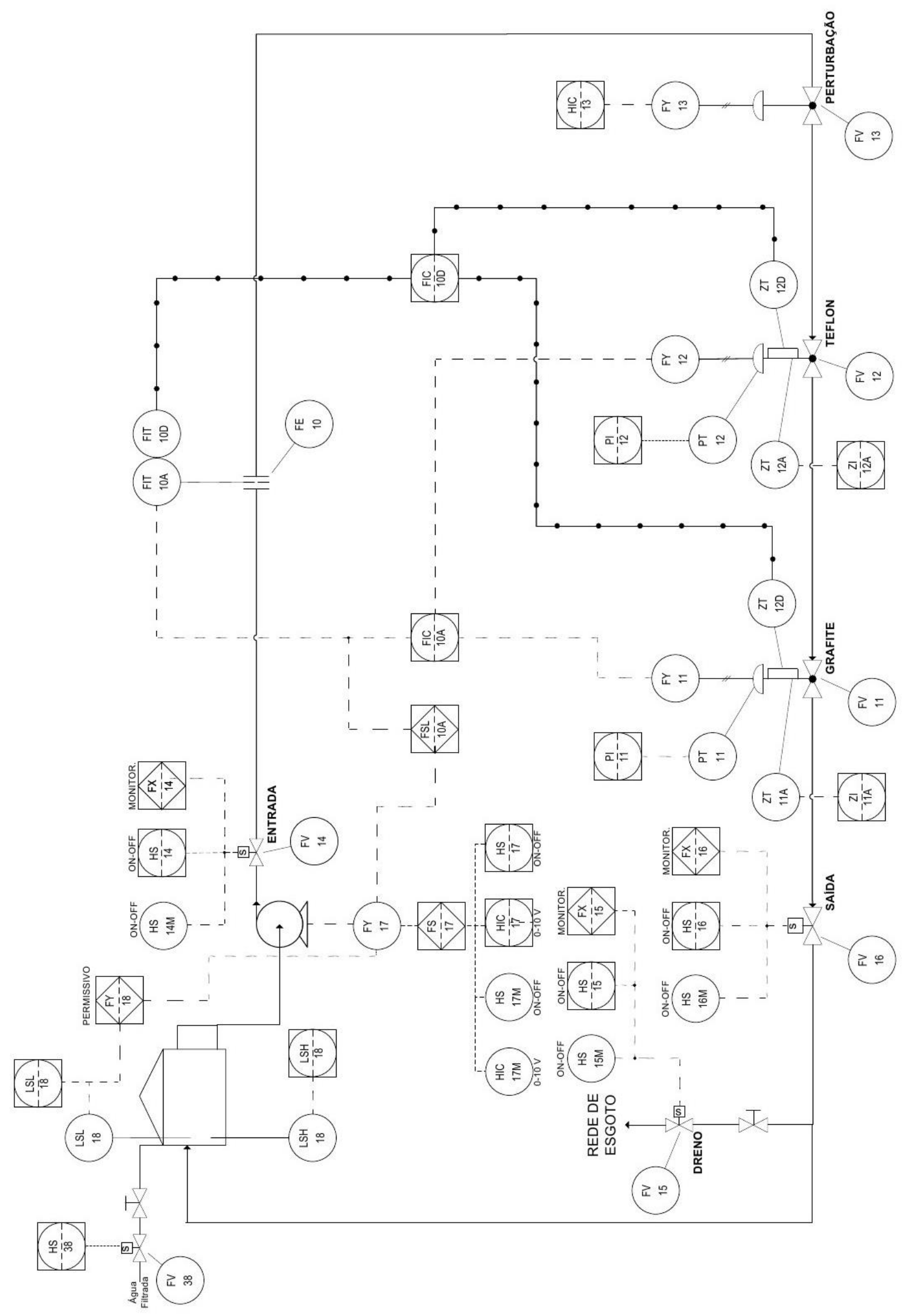


Figura 2: Válvula de controle da Planta de Vazão.

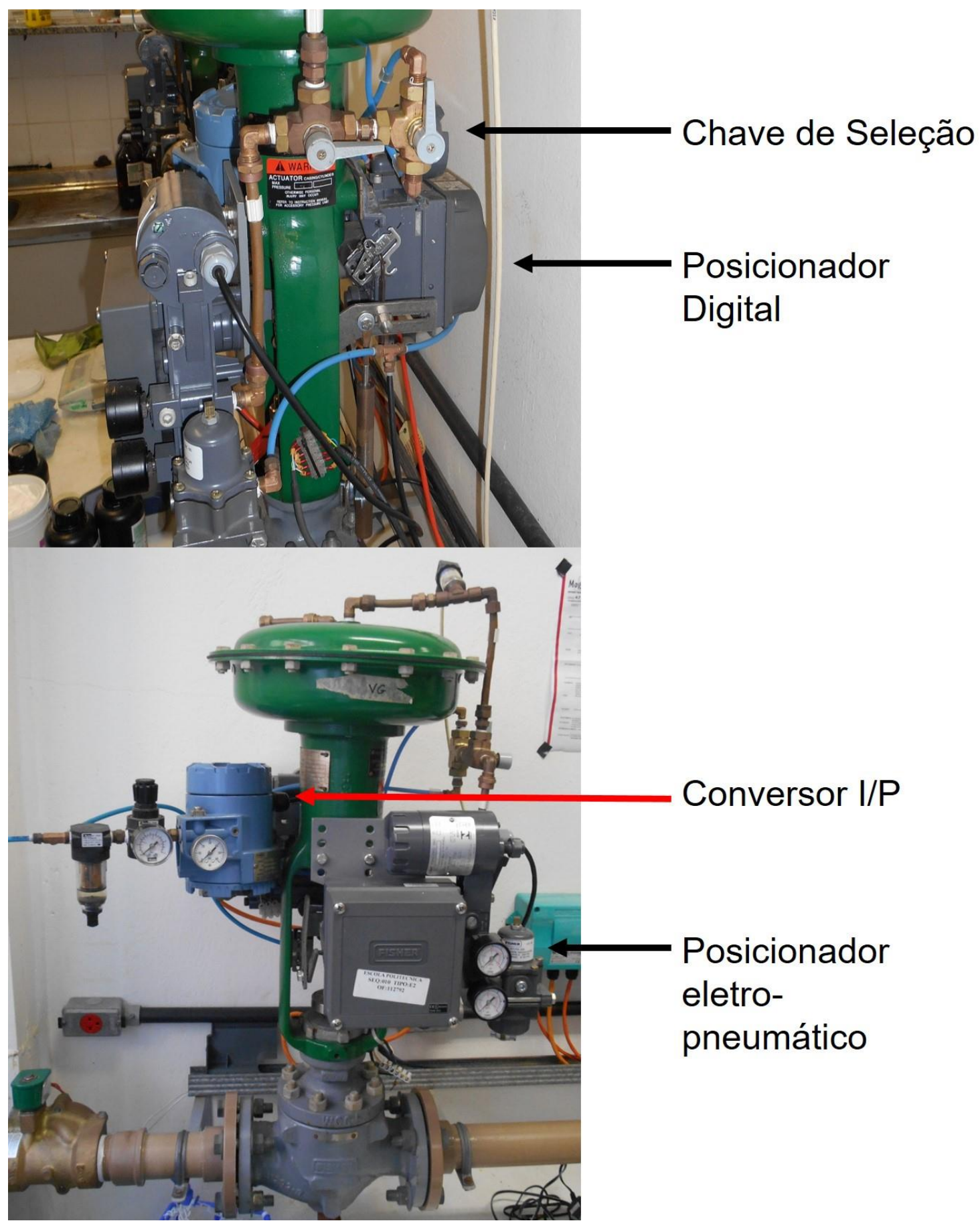

Fonte: Autor.

\subsection{Válvula Pneumática}

A estrutura geral de uma válvula pneumática de controle é mostrada na Figura 3. Esta válvula é aberta pela força elástica da mola e fechada pela pressão do ar. A taxa de fluxo é alterada de acordo com a posição do obturador, a qual é determinada pelo equilíbrio entre a força da mola e a força sobre o diafragma devido à pressão do ar. $\mathrm{O}$ diafragma é conectado à haste da válvula. A haste é movida contra a força do atrito 
estático ou dinâmico causado por uma gaxeta, a qual é um dispositivo de selagem para evitar a fuga do fluido de processo. O movimento suave da haste é impedido pelo excessivo atrito estático. A posição da válvula não pode ser alterada até que a saída do controlador ultrapasse este atrito estático, e a haste pode escorregar e saltar quando o atrito estático é superado. Uma vez que a válvula está em movimento, o movimento da haste é afetado pelo atrito dinâmico que é, geralmente, menor do que o atrito estático, e após um salto inicial, o movimento prossegue suavemente. O movimento só para quando a força elástica da mola e a força devido ao atrito equilibram exatamente a força devida à pressão do ar (MOHIEDDINE; HUANG, 2010).

Figura 3: Esquema de uma válvula com atuador pneumático.

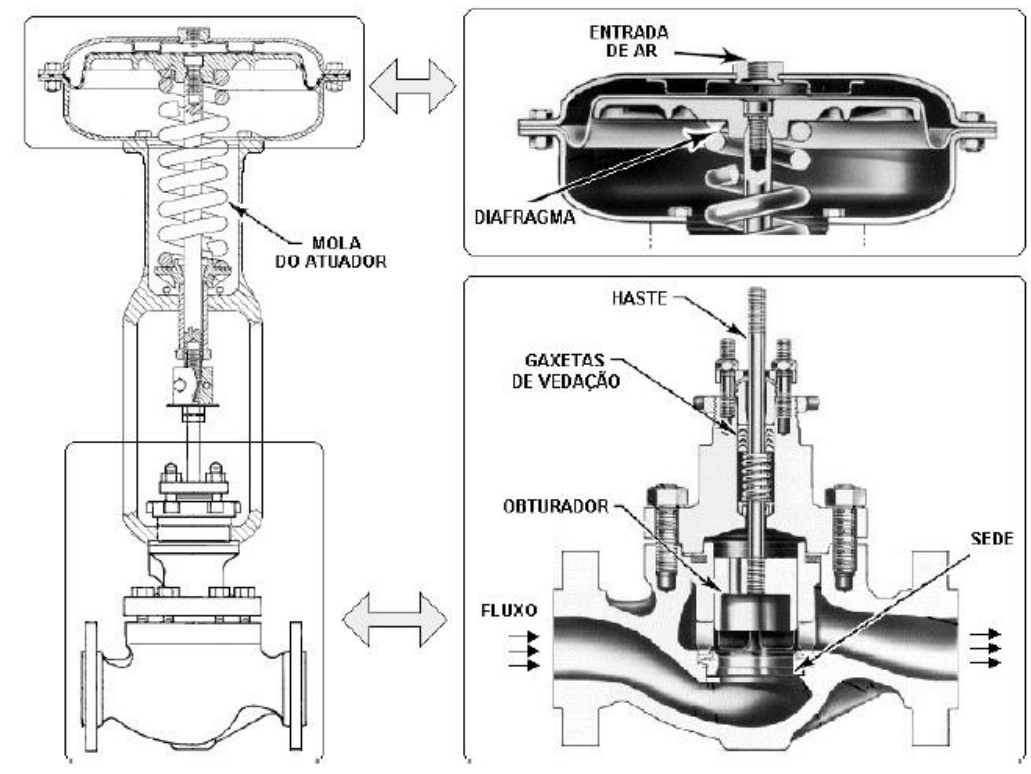

Autor: Romano (2009).

\subsection{Plataforma 800xA da ABB}

A ABB é uma empresa de engenharia de âmbito mundial com produtos em diversas áreas. Uma dessas áreas é sistemas de automação, onde a Plataforma 800xA é amplamente utilizada em indústrias de todo o mundo. A Plataforma 800xA é um Sistema Digital de Controle Distribuído (SDCD), criando uma plataforma flexível e colaborativa, com grandes possibilidades de integração. Como se pode observar na Figura ??, vê-se o esquema geral de como o sistema $800 \mathrm{xA}$ da $A B B$ tem que estar conectado. A plataforma pode ser acessada com interfaces diferentes, personalizadas para os operadores, engenheiros, pessoal de manutenção, etc. Isso permite que os usuários se concentrem na sua própria tarefa e, assim, trabalhem de forma mais eficiente.

Um problema comum na indústria de hoje é o custo da modernização. Motivar o custo de atualização de todos os equipamentos mais antigos muitas vezes é impensável. Portanto, a solução é construir sobre o sistema que já se tem. O sistema 800xA está ligado através de servidores de conectividade, fornecendo dados dos controladores para os locais 
de trabalho do operador, coleção de dados históricos etc. Nesta plataforma, equipamentos mais antigos podem ser instalados lado a lado com controladores modernos. Isso torna possível para os clientes atualizar os seus sistemas mais antigos. O sistema 800xA é usado em uma ampla variedade de aplicações, como é o caso de Petróleo e Gás, Petroquímica, Biotecnologia/Farmacêutica, Energia entre outras (SKILLSÄTER, 2011).

A seguir apresenta a tela de supervisão e controle $(S C A D A)$ mostrada na Figura 4.

Figura 4: SCADA da Planta de Vazão.

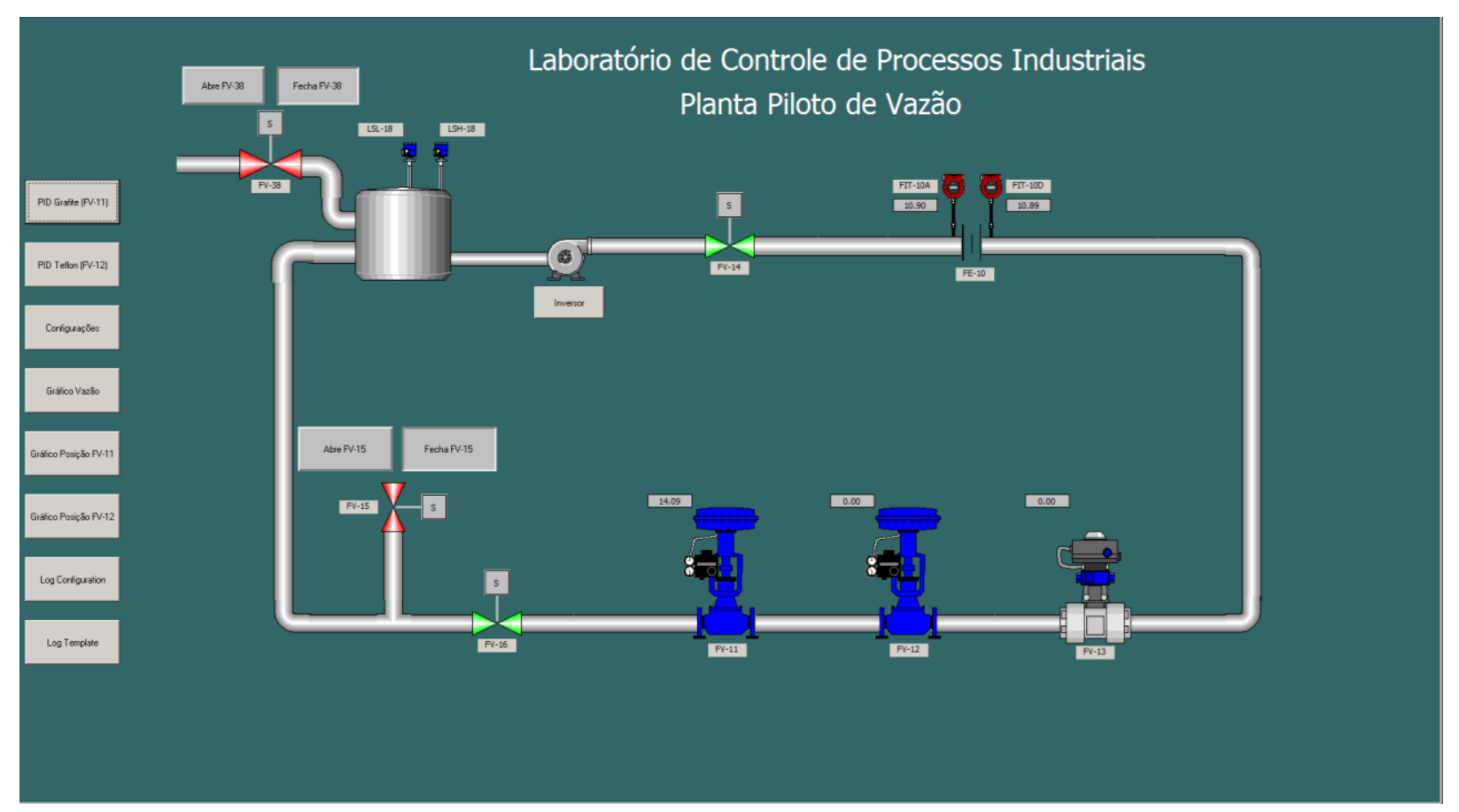

Fonte: Autor. 


\section{$3 \quad$ Análise do atrito estático (Stiction)}

\subsection{Problemas de uma malha de controle}

Nas indústrias de processos, existem muitas causas que geram um mau funcionamento em malhas de controle, os quais não são sempre ocasionados por uma má sintonia do respectivo controlador. Como se afirma em (SKILlSÄTER, 2011), estudos realizados desde o ano de 1993 na indústria de celulose e de papel, mostraram que mais de 30\% de todas as malhas de controle em um moinho apresentaram problemas com os equipamentos. Os problemas mais comumente encontrados são mencionados a seguir.

\subsubsection{Atrito estático (Stiction)}

Uma das causas mais comuns que gera oscilações é a presença de alto atrito em válvulas de controle (SKILLSÄTER, 2011). Isto significa que a válvula está presa em uma determinada posição e que uma maior saída do controlador é necessária, isto para começar a movê-la. Uma vez que o atrito dinâmico é menor, a válvula de controle pode ser facilmente movimentada para uma nova posição, mas quando a válvula para, vai ficar presa novamente. Normalmente, estas posições de parada estão em lados opostos do set point desejado. Isto quer dizer que o controlador tentará mover imediatamente a válvula na direção oposta. Este tipo de comportamento muitas vezes é detectado facilmente nos sinais da variável do processo e na saída do controlador, sendo que a variável de processo tem a forma de uma onde quadrada e a saída do controlador tem a forma de dentes de serra.

Em (KVAM, 2009) afirma-se que o Stiction é uma não-linearidade que apresenta ciclos limite. Um ciclo limite é uma onda periódica no retrato de fase (representação geométrica de todas as trajetórias de um sistema dinâmico) e indica que o sistema apresenta oscilações. Em (CHOUDHURY; THORNHILL; SHAH, 2005) se define o Stiction da seguinte forma: "Uma propriedade de um elemento de tal forma que o seu movimento suave em resposta a uma entrada variável é precedido por um salto abrupto chamado slip-jump". 


\subsubsection{Banda morta}

Representa simplesmente o valor de um sinal de entrada que precisa ser mudado antes que a saída mude. A presença da banda morta pode levar a um comportamento lento, seguido por um aumento da variância e oscilações (SKILLSÄTER, 2011).

Em (KVAM, 2009) se define a banda morta da seguinte forma: "O intervalo através do qual um sinal de entrada pode ser variado, mediante inversão de direção, sem iniciar uma mudança observável no sinal de saída".

\subsubsection{Backlash}

Em um sistema mecânico em que os elementos não estão diretamente ligados um ao outro, haverá backlash. Esta não linearidade possui dinâmica, sendo que o seu estado depende da entrada atual e do estado passado. Para entender melhor isto, pode-se observar a Figura 5, onde se tem duas rodas de engrenagem. Enquanto as rodas têm a mesma direção de movimento, o backlash não tem efeito, mas quando a direção muda, tem-se claramente a presença do backlash. Isto é devido ao fato que leva algum tempo para que os dentes da engrenagem se agarrem um ao outro novamente (SKILLSÄTER, 2011).

Em (KVAM, 2009) se define o backlask da seguinte forma: "Um movimento relativo entre as partes mecânicas que interatuam, resultantes do afrouxamento quando o movimento é invertido".

Figura 5: Rodas de engrenagem.

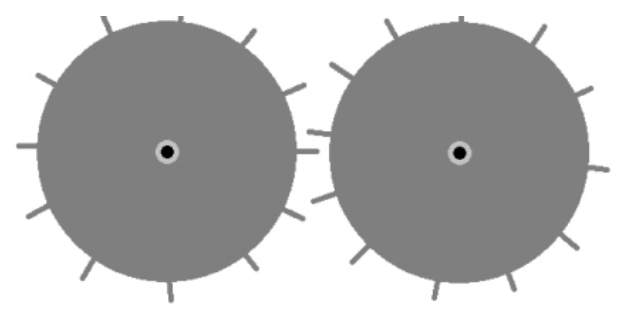

Autor: Skillsäter (2011).

\subsubsection{Histerese}

Outro fenômeno que é importante definir, o qual gera não-linearidades em um processo é a histerese. Esta é a propriedade evidenciada pela dependência do valor de saída, para uma excursão dada da entrada, sobre a história de excursões anteriores e a direção do movimento atual (KVAM, 2009). 
Os conceitos aqui definidos podem ser observados nas Figuras 6 e 7 .

Figura 6: Não-linearidades da válvula pneumática.

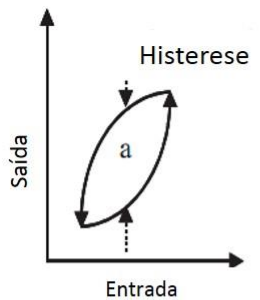

(a) Histerese

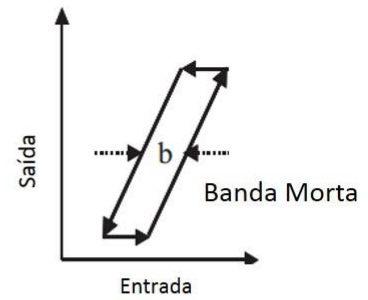

(b) Banda Morta

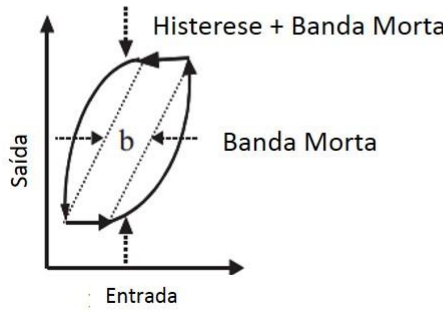

(c) Histerese + Banda Morta

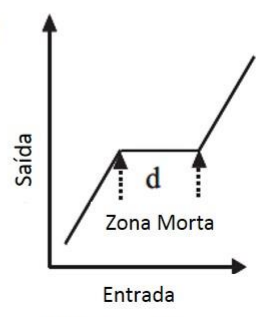

(d) Zona Morta

Autor: Kvam (2009).

Figura 7: Curva de assinatura de uma válvula com efeito do stiction.

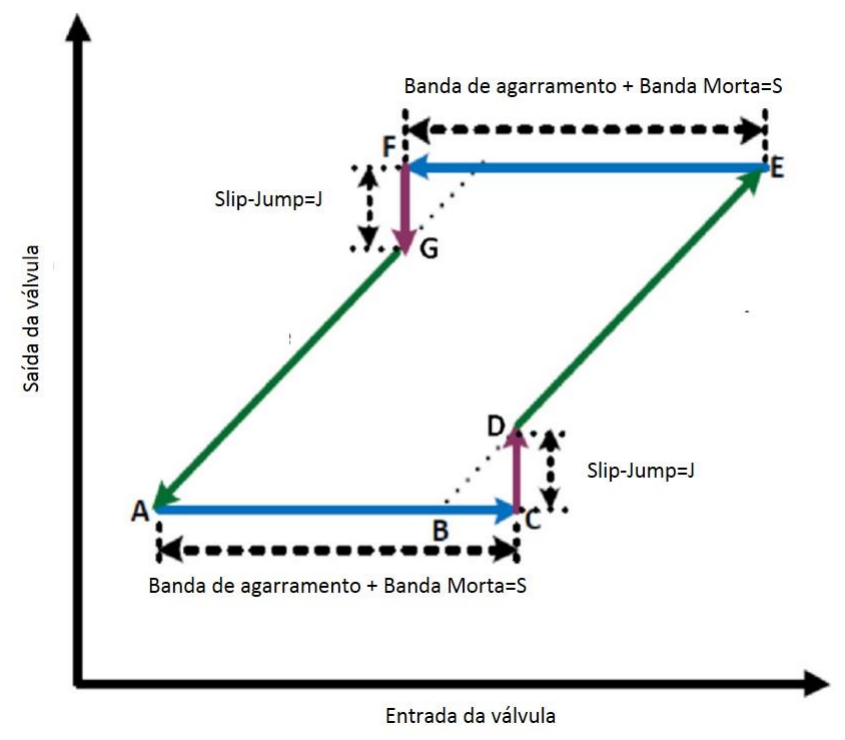

Autor: Daneshwar e Noh (2014).

Na Figura 7 pode-ser ver a assinatura de uma válvula de controle com stiction. A figura é composta por quatro componentes: banda morta, banda de agarramento, slip-jump e movimento de fase. Quando a válvula descansa ou muda de direção no ponto A, a válvula fica agarrada. Quando o sinal do controlador supera a banda morta (AB) e a banda de agarramento $(\mathrm{BC})$ da válvula, a válvula vai para uma nova posição (ponto $\mathrm{D}$ ) e continua 
a mover-se. A válvula move-se então entre os pontos D e E. Neste caso, a magnitude da banda morta é zero e apenas a banda de agarramento está presente. Este fenômeno ocorre no movimento inverso da válvula (caminho E-A). Para o próximo período de trabalho, completa-se o ciclo de histerese. Como é mostrado na Figura 7, a única parte linear da válvula está na sua fase de movimento. Portanto, a não-linearidade ocorre na banda de agarramento mais a banda morta $(S)$ e o slip-jump $(J)$. Os parâmetros $S$ e $J$ podem capturar as verdadeiras características de não-linearidade na válvula de controle com stiction.

\subsection{Modelagem do Stiction}

Muitos estudos têm sido realizados para definir e detectar o atrito estático ou stiction. Os modelos de válvulas de controle com stiction podem ser classificados em dois grupos: o primeiro são os modelos empíricos, os quais têm por finalidade relacionar a entrada e saída do sistema, como se pode observar na Figura 7. O outro grupo são os modelos físicos, os quais utilizam o balanço de forças para conseguir prever o seu movimento. A desvantagem de um modelo baseado na física, é que exige um conhecimento das quantidades, tais como a massa das partes em movimento e as forças de atrito, o que torna estes modelos mais complicados para estudos industriais. Na prática industrial, o atrito estático e outros problemas relacionados são identificados em termos da percentagem de deslocamento da válvula ou na amplitude do sinal de entrada da válvula. Por outro lado, um modelo empírico é útil porque ele precisa de apenas alguns parâmetros a serem especificados, os quais são fáceis de definir, em termos de percentagem e do sinal de entrada e saída (MOHIEDDINE; HUANG, 2010).

(CHOUDHURY; THORNHILL; SHAH, 2005) desenvolveram um modelo do stiction do tipo "data-driven". Duas classes principais de modelos empíricos de stiction têm aparecido na literatura, eles são chamados de modelos de um parâmetro e de dois parâmetros.

\subsubsection{Modelos empíricos}

\subsubsection{Modelos do stiction de um parâmetro}

Em (STENMAN; GUSTAFSSON; FORSMAN, 2003) relatou-se um modelo empírico de stiction de um parâmetro. O modelo é descrito a seguir:

$$
y(k)=\left\{\begin{array}{c}
u(k-1) \text { se } u(k)-y(k-1)<d \\
u(k) \text { Caso Contrário }
\end{array}\right.
$$

sendo que $u$ e $y$ são os sinais de entrada e saída da válvula, respectivamente, $d$ é a banda de agarramento da válvula. O modelo compara a diferença entre a entrada atual da 
válvula e sua saída anterior com a banda de agarramento.

O modelo de um parâmetro não é o mais adequado como modelo de atrito estático da válvula, devido a que não considera a banda morta, a qual limita a sua utilização.

\subsubsection{Modelo empírico de dois parâmetros}

Para um modelo de atrito estático, os principais objetivos são os seguintes: modelar a tendência da válvula, para manter-se em movimento uma vez que começou, até que a entrada mude de direção ou a velocidade tenda a zero, e também incluir os efeitos da banda morta e do slip-jump. O modelo de stiction de dois parâmetros apareceu pela primeira vez em (CHOUDHURY; THORNHILL; SHAH, 2004). Os parâmetros de atrito deste modelo podem ser diretamente relacionados com os dados de uma planta. O modelo requer apenas o sinal de saída do controlador e a especificação de banda morta mais a banda de agarramento $(S)$ e o slip-jump $(J)$, como é mostrado na Figura 7 .

\subsubsection{Modelo de Kano}

O modelo com dois parâmetros foi modificado por (KANO et al., 2004) tentando relacionar os parâmetros $S$ e $J$ com a força elástica, a pressão do ar e a força de atrito. No modelo de Kano, $S$ corresponde ao somatório do atrito estático $\left(f_{s}\right)$ e dinâmico $\left(f_{d}\right)$ e $J$ corresponde à diferença entre o atrito estático $\left(f_{s}\right)$ e dinâmico $\left(f_{d}\right)$.

$$
\begin{aligned}
& S=f_{s}+f_{d} \\
& J=f_{s}-f_{d}
\end{aligned}
$$

Tendo isto em mente, eles ofereceram um diagrama de fluxo alternativo para simular o stiction. O diagrama é apresentado na Figura 8.

Como se pode ver na Figura 8, a entrada e saída deste modelo da válvula com stiction são a saída do controlador $u$ e a posição da válvula $y$, respectivamente. Os dois primeiros ramos no diagrama de fluxo verificam se o limite superior e o limite inferior da saída do controlador estão satisfeitos. No modelo de Kano, dois estados da válvula são explicitamente distinguidos, indicado pela variável stp. No estado em movimento, stp tem o valor de 0 , enquanto no estado em repouso stp tem o valor de 1 . Ademais, a saída do controlador no momento que o estado da válvula começa a mudar, de estar em movimento para repouso, é definido como us. us é atualizado e o estado é alterado para o estado de repouso $(s t p=1)$ somente quando a válvula para ou muda de direção $(\Delta u(t)-\Delta u(t-1) \leq 0)$, enquanto em seu estado de movimento $(s t p=0)$. Depois, as duas condições seguintes concernentes à diferença entre $u(t)$ e us são verificadas, a menos que a válvula se encontre em movimento. A primeira condição julga se a válvula muda a 
Figura 8: Diagrama de fluxo do modelo de Kano.

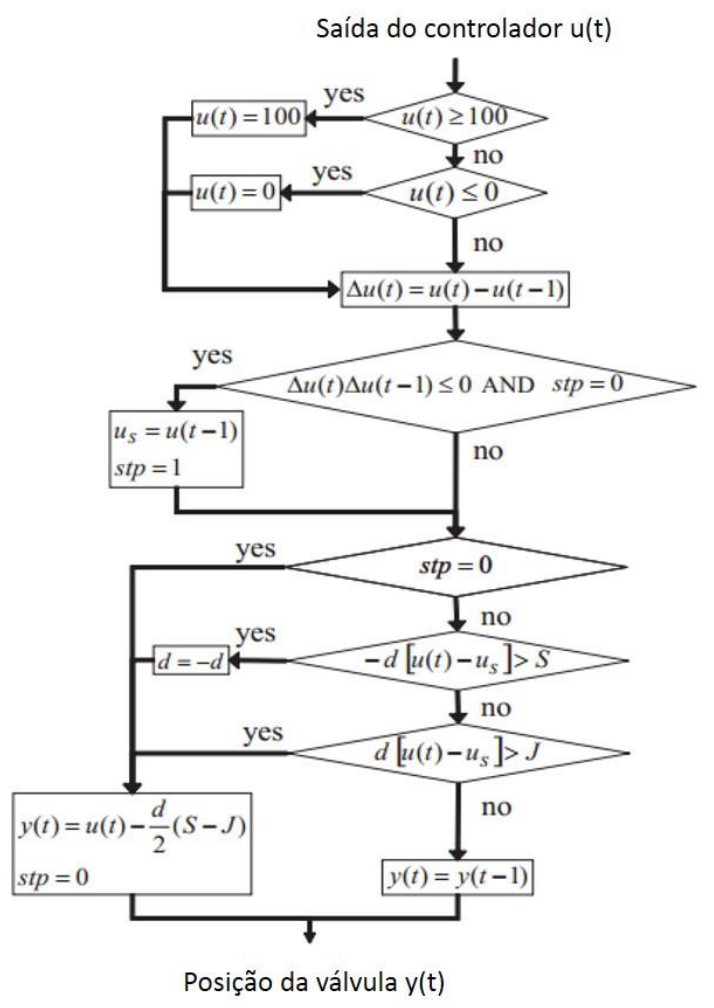

Autor: Kano et al. (2004).

sua direção e supera o stiction máximo (correspondente aos pontos C e F da Figura 9). Aqui, $d= \pm 1$ indica o sentido da força de atrito. A segunda condição julga se a válvula se move em uma direção similar e supera o atrito. Se uma destas duas condições for satisfeita, ou a válvula estiver em movimento, a posição da válvula é atualizada através da seguinte equação:

$$
y(t)=u(t)-d \cdot f_{d}+u(t)-\frac{d(S-J)}{2}
$$

Por outro lado, a posição da válvula é inalterada se a válvula permanece em um estado de repouso.

Em (GARCIA, 2008) foi feita uma análise dos modelos de stiction, onde se concluiu que, entre os modelos empíricos propostos na literatura, foi o proposto por Kano o que apresenta um melhor desempenho.

\subsubsection{Modelos Físicos}

Considerando a válvula apresentada na Figura 3, tem-se o seguinte balanço de forças: 
Figura 9: Curva de assinatura correspondente ao modelo de Kano.

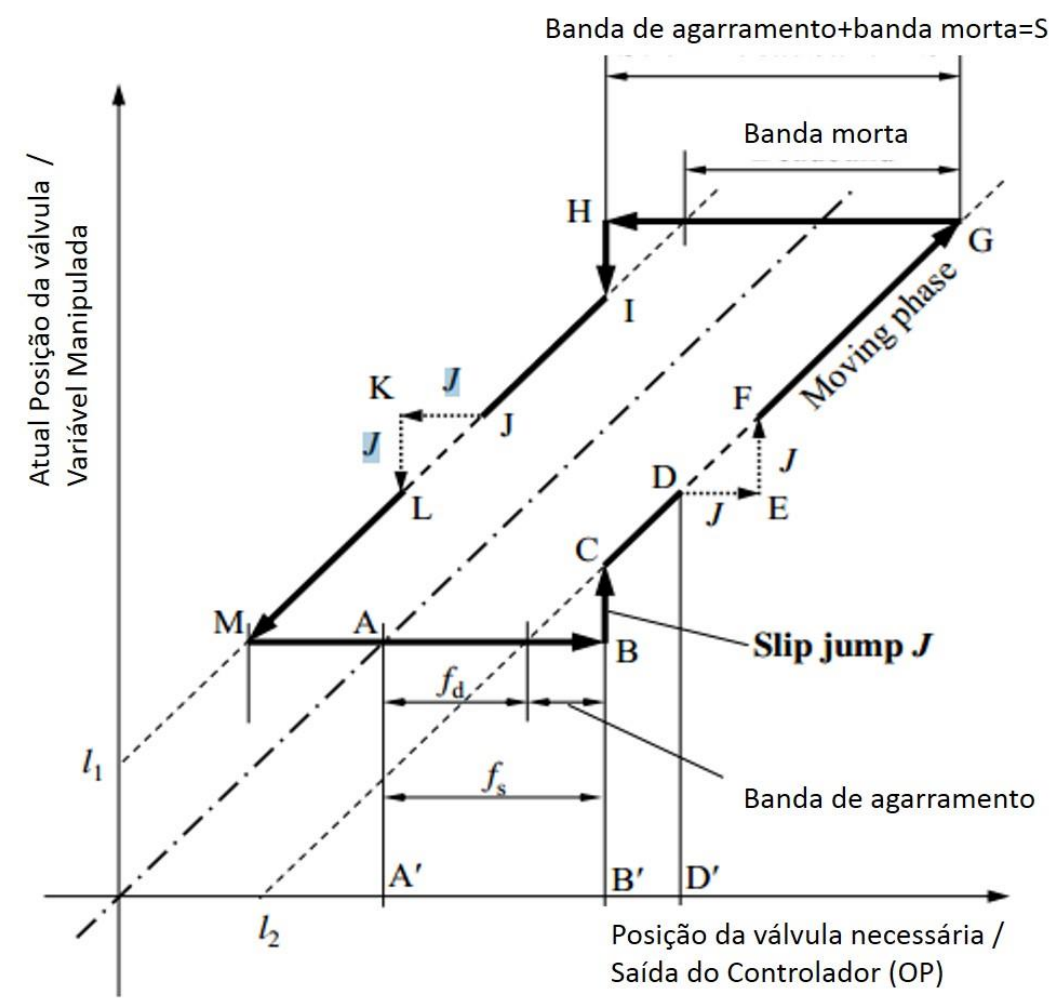

Autor: Mohieddine e Huang (2010).

$$
m \frac{d^{2} x}{d t^{2}}=F_{\text {pressão }}-F_{\text {mola }}-F_{\text {atrito }}-F_{\text {fluido }}-F_{i}
$$

sendo que $F_{\text {pressao }}=S_{a} P$ é a força aplicada pela pressão no diafragma do atuador, sendo $S_{a}$ a área do diagrama e $P$ a pressão no atuador; $F_{\text {mola }}=K x$ é a força aplicada pela mola do atuador, sendo $K$ a constante de elasticidade da mola; $F_{\text {fluido }}$ é a força aplicada pelo fluido de processo no obturador da válvula; $F_{\text {atrito }}$ é a força de atrito na haste da válvula e $F_{i}$ é uma força extra de assentamento do obturador na sede da válvula. $m$ é a massa das partes móveis da válvula (obturador + haste) e $x$ é a posição da haste da válvula.

Em (KAYIHAN; DOYLE, 2000) afirmou-se que as forças $F_{\text {fluido }}$ e $F_{i}$ podem ser desconsideradas por serem muito pequenas em comparação com as outras forças envolvidas. A nova forma do balanço de forças é:

$$
m \frac{d^{2} x}{d t^{2}}=F_{\text {pressão }}-F_{\text {mola }}-F_{\text {atrito }}
$$

A grande diferença que existe entre os diferentes modelos físicos de válvulas de controle que existem, está na estratégia de calcular $F_{\text {atrito }}$. Pelos estudos feitos em (GARCIA, 2008), se observa que o modelo físico de Karnopp apresenta um bom desempenho. A força de atrito no modelo de Karnopp está definida da seguinte forma: 


$$
F_{\text {atrito }}=\left\{\begin{array}{cc}
F c \cdot \operatorname{sign}(\dot{x})+F_{V} \cdot \dot{x} & \text { se }|\dot{x}| \geq D V \\
F_{\text {pressão }}-k \cdot x & \text { se }|\dot{x}|<D V e\left|F_{\text {pressão }}-k \cdot x\right| \leq F_{S} \\
F_{S} \cdot \operatorname{sign}\left(F_{\text {pressão }}-k \cdot x\right) & \text { se }|\dot{x}|<D V e\left|F_{\text {pressão }}-k \cdot x\right|>F_{S}
\end{array}\right.
$$

$F_{c}, F_{s}$ e $F_{v}$ são os parâmetros do modelo e correspondem aos coeficientes de atrito de Coulomb, estático e viscoso, respectivamente. $x$ é a posição da haste, $\dot{x}$ é a velocidade da haste e $D V$ é a velocidade limite.

Também em (GARCIA, 2008) é mostrado outro modelo para calcular a força do atrito, este modelo é conhecido como modelo de atrito clássico. Este modelo é representado pela equação (3.8):

$$
F_{\text {atrito }}=\left[F_{c}+\left(F_{S}-F_{C}\right) e^{-\frac{\dot{x}^{2}}{V_{s}}}\right] \operatorname{sign}(\dot{x})+F_{v} \cdot \dot{x}
$$

onde a função $\operatorname{sign}(\dot{x})$ é:

$$
\operatorname{sign}(\dot{x})=\left\{\begin{array}{c}
-1 \text { se } \dot{x}<0 \\
0 \text { se } \dot{x}=0 \\
1 \text { se } \dot{x}>0
\end{array}\right.
$$

e $V_{s}$ é a velocidade de Stribeck (STRIBECK, 1902). A função sign() tem uma descontinuidade, sendo que alguns algoritmos proposto neste trabalho necessitam de um sistema contínuo e suave. Por isso no trabalho realizado por (KAYIHAN; DOYLE, 2000) troca-se a função sign pela função tangente hiperbólica, a qual tem um comportamento muito parecido à função sign(), só que é contínua e suave. A nova forma do modelo é apresentada na equação (3.10).

$$
F_{\text {atrito }}=\left[F_{c}+\left(F_{S}-F_{C}\right) e^{-\dot{\dot{x}}^{2}}\right] \cdot \tanh (\sigma \dot{x})+F_{v} \cdot \dot{x}
$$

onde $\sigma$ é uma constante positiva. A Figura 10 mostra o comportamento da função $\tanh (\sigma$. $\dot{x})$

No trabalho realizado por (ROMANO; GARCIA, 2008) afirma-se que o atrito viscoso pode ser desconsiderado no modelo de atrito clássico, devido à ordem de grandeza das forças atuantes na haste da válvula. Então a mudança do modelo de atrito clássico é mostrada na equação (3.11).

$$
F_{\text {atrito }}=\left[F_{c}+\left(F_{S}-F_{C}\right) e^{-{\frac{\dot{x}}{V_{s}}}^{2}}\right] \cdot \tanh (\sigma \dot{x})
$$


Figura 10: Comparação das funções tangente hiperbólica e sign.

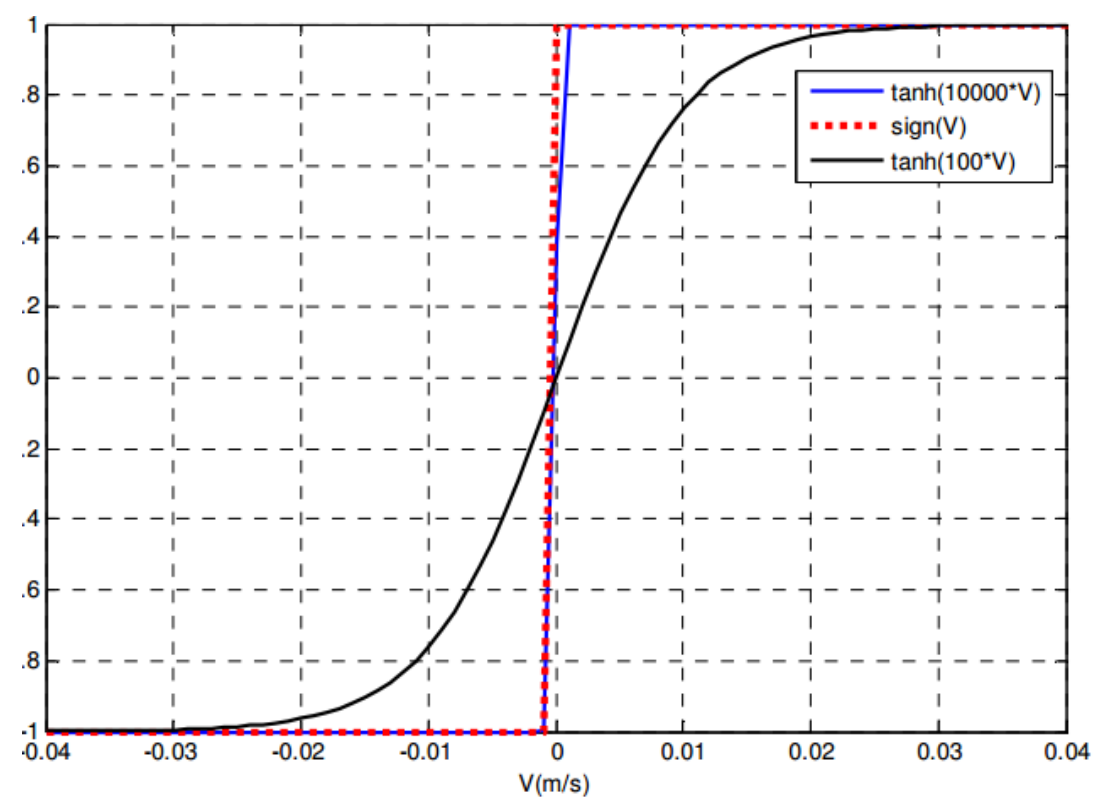

Autor: Baeza (2013).

Para o projeto dos controladores, o modelo de atrito clássico representado pela equação (3.11) será utilizado, pois estes controladores precisam de um modelo contínuo. A Tabela 1 apresenta os parâmetros estimados da válvula de controle com gaxetas de grafite.

Tabela 1: Parâmetros estimados da válvula de controle com gaxetas de grafite (SILVA, 2013).

\begin{tabular}{cc}
\hline Parâmetro & Valor \\
\hline $\mathrm{m}$ & $1,6 \mathrm{~kg}$ \\
$F_{S}$ & $773 \mathrm{~N}$ \\
$F_{C}$ & $684 \mathrm{~N}$ \\
$F_{V}$ & $2,32 \cdot 10^{-4} \mathrm{~N} \cdot \mathrm{s} / \mathrm{m}$ \\
$K$ & $2,10 \cdot 10^{-5} \mathrm{~N} / \mathrm{m}$ \\
$S_{a}$ & $0,0445 \mathrm{~m}^{2}$
\end{tabular}




\section{Compensadores de atrito}

As não-linearidades nas válvulas de controle têm sido identificadas como a maior fonte de variabilidade nas malhas de controle, as quais ocasionam uma diminuição no desempenho, gerando perdas de produção como também financeiras. É por isso que existe a necessidade da implementação de estratégias que não impliquem no investimento em equipamentos custosos. Estas estratégias são métodos de compensação do atrito, os quais podem ser implementados mediante um $P L C$ ou $S D C D$, que são equipamentos muito comuns na indústria, portanto não geram gastos extras.

A seguir vai-se explicar os diferentes métodos de compensação de atrito que foram implementados neste trabalho.

\subsection{Métodos para compensar o stiction}

\subsubsection{Compensador CR}

Como já foi dito anteriormente, o backlash é um fenômeno que gera uma banda morta. Em (HÄGGLUND, 2007) foi proposta uma estratégia para compensar este fenômeno que também é um dos efeitos gerados pelo stiction. Normalmente, uma válvula de controle não se move por sua própria conta ou quando o sinal de controle é constante, a menos que o posicionador seja instável. Portanto, pode-se dizer que a posição da haste da válvula com respeito ao backlash é dada pelo sinal de controle e da sua história. (HÄGGLUND, 2007) descreve uma forma para compensar este fenômeno, a qual é fazer saltar o sinal de controle através do backlash cada vez que a ação de controle é invertida. A equação que descreve isto é apresentada a seguir:

$$
u=u_{c}+u_{F F}
$$

sendo que $u_{c}$ é a saída do controlador e $u_{F F}$ é a compensação para o backlash. A expressão ideal para o compensador de backlash tem a seguinte forma:

$$
u_{F F}=\frac{d}{2} \operatorname{sign}\left(\frac{d u_{c}}{d t}\right)
$$


onde $d$ é a banda morta. Como na indústria não é possível oferecer uma situação ideal, (IVAN; LAKSHMINARAYANAN, 2009) apresenta uma modificação para este compensador. Os autores utilizaram a mesma metodologia de (HÄGGLUND, 2007) para compensar a banda morta e a banda de agarramento gerada pelo atrito. A Equação (4.3) representa o método proposto. Este método foi chamado de Constant Reinforcement $(C R)$ :

$$
u_{F F}=\frac{S}{2} \operatorname{sign}\left(\frac{d u_{c}}{d t}\right)
$$

O termo $u_{c}$ é o sinal de controle e $S$ o parâmetro de atrito do modelo de Kano. A Figura 11 mostra o esquema geral deste compensador.

Figura 11: Diagrama de blocos do compensador CR1.

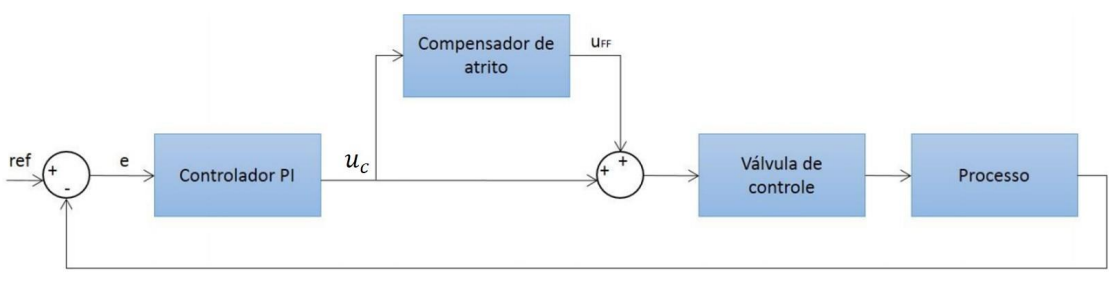

Fonte: Autor.

Também (HÄGGLUND, 2007) considera outra alternativa para compensar o backlash, onde se propõe em vez de considerar o sinal da derivada do compensador, considerar o sinal de erro. A estrutura geral deste compensador, denominado CR2, é mostrada na Figura 12.

Figura 12: Diagrama de blocos do compensador CR2.

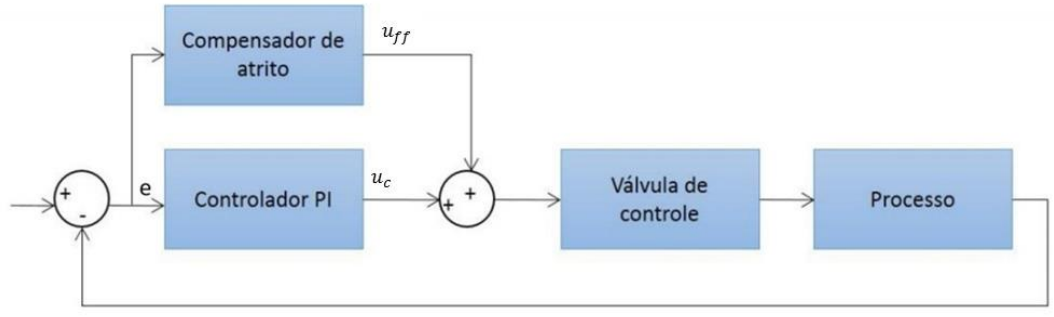

Fonte: Autor.

$$
u_{F F}=\frac{S}{2} \operatorname{sign}(e(t))
$$




\subsubsection{Compensador Knocker}

A metodologia apresentada em (HÄGGLUND, 2002) para compensar o efeito do atrito estático (Stiction) nas válvulas de controle consiste na adição de impulsos ao sinal de controle. Cada impulso tem uma carga energética relativamente pequena. A ideia é adicionar pulsos curtos de igual amplitude e duração na direção da taxa de variação do sinal de controle ao sinal de controle. A energia fornecida por cada pulso deve ser exatamente a suficiente para superar o atrito estático, sendo que esta energia gera um pequeno movimento na haste da válvula. Estes pulsos têm que ser somados à saída de um controlador de ação integral para conseguir os movimentos pequenos desejados. A estrutura deste compensador se pode observar na Figura 13.

Figura 13: Diagrama de blocos para o compensador Knocker.

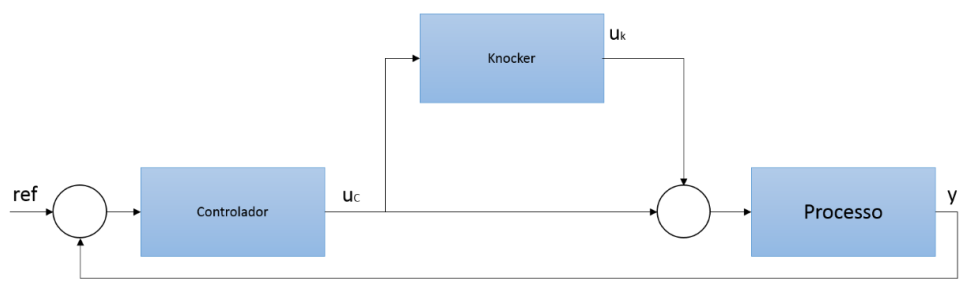

Fonte: Autor.

O sinal de controle consiste na seguinte expressão:

$$
u(t)=u_{c}(t)+u_{k}(t)
$$

sendo que $u_{c}(t)$ é a saída do controlador e $u_{k}(t)$ a saída do compensador Knocker. A saída $u_{k}(t)$ é a sequência de pulsos, caracterizada por três parâmetros: o tempo entre cada pulso $\left(h_{k}\right)$, a amplitude do pulso $(a)$ e a largura do pulso $(\tau)$. A variável $t_{p}$ é o instante de início do pulso anterior. A seguir se mostra a equação que representa o valor de $u_{k}(t)$ :

$$
u_{k}(t)=\left\{\begin{array}{cc}
a \cdot \operatorname{sign}\left(u_{c}(t)-u_{c}\left(t_{p}\right)\right) & t \leq t_{p}+h_{k}+\tau \\
0 & t>t_{p}+h_{k}+\tau
\end{array}\right.
$$

A estrutura dos pulsos do compensador Knocker tem a forma apresentada na Figura 14.

Em (HÄGGLUND, 2002), recomenda-se no momento da escolha dos parâmetros do compensador, no caso do pulso de amplitude $a$, que o valor esteja no intervalo de $1 \%<a<4 \%$, lembrando que a saída do compensador é adicionada ao sinal de controle. Se a amplitude for grande demais, a válvula abre muito, o que poderia tornar o sistema incontrolável. Para o caso de $\tau$, não pode ser menor do que o período de amostragem, o autor recomenda tomar um valor de uma ou duas vezes o período de amostragem. Para a variável $h_{k}$, se 
Figura 14: Pulsos do compensador Knocker.

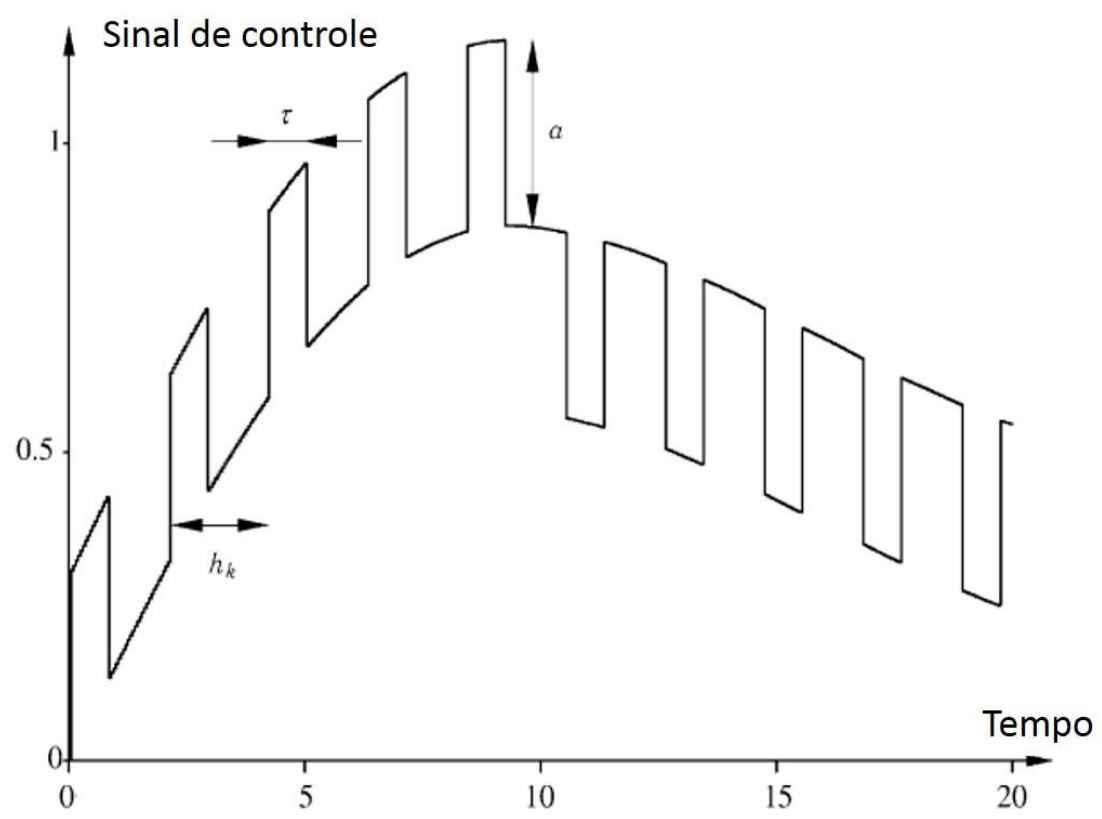

Autor: Hägglund (2002).

recomenda um valor entre duas a cinco vezes o período de amostragem.

Em (SRINIVASAN; RENGASWAMY, 2005) fez-se um estudo para a compensação do atrito estático. Os autores fizeram uma pesquisa, tentando relacionar a variável a com respeito ao atrito estático presente na válvula de controle. Eles concluíram que um valor adequado para $a$, com base em um modelo de um parâmetro é o seguinte:

$$
a=\frac{d}{2}
$$

Em (SILVA, 2013), o valor de $a$ foi escolhido mediante os parâmetros do modelo de Kano, isto com o fim de compensar o efeito da banda morta e da banda de agarramento (slip-jump). A equação que apresenta o valor de a é:

$$
a=\frac{S}{2}
$$

\subsubsection{Compensador Two-move}

A presença do stiction nas válvulas de controle ocasiona que a haste da válvula não possa alcançar a sua saída em estado estacionário. Uma forma de solucionar isto é adicionar um sinal de compensação à saída do controlador, o qual obrigaria a haste alcançar e manter-se no seu valor de estado estacionário. Em (SRINIVASAN; RENGASWAMY, 2008) foi proposto um novo método para realizar a compensação do atrito estático, este método 
é chamado two-move. A finalidade deste compensador é conseguir uma redução da variabilidade da variável de processo e também a variabilidade existente na haste da válvula de controle. Este compensador deve ser executado no momento em que a variável controlada se encontre oscilando ao redor do set-point. O compensador two-move está baseado no modelo de um parâmetro.

A estratégia do compensador two-move está baseada na implementação de dois movimentos. O primeiro consiste em tirar a haste da válvula de controle que se encontra em uma posição agarrada. O segundo movimento consiste em levar esta haste até a posição correspondente ao valor de referência. No momento de realizar o primeiro movimento, este deve ser suficientemente forte para conseguir que no segundo movimento a haste da válvula de controle consiga atingir a referência desejada e superar o efeito do atrito estático. As seguintes equações representam o compensador two-move:

$$
\begin{gathered}
1^{o} \text { Movimento: } u_{k}(t)=\operatorname{sgn}\left(\frac{d u_{c}}{d t}\right)\left(\left|u_{c}(t)\right|+d\right) \\
2^{o} \text { Movimento }: u_{k}(t+1)=-u_{c}(t+1)
\end{gathered}
$$

sendo que $d$ é a banda de agarramento do modelo de um parâmetro. O problema deste modelo, como já foi mencionado, é ele que não considera a existência da banda morta, que é um fenômeno muito comum em válvulas de controle. Em (CUADROS, 2012) fez-se uma modificação, adaptando o compensador two-move a um modelo de dois parâmetros, conforme se indica a seguir:

$$
\begin{gathered}
1^{o} \text { Movimento: } u_{k}(t)=\operatorname{sgn}\left(\frac{d u_{c}(t)}{d t}\right)\left(\left|u_{c}(t)\right|\right)+d \\
2^{o} \text { Movimento : }\left\{\begin{array}{cc}
u_{k}(t+1)=-\left(u_{c}(t+1)-u_{s s}\right) & e(t+1)>0 \\
u_{k}(t+1)=-\left(u_{c}(t+1)-u_{s s}-S-J\right) & e(t+1)<0
\end{array}\right.
\end{gathered}
$$

onde $u_{s s}$ é o sinal de controle, o qual consegue estabilizar a haste na referência desejada. Com a finalidade de melhorar este compensador e fazê-lo menos complicado, (CUADROS, 2012) realizou uma nova proposta do compensador two-move, a qual pretendia não depender do conhecimento do valor de $u_{s s}$. A nova estratégia implementada em (CUADROS, 2012) tem como novidade que agora será um compensador de quatro movimentos, os quais consistem no seguinte: o primeiro movimento afasta a haste da válvula de controle da posição onde se encontra presa. O segundo movimento é necessário para mudar a direção do movimento da válvula com o objetivo de atingir a posição desejada. O terceiro movimento tem o mesmo sentido do outro e é utilizado para calcular o ganho estacionário 
do processo. O último movimento leva a haste da válvula à posição desejada em estado estacionário. Em (ELY; LONGHI, 2011), se realizou um estudo sobre o compensador twomove. Eles propuseram uma nova versão deste compensador, pois embora o compensador proposto em (CUADROS, 2012) conseguisse melhorar o desempenho do compensador twomove original, ainda é sensível a perturbações. A proposta feita em (ELY; LONGHI, 2011) considera que a saída do compensador $(O P C)$ não é somada ao sinal do controlador, mas a saída do compensador é enviada à válvula de controle. O esquema proposto é apresentado na Figura 15.

Figura 15: Diagrama de blocos para o compensador Two-move modificado.

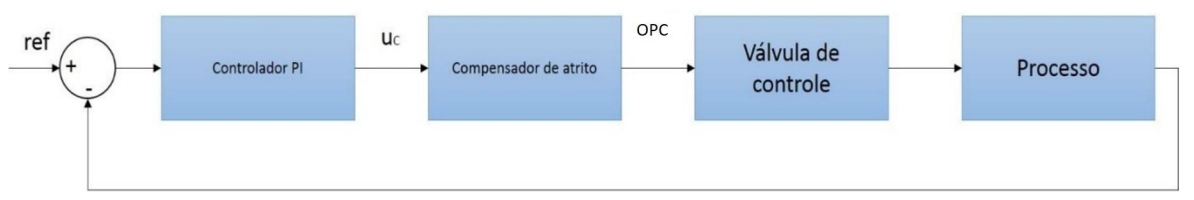

Fonte: Autor.

Os dois movimentos propostos são expressos mediante as seguintes equações:

$$
\begin{gathered}
1^{o} \text { Movimento: } O P C\left(t_{k}\right)=O P C\left(t_{k-1}\right) \\
+\operatorname{sgn}\left(u_{c}\left(t_{k}\right)-O P C\left(t_{k-1}\right)\right)\left(\left|u_{c}\left(t_{k}\right)-O P C\left(t_{k-1}\right)\right|+d\right)
\end{gathered}
$$

$2^{o}$ Movimento : $O P C\left(t_{k}-1\right)=O P C\left(t_{k}\right) \operatorname{sgn}\left(u_{c}\left(t_{k}\right)-O P C\left(t_{k}\right)\right)+d$

onde $t_{k}$ é o instante de amostragem atual. Este modelo tem quer ser adaptado ao modelo de dois parâmetros. Como se pode observar em (SILVA, 2013), adiciona-se o cálculo da direção do movimento a ser realizado (dir) e também o parâmetro do modelo de um parâmetro $d$ é substituído pelo parâmetro $J$. As equações que descrevem as mudanças e ação do compensador são apresentadas a seguir:

- Se $\left|u_{c}\left(t_{k}\right)-O P C\left(t_{k-1}\right)\right|>J$

$$
O P C\left(t_{k}\right)=u_{c}\left(t_{k}\right) \text { e } \operatorname{dir}\left(t_{k}\right)=\operatorname{sgn}\left(u_{c}\left(t_{k}\right)-O P C\left(t_{k-1}\right)\right)
$$

- Se $B O P<\left|u_{c}\left(t_{k}\right)-O P C\left(t_{k-1}\right)\right| \leq J$

$1^{o}$ Movimento : OPC $\left(t_{k}\right)=O P C\left(t_{k+1}\right)+\left(\left|u_{c}\left(t_{k}\right)-O P C\left(t_{k-1}\right)\right|+J\right) \operatorname{sgn}\left(u_{c}\left(t_{k}\right)-\right.$ $\left.O P C\left(t_{k-1}\right)\right)$ 


$$
\begin{gathered}
\operatorname{dir}\left(t_{k}\right)=\operatorname{sgn}\left(u_{c}\left(t_{k}\right)-O P C\left(t_{k-1}\right)\right) \\
2^{o} \text { Movimento : OPC }\left(t_{k}\right)=O P C\left(t_{k+1}\right)-\operatorname{Jsgn}\left(u_{c}\left(t_{k}\right)-O P C\left(t_{k-1}\right)\right) \\
\operatorname{dir}\left(t_{k}\right)=-\operatorname{dir}\left(t_{k-1}\right)
\end{gathered}
$$

- Se $\left|u_{c}\left(t_{k}\right)-O P C\left(t_{k-1}\right)\right|<B O P$

$$
\begin{gathered}
O P C\left(t_{k}\right)=O P C\left(t_{k-1}\right) \\
\operatorname{dir}\left(t_{k}\right)=\operatorname{dir}\left(t_{k-1}\right)
\end{gathered}
$$

onde BOP é a banda de tolerância utilizada para desativar o compensador no caso em que a variabilidade seja eliminada ou não apareça por momentos no processo.

\subsubsection{Controle não-linear por modos deslizantes}

A seguir são introduzidos os conceitos necessários para o desenvolvimento de um compensador baseado em controle não-linear por modos deslizantes.

\subsubsection{Linearização Exata}

É muito comum na indústria encontrar processos não-lineares, pelo que em alguns casos é necessário calcular uma relação linear entre a entrada e saída do sistema, para que seja possível implementar técnicas de controle. Antes de implementar uma metodologia de controle não-linear, o sistema tem que ser linearizado em malha fechada. A técnica usada para realizar esta ação se conhece como técnica de linearização por realimentação (feedback linearization).

Em (KHALIL, 2002) fez-se um estudo desta técnica, onde o objetivo foi elaborar uma lei de controle que faz que o sistema não-linear em malha fechada tenha um comportamento de um sistema linear. Considere o seguinte sistema não-linear:

$$
\left\{\begin{array}{c}
\dot{x}=f(x)+g(x) u \\
y=h(x)
\end{array}\right.
$$

onde $x$ é o vetor de estados, $\dot{x}$ é a derivada temporal do vetor de estados, $u$ é a entrada do modelo, $f(x), g(x)$ e $h(x)$ são funções que descrevem o comportamento matemático do sistema. Procuram-se as condições necessárias para obter uma realimentação não linear da seguinte forma: 


$$
u=\alpha(x)+\beta(x) v
$$

E uma mudança de variáveis:

$$
z=T(x)
$$

sendo que esta mudança transforma o sistema não-linear em uma forma linear equivalente. A ideia é representar o novo sistema por meio da transformação z da seguinte forma:

$$
\dot{z}=A \cdot z+b \cdot v
$$

onde $v$ é a nova entrada do sistema. Para poder aplicar o método da linearização exata, primeiro é necessário definir o conceito de grau relativo: o grau relativo de um sistema é o número de vezes que a saída do sistema tem que ser derivada para que o sinal $u$ (entrada) apareça de forma explícita na equação. Um sistema possui grau relativo $p$ se são satisfeitas as condições apresentadas a seguir:

1. $L_{g} L_{f}^{k} h(x)=0$, para todo $k=0 \ldots p-2$

2. $L_{g} L_{f}^{p-1} h(x) \neq 0$

sendo que:

- $L_{f} h(x)$ é a derivada de Lie de $h(x)$ com respeito a $f(x)$.

- $L_{g} h(x)$ é a derivada de Lie de $h(x)$ com respeito a $g(x)$.

Só se o sistema mostrado na Equação (4.15) tem grau relativo $p=n$, a linearização exata tem solução, isto significa que se a dimensão do sistema for igual ao grau relativo do sistema, o problema da linearização poderá ser resolvido por meio da seguinte lei de controle, proposta em (ISIDORI, 1988):

$$
\begin{aligned}
& \alpha(X)=\frac{-L_{f}^{p} h(x)}{L_{g} L_{f}^{p-1} h(x)} \\
& \beta(x)=\frac{1}{L_{g} L_{f}^{p-1} h(x)}
\end{aligned}
$$


A mudança de coordenadas $z=T(x)$ é dada por:

$$
\begin{gathered}
z_{1}=h(x) \\
z_{2}=L_{f} h(x) \\
\cdots \\
z_{n}=L_{f}^{(n-1)} h(x)
\end{gathered}
$$

\subsubsection{Linearização do sistema dinâmico da válvula de controle}

O sistema dinâmico da válvula de controle no espaço de estados é descrito na Equação (4.21), sem considerar perturbações para a linearização.

$$
\left\{\begin{array}{c}
\dot{x}_{1}=x_{2} \\
\dot{x_{2}}=\frac{K_{p} S_{a}}{m} u-\frac{F_{\text {atrito }}}{m}-\frac{K x_{1}}{m} \\
\dot{x}_{3}=\frac{v\left(x_{1}\right)-x_{3}}{\tau} \\
y=x_{3}
\end{array}\right.
$$

onde:

- $x_{1}$ é a posição da haste.

- $\dot{x}_{1}=x_{2}$ é a velocidade da haste.

- $x_{3}$ é a vazão.

- y é a saída da planta (vazão).

- $v(x)$ é a função de ganhos estáticos entre a vazão e a posição (curva característica da válvula) (HIDALGO, 2015).

Substituindo-se a equação (3.8) na equação (4.21) e reorganizando a expressão, tem-se:

$$
\left\{\begin{array}{c}
\dot{x}_{1}=x_{2} \\
\dot{x}_{3}=\frac{v\left(x_{1}\right)-x_{3}}{\tau} \\
\dot{x}_{2}=\frac{1}{m} \cdot\left[u \cdot K_{p} \cdot S_{a}-K \cdot x_{1}-\left(F_{c}+\left(F_{s}-F_{c}\right) \cdot e^{-\left(\frac{x_{2}}{V_{s}}\right)^{2}}\right) \cdot \tanh \left(\sigma \cdot x_{2}\right)-F_{v} \cdot x_{2}\right] \\
y=x_{3}
\end{array}\right.
$$

Depois da descrição de estados da planta, vai-se realizar o projeto da lei de controle linearizante. O primeiro passo é calcular o grau relativo do sistema. Para isso, vai-se derivar a saída quantas vezes for necessário, até conseguir que a entrada $u$ esteja presente na equação. A seguir se apresenta o resultado final na equação (4.23): 


$$
\dddot{y}=\frac{v^{\prime \prime}\left(x_{1}\right) x_{2}^{2}}{\tau}+\frac{v^{\prime}\left(x_{1}\right)}{\tau}\left(\frac{K_{p} S_{a}}{m} u-\frac{F_{\text {atrito }}}{m}-\frac{K x_{1}}{m}\right)-\frac{v^{\prime}\left(x_{1}\right) x_{2}}{\tau^{2}}+\frac{v\left(x_{1}\right)}{\tau^{3}}-\frac{x_{3}}{\tau^{3}}
$$

onde:

- $\dddot{y}$ é a derivada de terceira ordem da vazão.

Depois de analisar a equação (4.23), pode-se ver que na terceira derivada da saída, a entrada da planta $u$ aparece explicitamente na equação, isto significa que o sistema possui um grau relativo de três e a ordem do sistema também é três, portanto haverá linearização.

Tomando a equação (4.16), a lei de controle linearizante para a válvula de controle é apresentada na equação (4.24):

$$
\tilde{u}=\frac{1}{K_{p} S_{a}}\left(K x_{1}+F_{\text {atrito }}\right)+\frac{m}{K_{p} S_{a} v^{\prime}\left(x_{1}\right)}\left(\frac{v^{\prime}\left(x_{1}\right) x_{2}}{\tau}-v^{\prime \prime}\left(x_{1}\right) x_{2}^{2}+\frac{x^{3}}{\tau^{2}}-\frac{v\left(x_{1}\right)}{\tau^{2}}\right)
$$

No trabalho realizado por (HIDALGO, 2015), afirma-se que alguns termos da equação (4.24) podem ser desprezados. A nova lei de controle linearizante é apresentada a seguir:

$$
\tilde{u}=\frac{1}{K_{p} S_{a}}\left(K x_{1}+F_{\text {atrito }}\right)
$$

\subsubsection{Modos Deslizantes}

Este tipo de controle pode-se definir como a aplicação de um sinal de controle que muda em alta frequência e consegue levar o estado do sistema a um campo escalar $s(X)$, o qual é conhecido como superfície de escorregamento. Em outras palavras, este controlador conhece o comportamento atual de um sistema e a sua saída leva o sistema a uma posição desejada. A superfície é definida de tal forma que o estado cumpra as especificações desejadas (EDWARDS; SPURGEON, 1998).

A leis de controle por modos desliante apresenta as seguintes vantagens: robustez frente às incertezas dos parâmetros e certas dinâmicas não modeladas, imune a perturbações etc. Um dos aspectos mais interessantes dos modos deslizantes é a natureza descontínua da ação de controle. Considere o seguinte sistema: 


$$
x^{(n)}=f(X)+b(X) u
$$

onde o escalar $x$ é a saída de interesse, $u$ é a entrada de controle, $X$ é o vetor de esta$\operatorname{dos} X=\left[\begin{array}{llll}x & \dot{x} & \ldots & x^{(n-1)}\end{array}\right]^{T}, n$ é a dimensão do sistema, $f(X)$ é a função que descreve o sistema e $b(X)$ o ganho de controle. Suponha uma estimativa para a dinâmica de $f=\hat{f}$. A estimação do erro sobre a função $f$ está limitada por uma função que é conhecida $F=F(x, \dot{x})$ :

$$
|\hat{f}-f| \leq F
$$

A finalidade deste controle é conseguir que o estado $X$ possa realizar um seguimento nos tempos específicos em que varia o vetor de estados dinâmicos $X_{d}=\left[\begin{array}{llll}x_{d} & \hat{x}_{d} & \ldots & x_{d}^{(n-1)}\end{array}\right]^{T}$. $\mathrm{O}$ vetor de erro de seguimento pode-se expressar como:

$$
\tilde{X}=X-X_{d}=\left[\begin{array}{llll}
\tilde{x} & \dot{\tilde{x}} \ldots & \tilde{x}^{(n-1)}
\end{array}\right]^{T}
$$

A superfície de escorregamento está definida pela equação:

$$
s(X)=\left(\frac{d}{d t}+\lambda\right)^{n-1} \tilde{x}
$$

onde $\lambda$ é uma constante estritamente positiva correspondente à largura de banda do sistema de controle. A superfície de escorregamento caracteriza-se pelas seguintes condições de invariância:

$$
s(X)=0, \frac{d s(X)}{d t}=0
$$

Se o sistema estiver fora da superfície de escorregamento, isto é, quando $s(X) \neq 0$, usa-se uma ação de controle $u(t)$ tal que: $\frac{d s(X)}{d t}<0$ quando $s(X)>0$ e $\frac{d s(X)}{d t}>0$ quando $s(X)<0$, com uma forma descontínua dada pela seguinte expressão: 


$$
u=\left\{\begin{array}{l}
u^{+} \text {para } s(x)>0 \\
u^{-} \text {para } s(x)<0
\end{array}\right.
$$

A lei de controle por modos deslizantes tem a seguinte forma genérica:

$$
u=\frac{\left(\hat{u}-K_{c} \cdot \operatorname{sgn}(s)\right)}{\hat{b}(x)}
$$

O ganho $K_{c}$ é definido a fim de cumprir a condição de escorregamento e compensar os erros que existem entre o modelo e o sistema real.

\subsubsection{Camada Limite}

A lei de controle mostrada na Equação (4.32) possui um termo descontínuo, que depende do valor da variável $s$. Isto pode ocasionar uma oscilação elevada de alta frequência na ação de controle quando o sistema encontra-se próximo à superfície $s(t)$. Este comportamento conhece-se como chattering. Na Figura 16 se mostra esse efeito.

Figura 16: Efeito Chattering.

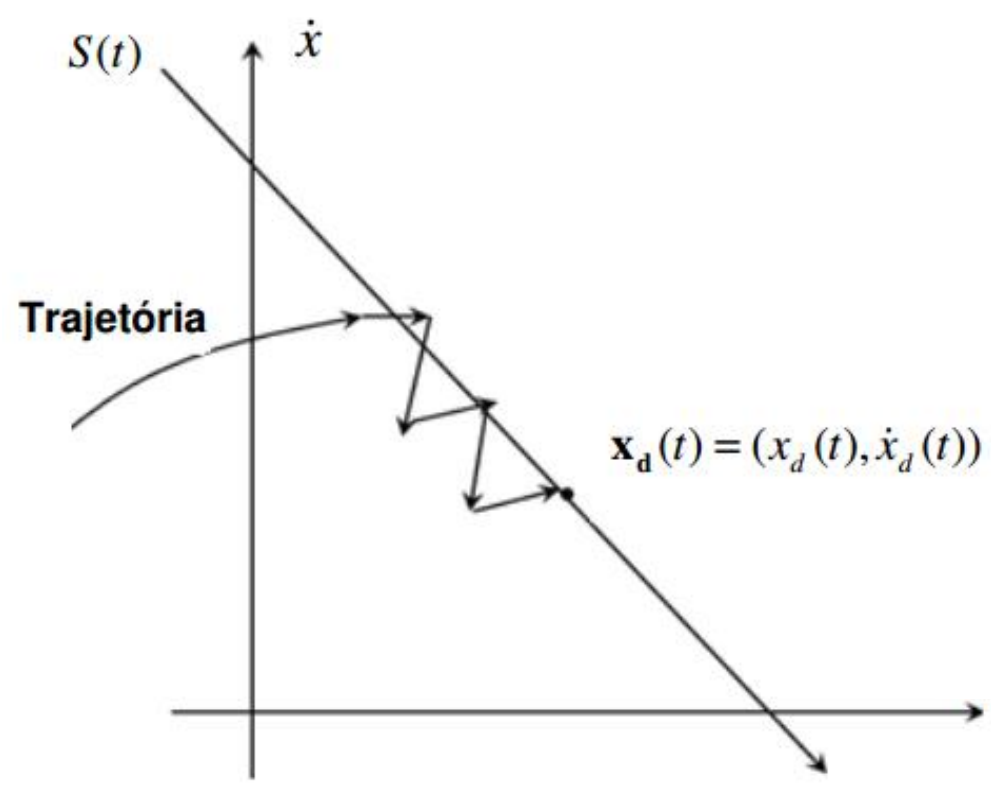

Autor: Agostinho (2009).

Para conseguir diminuir ou suavizar o efeito do chaveamento do sinal de controle, em (SLOTINE; LI, 1991) sugere-se trocar a função sign pela função saturação. Então a nova 
lei de controle tem a seguinte forma:

$$
u=\frac{\left(\hat{u}-K_{c} \cdot \operatorname{sat}\left(\frac{s}{\Phi}\right)\right)}{\hat{b}(x)}
$$

sendo que $\Phi$ é a camada limite e:

$$
\operatorname{sat}\left(\frac{s}{\Phi}\right)=\left\{\begin{array}{c}
\left(\frac{s}{\Phi}\right) \text { se }|s| \leq \Phi \\
\operatorname{sgn}(s) \text { se }|s|>\Phi
\end{array}\right.
$$

Mediante esta estratégia pode-se eliminar o efeito do chaterring, porém introduz-se um erro de acompanhamento:

$$
|\tilde{y}| \leq \frac{\phi}{\lambda^{(n-1)}}
$$

\subsubsection{Modos Deslizantes Integrador}

Em (SLOTINE; LI, 1991) adicionou-se uma ação integrativa no controlador, com o objetivo de eliminar possíveis diferenças em estado estacionário (offsets) que existem entre o valor real e o valor desejado. Adicionar um integrador ocasiona um aumento da ordem do sistema. Para um sistema de segunda ordem a superfície de escorregamento $s$ se apresenta na equação (4.36):

$$
s(X)=\left(\frac{d}{d t}+\lambda\right)^{2} \int_{0}^{t} \tilde{x} \cdot d r=\dot{\tilde{x}}+2 \lambda \tilde{x}+\lambda^{2} \int_{0}^{t} \tilde{x} \cdot d r
$$

O novo termo da lei de controle é o seguinte:

$$
\hat{u}=-\hat{u}(x)+\ddot{x}_{d}-2 \lambda \dot{\tilde{x}}-\lambda^{2} \tilde{x}
$$




\section{Simulação dos compensadores de atrito}

Neste capítulo vão ser simulados os compensadores de atrito implementados em (SILVA, 2013) mediante um modelo da Planta Piloto de Vazão projetado em (MORA, 2014). A seguir se apresentam os resultados obtidos utilizando um controlador PI sintonizado pelo método da Síntese Direta e os compensadores CR1, CR2 e Knocker, Two-move e controlador por modos deslizantes com e sem integrador.

Neste trabalho de Mestrado, para sintonizar os controladores PI para a malha de vazão, utilizou-se o método da Síntese Direta. O processo foi modelado como um modelo de primeira ordem com tempo morto, como pode-se ver na equação (5.1).

$$
G_{p}(s)=\frac{K_{p} e^{-\Theta s}}{1+\tau s}
$$

Os parâmetros do controlador foram calculados a partir da resposta do sistema a um degrau variando entre $30 \%$ e $70 \%$ no sinal de controle do conversor I/P, sendo que:

- $K_{p}$ é o ganho do processo. Pode ser calculado como $\frac{\Delta V}{\Delta u}$, onde $\Delta V$ é a variação da vazão e $\Delta u$ é a variação do sinal de controle.

- $\Theta$ é o tempo morto. Pode ser calculado verificando quanto tempo depois do degrau de entrada, a saída do processo começa a mudar seu valor.

- $\tau$ é a constante de tempo. É calculado como a diferença entre o momento em que a saída do processo começa a mudar seu valor até o instante no qual a saída atinge o 63,2\% da sua variação total.

A tabela 2 apresenta os valores obtidos para o modelo de primeira ordem mais tempo morto do processo.

Tabela 2: Parâmetros do modelo de primeira ordem mais tempo morto do processo.

\begin{tabular}{ccc}
\hline$K_{p}[$ Adim $]$ & $\tau[\mathrm{s}]$ & $\Theta[\mathrm{s}]$ \\
\hline$-1,032$ & 2,5317 & 0,15 \\
\hline
\end{tabular}




\subsection{Sintonia do controlador PI para a malha de vazão}

A estratégia do método consiste na obtenção de um controlador baseando-se na saída ou resposta do sistema em malha fechada. Tendo em conta o diagrama apresentado na Figura 17, sua função de transferência em malha fechada pode ser expressa pela Equação $(5.2)$.

Figura 17: Sistema em malha fechada.

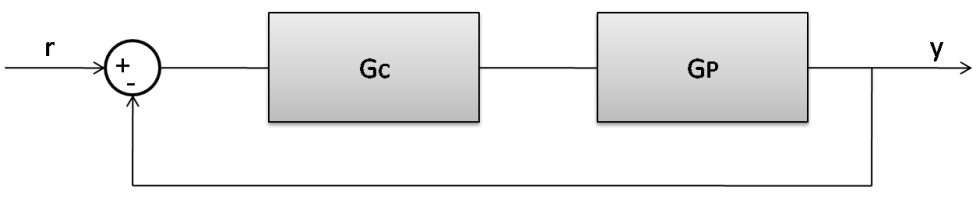

Fonte: Autor.

$$
H(s)=\frac{G_{p}(s) G_{c}(s)}{1+G_{p}(s) G_{c}(s)}
$$

sendo que $H(s)$ é a função de transferência da malha fechada, $G_{p}(s)$ é a função de transferência do processo e $G_{c}(s)$ é a função de transferência do controlador.

Em (TAN L.; RAJA AHMAD; IBRAHIM; TAIP, 2011) apresenta-se a forma da função de transferência $H(s)$. A especificação da função de transferência em malha fechada é fundamental para que o controlador tenha um ótimo desempenho. A função de transferência desejada é mostrada a seguir:

$$
H(s)=\frac{e^{-\Theta s}}{\lambda s+1}
$$

onde $\lambda$ é a constante de tempo da resposta em malha fechada desejada e $\Theta$ o tempo morto do sistema. Então, o controlador tem a seguinte estrutura:

$$
G_{c}(s)=\frac{1}{G_{p}(s)} \cdot\left(\frac{H(s)}{1-H(s)}\right)
$$

Considerando a Equação (5.1) e substituindo-se a Equação (5.3) na Equação (5.4) obtém-se a seguinte expressão: 


$$
\begin{gathered}
G_{c}(s)=\frac{\tau s+1}{K_{p} \cdot e^{-\Theta s}} \cdot\left(\frac{e^{-\Theta s}}{\lambda s+1-e^{-\Theta s}}\right) \\
G_{c}(s)=\frac{\tau s+1}{K_{p} \cdot\left(\lambda s+1-e^{-\Theta s}\right)}
\end{gathered}
$$

Aplicando-se a série de Taylor ao termo $e^{(-\Theta s)}$ e truncando-a, obtém-se uma aproximação igual a $1-\Theta s$, portanto a função de transferência do controlador PI fica da seguinte forma:

$$
G_{c}(s)=\frac{\tau s+1}{K_{p} \cdot(\lambda+\Theta) s}=\frac{\tau}{K_{p} \cdot(\lambda+\Theta)} \cdot\left(1+\frac{1}{\tau s}\right) \equiv K_{c}\left(1+\frac{1}{T_{i} s}\right)
$$

A equação anterior mostra que só o ganho $K_{c}$ depende de $\lambda$. Quanto menor for o valor de $\lambda$ mais agressivo será o controlador. Para um valor de $\lambda$ de $3.4 \mathrm{~s}$, os resultados obtidos do controlador PI são apresentados na tabela 3.

Tabela 3: Parâmetros do controlador PI obtida pelo método da Síntese Direta.

\begin{tabular}{ccc}
\hline Válvula & $K_{c}$ & $T_{i}[\mathrm{~s}]$ \\
\hline Grafite & 0,75 & 2,5317 \\
\hline
\end{tabular}

\subsection{Simulações apenas com controlador PI para o modelo da válvula com gaxetas de grafite}

As Figuras 18 a 19 apresentam os resultados obtidos empregando apenas o controlador PI no modelo da válvula com gaxetas de grafite.

É evidente que o modelo da válvula com gaxetas de grafite apresenta um nível alto de atrito. A válvula apresenta oscilações em torno do valor de referência. Estas oscilações em um processo real reduzem a eficiência e a qualidade do produto final.

Analisando-se o sinal de controle mostrado na Figura 19, o controlador apresenta variabilidade, o que diminui a vida útil dos equipamentos, como o desgate nas gaxetas gerado pelo movimento da haste. A Figura20 representa a posição da haste do modelo da válvula com gaxetas de grafite.

Em (SILVA, 2013) modificou-se a sintonia do controlador com o objetivo de remover as oscilações. Com base na teoria apresentada em (MOHAMMAD; HUANG, 2012) aumentou-se o valor de $T_{i}$. Os valores utilizados foram os seguintes: $T_{i}=12 \mathrm{~s}$ e $T_{i}=16 \mathrm{~s}$, mantendo-se 
Figura 18: Vazão para o modelo da válvula com gaxetas de grafite com controlador PI.

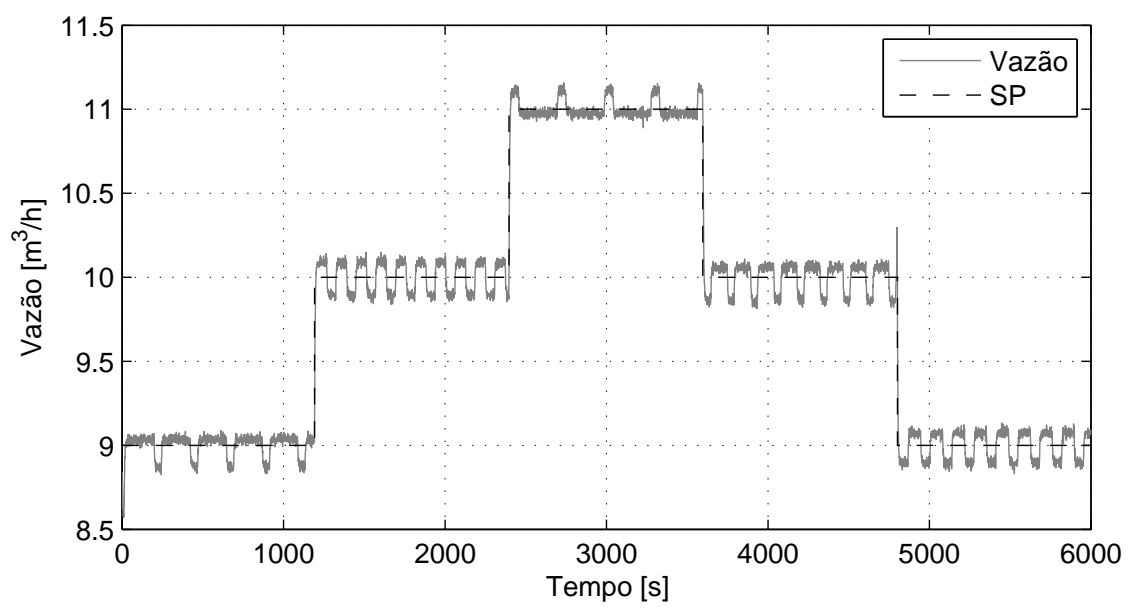

Fonte: Autor.

Figura 19: Sinal de controle para o modelo da válvula com gaxetas de grafite com controlador PI.

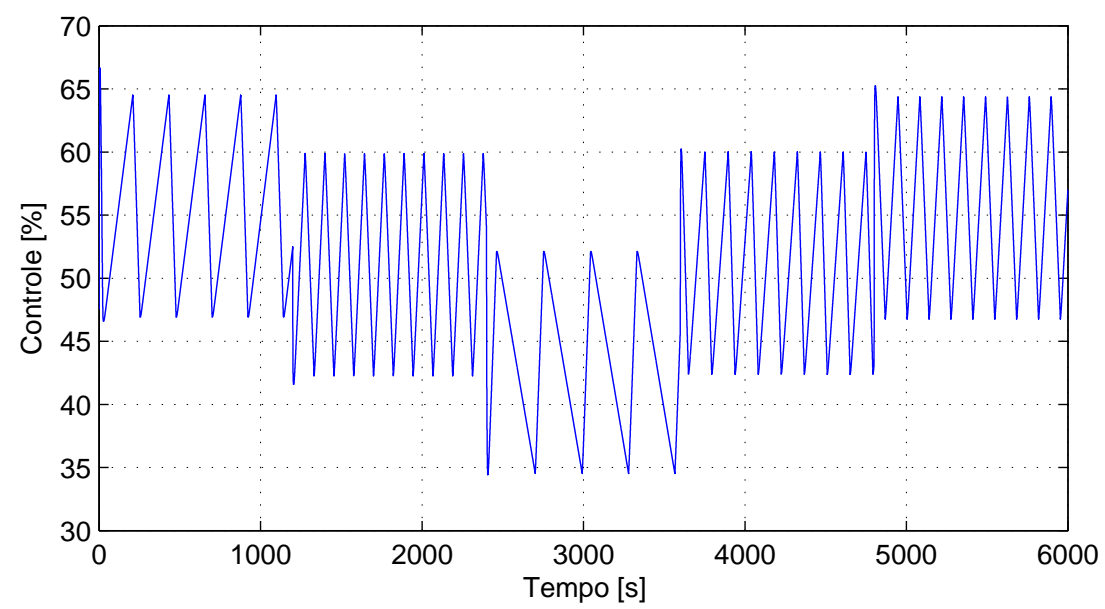

Fonte: Autor.

Figura 20: Posição da haste do modelo da válvula com gaxetas de grafite com controlador PI.

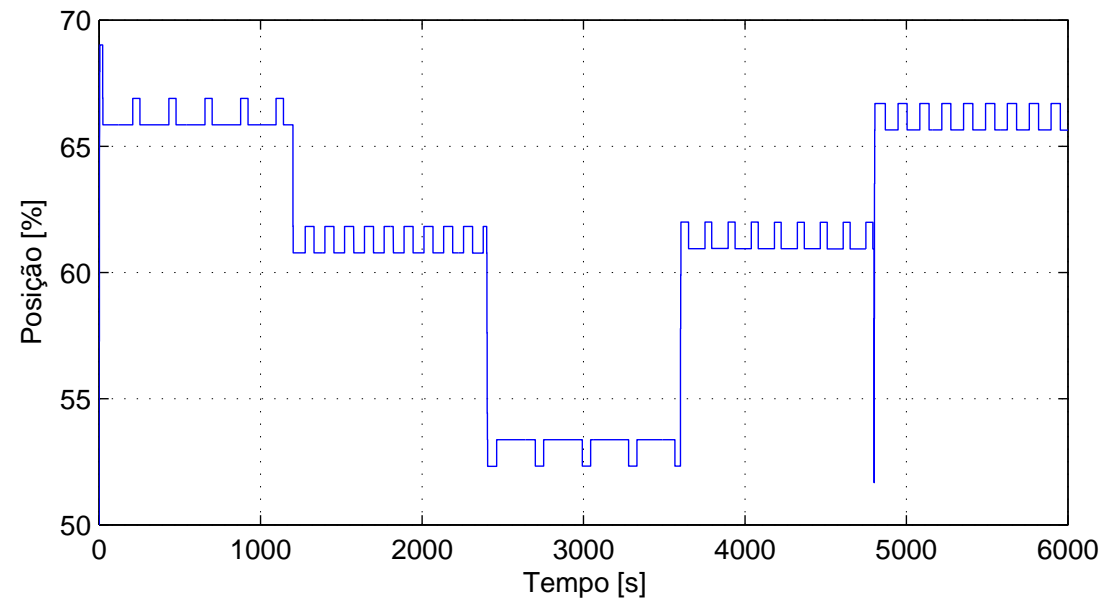

Fonte: Autor. 
o valor de $K_{c}$ original. As Figuras 21 a 25 apresentam os resultados obtidos nas simulações para o modelo da válvula com gaxetas de grafite.

Figura 21: Vazão para o modelo da válvula com gaxetas de grafite com controlador PI ( $T_{i}$ aumentado para $\left.12 \mathrm{~s}\right)$.

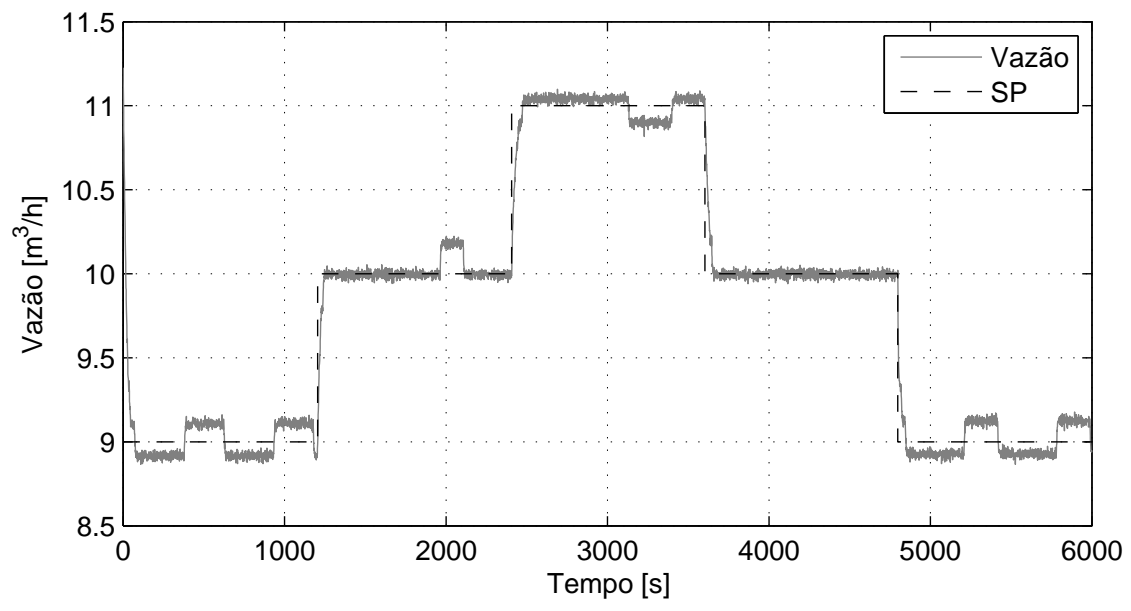

Fonte: Autor.

Figura 22: Sinal de controle para o modelo da válvula com gaxetas de grafite com controlador PI ( $T_{i}$ aumentado para $\left.12 \mathrm{~s}\right)$.

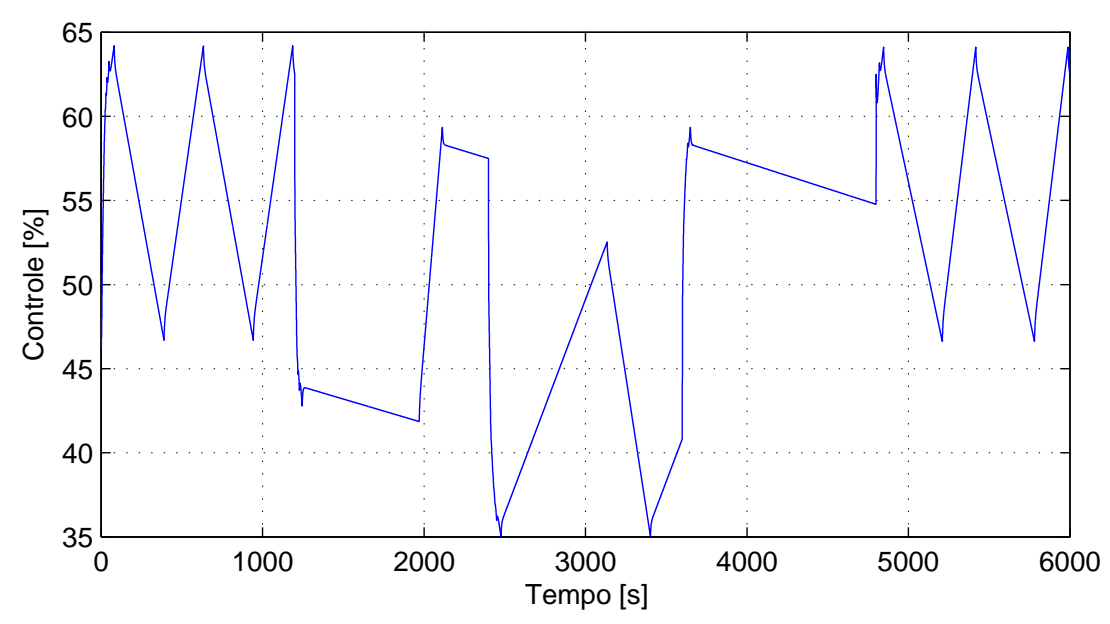

Fonte: Autor.

Pode-se ver nas Figuras 21 a 25 que ao aumentar o valor de $T_{i}$, consegue-se diminuir a variabilidade presente na variável controlada e no sinal de controle, porém o controlador PI com diferentes sintonias não conseguiu remover completamente a variabilidade.

Para uma melhor análise dos resultados são utilizados três índices de desempenho. O primeiro índice corresponde à integral do erro absoluto vezes o tempo (ITAE), a Equação (5.8) corresponde a este índice onde $e(\tau)$ é o erro da variável controlada em relação ao set-point. O segundo índice corresponde à integral do erro absoluto (IAE) e se representa mediante a Equação (5.9). O terceiro índice é $D_{v}$ e se representa mediante a Equação (5.10). Este índice está relacionado ao desgaste gerado na válvula de controle onde $x(k)$ 
Figura 23: Posição da haste do modelo da válvula com gaxetas de grafite com controlador PI ( $T_{i}$ aumentado para $\left.12 \mathrm{~s}\right)$.

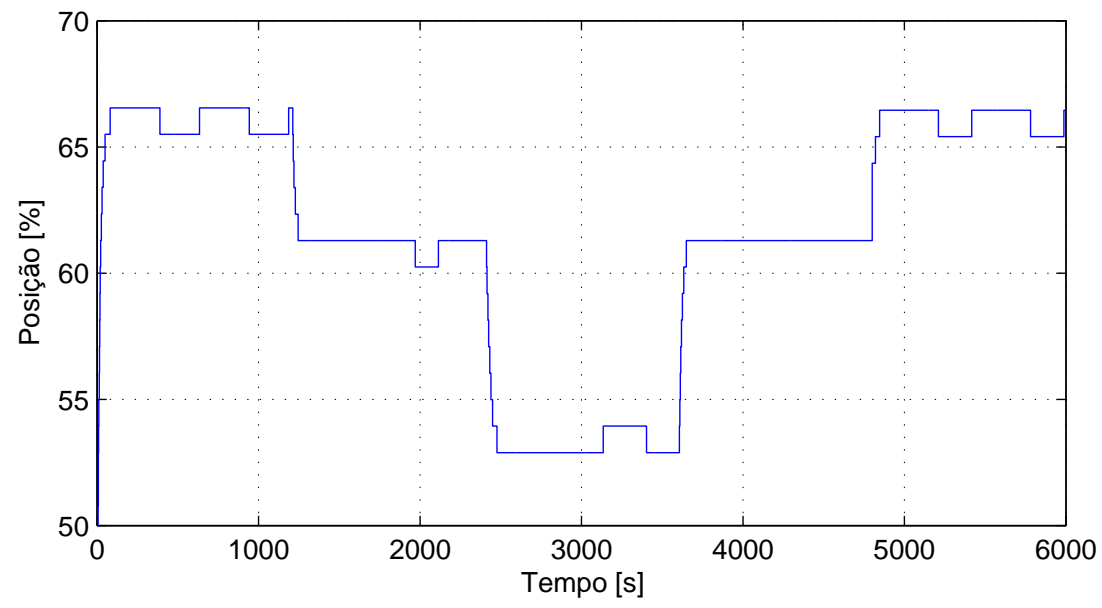

Fonte: Autor.

Figura 24: Vazão para o modelo da válvula com gaxetas de grafite com controlador PI ( $T_{i}$ aumentado para $\left.16 \mathrm{~s}\right)$.

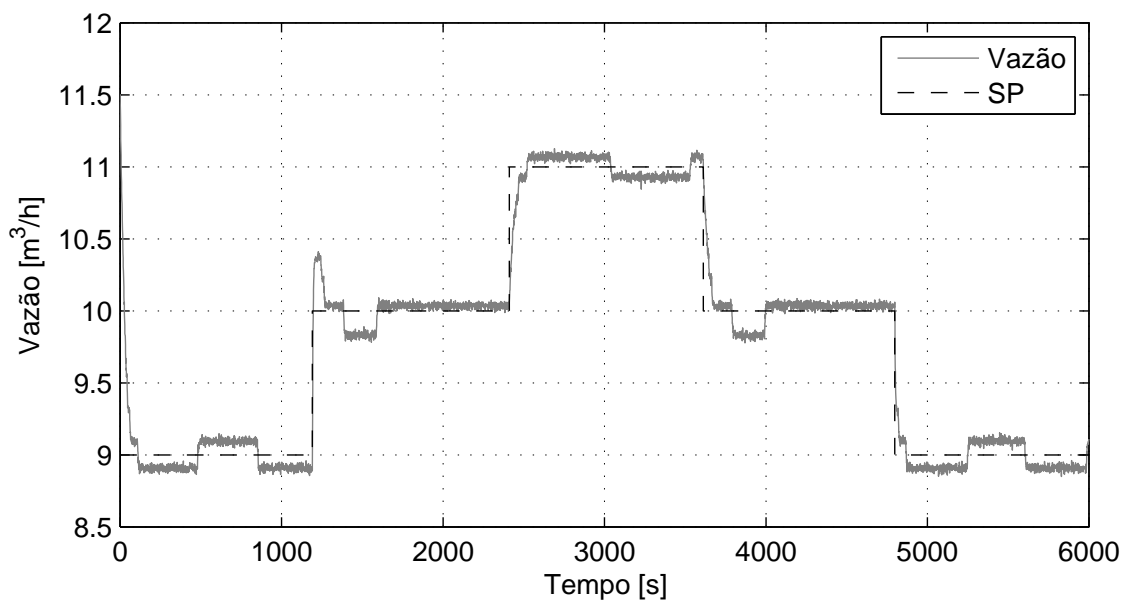

Fonte: Autor.

é a posição da haste.

$$
I T A E=\int_{t_{0}}^{t}|\tau e(\tau)| d \tau
$$

$$
I A E=\int_{t_{0}}^{t}|e(\tau)| d \tau
$$


Figura 25: Sinal de controle para o modelo da válvula com gaxetas de grafite com controlador PI ( $T_{i}$ aumentado para $\left.16 \mathrm{~s}\right)$.

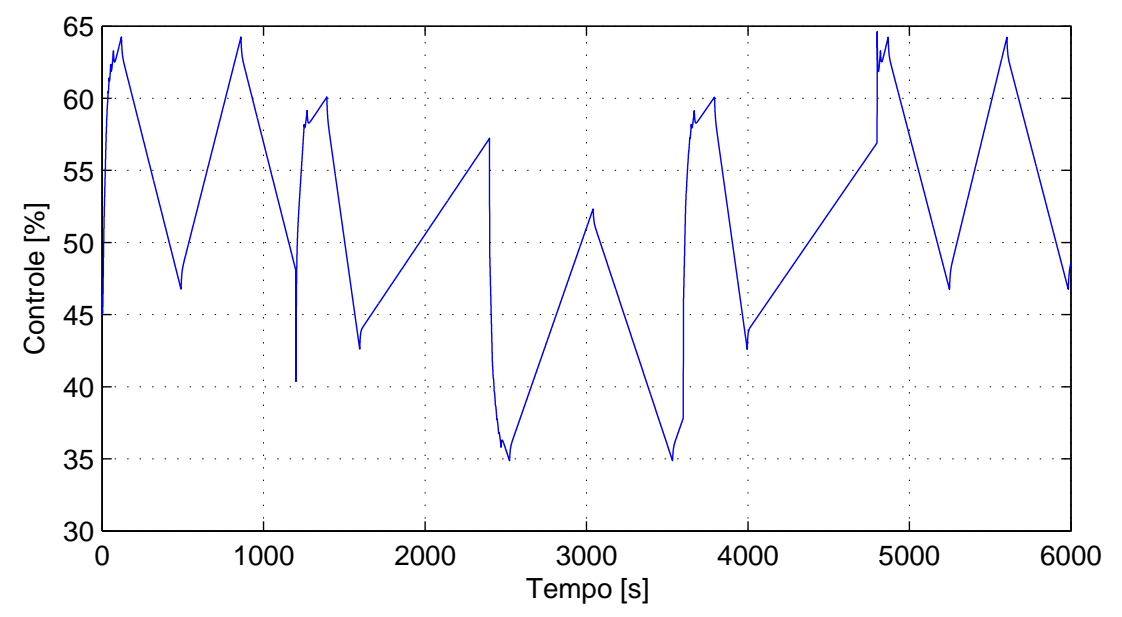

Fonte: Autor.

Figura 26: Posição da haste do modelo da válvula com gaxetas de grafite com controlador PI ( $T_{i}$ aumentado para $\left.16 \mathrm{~s}\right)$.

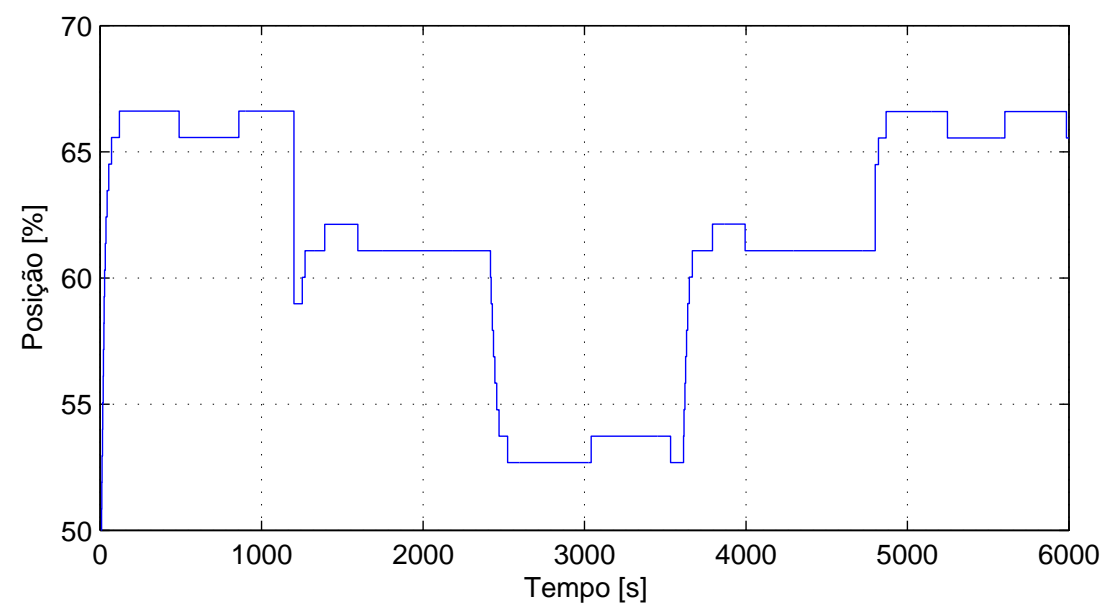

Fonte: Autor.

$$
D_{v}=\sum|x(k)-x(k-1)|
$$

A Tabela 4 apresenta os valores obtidos para os índices de desempenho para o modelo da válvula com gaxetas de grafite.

Pode-se observar que quando o tempo integral do controlador é aumentado para 16s, o ITAE aumenta o valor obtido com relação à sintonia original, apesar de se conseguir uma redução da variabilidade dos atuadores, mas a largura dos patamares em que a vazão fica constante aumentou, isto faz com que o índice ITAE seja maior. No caso do controlador com $T_{i}$ aumentado para $12 \mathrm{~s}$, o ITAE é menor do que com o controlador original. Pode-se 
Tabela 4: Índices de desempenho das simulações com diferentes sintonias do controlador PI (válvula com gaxetas de grafite).

\begin{tabular}{cccc}
\hline Ensaio & ITAE [\%] & IAE [\%] & $D_{v}[\%]$ \\
\hline Apenas PI $\left(T_{i}=2,5317 \mathrm{~s}\right)$ & 227,6359 & 427,7203 & 207,4789 \\
Apenas PI $\left(T_{i}=12 \mathrm{~s}\right)$ & 197,1976 & 405,8373 & 118,5790 \\
Apenas PI $\left(T_{i}=16 \mathrm{~s}\right)$ & 251,4067 & 516,5896 & 122,4101 \\
\hline
\end{tabular}

ver que as sintonias aumentadas conseguem diminuir o desgaste na válvula de controle, como indica o índice $D_{v}$. Só a sintonia com $T_{i}=12 \mathrm{~s}$ consegue melhorar o índice IAE. Segundo os índices de desempenho, o controlador PI com $T_{i}=12 \mathrm{~s}$ apresentou o melhor desempenho.

\subsection{Simulações com compensadores CR1, CR2, Knoc- ker e Two-move para o modelo da válvula com gaxetas de grafite}

Os parâmetros utilizados para os compensadores CR1, CR2, Knocker e Two-move são mostrados nas Tabelas 5 e 6.

Tabela 5: Parâmetros S e J para o projeto dos compensadores CR1, CR2 Knocker e Two-move (SILVA, 2013).

\begin{tabular}{cc}
\hline Parâmetro & Valor $[\%]$ \\
\hline $\mathrm{S}$ & 18,76 \\
$\mathrm{~J}$ & 1.03 \\
\hline
\end{tabular}

Tabela 6: Parâmetros para o projeto do compensador Knocker.

\begin{tabular}{cc}
\hline Parâmetro & Valor \\
\hline$a$ & $9,38[\%]$ \\
$h_{k}$ & $0,005[\mathrm{~s}]$ \\
$\tau$ & $0,002[\mathrm{~s}]$ \\
\hline
\end{tabular}

O valor do parâmetro $B O P$ para o projeto do compensador Two-move é $1 \cdot 10^{-3}$. As Figuras 27 a 38 apresentam os resultados obtidos das simulações com os compensadores CR1, CR2, Knocker e Two-move utilizando a sintonia do PI apresentada na Tabela 3.

Ao analisar os resultados obtidos, pode-se ver que os compensadores de atrito conseguem eliminar as oscilações da variável do processo do modelo da válvula com gaxetas de grafite. O aumento do desgaste da válvula com os compensadores aparentemente é maior do que o desgate gerado pelos controladores PI. 
Figura 27: Vazão para o modelo da válvula com gaxetas de grafite com compensador CR1.

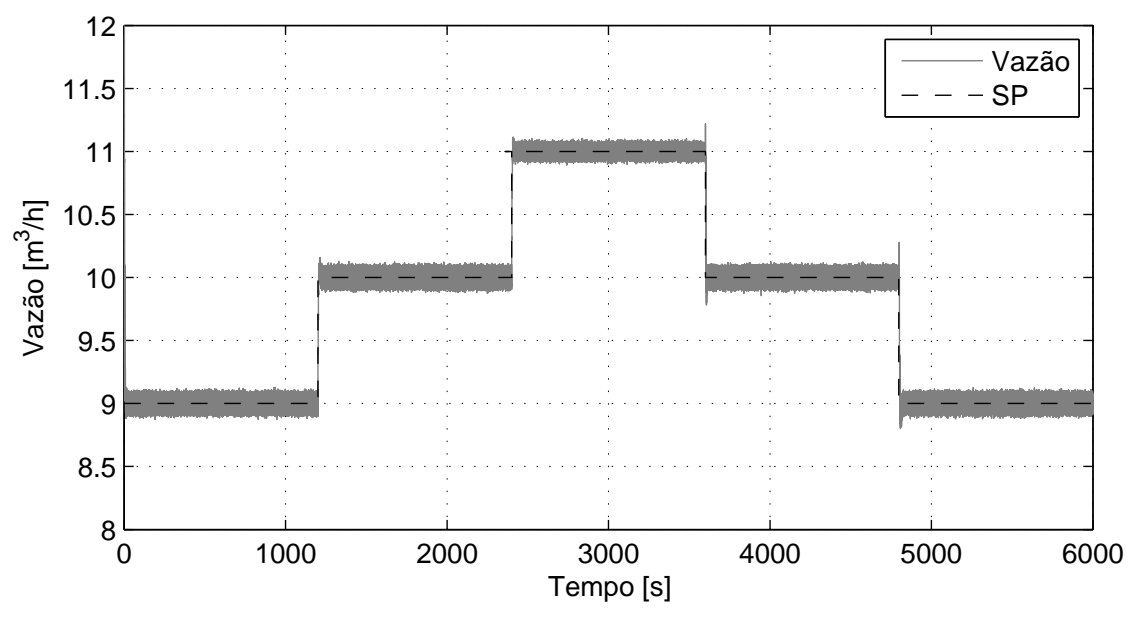

Fonte: Autor.

Figura 28: Sinal de controle para o modelo da válvula com gaxetas de grafite com compensador CR1.

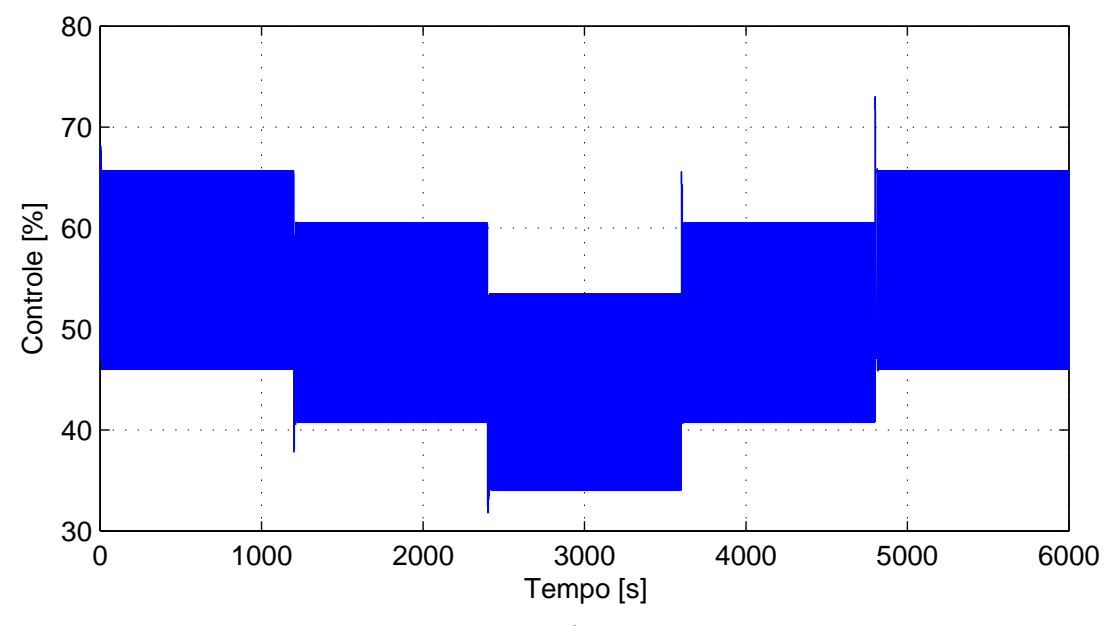

Fonte: Autor.

A Tabela 7 apresenta os valores obtidos para os índices de desempenho.

Tabela 7: Índices de desempenho das simulações com os compensadores de atrito (válvula com gaxetas de grafite).

\begin{tabular}{cccc}
\hline Ensaio & ITAE [\%] & IAE [\%] & $D_{v}[\%]$ \\
\hline Apenas PI (sintonia original) & 227,6359 & 427,7203 & 207,4789 \\
CR1 & 103,4458 & 210,56451 & 3357,1 \\
CR2 & 108,1391 & 221,3702 & 3192,6 \\
Knocker & 251,4267 & 506,6238 & 1562,2 \\
Two-move & 68,6201 & 140,1 & 11773 \\
\hline
\end{tabular}

Pode-se ver nos resultados que os compensadores de atrito se mostram eficazes, sendo que o compensador Two-move apresentou o menor ITAE. Os métodos conseguem diminuir a variabilidade da variável controlada. A grande desvantagem é um aumento drástico 
Figura 29: Posição da haste para o modelo da válvula com gaxetas de grafite com compensador CR1.

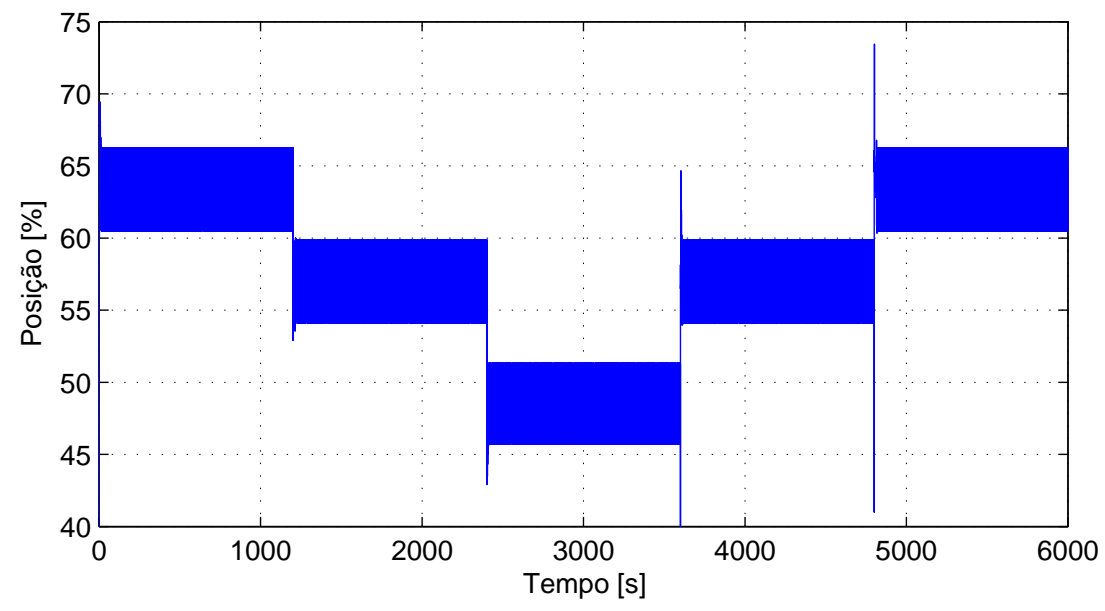

Fonte: Autor.

Figura 30: Vazão para o modelo da válvula com gaxetas de grafite com compensador CR2.

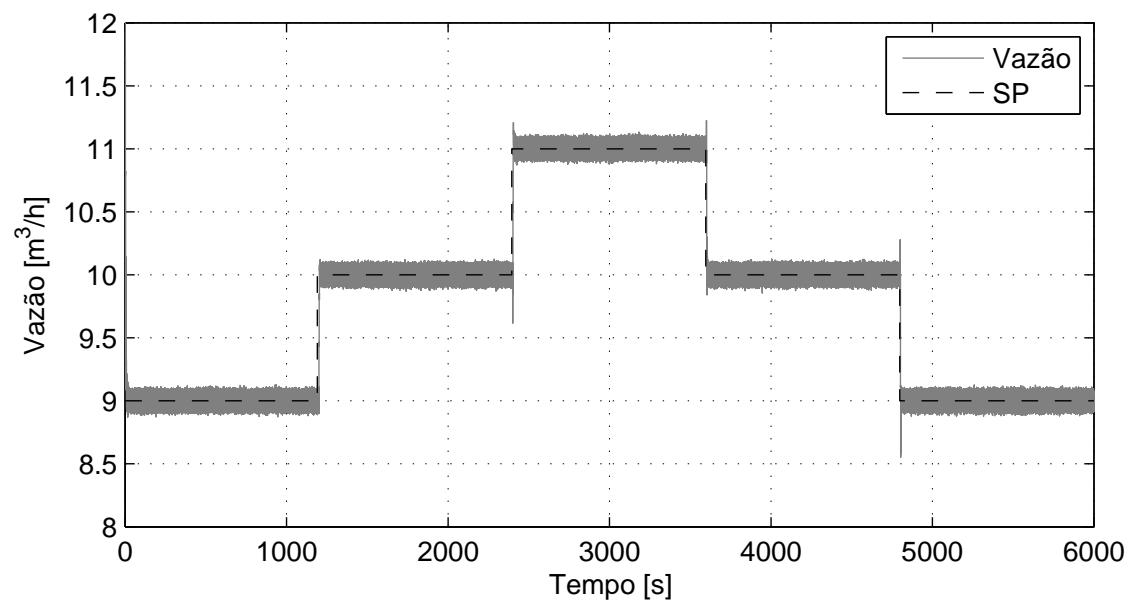

Fonte: Autor.

no desgate da válvula de controle, chegando a valores de vinte vezes maiores do que os obtidos pelo controlador PI, como indica o índice $D_{v}$.

\subsection{Simulações dos controladores por modos desli- zantes para o modelo da válvula com gaxetas de grafite}

Os parâmetros utilizados para os controladores por modos deslizantes e modos deslizantes integrador são mostrados nas Tabelas 8 e 9.

As Figuras 39 a 54 apresentam os resultados obtidos das simulações com os contro- 
Figura 31: Sinal de controle para o modelo da válvula com gaxetas de grafite com compensador CR2.

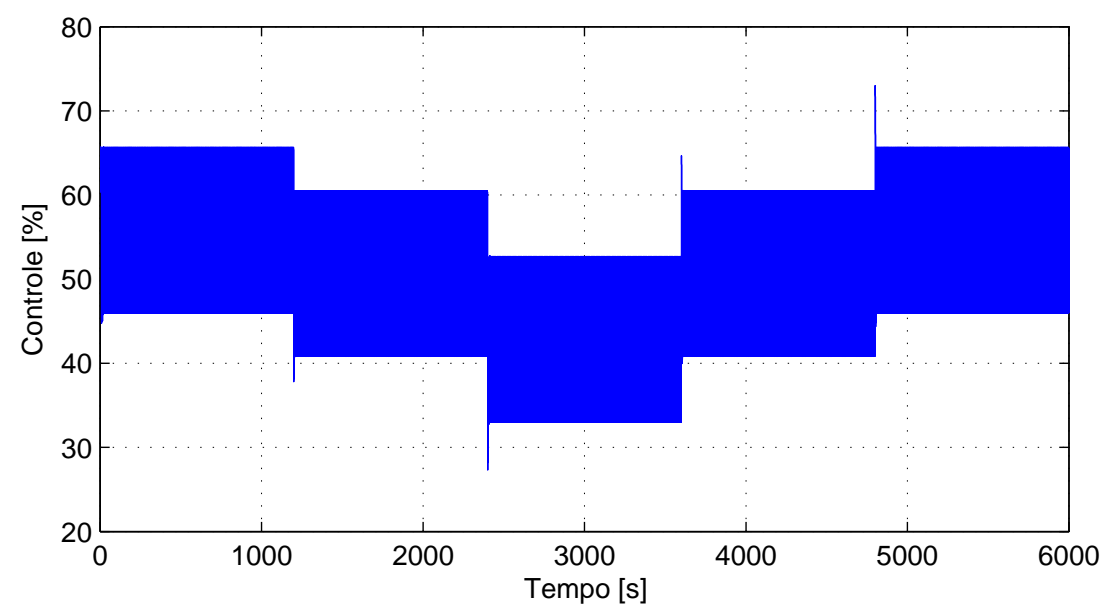

Fonte: Autor.

Figura 32: Posição da haste para o modelo da válvula com gaxetas de grafite com compensador CR2.

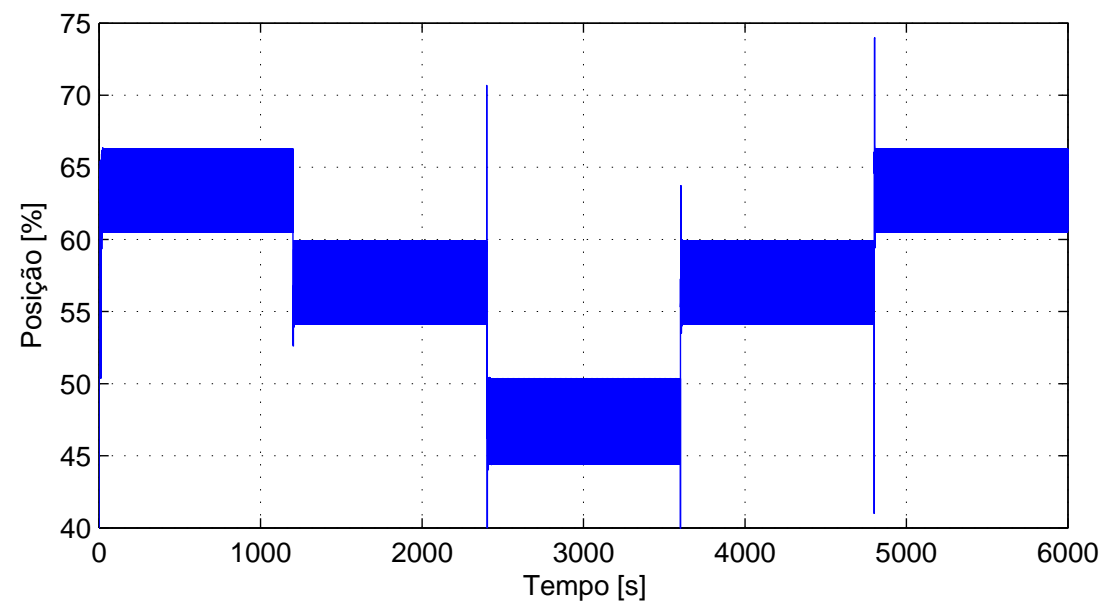

Fonte: Autor.

Tabela 8: Parâmetros para o projeto do controlador por modos deslizantes.

\begin{tabular}{cc}
\hline Parâmetro & Valor \\
\hline$k_{c}$ & 1200 \\
$\Phi$ & 200 \\
$\lambda$ & 0,15 \\
\hline
\end{tabular}

Tabela 9: Parâmetros para o projeto do controlador por modos deslizantes integrador.

\begin{tabular}{cc}
\hline Parâmetro & Valor \\
\hline$k_{c}$ & 1000 \\
$\Phi$ & 1,33 \\
$\lambda$ & 0,005 \\
\hline
\end{tabular}

ladores por modos deslizantes e modos deslizantes integrador utilizando a sintonia do PI apresentada na Tabela 3. A Tabela 10 apresenta os valores obtidos para os índices de 
Figura 33: Vazão para o modelo da válvula com gaxetas de grafite com compensador Knocker.

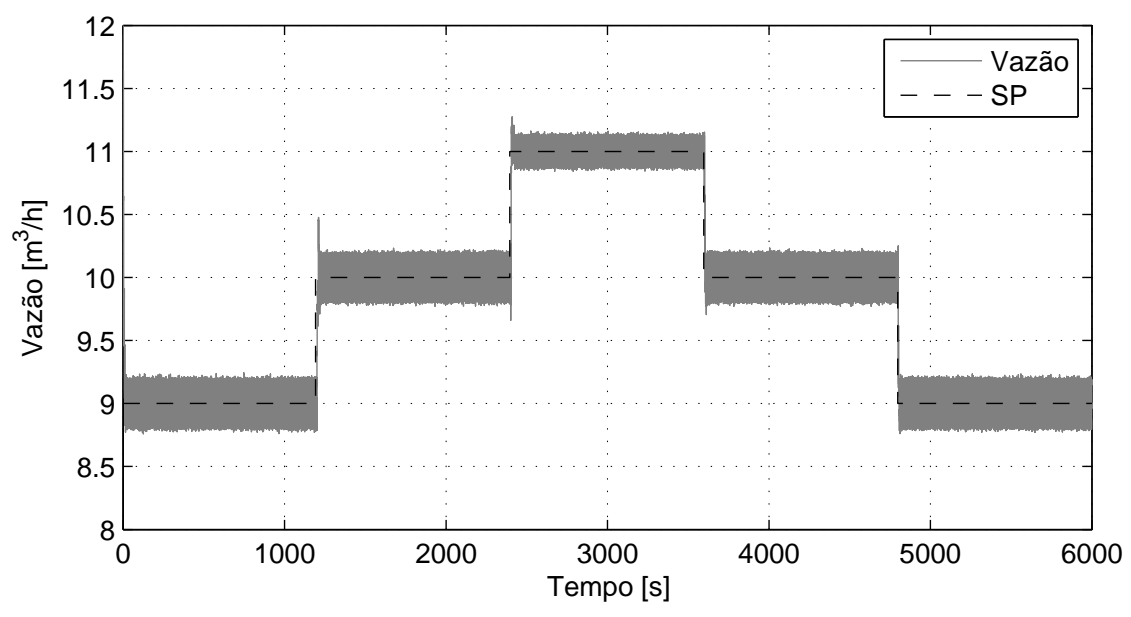

Fonte: Autor.

Figura 34: Sinal de controle para o modelo da válvula com gaxetas de grafite com compensador Knocker.

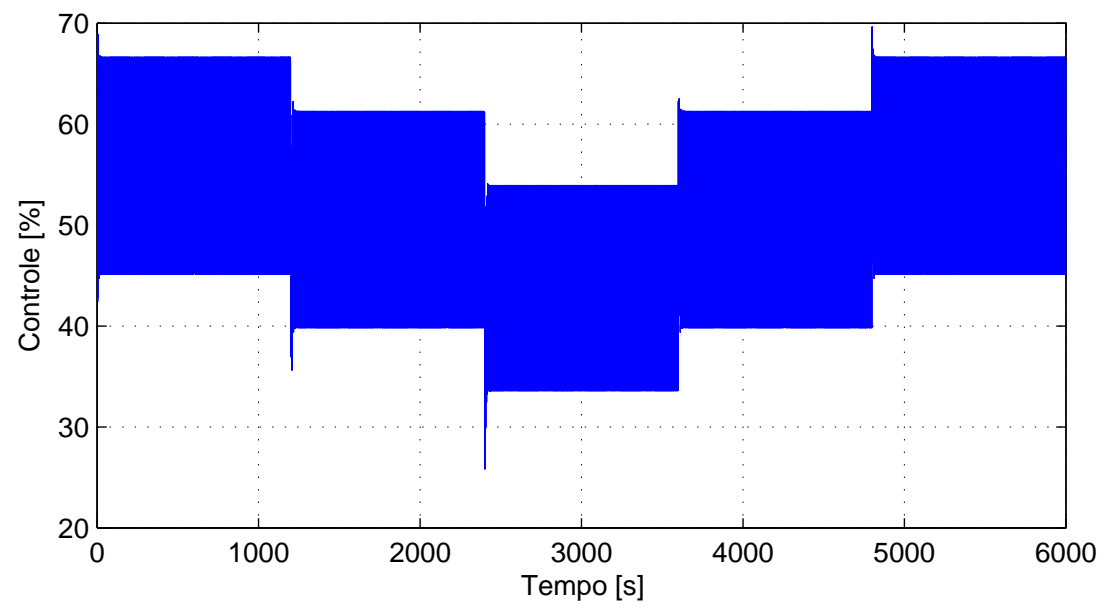

Fonte: Autor.

desempenho.

Depois de analisar os resultados obtidos, é claro que os controladores tentam levar a superfície de escorregamento ao redor de 0, mesmo assim a superfície oscila muito em torno desse valor, o que significa um aumento no movimento da posição do haste da válvula, o qual produz um grande aumento no desgaste da válvula.

Ao observar a Tabela 10, é evidente que os controladores por modos deslizantes e modos deslizantes integrador não apresentam grandes melhorias nos índices de desempenho. O controlador que apresentou o menor índice ITAE e menor IAE foi o controlador por modos deslizantes integrador sem chattering. Ao analisar o índice $D_{v}$ pode-se ver que nenhum controlador conseguiu diminuir o desgaste gerado na válvula de controle.

Na Tabela 11 se apresentam todos os índices obtidos nos resultados do modelo da 
Figura 35: Posição da haste para o modelo da válvula com gaxetas de grafite com compensador Knocker.

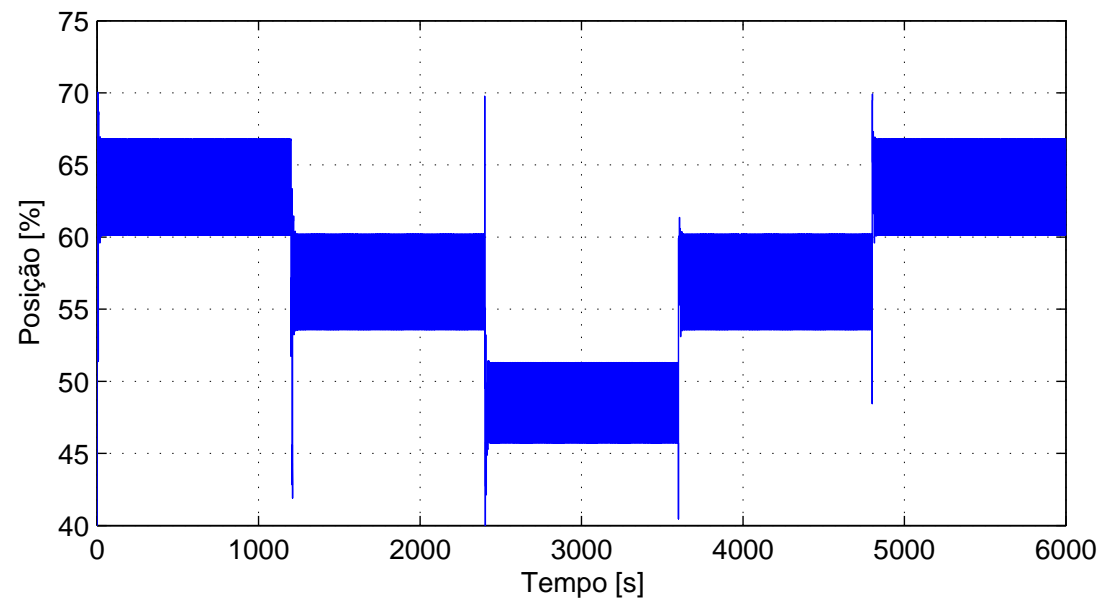

Fonte: Autor.

Figura 36: Vazão para o modelo da válvula com gaxetas de grafite com compensador Two-move.

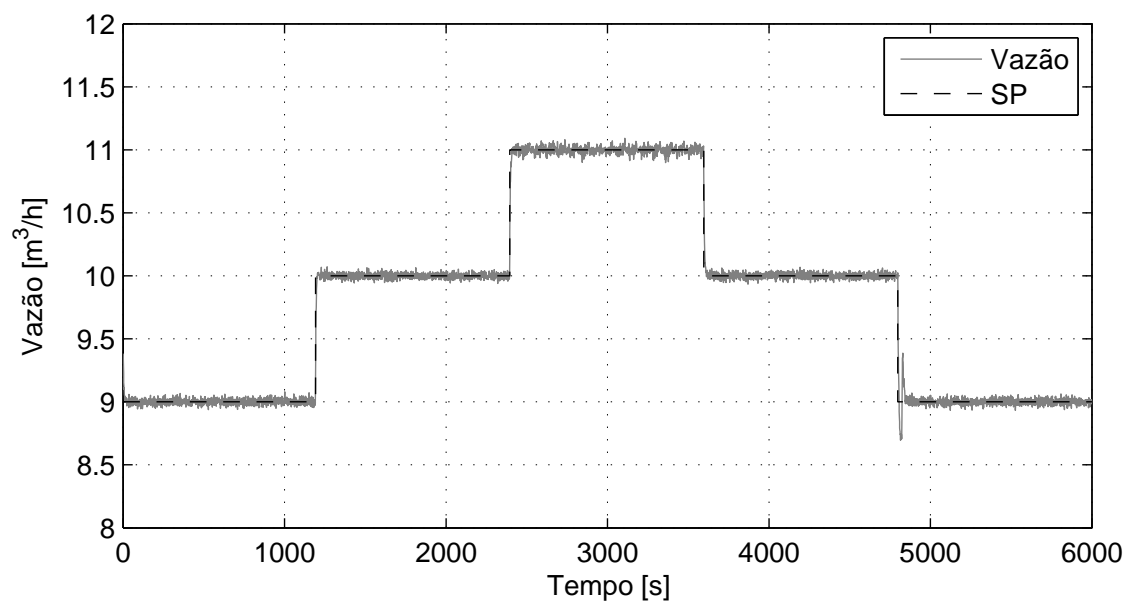

Fonte: Autor.

Tabela 10: Índices de desempenho das simulaçães dos controladores por modos deslizantes e modos deslizantes integrador.

\begin{tabular}{cccc}
\hline Ensaio & ITAE [\%] & IAE [\%] & $D_{v}[\%]$ \\
\hline Apenas PI (sintonia original) & 227,6359 & 427,7203 & 207,4789 \\
MDC & 239,8081 & 502,6274 & 4615,3 \\
MDS & 220,1491 & 484,6628 & 9459,8 \\
MDIC & 180,1721 & 419,3560 & 6661,7 \\
MDIS & 176,0392 & 405,6376 & 6161,4 \\
\hline
\end{tabular}

Planta de Vazão. Resumindo, pode-se ver que conforme sugerem os índices de desempenho, os compensadores CR1 e CR2 foram os que apresentaram melhores resultados nas simulações para compensar o atrito em uma válvula de controle. 
Figura 37: Sinal de controle para o modelo da válvula com gaxetas de grafite com compensador Two-move.

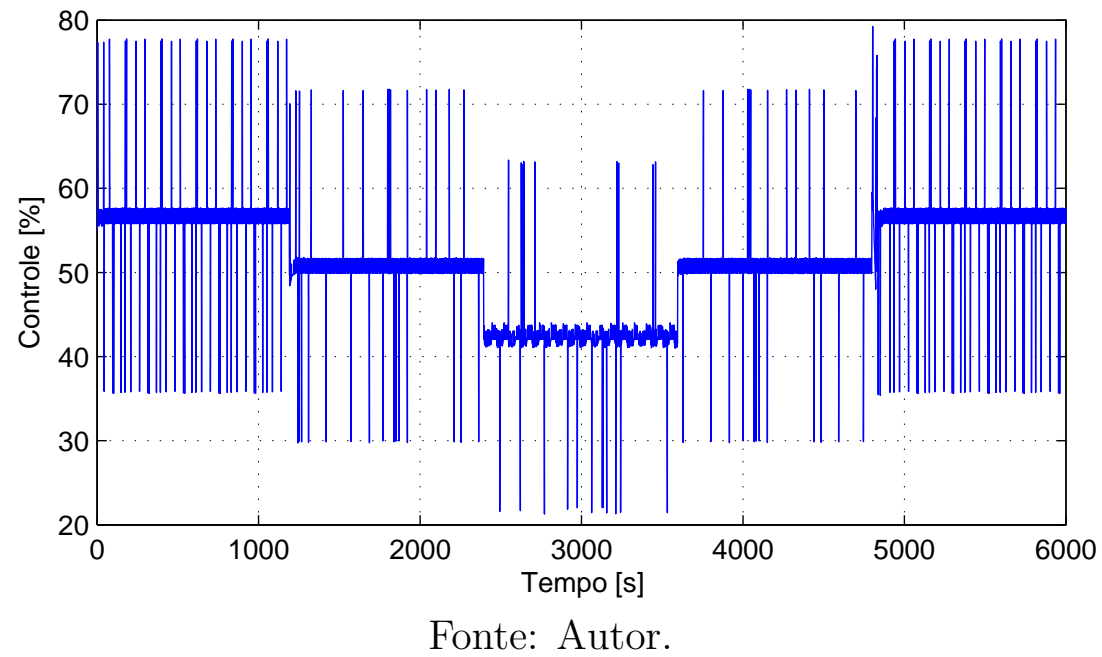

Figura 38: Posição da haste para o modelo da válvula com gaxetas de grafite com compensador Two-move.

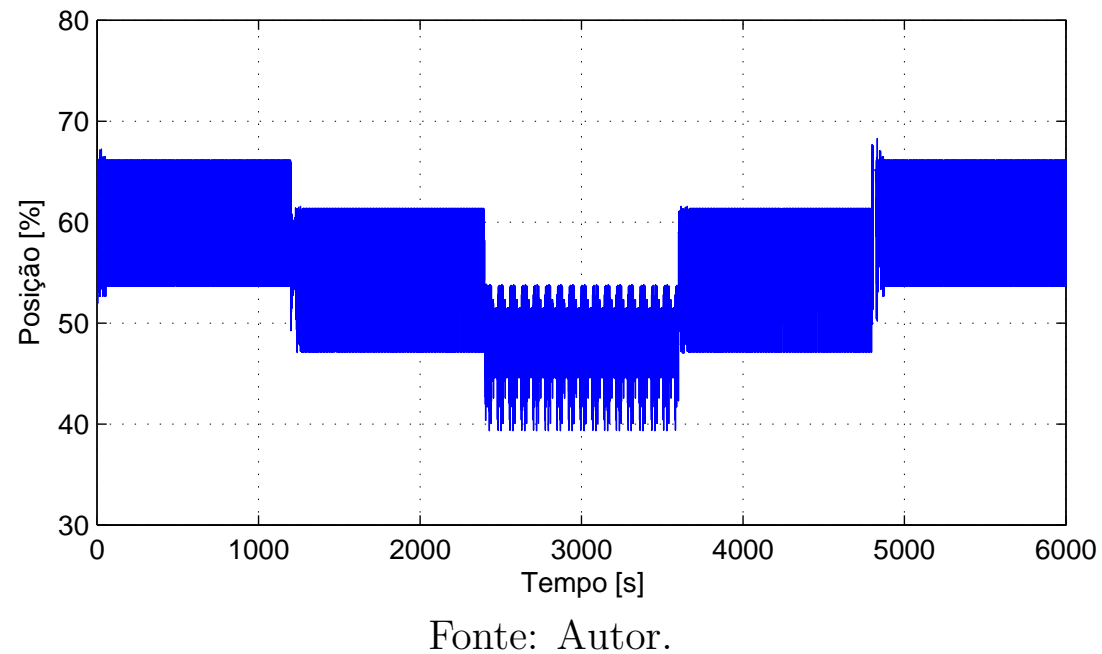

Figura 39: Vazão para o modelo da válvula com gaxetas de grafite para o controlador por modos deslizantes com chattering.

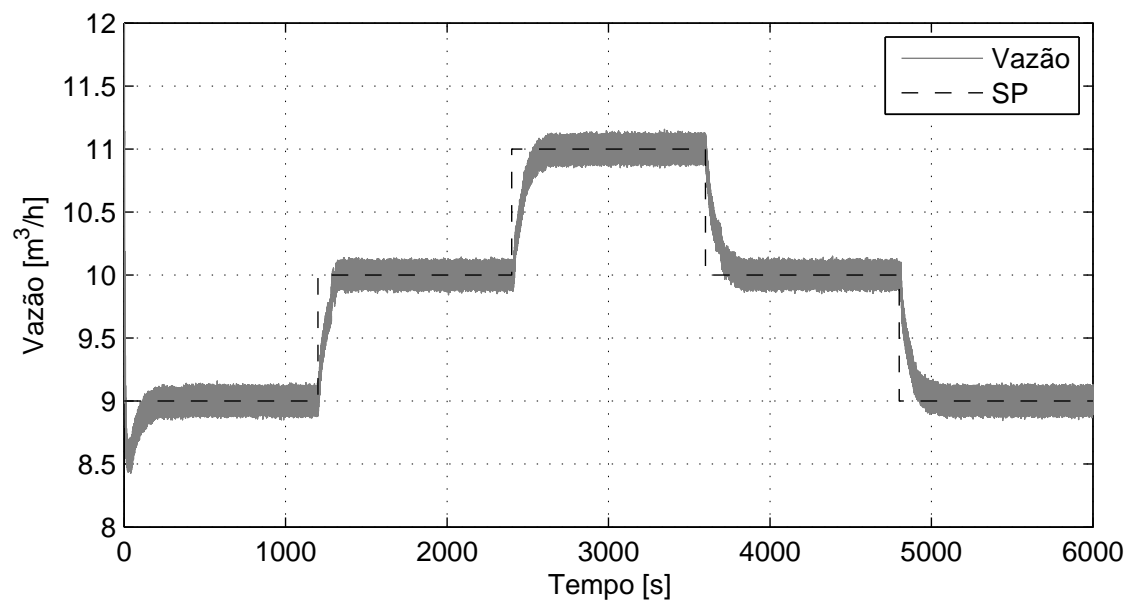

Fonte: Autor. 
Figura 40: Sinal de controle para o modelo da válvula com gaxetas de grafite para o controlador por modos deslizantes com chattering.

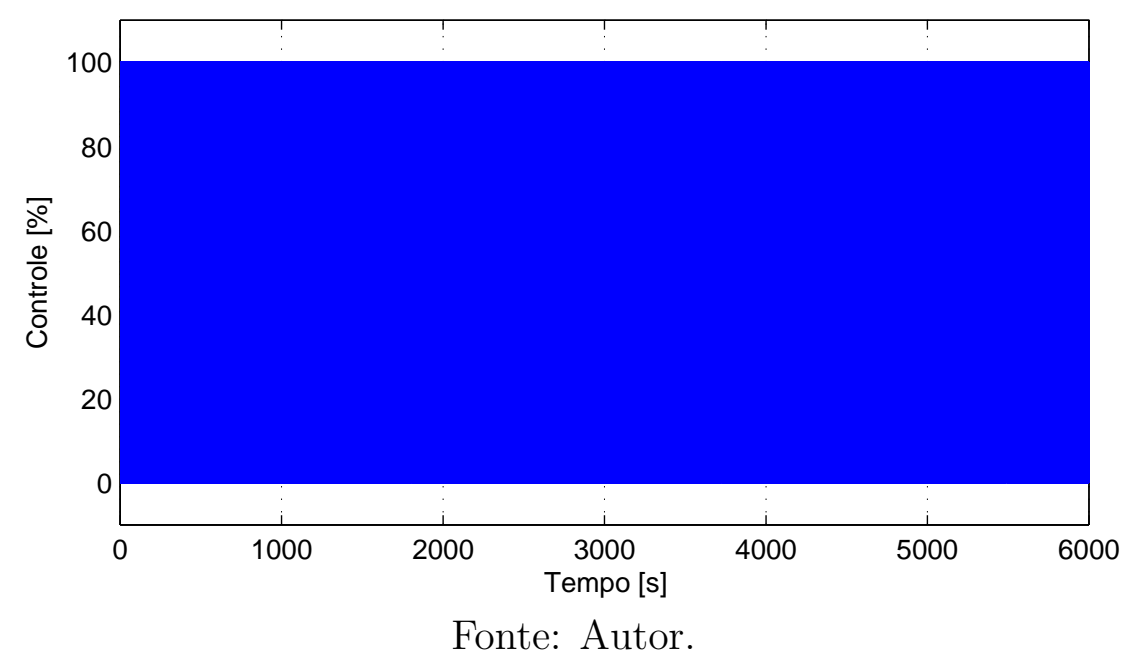

Figura 41: Posição da haste para o modelo da válvula com gaxetas de grafite para o controlador por modos deslizantes com chattering.

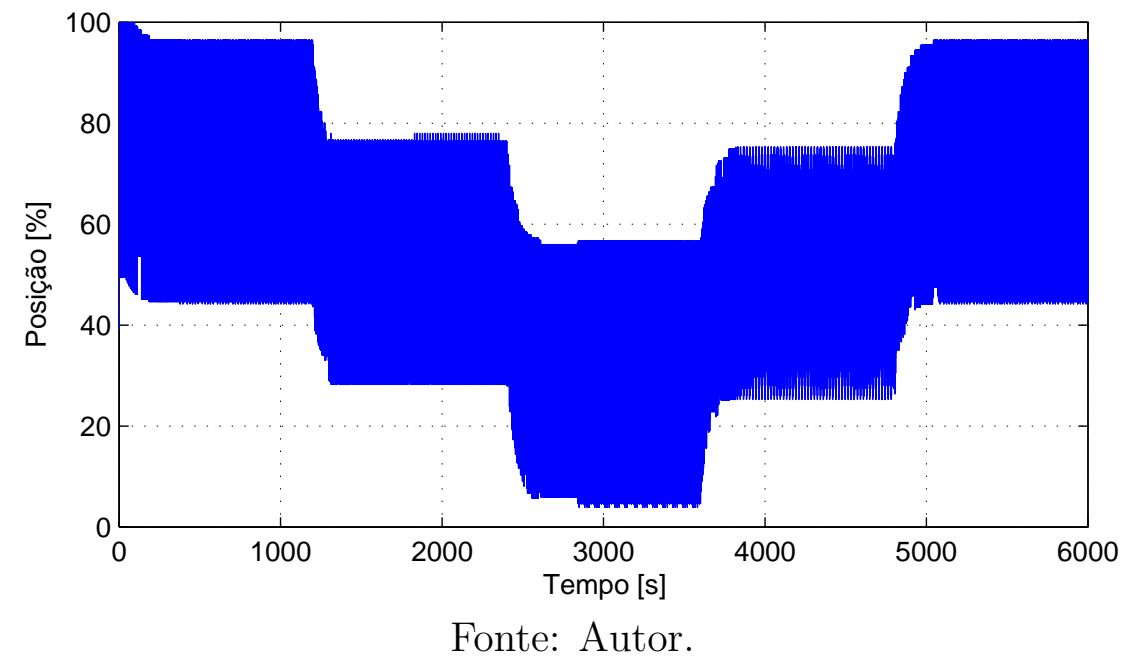

Figura 42: Superfície de escorregamento para o controlador por modos deslizantes com chattering.

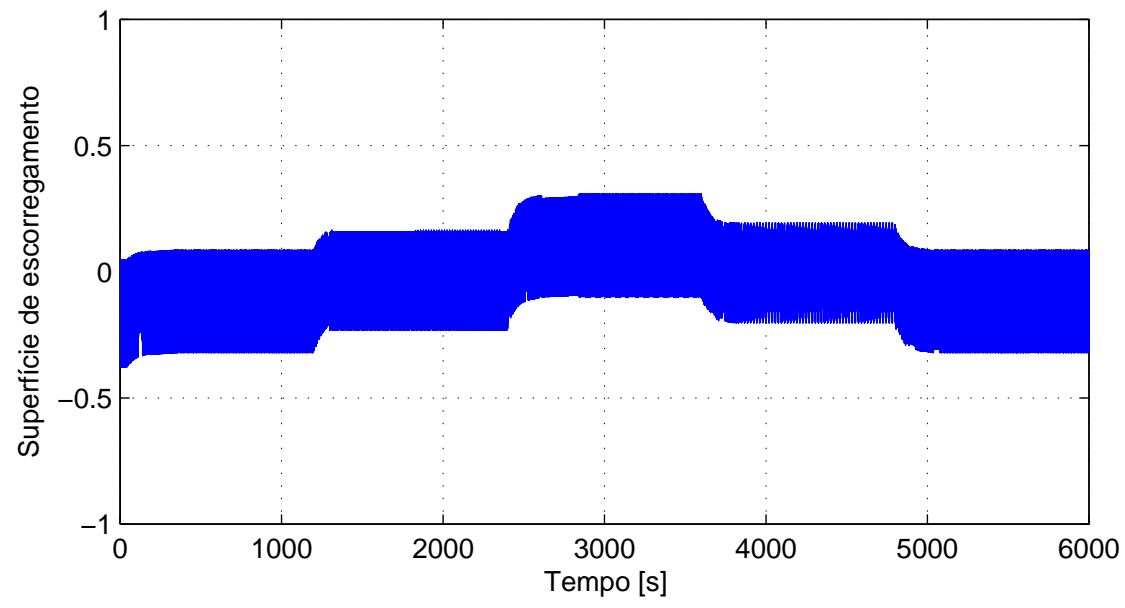

Fonte: Autor. 
Figura 43: Vazão para o modelo da válvula com gaxetas de grafite para o controlador por modos deslizantes sem chattering.

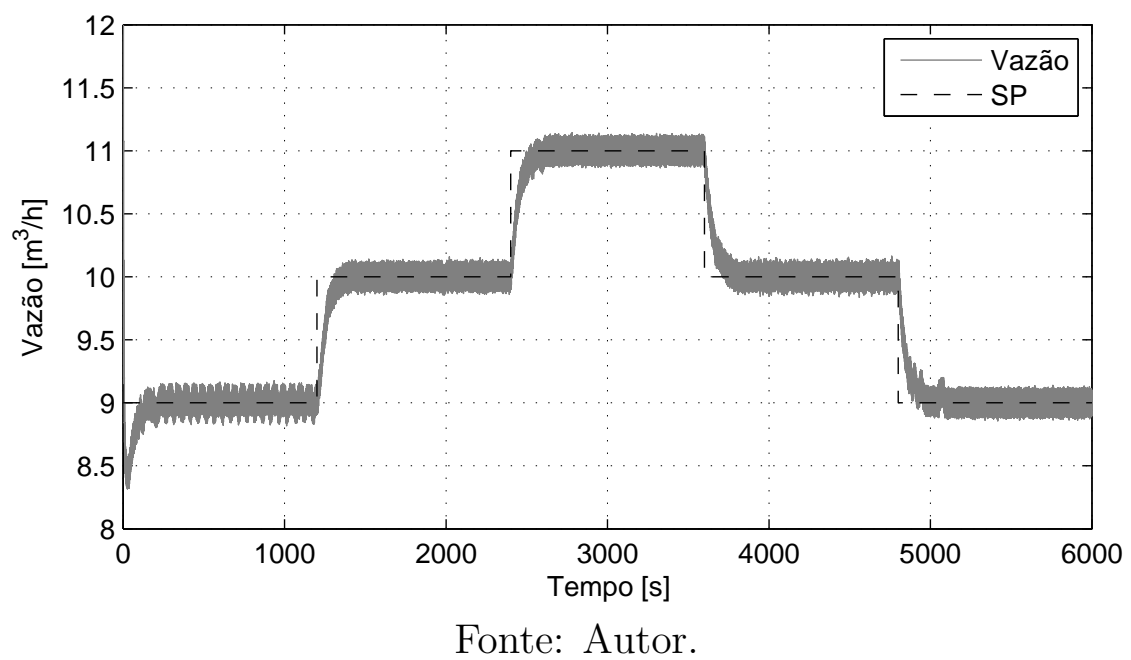

Figura 44: Sinal de controle para o modelo da válvula com gaxetas de grafite para o controlador por modos deslizantes sem chattering.

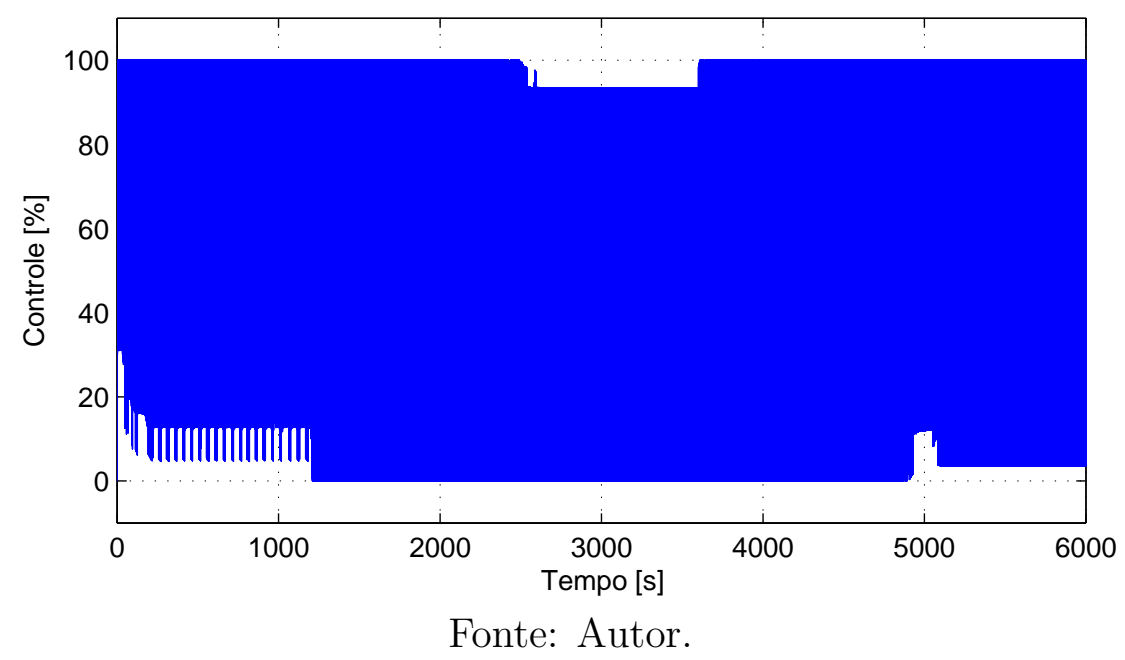

Figura 45: Posição da haste para o modelo da válvula com gaxetas de grafite para o controlador por modos deslizantes sem chattering.

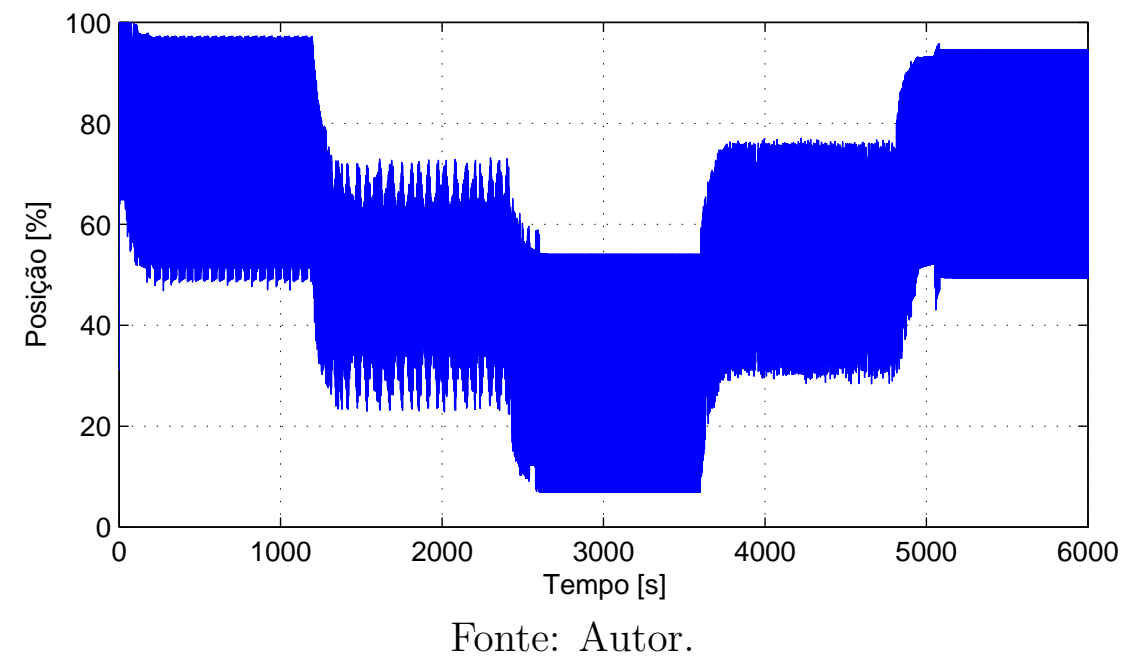


Figura 46: Superfície de escorregamento para o controlador por modos deslizantes sem chattering.

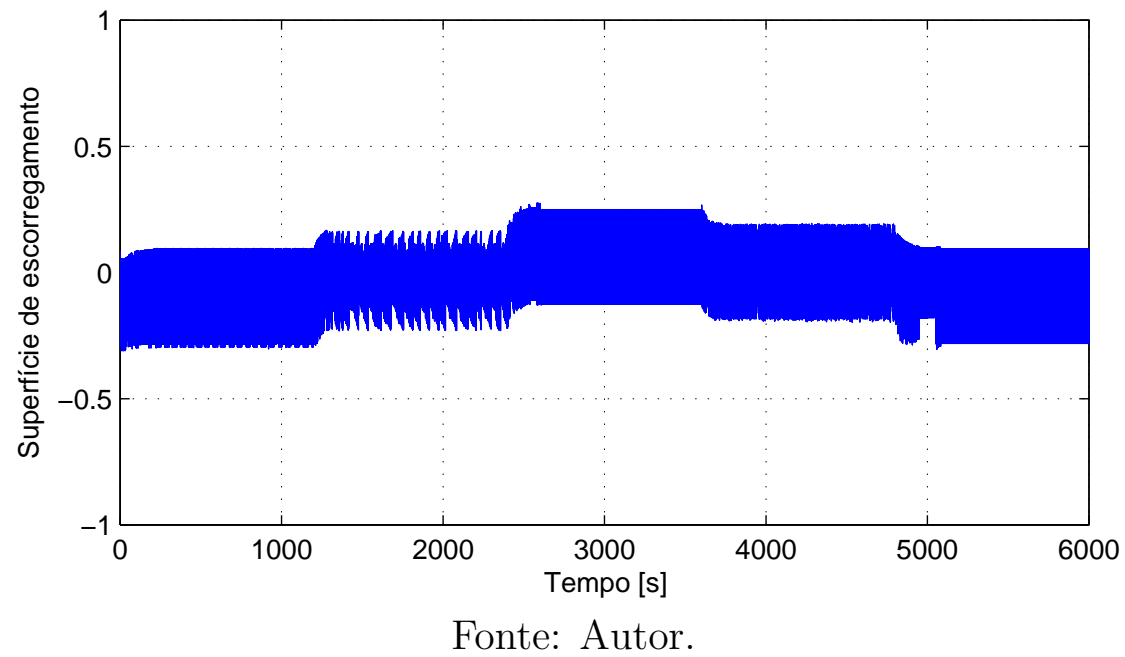

Figura 47: Vazão para o modelo da válvula com gaxetas de grafite para o controlador por modos deslizantes integrador com chattering.

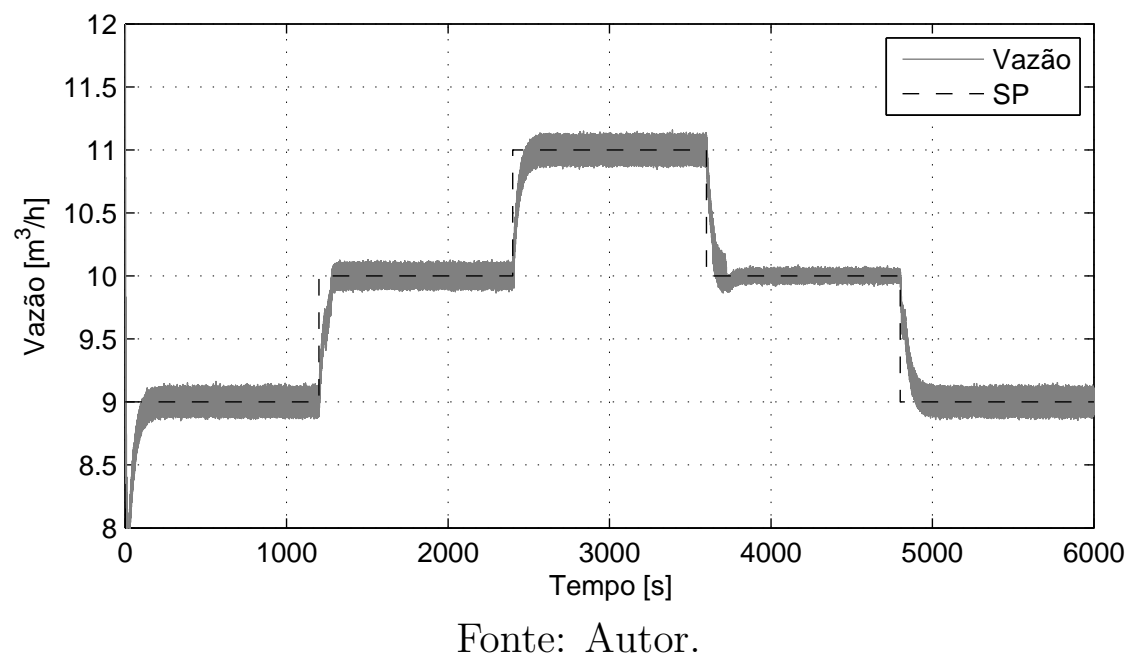

Figura 48: Sinal de controle para o modelo da válvula com gaxetas de grafite para o controlador por modos deslizantes integrador com chattering.

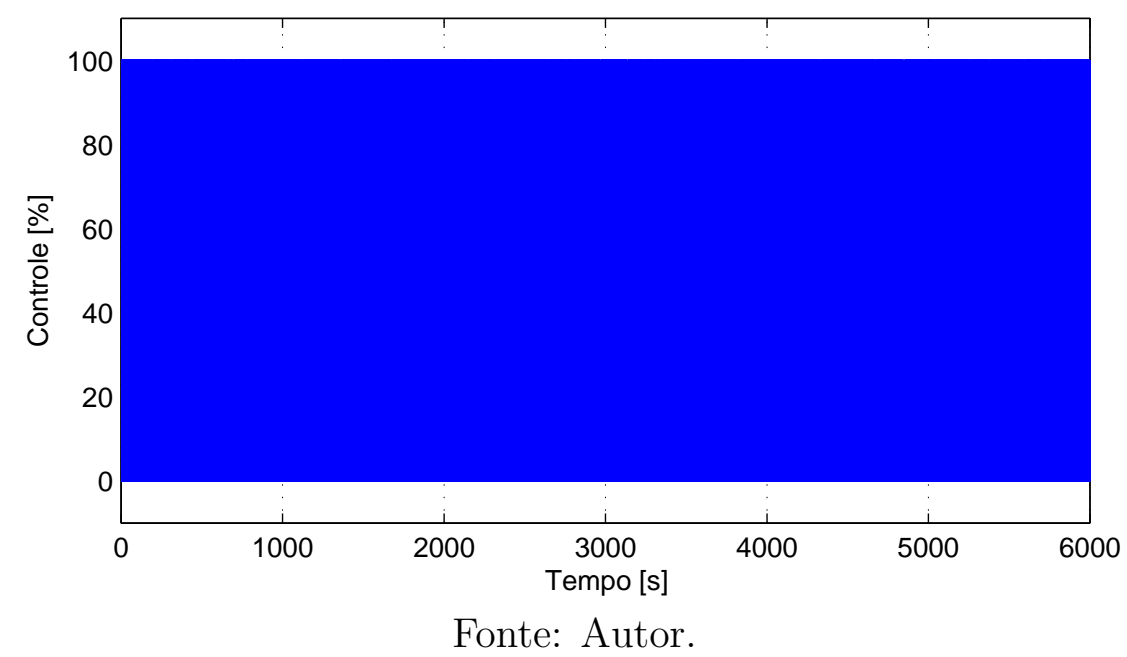


Figura 49: Posição da haste para o modelo da válvula com gaxetas de grafite para o controlador por modos deslizantes integrador com chattering.

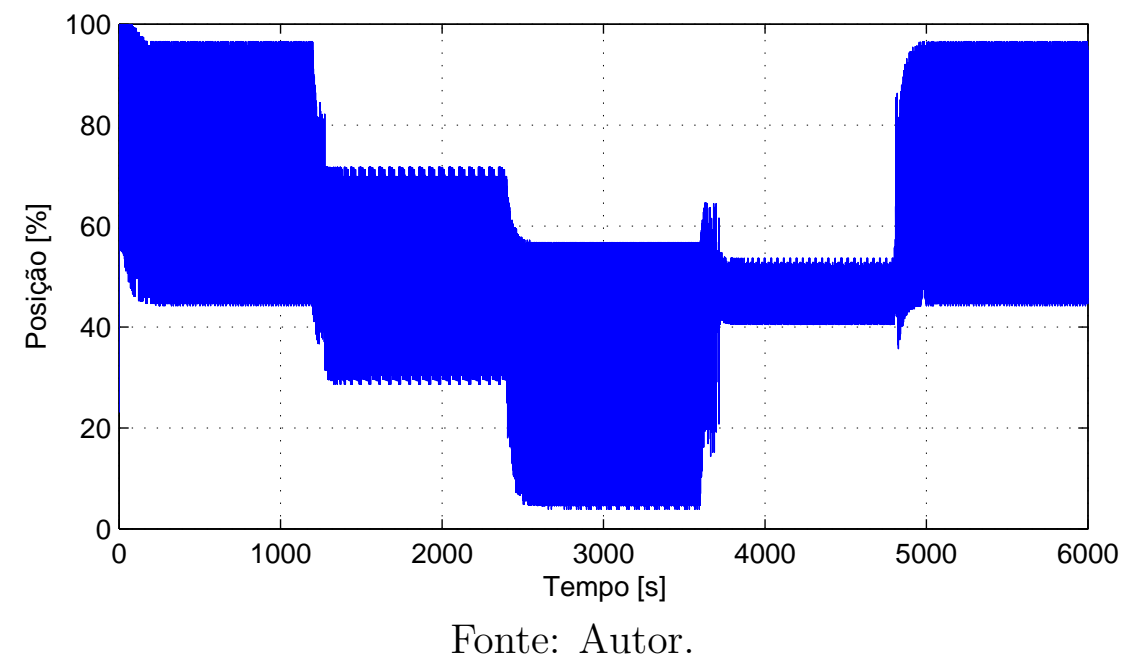

Figura 50: Superfície de escorregamento para o controlador por modos deslizantes integrador com chattering.

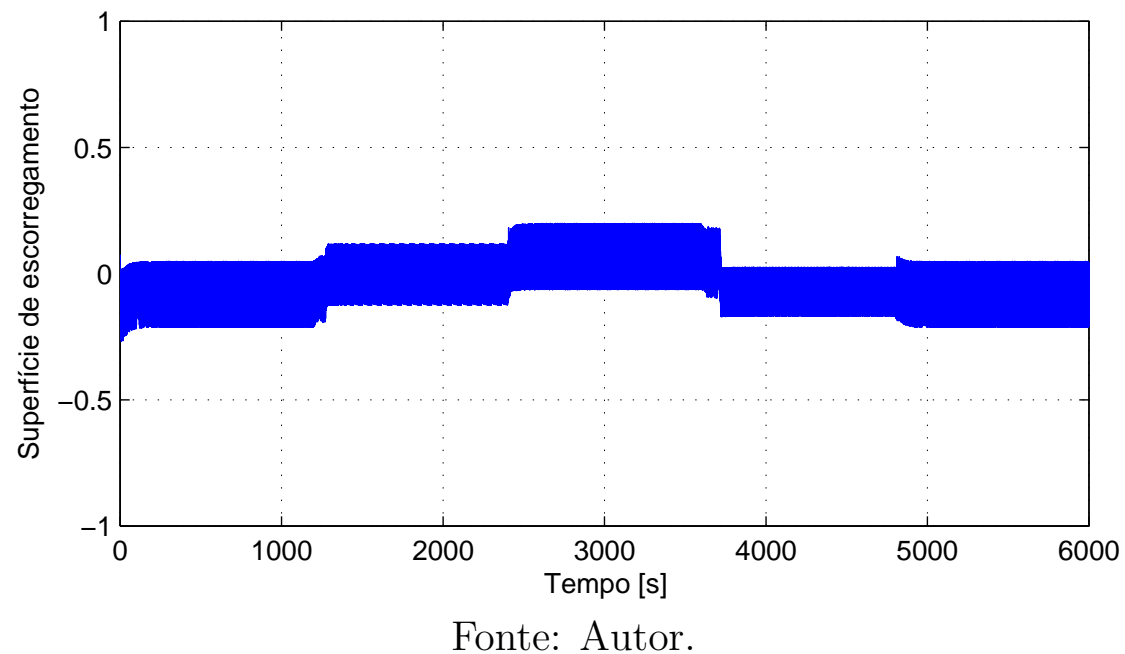

Figura 51: Vazão para o modelo da válvula com gaxetas de grafite para o controlador por modos deslizantes integrador sem chattering.

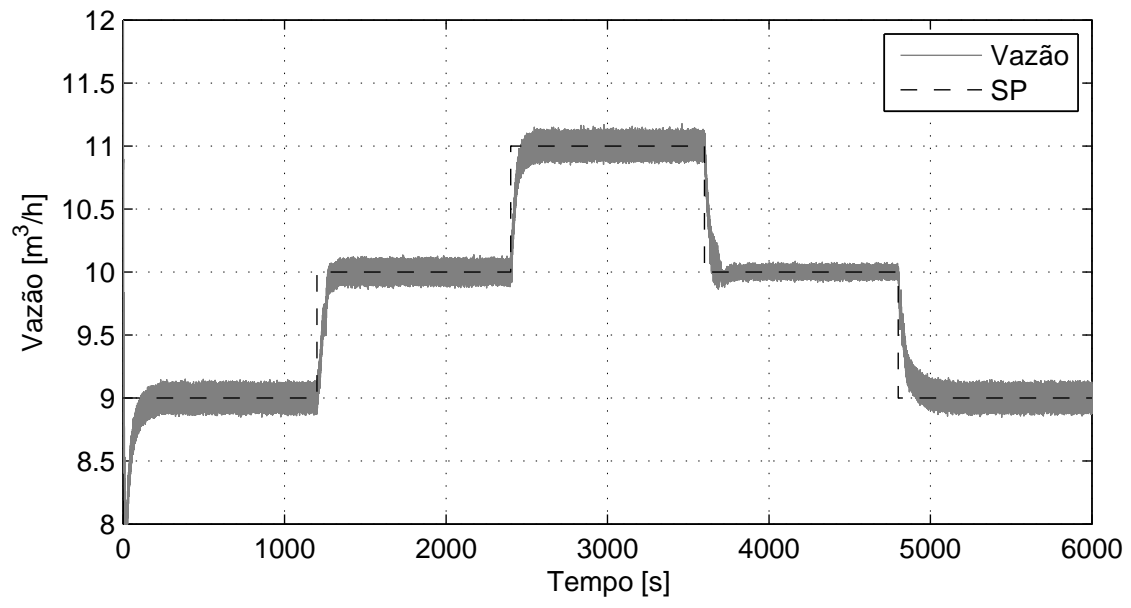

Fonte: Autor. 
Figura 52: Sinal de controle para o modelo da válvula com gaxetas de grafite para o controlador por modos deslizantes integrador sem chattering.

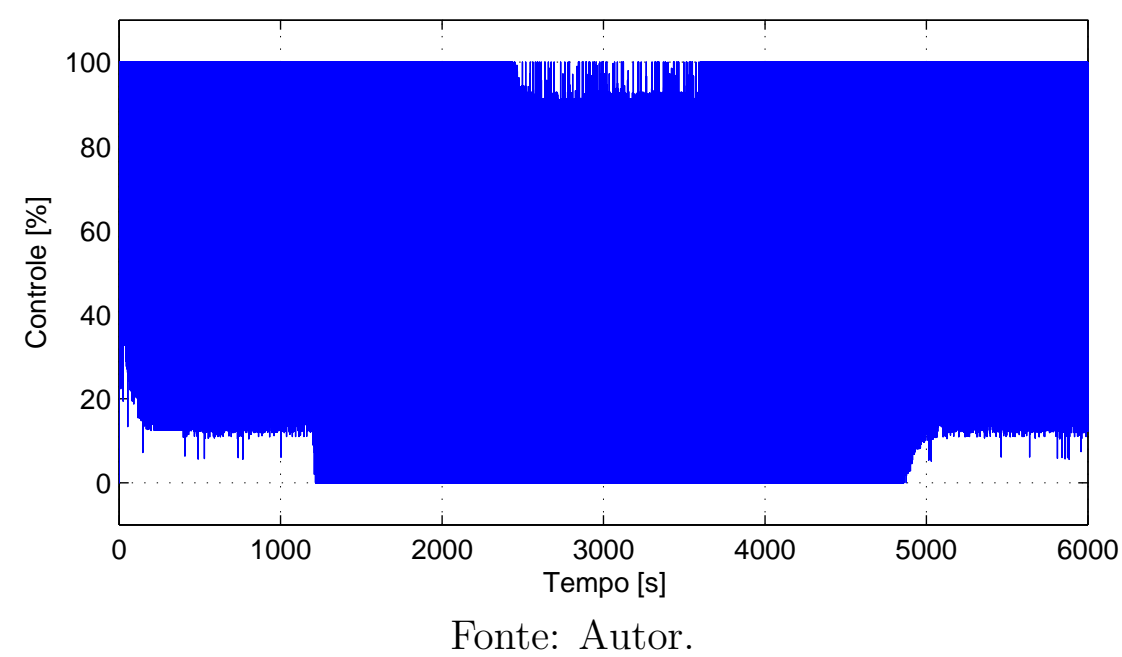

Figura 53: Posição da haste para o modelo da válvula com gaxetas de grafite para o controlador por modos deslizantes integrador sem chattering.

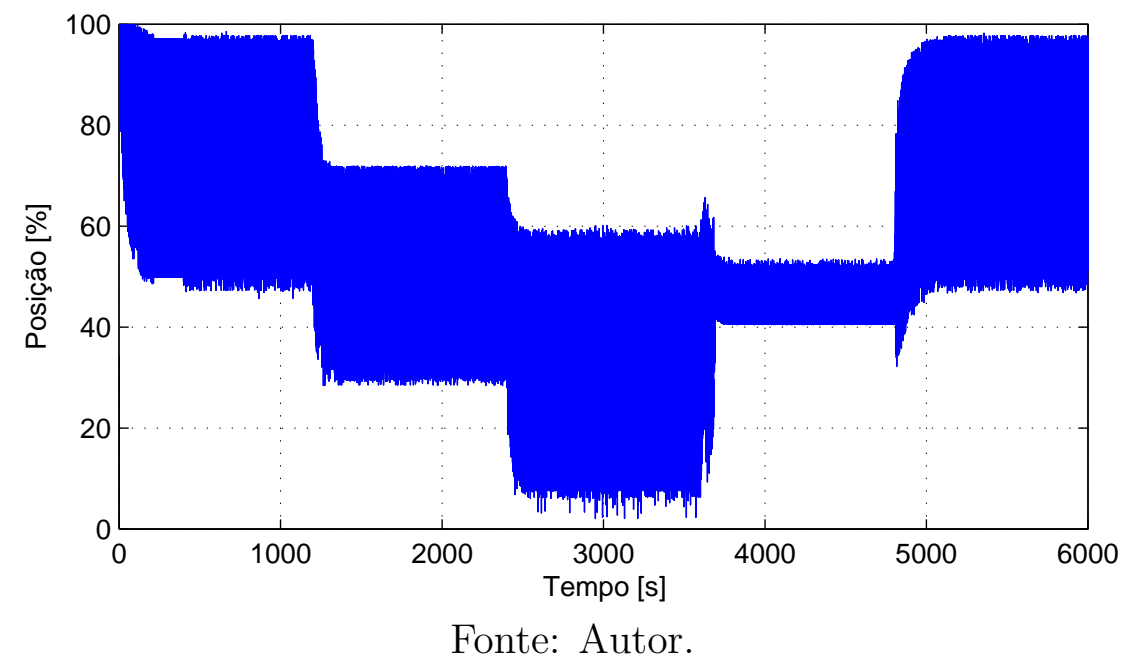

Figura 54: Superfície de escorregamento para o controlador por modos deslizantes integrador sem chattering.

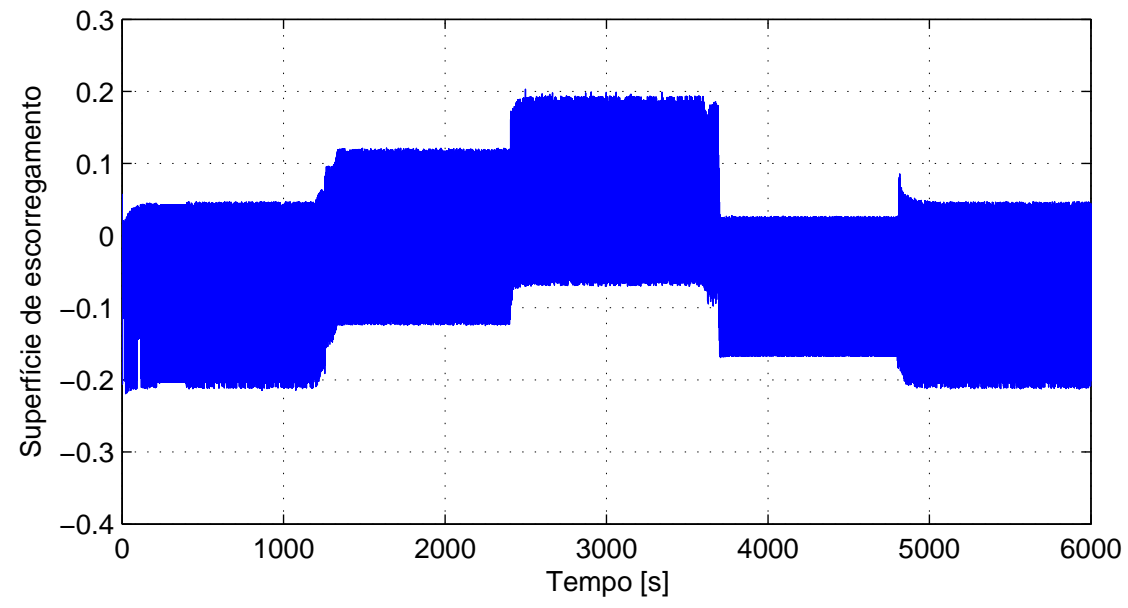

Fonte: Autor. 
Tabela 11: Índices de desempenho das simulaçães dos compensadores e controladores por modos deslizantes e modos deslizantes integrador.

\begin{tabular}{cccc}
\hline Ensaio & ITAE [\%] & IAE [\%] & $D_{v}[\%]$ \\
\hline Apenas PI (sintonia original) & 227,6359 & 427,7203 & 207,4789 \\
Apenas PI $\left(T_{i}=12 \mathrm{~s}\right)$ & 197,1976 & 405,8373 & 118,5790 \\
Apenas PI $\left(T_{i}=16 \mathrm{~s}\right)$ & 251,4067 & 516,5896 & 122,4101 \\
CR1 & 103,4458 & 210,56451 & 3357,1 \\
CR2 & 108,1391 & 221,3702 & 3192,6 \\
Knocker & 251,4267 & 506,6238 & 1562,2 \\
Two-move & 68,6201 & 140,1 & 11773 \\
MDC & 239,8081 & 502,6274 & 4615,3 \\
MDS & 220,1491 & 484,6628 & 9459,8 \\
MDIC & 180,1721 & 419,3560 & 6661,7 \\
MDIS & 176,0392 & 405,6376 & 6161,4 \\
\hline
\end{tabular}




\section{$6 \quad$ Resultados Experimentais}

Neste capítulo vão ser analisados os resultados obtidos depois da implementação na Planta Piloto de Vazão dos compensadores e controladores discutidos no Capítulo 4. A análise dos resultados também é realizada por meio dos índices de desempenho apresentados no capítulo anterior.

\subsection{Ensaios no modo servo}

Os ensaios apresentados a seguir foram realizados para um período de amostragem (T) de $10 \mathrm{~ms}$, que é o menor período possível do SDCD da ABB e também para um período de amostragem de $0,5 \mathrm{~s}$, que é um período de amostragem mais comum de encontrar na indústria. Também como foi feito nas simulações do capítulo anterior, o set-point de todos os ensaios é uma série de degraus, sendo que o valor inicial é de $9 \mathrm{~m}^{3} / h$, seguido por dois degraus positivos de $1 \mathrm{~m}^{3} / \mathrm{h}$ e depois por dois degraus negativos do mesmo valor, até chegar novamente ao valor inicial. A duração de cada degrau é de 20 minutos, isto com a finalidade de conseguir ver as oscilações na variável controlada.

\subsubsection{Resultados para o período de amostragem de $10 \mathrm{~ms}$}

\subsubsection{Apenas Controlador PI}

A Figura 55 apresenta o resultado obtido só com o controlador PI utilizando a sintonia apresentada na Tabela 3. É evidente a presença de um alto nível de atrito na válvula de grafite. Pode-se observar como a válvula apresenta oscilações ao redor do valor de referência.

Nas Figuras 56 e 57 pode-se ver o sinal de controle para o controlador PI e a posição da haste da válvula. Devido às oscilações que existem no processo, o esforço do controlador é maior e, portanto, a posição da haste vai mudar ao longo do processo, gerando um desgaste na gaxeta da válvula e diminuindo a vida útil dos equipamentos.

Com a finalidade de eliminar as oscilações do processo, considera-se novamente a teoria apresentada em (MOHAMMAD; HUANG, 2012) e que também foi utilizada no capítulo anterior. Vão-se utilizar mais duas sintonias para o controlador PI, com $T_{i}=12 \mathrm{~s}$ e 
Figura 55: Vazão obtida com o controlador PI $(T=10 \mathrm{~ms})$.

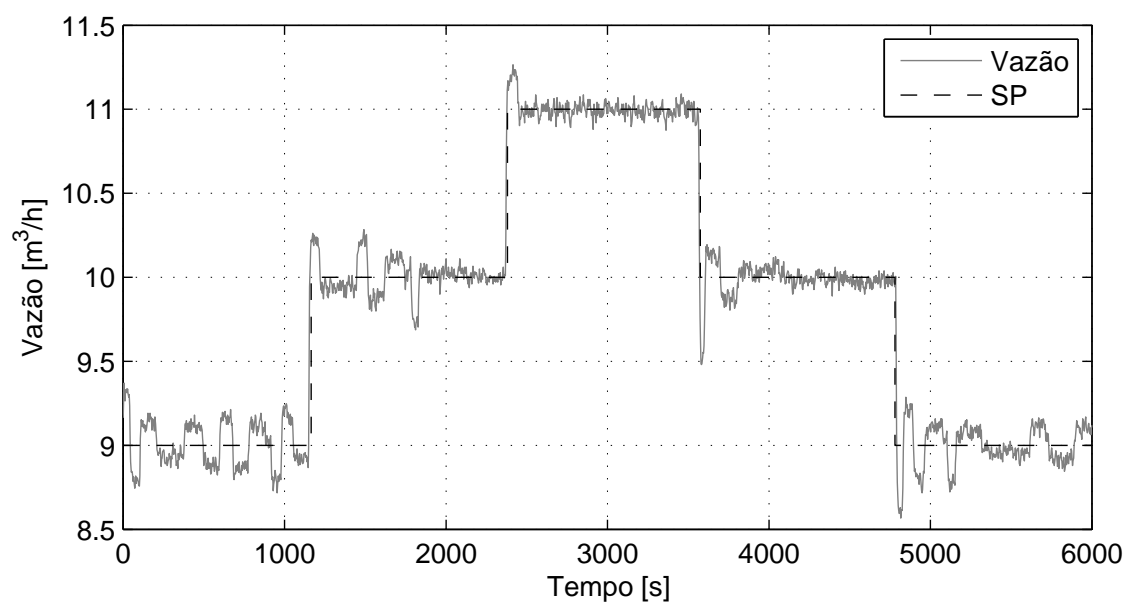

Fonte: Autor.

$T_{i}=16 \mathrm{~s}$, mantendo-se o valor original de $K_{c}$. Os resultados obtidos são apresentados nas Figuras 58 a 63.

Figura 56: Sinal de controle do controlador PI $(T=10 \mathrm{~ms})$.

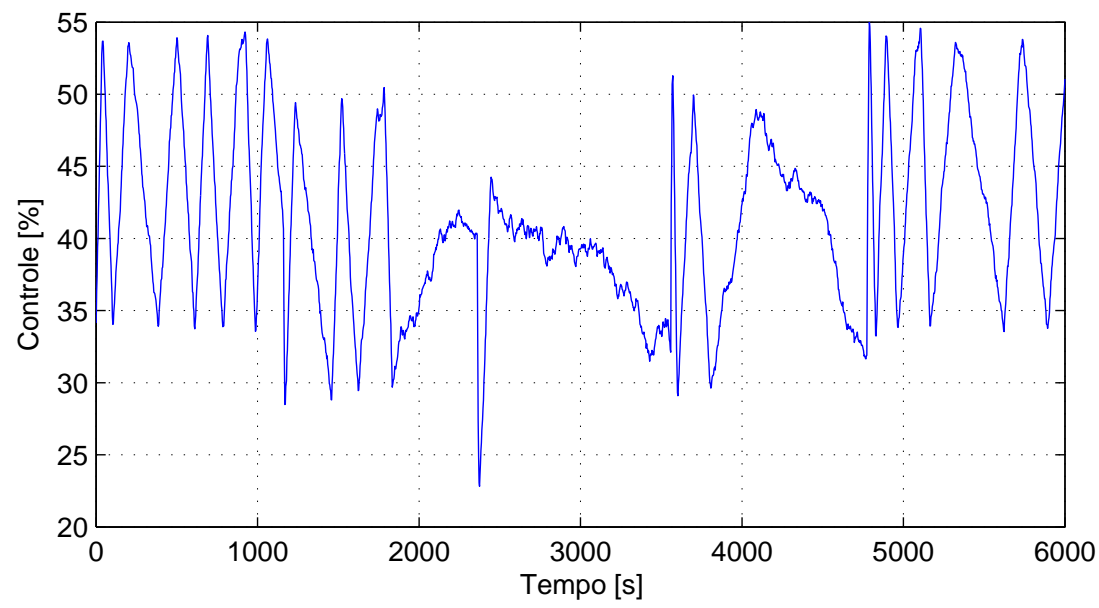

Fonte: Autor.

Depois de analisar os resultados obtidos para as novas sintonias do controlador PI, pode-se ver que os controladores conseguem diminuir as oscilações do processo. Para os resultados práticos foi utilizado um quarto índice, o tempo de subida $\left(t_{s}\right)$, que neste trabalho de mestrado é definido como a média dos intervalos de tempo entre uma mudança no valor de referência e o primeiro cruzamento da variável controlada com o set-point. Para uma melhor análise, na Tabela 12 são mostrados os valores dos índices de desempenho para as três sintonias do controlador PI.

Analisando-se os valores dos índices obtidos, é evidente que a sintonia do controlador PI com $T_{i}=12 \mathrm{~s}$ melhora os índices ITAE e IAE e também o desgaste da válvula é menor. $\mathrm{O}$ controlador PI com $T_{i}=16 \mathrm{~s}$ não consegue melhorar o índice ITAE com respeito à sintonia original do controlador PI, mas o índice IAE é menor, também consegue diminuir o desgaste da válvula. O controlador com $T_{i}=12 \mathrm{~s}$ foi quem aprensentou melhor desem- 
Figura 57: Posição da haste com controlador PI ( $T=10 \mathrm{~ms})$.

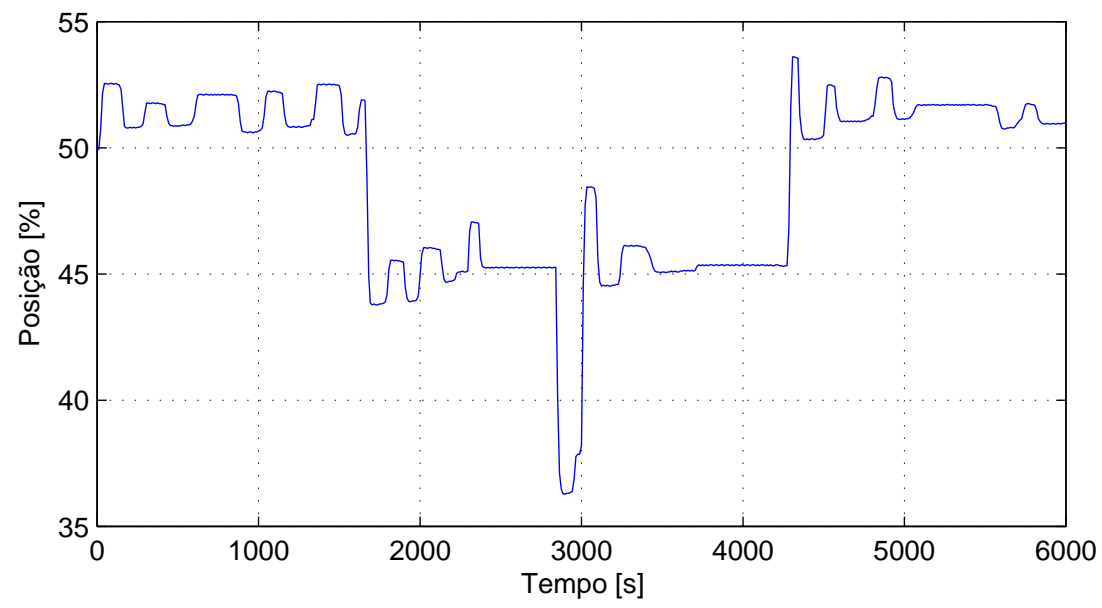

Fonte: Autor.

Figura 58: Vazão obtida com o controlador PI com $T_{i}=12 \mathrm{~s}(T=10 \mathrm{~ms})$.

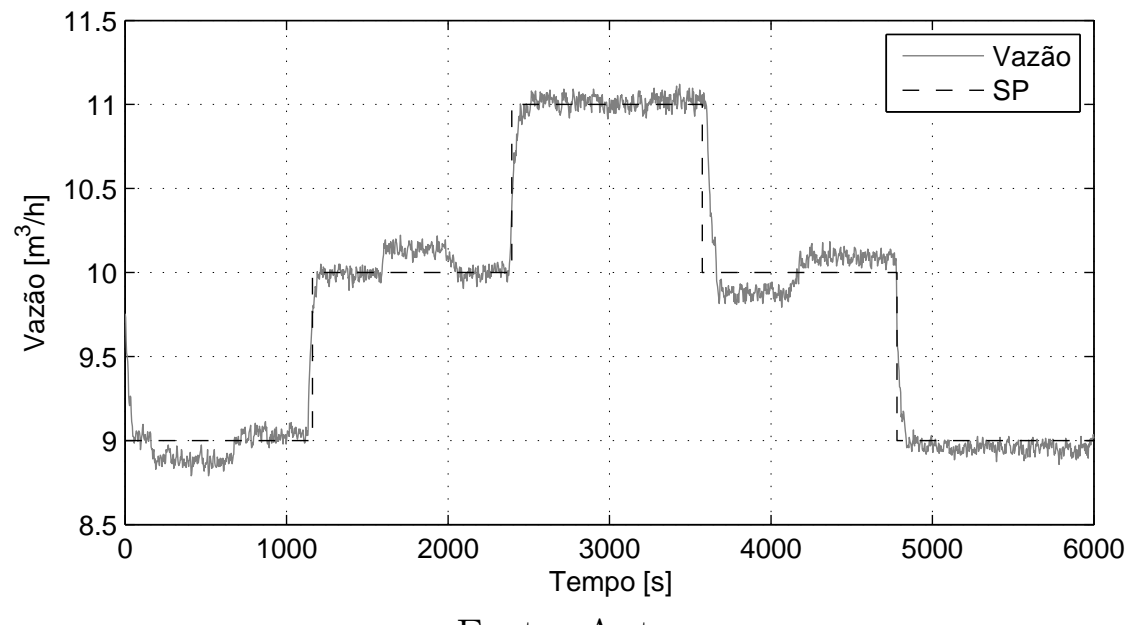

Fonte: Autor.

Figura 59: Sinal de controle do controlador PI com $T_{i}=12 \mathrm{~s}(T=10 \mathrm{~ms})$.

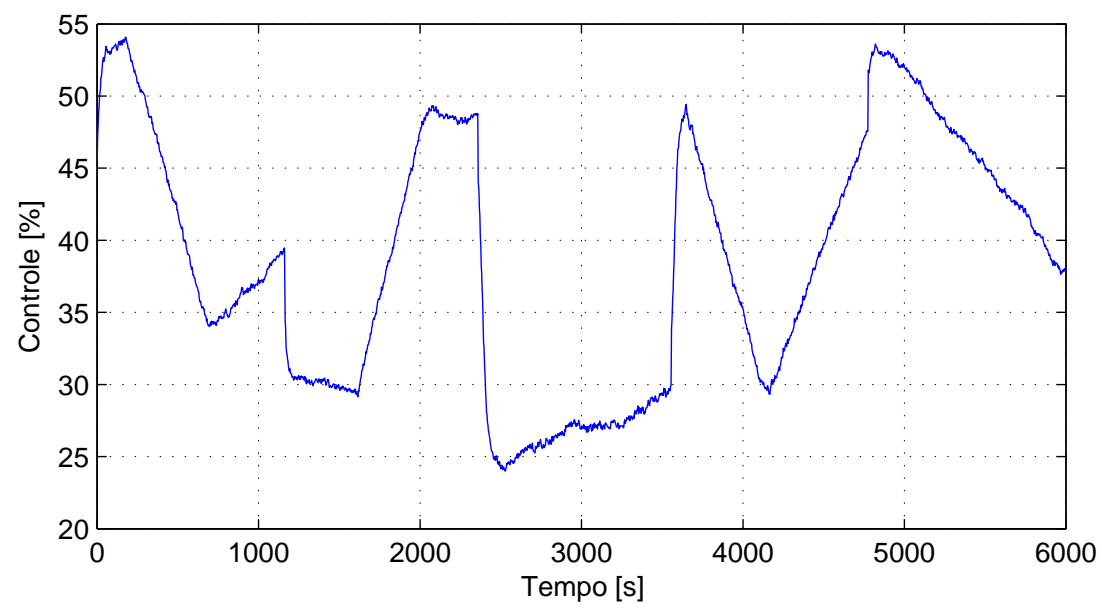

Fonte: Autor.

penho conforme indicam os índices IAE, ITAE e $D_{v}$. 
Figura 60: Posição da haste com controlador PI com $T_{i}=12 \mathrm{~s}(T=10 \mathrm{~ms})$.

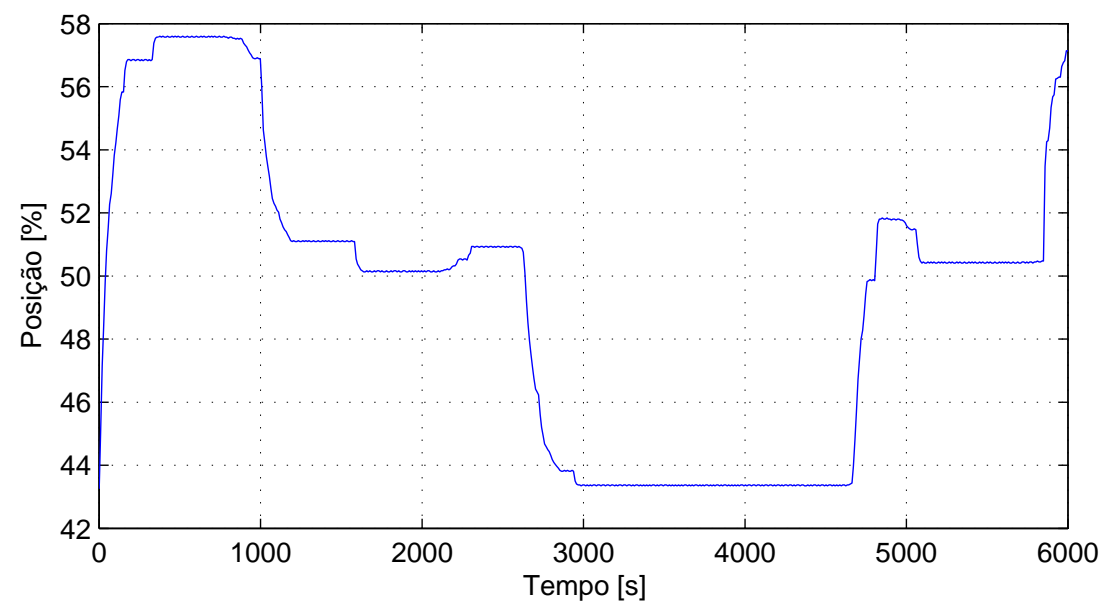

Fonte: Autor.

Figura 61: Vazão obtida com o controlador PI com $T_{i}=16 \mathrm{~s}(T=10 \mathrm{~ms})$.

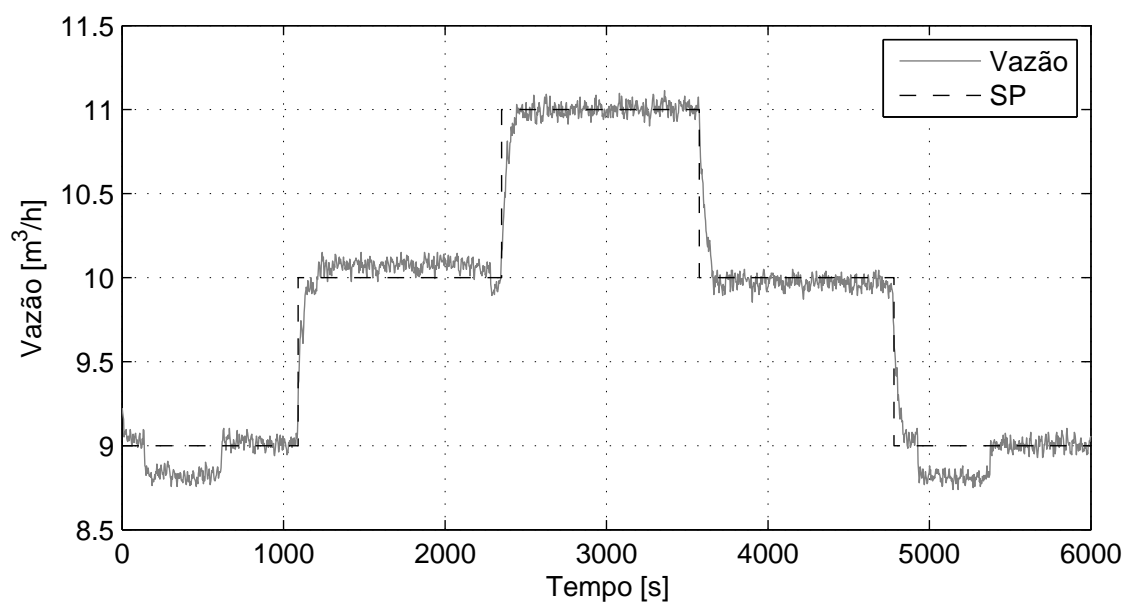

Fonte: Autor.

Figura 62: Sinal de controle do controlador PI com $T_{i}=16 \mathrm{~s}(T=10 \mathrm{~ms})$.

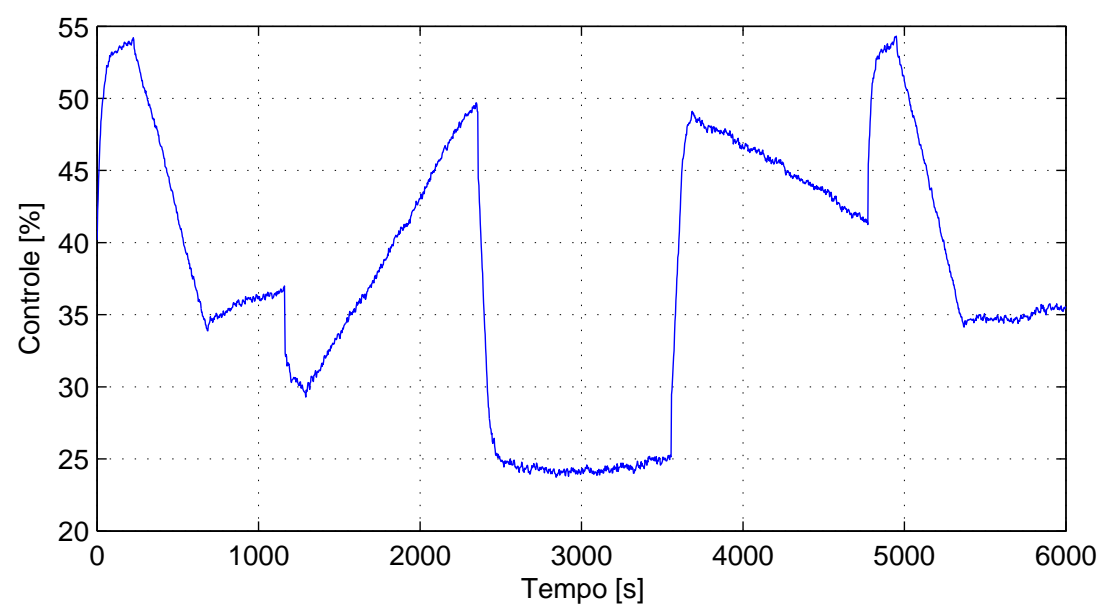

Fonte: Autor.

\subsubsection{Compensadores CR1, CR2, Knocker e Two-move}

Nas Figuras 64 a 75 se apresentam os resultados obtidos com os compensadores CR1, CR2, Knocker e Two-move utilizando a sintonia do PI aprensentada na Tabela 3 e os 
Figura 63: Posição da haste com controlador PI com $T_{i}=16 \mathrm{~s}(T=10 \mathrm{~ms})$.

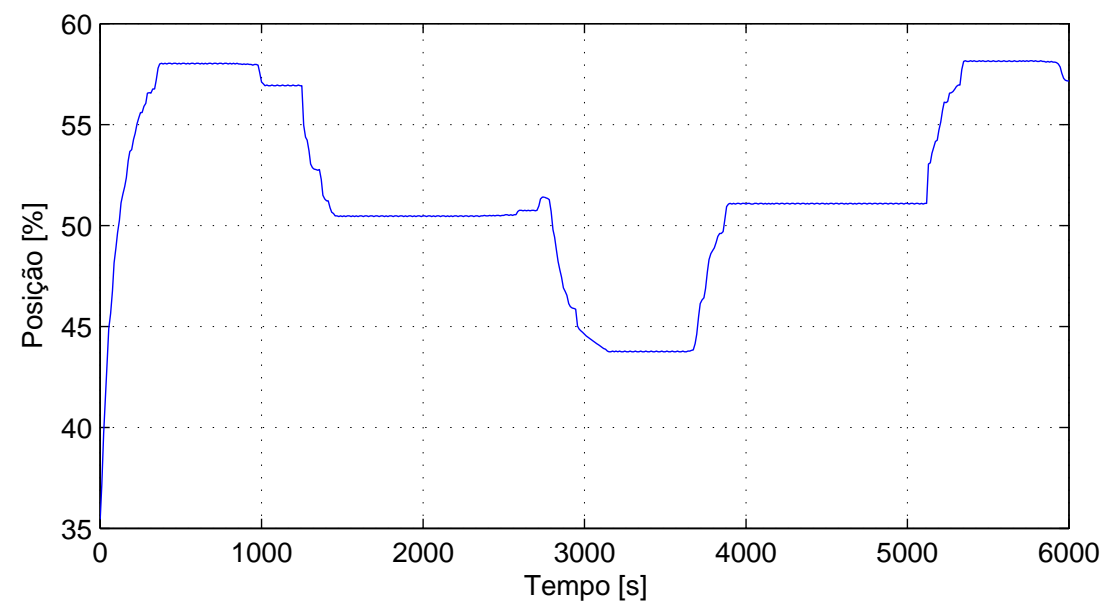

Fonte: Autor.

Tabela 12: Índices de desempenho dos controladores PI para o período de amostragem de $10 \mathrm{~ms}$.

\begin{tabular}{ccccc}
\hline Ensaio & ITAE [\%] & IAE [\%] & $D_{v}[\%]$ & $T_{s}[\mathrm{~s}]$ \\
\hline PI com $T_{i}=2,5317$ & 70,6723 & 157,2114 & 92,7779 & 9,87 \\
PI com $T_{i}=12$ & 68,4842 & 142,8988 & 58,4775 & 56,17 \\
PI com $T_{i}=16$ & 71,4831 & 155,9514 & 62,9296 & 68,99 \\
\hline
\end{tabular}

parâmetros apresentados nas Tabelas 5 e 6.

Figura 64: Vazão obtida com o compensador CR1 ( $T=10 \mathrm{~ms})$.

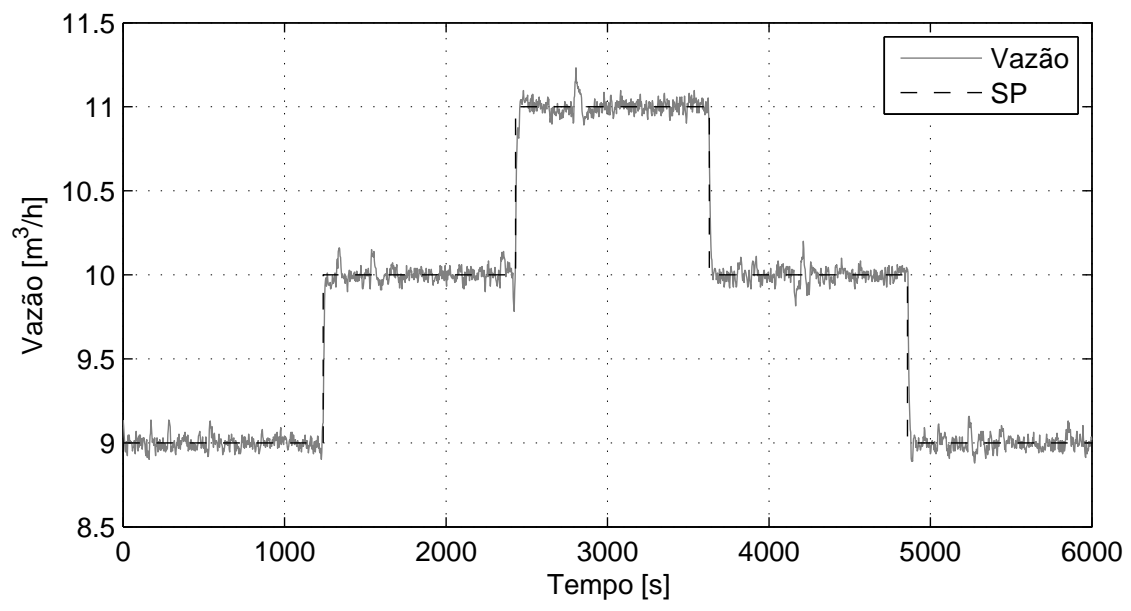

Fonte: Autor.

Analisando-se os gráficos obtidos, pode-se ver que os compensadores CR1, CR2 e Knocker têm um comportamento similar, eles conseguem reduzir as oscilações do processo sem aumentar consideravelmente o movimento da haste da válvula. O compensador Two-move também consegue reduzir as oscilções do processo, mas aumenta consideravelmente o movimento da haste da válvula. 
Figura 65: Sinal de controle com o compensador CR1 ( $T=10 \mathrm{~ms})$.

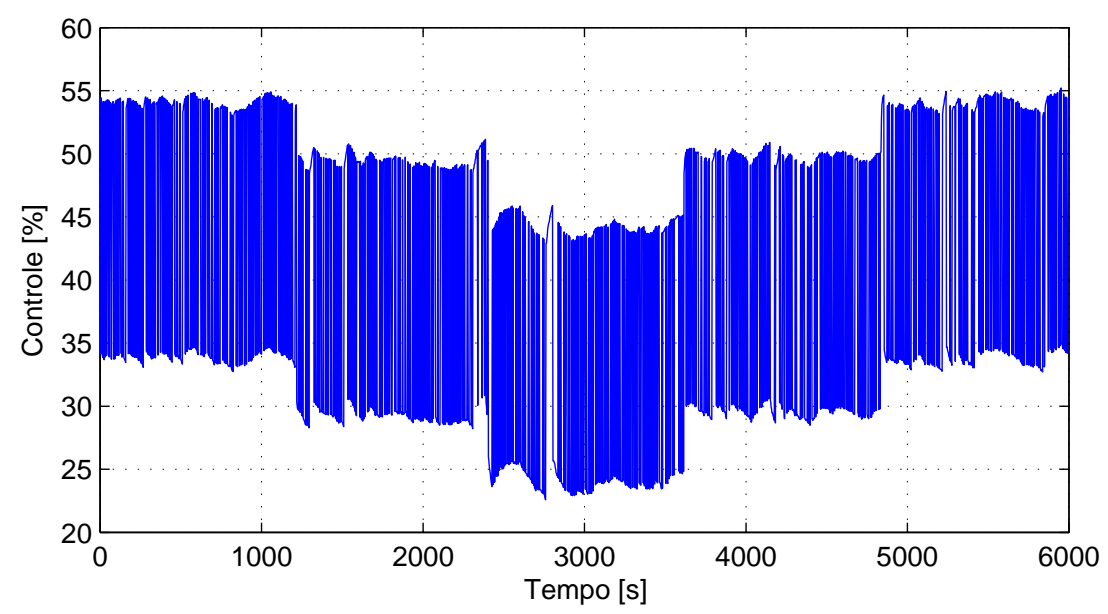

Fonte: Autor.

Figura 66: Posição da haste da válvula com o compensador CR1 ( $T=10$ ms).

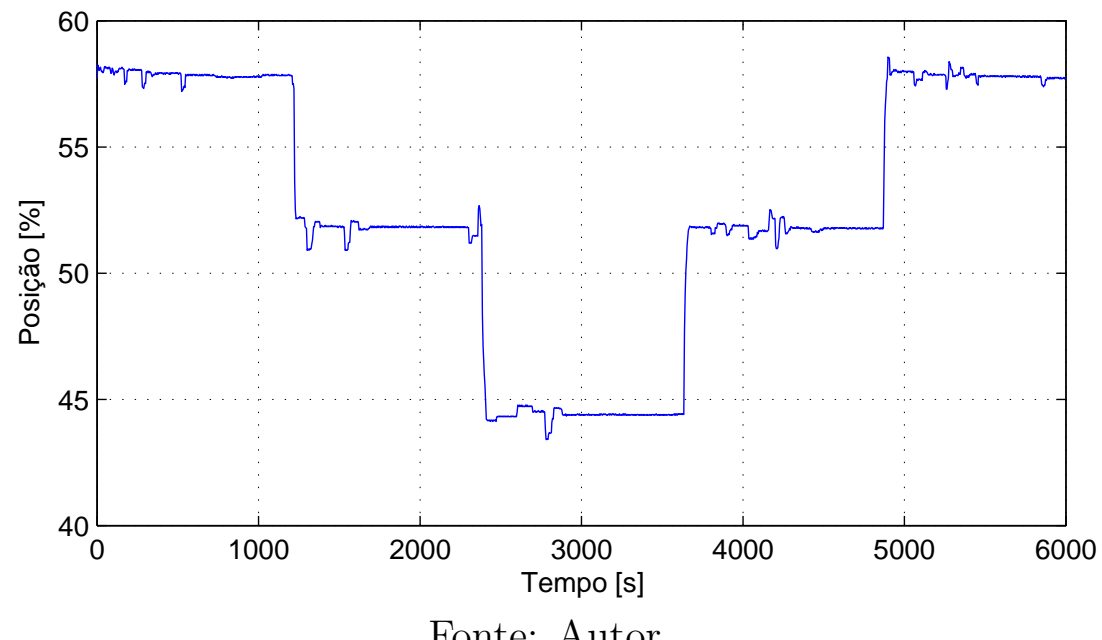

Figura 67: Vazão obtida com o compensador CR2 ( $T=10 \mathrm{~ms})$.

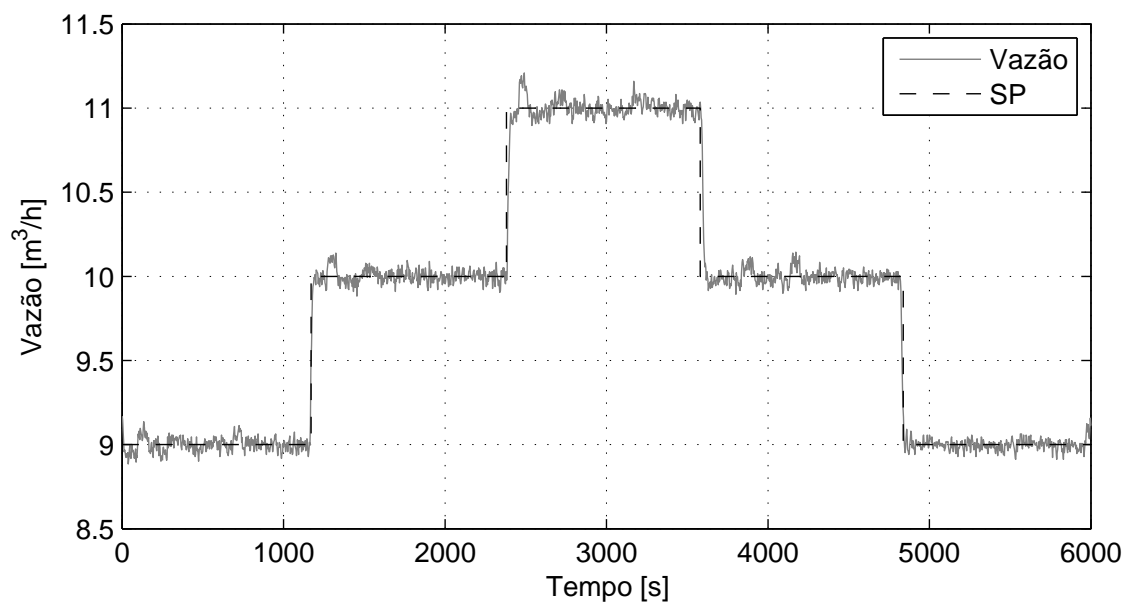

Fonte: Autor.

Para analisar melhor o anteriormente dito, na Tabela 13 são mostrados os índices de desempenho para os compensadores de atrito. 
Figura 68: Sinal de controle para o compensador CR2 ( $T=10 \mathrm{~ms})$.

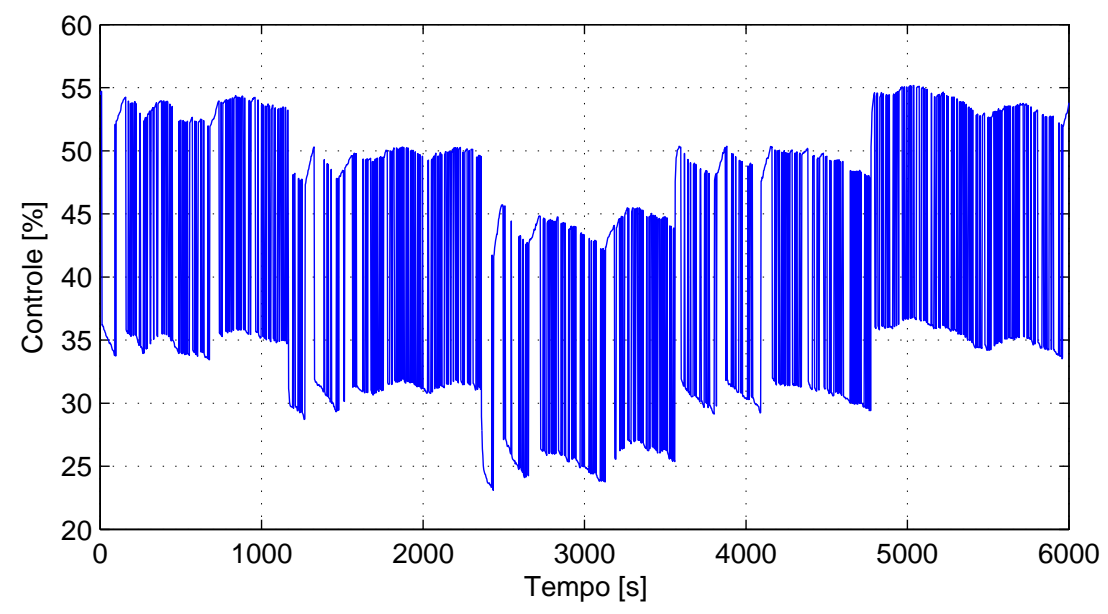

Fonte: Autor.

Figura 69: Posição da haste da válvula com o compensador CR2 ( $T=10 \mathrm{~ms}$ ).

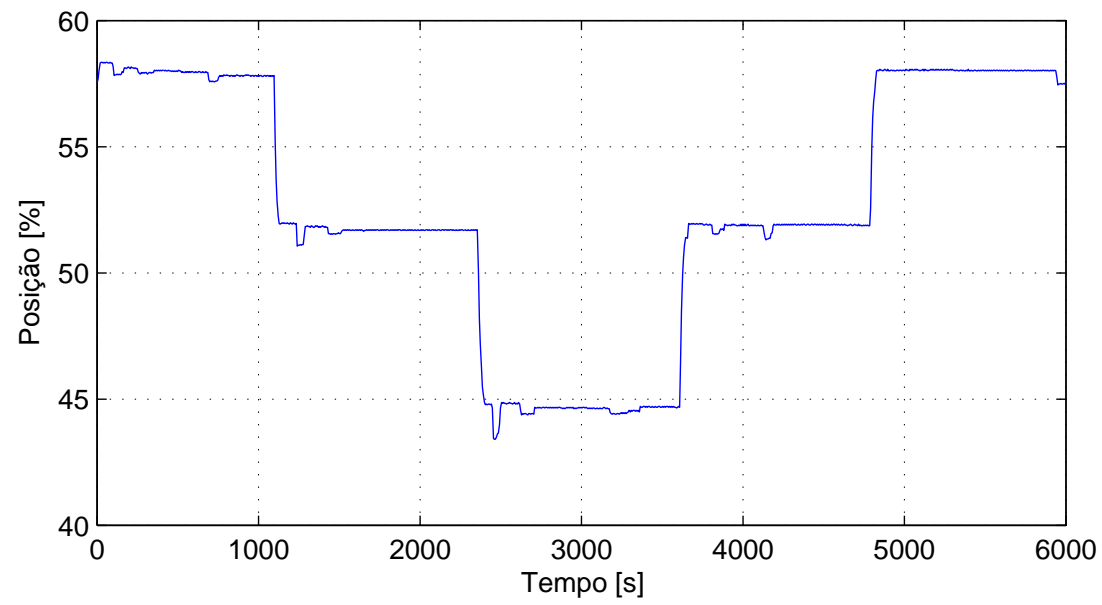

Fonte: Autor.

Figura 70: Vazão obtida com o compensador Knocker $(T=10 \mathrm{~ms})$.

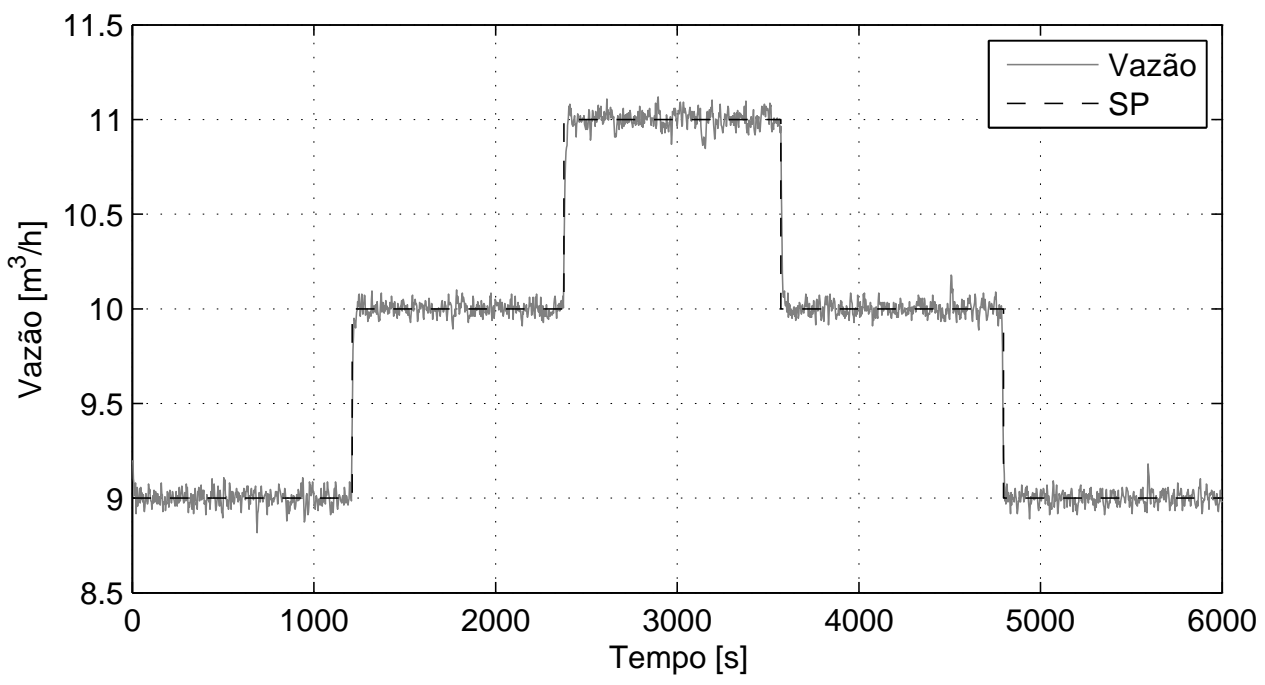

Fonte: Autor. 
Figura 71: Sinal de controle com o compensador Knocker $(T=10 \mathrm{~ms})$.

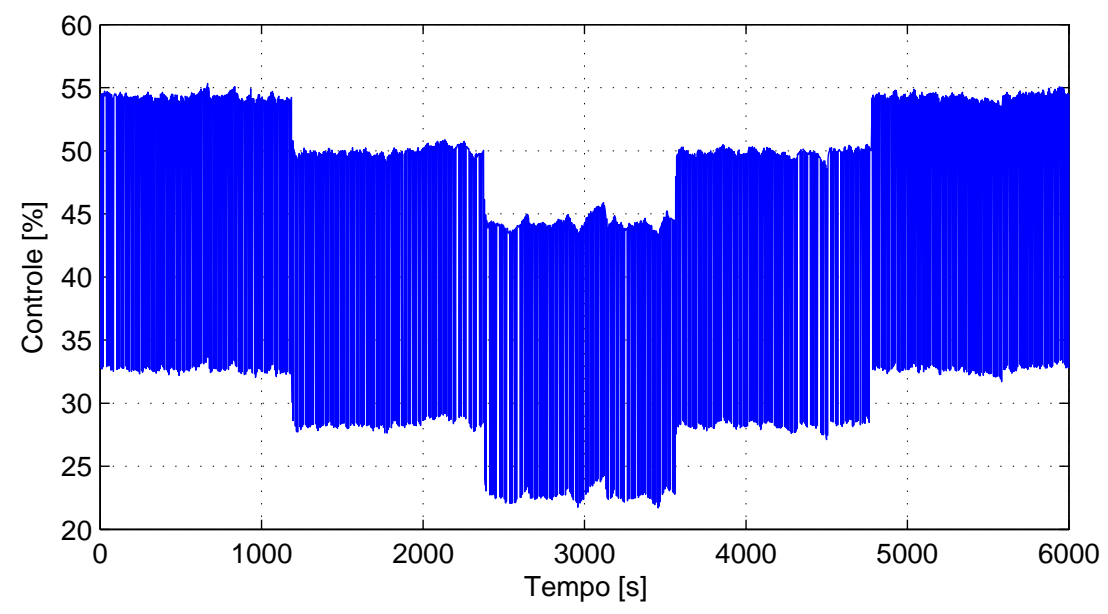

Fonte: Autor.

Figura 72: Posição da haste da válvula com o compensador Knocker ( $T=10$ ms).

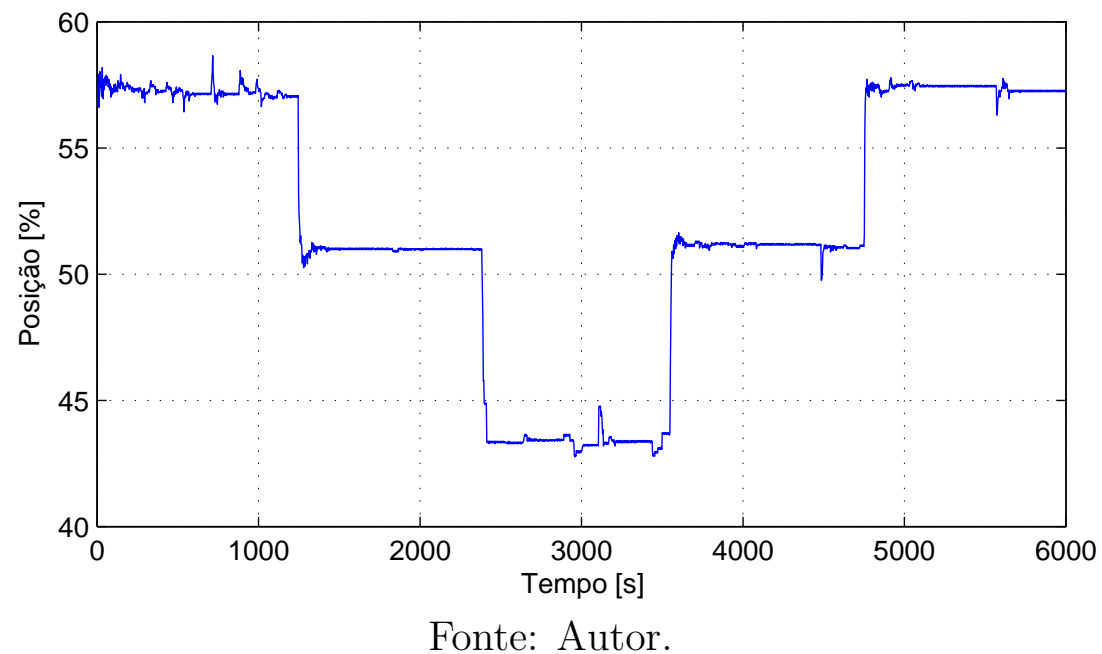

Figura 73: Vazão obtida com o compensador Two-move ( $T=10 \mathrm{~ms})$.

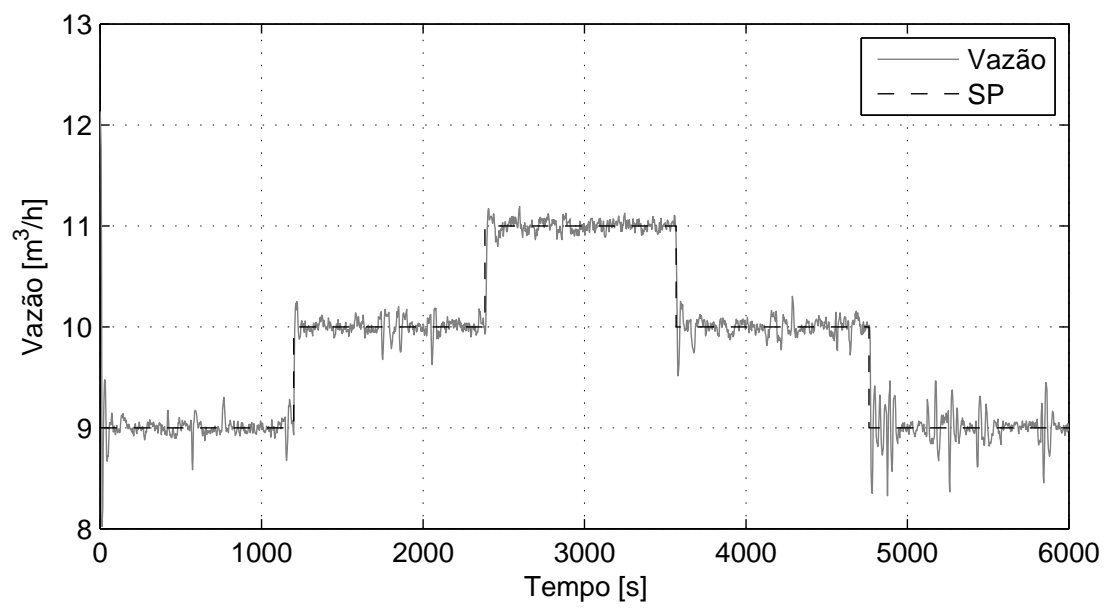

Fonte: Autor. 
Figura 74: Sinal de controle com o compensador Two-move ( $T=10 \mathrm{~ms})$.

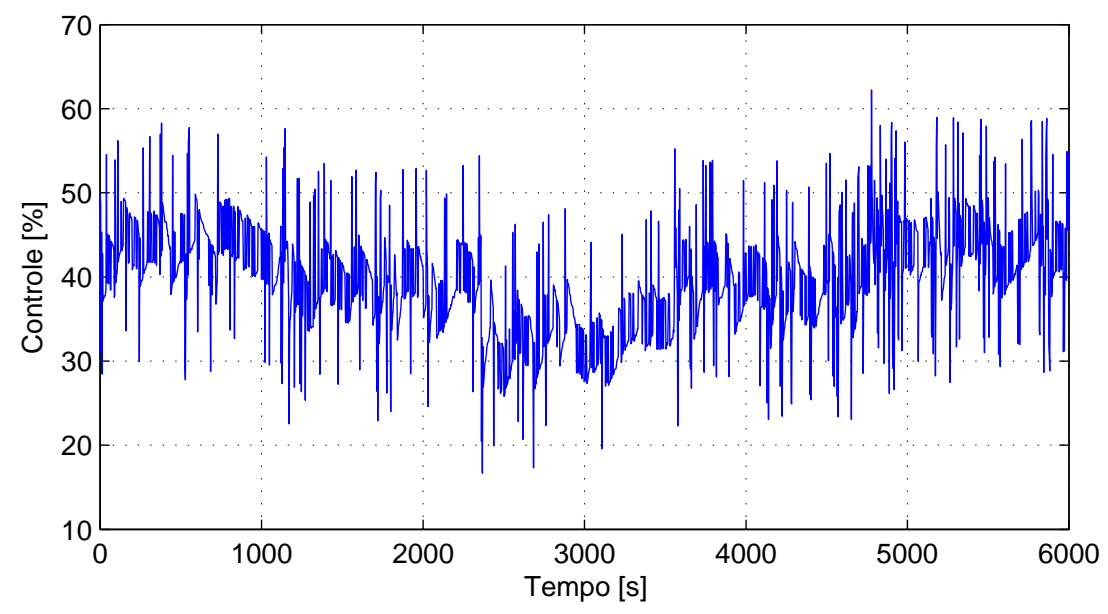

Fonte: Autor.

Figura 75: Posição da haste da válvula com o compensador Two-move ( $T=10 \mathrm{~ms}$ ).

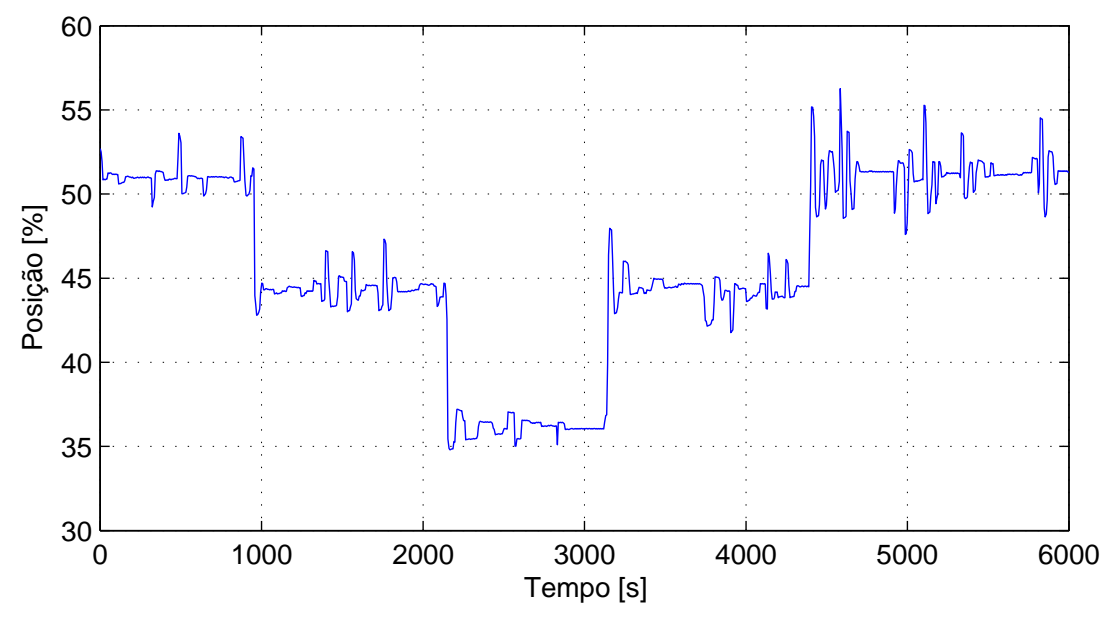

Fonte: Autor.

Tabela 13: Índices de desempenho dos compensadores de atrito para o período de amostragem de $10 \mathrm{~ms}$.

\begin{tabular}{ccccc}
\hline Ensaio & ITAE [\%] & IAE [\%] & $D_{v}[\%]$ & $T_{s}[\mathrm{~s}]$ \\
\hline PI com sintonia original & 70,6723 & 157,2114 & 92,7779 & 9,87 \\
CR1 & 40,3872 & 81,8368 & 103,3544 & 5,38 \\
CR2 & 35,0282 & 74,1215 & 60,0396 & 3,66 \\
Knocker & 36,2416 & 72,8161 & 203,9535 & 6,514 \\
Two-Move & 73,9207 & 149,8282 & 293,1594 & 7,0393 \\
\hline
\end{tabular}

Depois de analisar os resultados obtidos na Tabela 13, pode-se ver que os compensadores CR1, CR2 e Knocker melhoram o índice ITAE e o índice IAE. Além disso, o compensador CR2 consegue diminuir o desgaste na válvula, como fica evidente ao ver o índice $D_{v}$. O compensador Two-move não apresenta melhoras segundo os índices de desempenho. O compensador aumenta o índice ITAE, IAE e aumenta o desgaste na válvula de grafite, conforme indica o índice $D_{v}$. 


\subsubsection{Controlador por modos deslizantes}

Nas Figuras 76 a 91 se apresentam os resultados obtidos com os controladores por modos deslizantes e modos deslizantes integrador utilizando a sintonia do PI apresentada na Tabela 3 e os parâmetros apresentados nas Tabelas 8 e 9 .

Figura 76: Vazão para o controlador por modos deslizantes com chattering $(T=10 \mathrm{~ms})$.

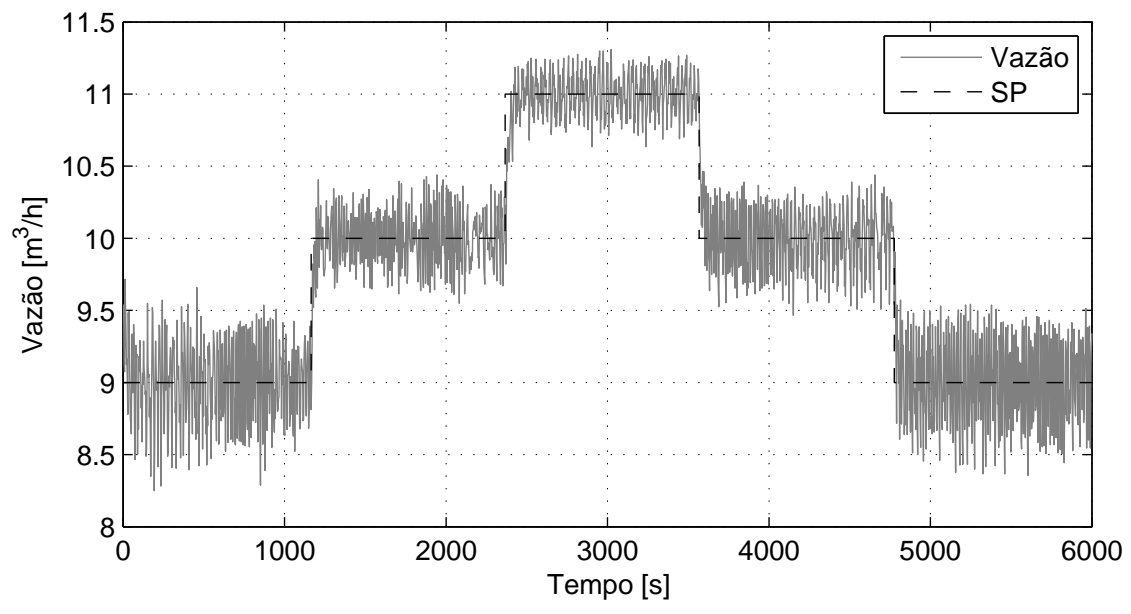

Fonte: Autor.

Figura 77: Sinal de controle para o controlador por modos deslizantes com chattering $(T=10 \mathrm{~ms})$.

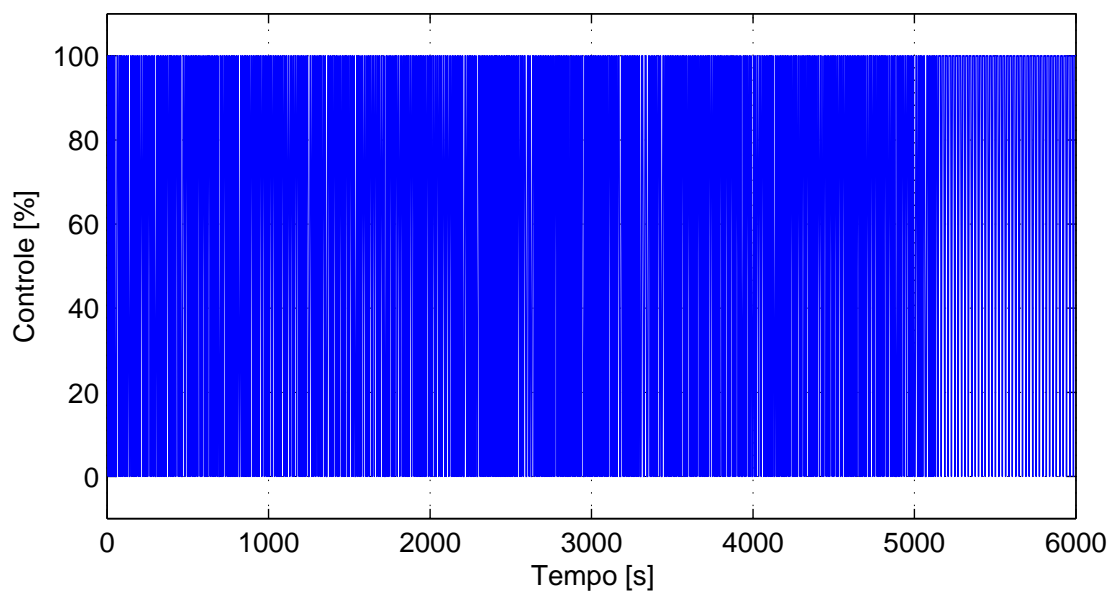

Fonte: Autor.

Depois de analisar os resultados obtidos, fica claro que os controladores conseguem levar a superfície de escorregamento ao redor de 0 , portanto eles trabalham de forma certa, mas também é evidente a importância do período de amostragem no comportamento dos controladores. Eles fazem oscilar muito a variável de processo, o que produz um grande aumento no desgaste da válvula. Para analisar melhor o comportamento dos controladores, na Tabela 14 apresentam-se os índices de desempenho.

Pode-se ver na Tabela 14 como os controladores por modos deslizantes e modos deslizantes integrador não conseguem melhorar os índices de desempenho. Nota-se que os 
Figura 78: Posição da haste da válvula para o controlador por modos deslizantes com chattering $(T=10 \mathrm{~ms})$.

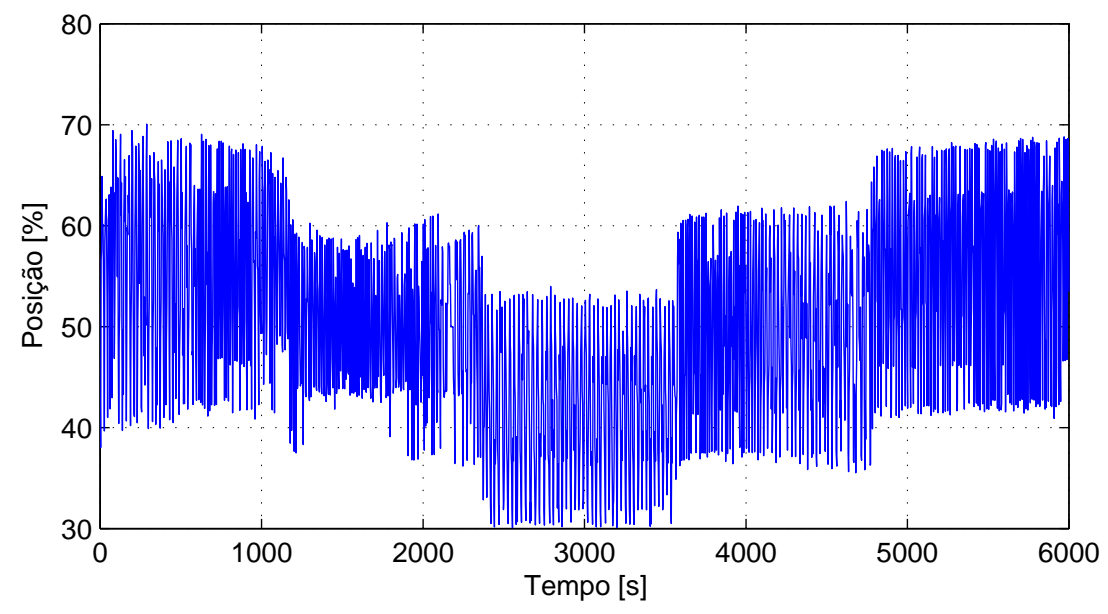

Fonte: Autor.

Figura 79: Superficie de escorregamento para o controlador por modos deslizantes com chattering $(T=10 \mathrm{~ms})$.

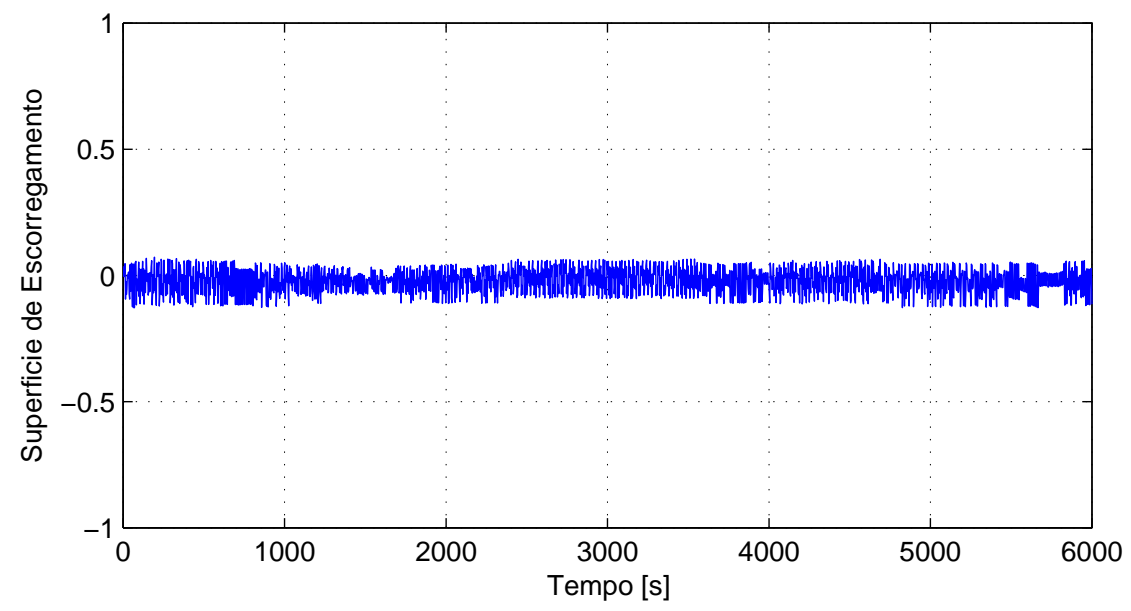

Fonte: Autor.

Figura 80: Vazão para o controlador por modos deslizantes sem chattering $(T=10 \mathrm{~ms})$.

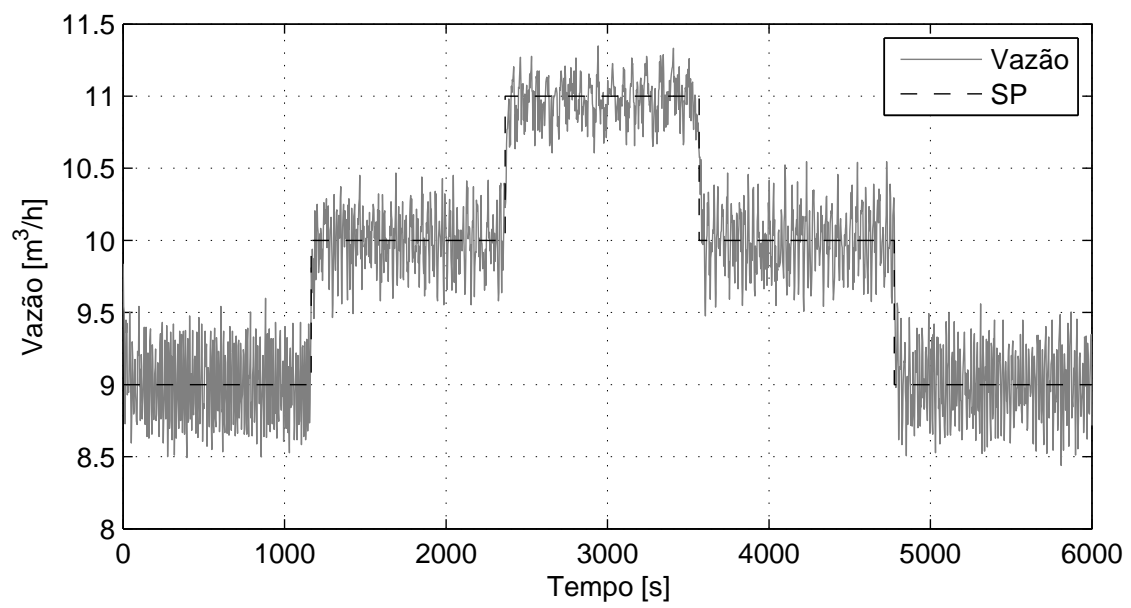

Fonte: Autor. 
Figura 81: Sinal de controle do controlador por modos deslizantes sem chattering $(T=10$ $\mathrm{ms})$.

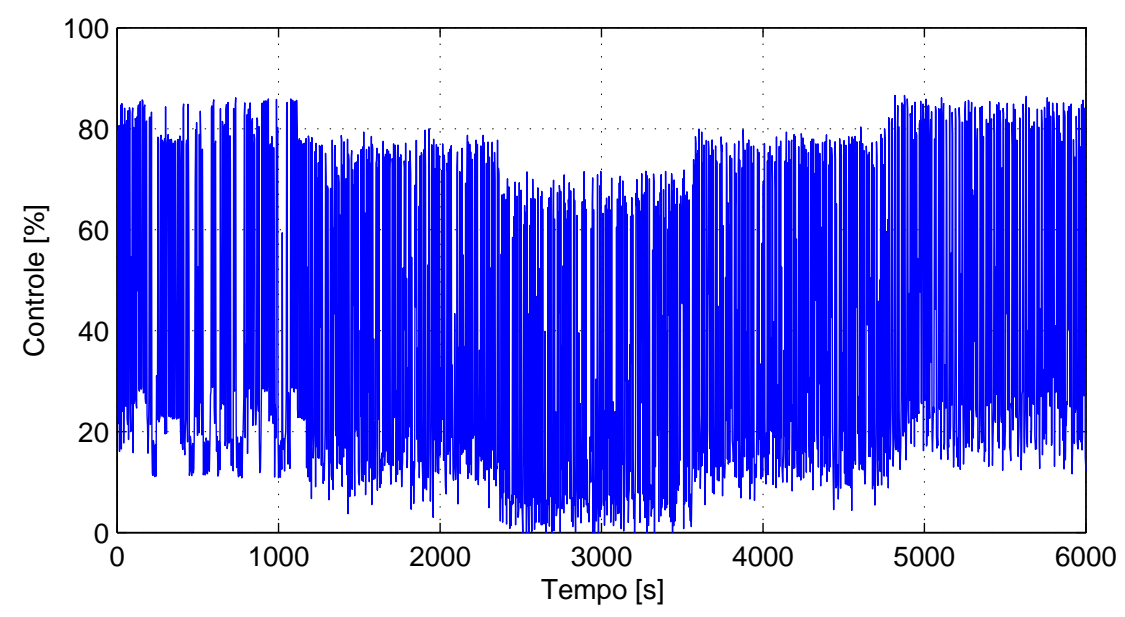

Fonte: Autor.

Figura 82: Posição da haste da válvula para o controlador por modos deslizantes sem chattering $(T=10 \mathrm{~ms})$.

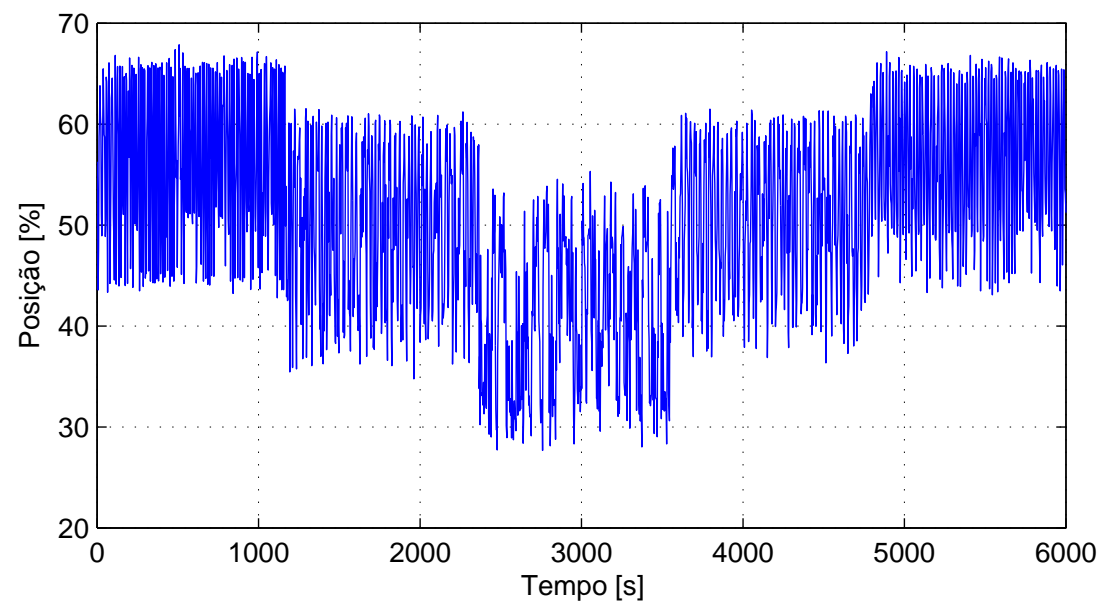

Fonte: Autor.

Tabela 14: Índices de desempenho dos controladores por modos deslizantes e modos deslizantes integrador para o período de amostragem de $10 \mathrm{~ms}$.

\begin{tabular}{ccccc}
\hline Ensaio & ITAE [\%] & IAE [\%] & $D_{v}[\%]$ & $T_{s}[\mathrm{~s}]$ \\
\hline PI com sintonia original & 70,6723 & 157,2114 & 92,7779 & 9,87 \\
MDC & 203,5561 & 398,4841 & 15482 & 117,92 \\
MDS & 181,6146 & 365,1713 & 12274 & 112,87 \\
MDIC & 326,5088 & 633,5760 & 27382 & 76,99 \\
MDIS & 252,0861 & 525,7047 & 23689 & 73,27 \\
\hline
\end{tabular}

controladores sem chattering apresentaram uma melhor resposta do que os controladores com chattering como era esperado, no entanto o aumento no desgaste da válvula é enorme em todos os casos. Portanto, pode-se dizer que os controladores por modos deslizantes não são uma boa escolha para tentar compensar o atrito existente em uma válvula de controle. 
Figura 83: Superficie de escorregamento para o controlador por modos deslizantes sem chattering $(T=10 \mathrm{~ms})$.

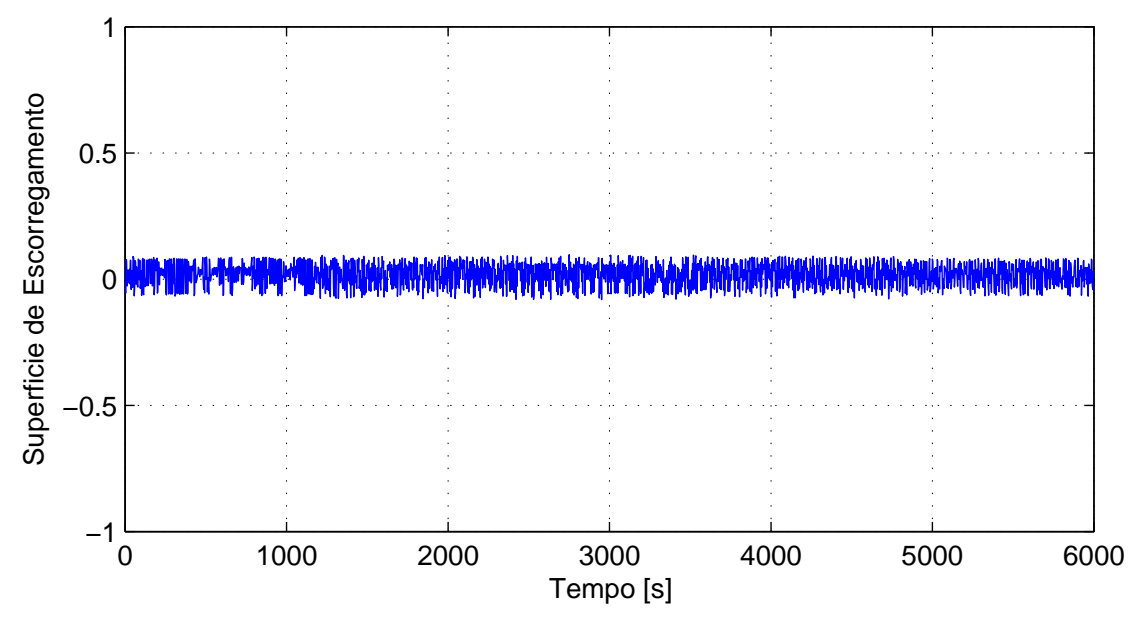

Fonte: Autor.

Figura 84: Vazão para o controlador por modos deslizantes integrador com chattering $(T=10 \mathrm{~ms})$.

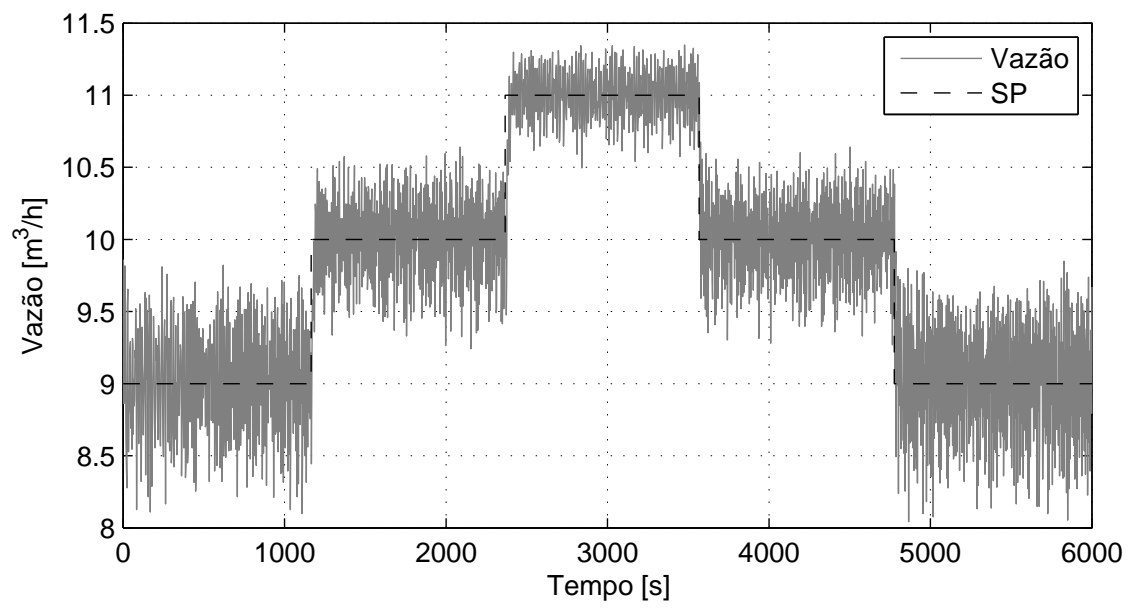

Fonte: Autor.

Na Tabela 15 são apresentados todos os índices obtidos nos resultados práticos da Planta de Vazão. Resumindo, pode-se ver que também o compensadores Two-move obteve o melhor resultado, conseguindo compensar o atrito em uma válvula de controle, diminuindo as oscilações da variável controlada mas aumentando o desgaste da válvula, conforme indica o índice $D_{v}$.

\subsubsection{Resultados para o período de amostragem de $0,5 \mathrm{~s}$}

A seguir são apresentados os resultados obtidos dos compensadores, com um período de amostragem de $0,5 \mathrm{~s}$, com a finalidade de comparar os experimentos realizados com um período de amostragem reduzido e com um período de amostragem tipicamente utilizado na indústria de processos. 
Figura 85: Sinal de controle do controlador por Modos deslizantes integrador com chattering $(T=10 \mathrm{~ms})$.

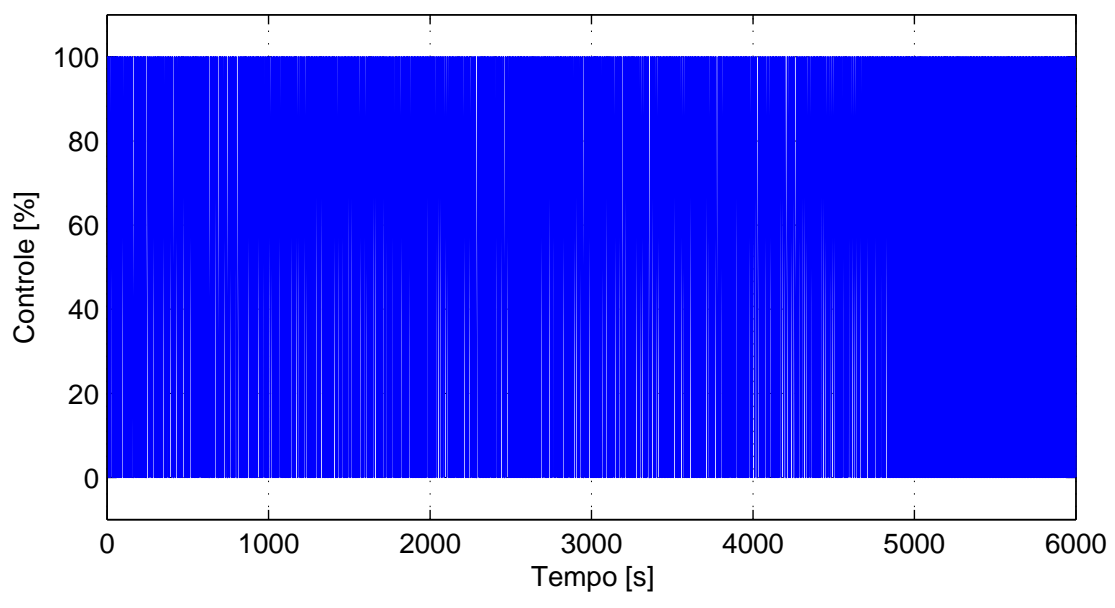

Fonte: Autor.

Figura 86: Posição da haste da válvula para o controlador por modos deslizantes integrador com chattering ( $T=10 \mathrm{~ms})$.

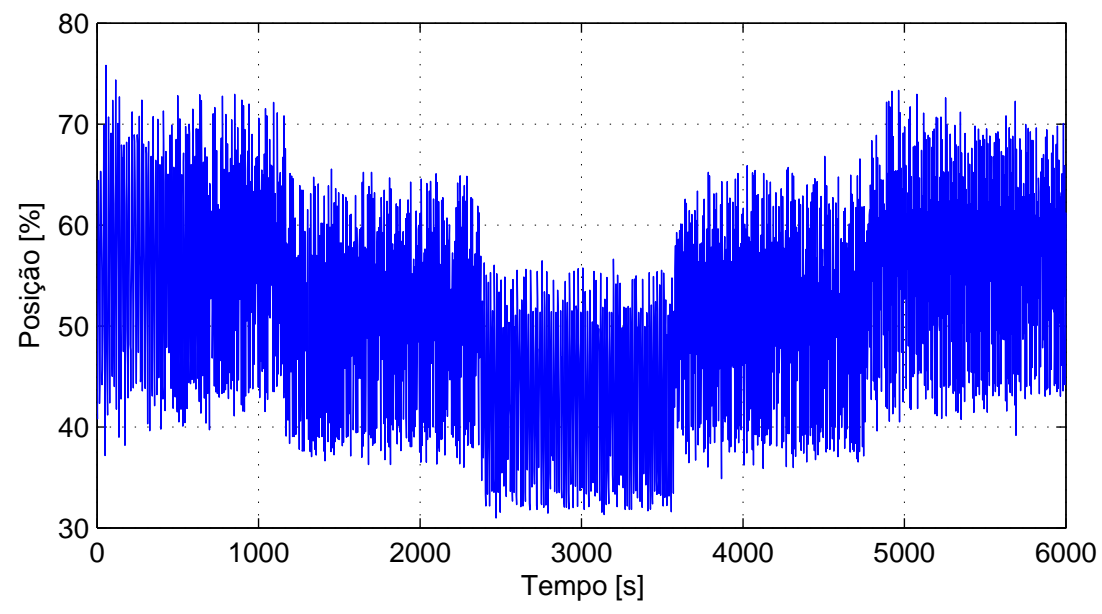

Fonte: Autor.

\subsubsection{Apenas Controlador PI}

Nas Figuras 92 a 100 apresentam-se os resultados obtidos com as diferentes sintonias do controlador PI.

Fica evidente a presença de um alto nível de atrito na válvula de grafite. Para este período de amostragem, também foi modificada a sintonia original do controlador PI. Os resultados obtidos para as sintonias com $T_{i}=12 \mathrm{~s}$ e $T_{i}=16 \mathrm{~s}$ são apresentados nas Figuras 95 a 100.

Para os dois tempos de amostragem, o comportamento dos controladores é similar. No caso da sintonia original do controlador PI, a variável de processo apresenta oscilações. Também observando a Figura 94 é claro que a posição da haste varia muito, portanto se produz um desgaste na válvula. 
Figura 87: Superficie de escorregamento para o controlador por modos deslizantes integrador com chattering $(T=10 \mathrm{~ms})$.

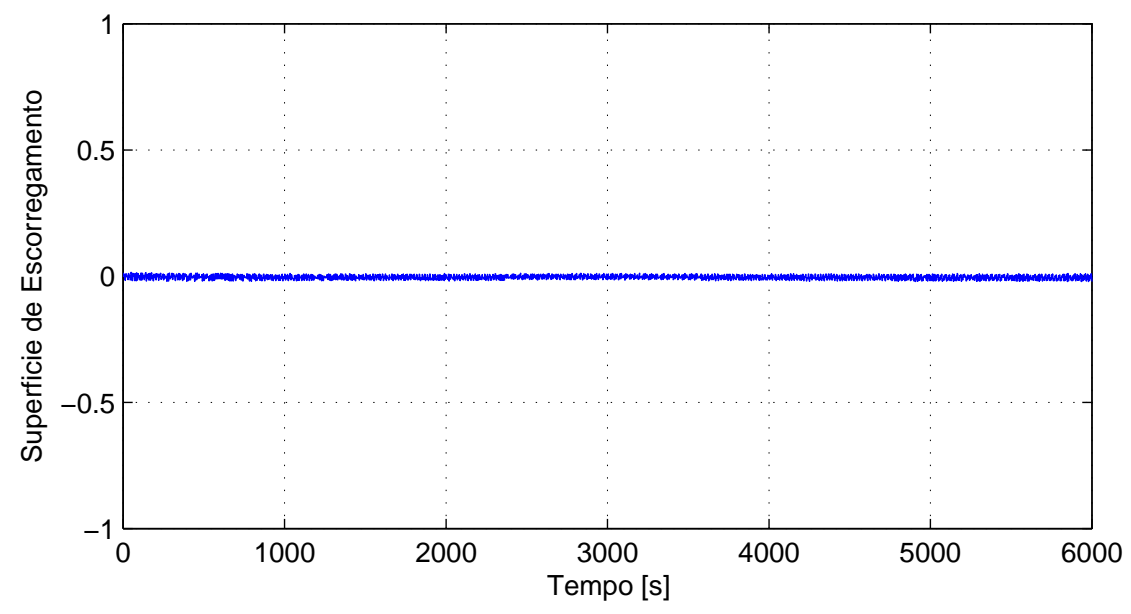

Fonte: Autor.

Figura 88: Vazão para o controlador por modos deslizantes integrador sem chattering $(T=10 \mathrm{~ms})$.

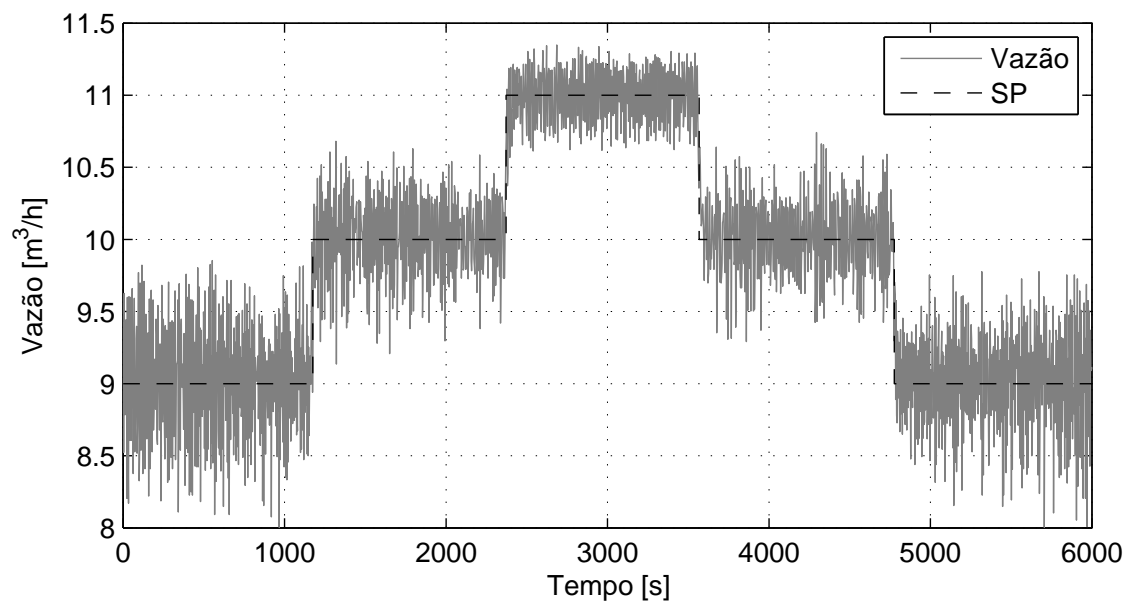

Fonte: Autor.

Para os controladores PI con $T_{i}=12 \mathrm{~s}$ e $T_{i}=16 \mathrm{~s}$, as oscilações na variável de processo diminuíram, assim como o desgaste na válvula é menor. Para uma melhor análise, na Tabela 16 são apresentados os índices de desempenho para os controladores PI.

Depois de observar os índices de desempenho, fica claro que as sintonias com o $T_{i}$ aumentado conseguem melhorar muito os índices de desempenho ITAE e IAE. Também fica evidente como se consegue uma diminuição considerável no desgaste da válvula, como indicado pelo índice $D_{v}$. 
Figura 89: Sinal de controle do controlador por modos deslizantes integrador sem chatte$\operatorname{ring}(T=10 \mathrm{~ms})$.

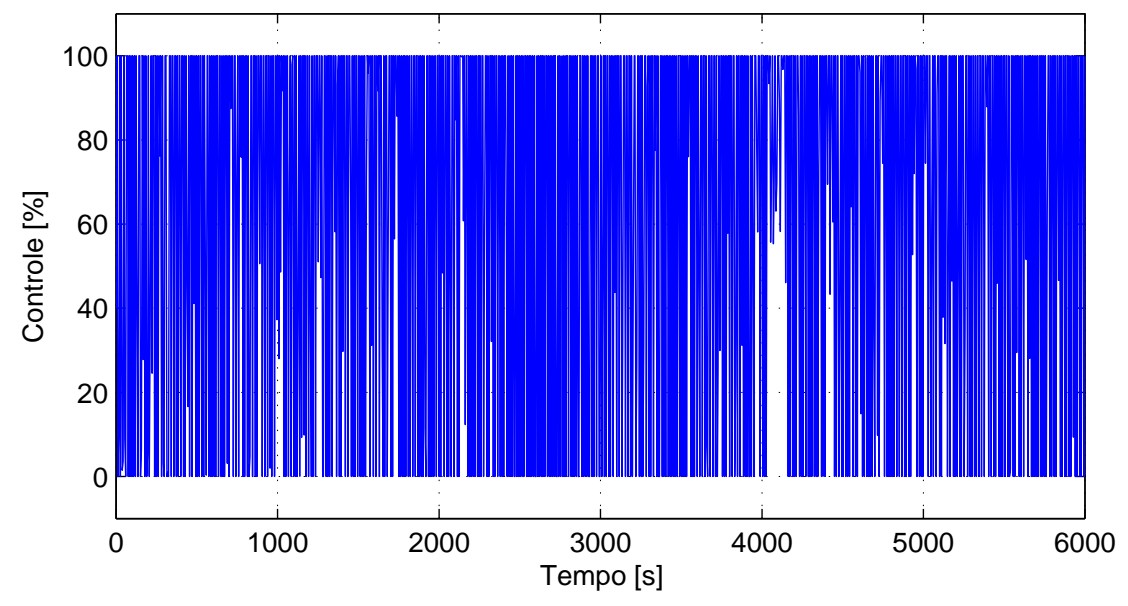

Fonte: Autor.

Figura 90: Posição da haste da válvula para o controlador por modos deslizantes integrador sem chattering $(T=10 \mathrm{~ms})$.

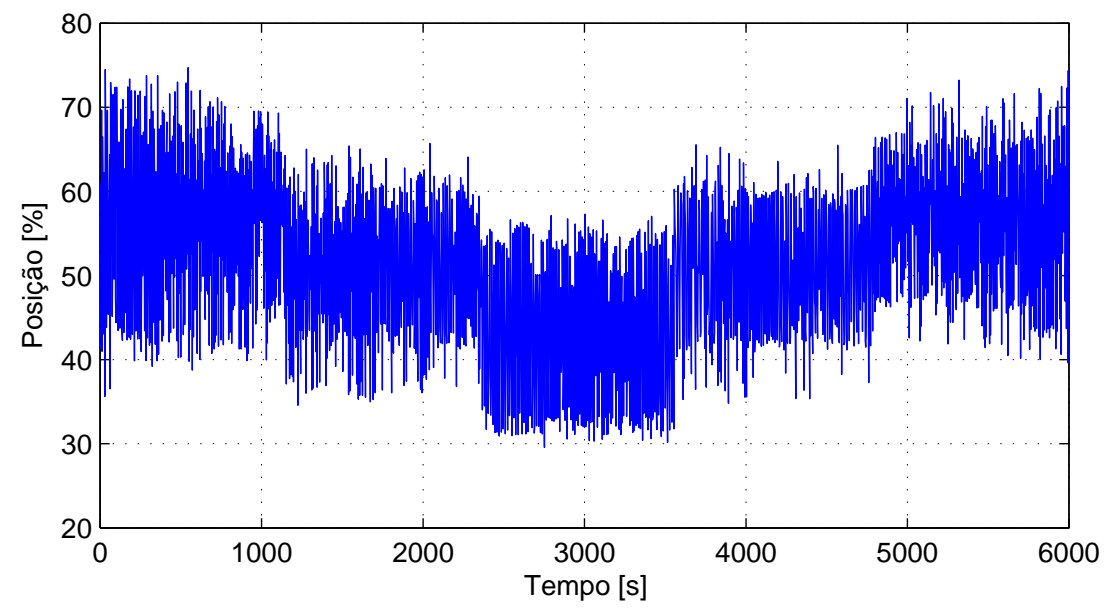

Fonte: Autor.

\subsubsection{Compensadores CR1, CR2, Knocker e Two-move}

Nas Figuras 101 a 112 se apresentam os resultados obtidos com os compensadores CR1, CR2, Knocker e Two-move utilizando a sintonia do PI apresentada na Tabela 3 e os parâmetros apresentados nas Tabelas 5 e 17.

Observando-se a Figura 101 pode-se ver que o compensador CR1 consegue diminuir as oscilações na variável do processo. Também pode-se ver na Figura 103 um aumento no sinal de controle. A posição da haste da válvula não apresenta movimentos fortes, portanto o desgaste da válvula é menor do que o desgaste gerado pelo controlador PI original.

Analisando-se a Figura 104 pode-se ver que o compensador CR2 também consegue diminuir as oscilações. Também pode-se ver na Figura 105 que o sinal de controle é um pouco menor do que o sinal de controle do compensador CR1. A Figura 106 não apresenta 
Figura 91: Superficie de escorregamento para o controlador por modos deslizantes integrador sem chattering $(T=10 \mathrm{~ms})$.

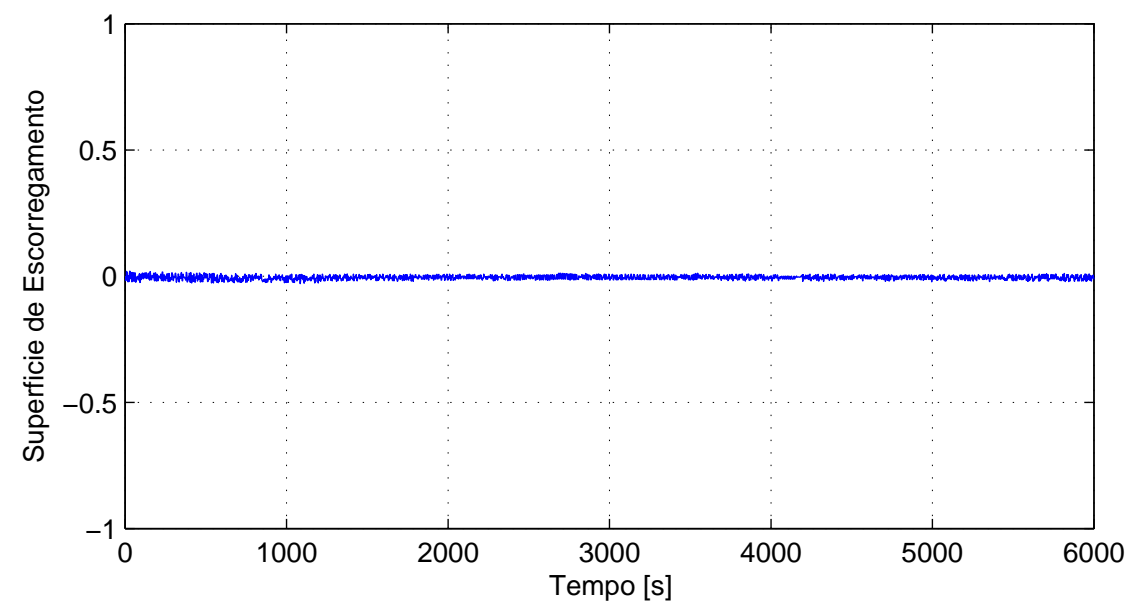

Fonte: Autor.

Tabela 15: Índices de desempenho dos compensadores e controladores para o período de amostragem de $10 \mathrm{~ms}$.

\begin{tabular}{ccccc}
\hline Ensaio & ITAE [\%] & IAE [\%] & $D_{v}[\%]$ & $T_{s}[\mathrm{~s}]$ \\
\hline PI com $T_{i}=2,54$ & 70,6723 & 157,2114 & 92,7779 & 9,87 \\
PI com $T_{i}=12$ & 68,4842 & 142,8988 & 58,4775 & 56,17 \\
PI com $T_{i}=16$ & 71,4831 & 155,9514 & 62,9296 & 68,99 \\
CR1 & 40,3872 & 81,8368 & 103,3544 & 5,38 \\
CR2 & 35,0282 & 74,1215 & 60,0396 & 3,66 \\
Knocker & 36,2416 & 72,8161 & 203,9535 & 6,514 \\
Two-Move & 73,9207 & 149,8282 & 293,1594 & 7,0393 \\
MDC & 203,5561 & 398,4841 & 15482 & 117,92 \\
MDS & 181,6146 & 365,1713 & 12274 & 112,87 \\
MDIC & 326,5088 & 633,5760 & 27382 & 76,99 \\
MDIS & 252,0861 & 525,7047 & 23689 & 73,27 \\
\hline
\end{tabular}

Figura 92: Vazão obtida com o controlador PI $(T=0,5 \mathrm{~s})$.

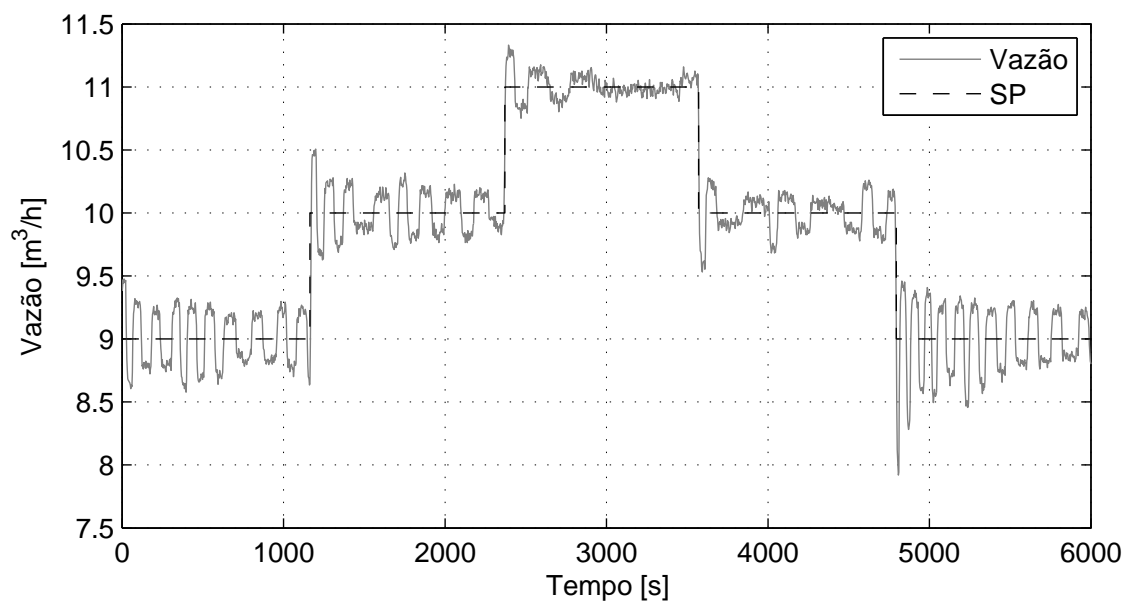

Fonte: Autor. 
Figura 93: Sinal de controle do controlador PI $(T=0,5 \mathrm{~s})$.

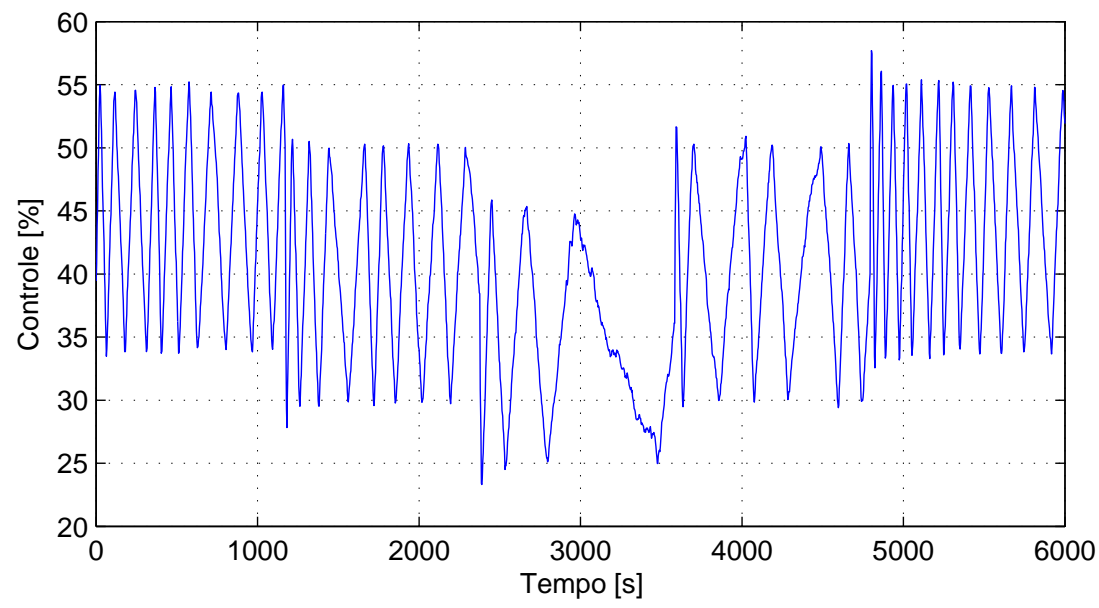

Fonte: Autor.

Figura 94: Posição da haste com controlador PI ( $T=0,5 \mathrm{~s})$.

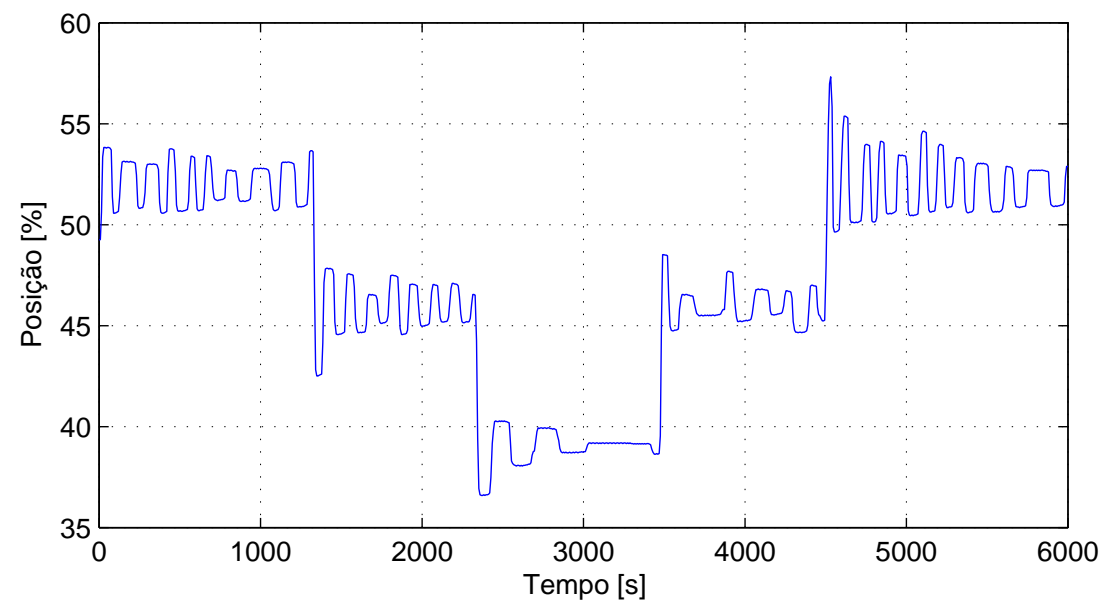

Fonte: Autor.

Figura 95: Vazão obtida com o controlador PI com $T_{i}=12(T=0,5 \mathrm{~s})$.

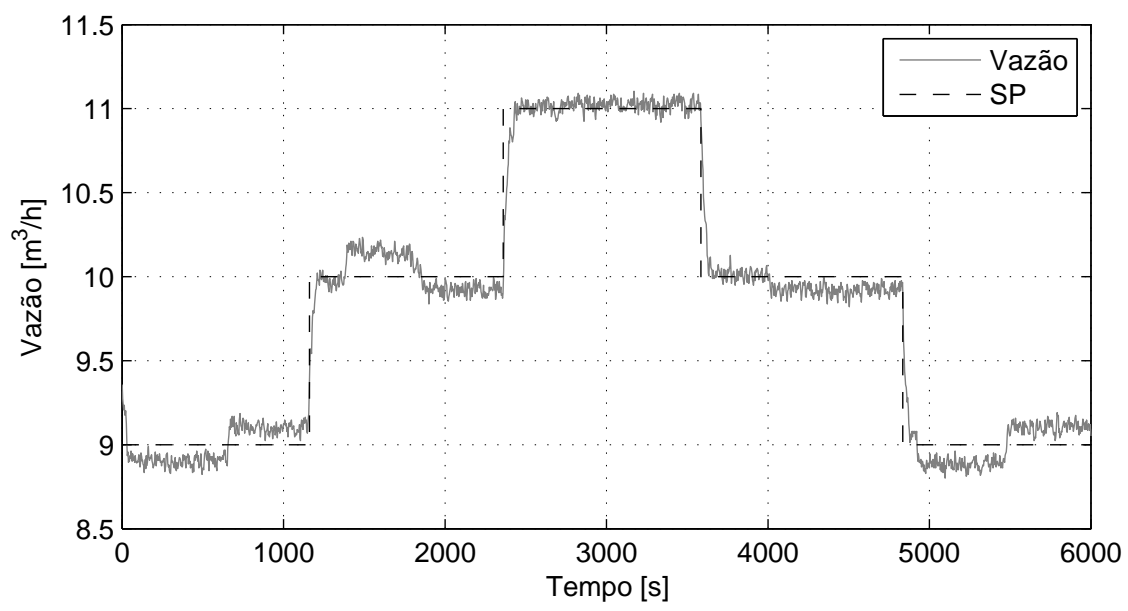

Fonte: Autor.

um grande desgaste na válvula. 
Figura 96: Sinal de controle do controlador PI com $T_{i}=12(T=0,5 \mathrm{~s})$.

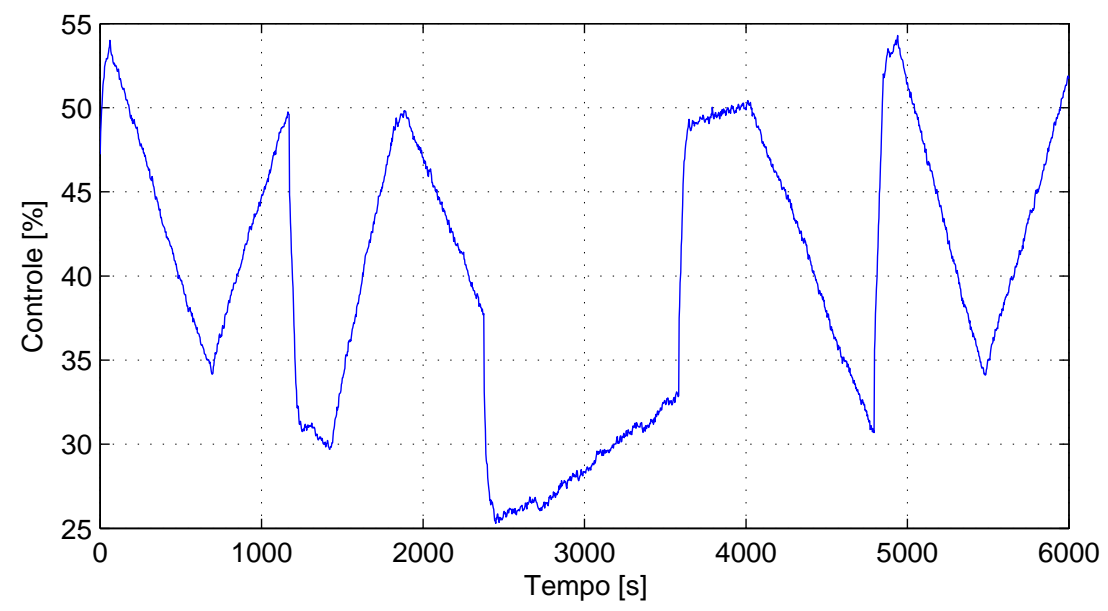

Fonte: Autor.

Figura 97: Posição da haste com controlador PI com $T_{i}=12(T=0,5 \mathrm{~s})$.

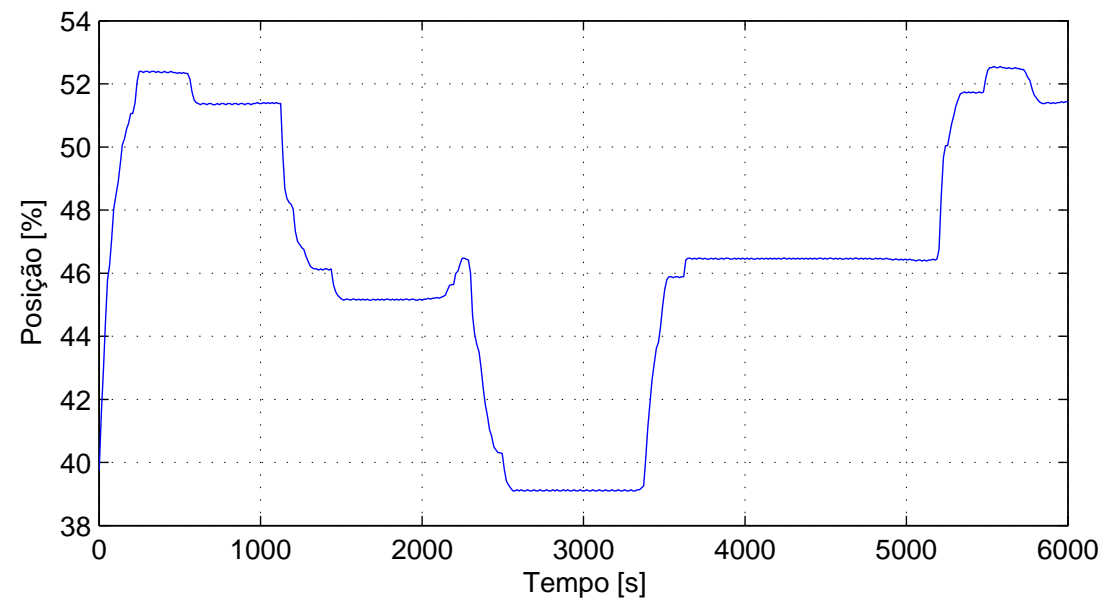

Fonte: Autor.

Figura 98: Vazão obtida com o controlador PI com $T_{i}=16(T=0,5 \mathrm{~s})$.

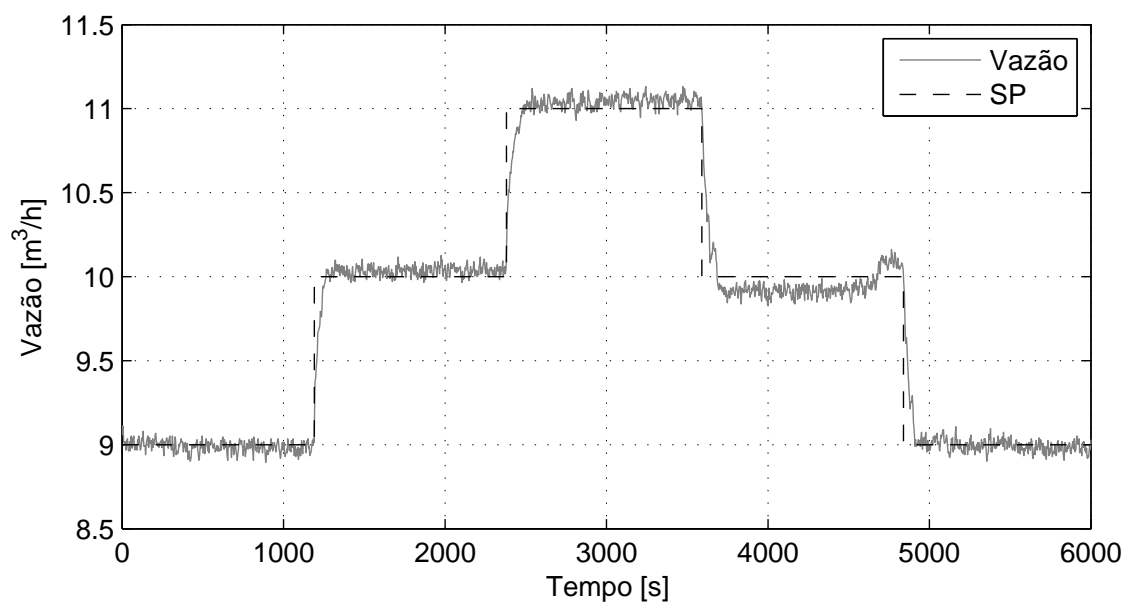

Fonte: Autor.

Depois de analisar as Figuras 107 a 109 é evidente como o período de amostragem afeta o desempenho do compensador Knocker. Pode-se ver que o compensador Knocker 
Figura 99: Sinal de controle do controlador PI $\operatorname{com} T_{i}=16(T=0,5 \mathrm{~s})$.

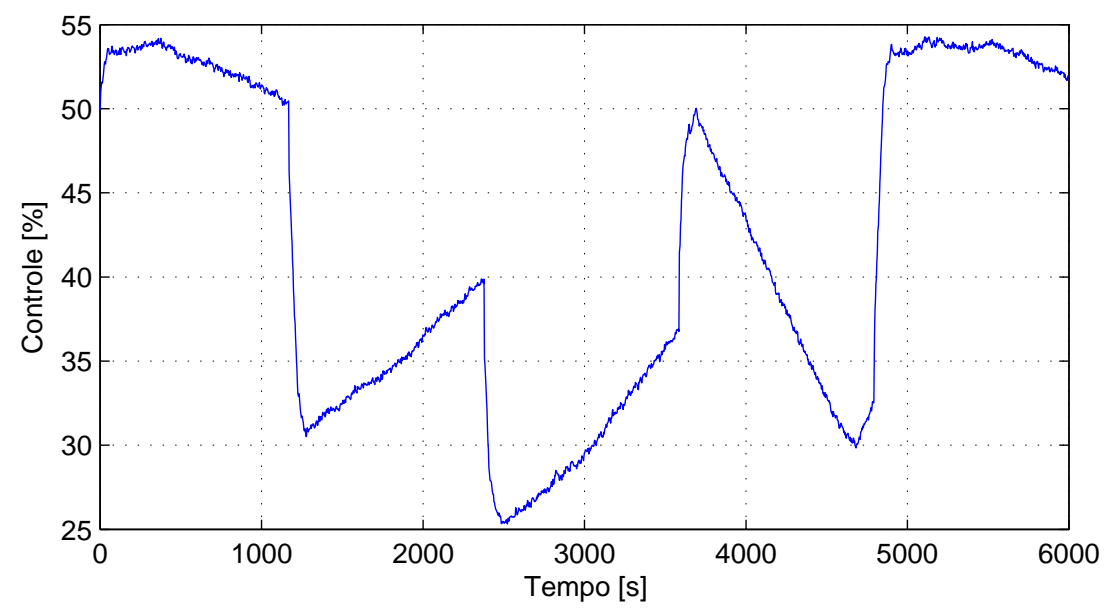

Fonte: Autor.

Figura 100: Posição da haste com controlador PI com $T_{i}=16(T=0,5 \mathrm{~s})$.

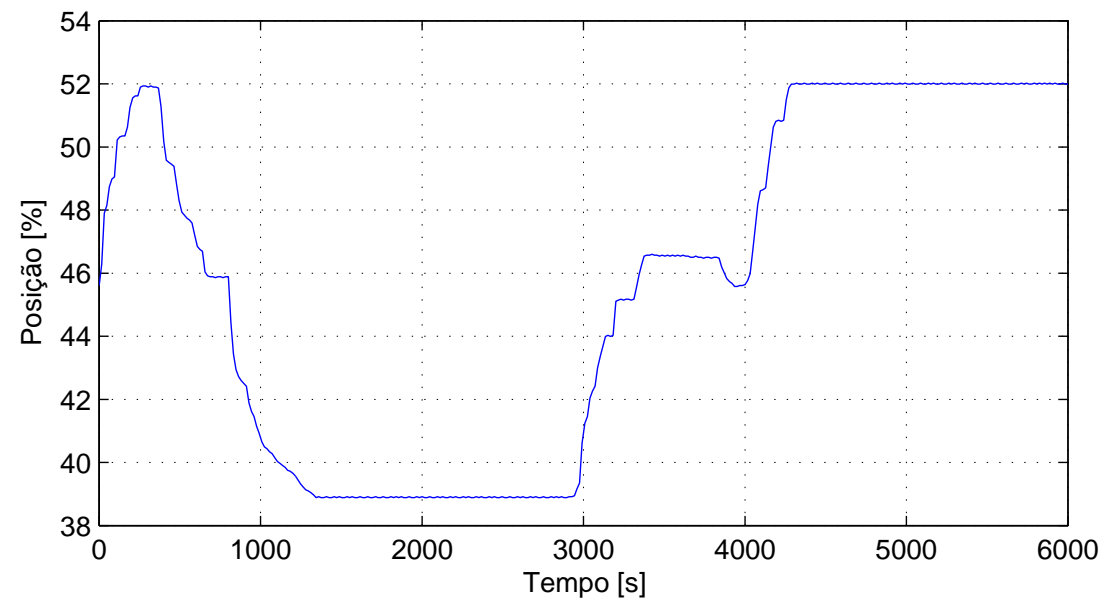

Fonte: Autor.

Tabela 16: Índices de desempenho do controlador PI com diferentes sintonias para o período de amostragem de $0,5 \mathrm{~s}$.

\begin{tabular}{ccccc}
\hline Ensaio & ITAE [\%] & IAE [\%] & $D_{v}[\%]$ & $T_{s}[\mathrm{~s}]$ \\
\hline PI com $T_{i}=2,5317$ & 156,9031 & 316,8347 & 239,4659 & 11,1275 \\
PI com $T_{i}=12$ & 82,0028 & 180,9308 & 50,7913 & 74,5125 \\
PI com $T_{i}=16$ & 62,5120 & 124,3063 & 40,1128 & 97,5 \\
\hline
\end{tabular}

Tabela 17: Parâmetros para o projeto do compensador Knocker para o período de amostragem de $0,5 \mathrm{~s}$.

\begin{tabular}{cc}
\hline Parâmetro & Valor \\
\hline$a$ & $9,38[\%]$ \\
$h_{k}$ & $2,5[\mathrm{~s}]$ \\
$\tau$ & $1[\mathrm{~s}]$ \\
\hline
\end{tabular}

faz oscilar mais a variável de processo do que os compensadores CR1 e CR2. Também pode-se ver que o sinal de controle é maior e o desgaste na válvula aumenta. 
Figura 101: Vazão obtida com o compensador CR1 $(T=0,5 \mathrm{~s})$.

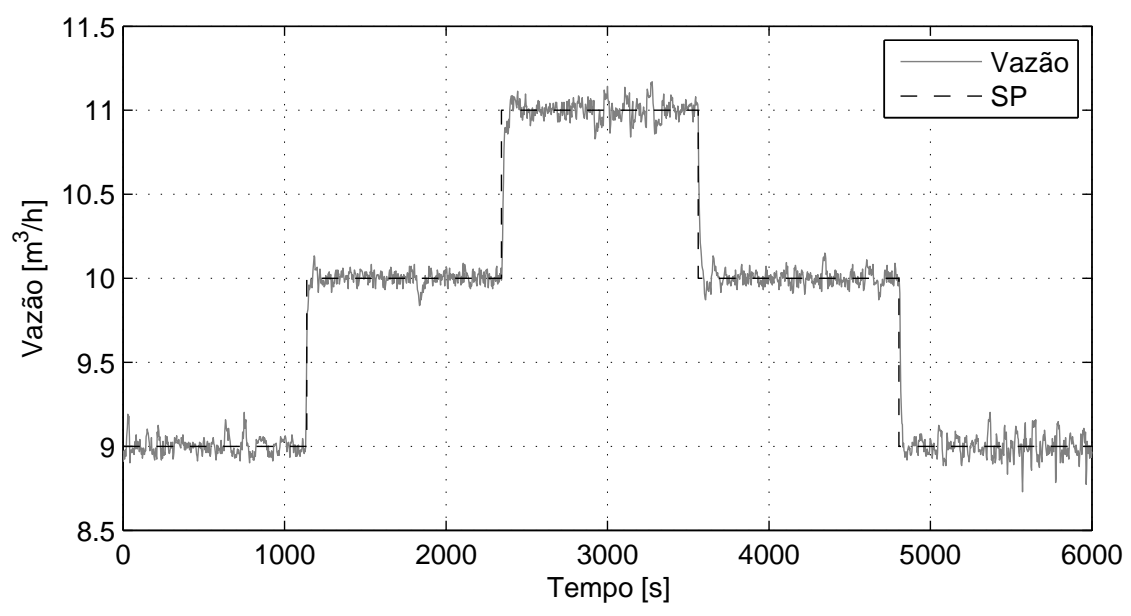

Fonte: Autor.

Figura 102: Sinal de controle do compensador CR1 $(T=0,5 \mathrm{~s})$.

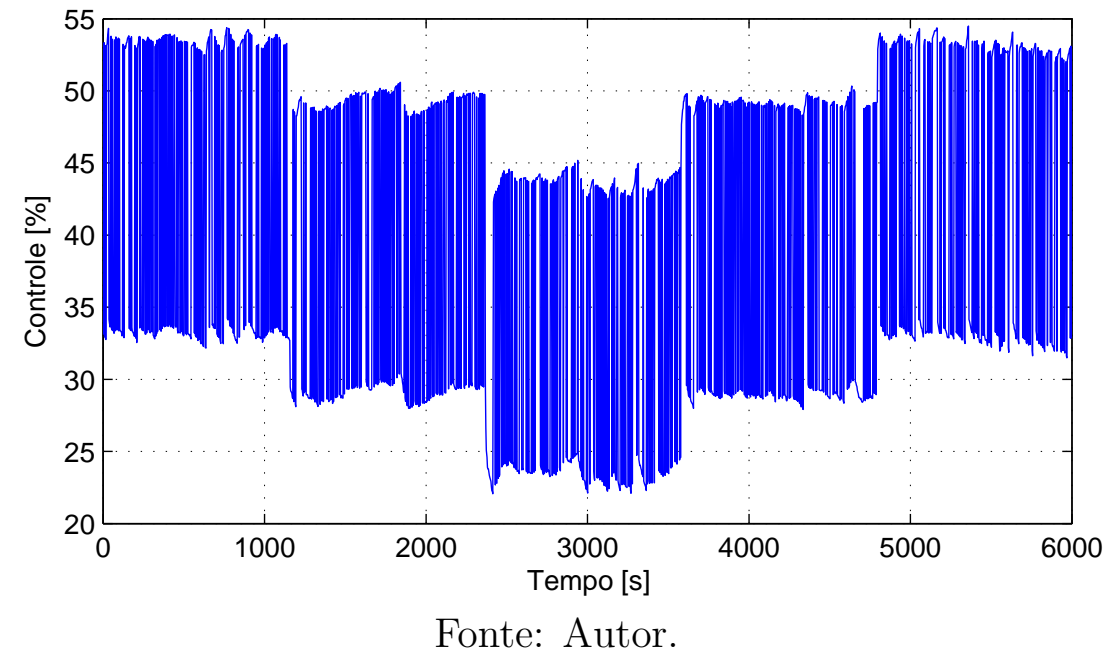

Figura 103: Posição da haste da válvula com o compensador CR1 ( $T=0,5 \mathrm{~s})$.

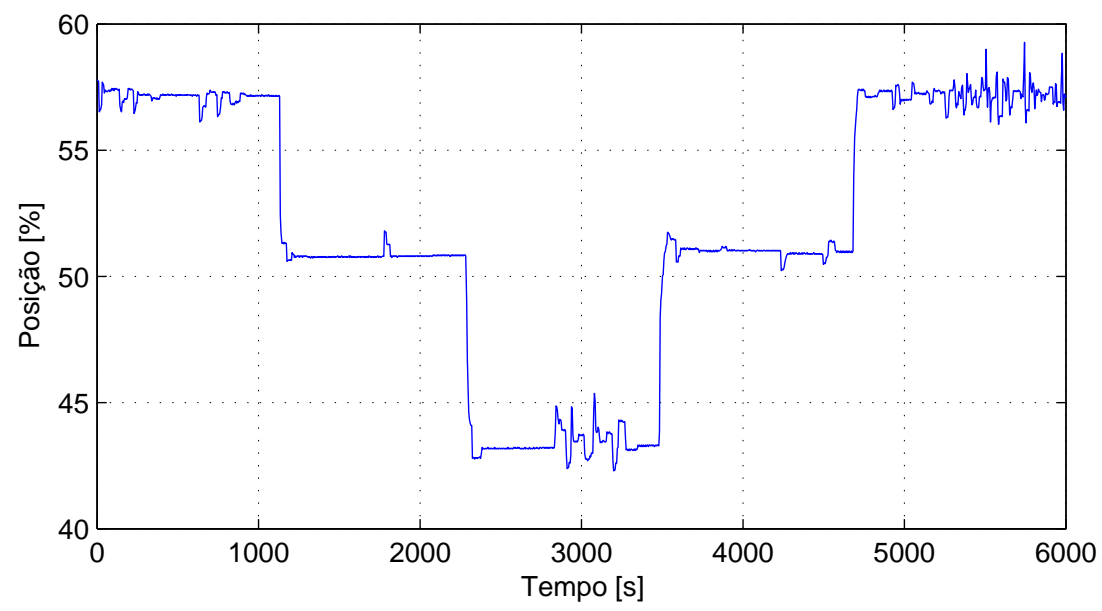

Fonte: Autor. 
Figura 104: Vazão obtida com o compensador CR2 $(T=0,5 \mathrm{~s})$.

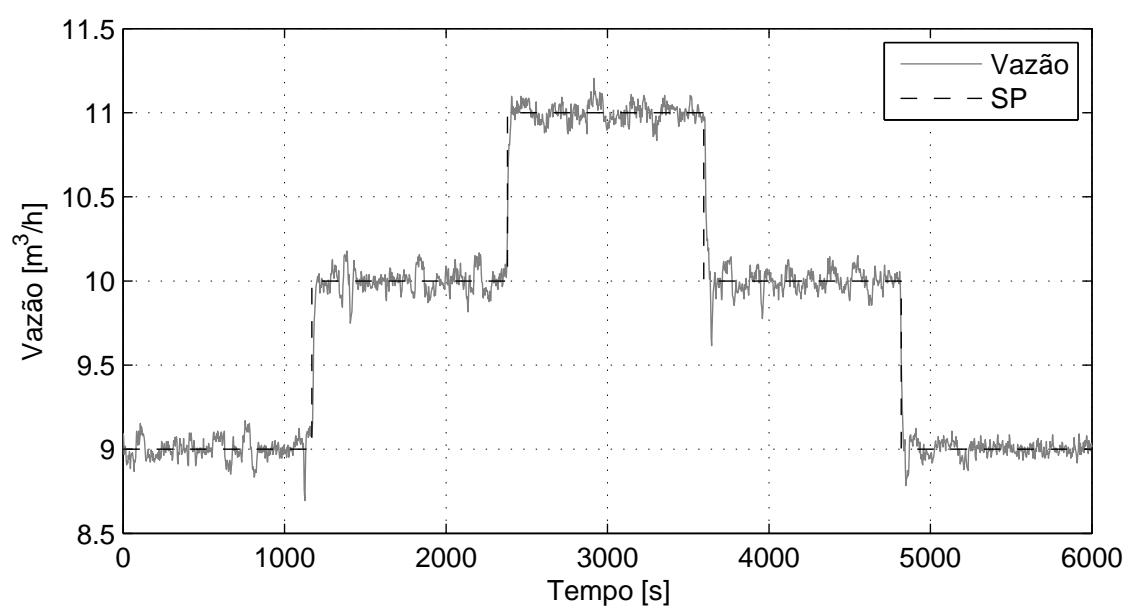

Fonte: Autor.

Figura 105: Sinal de controle do compensador CR2 $(T=0,5 \mathrm{~s})$.

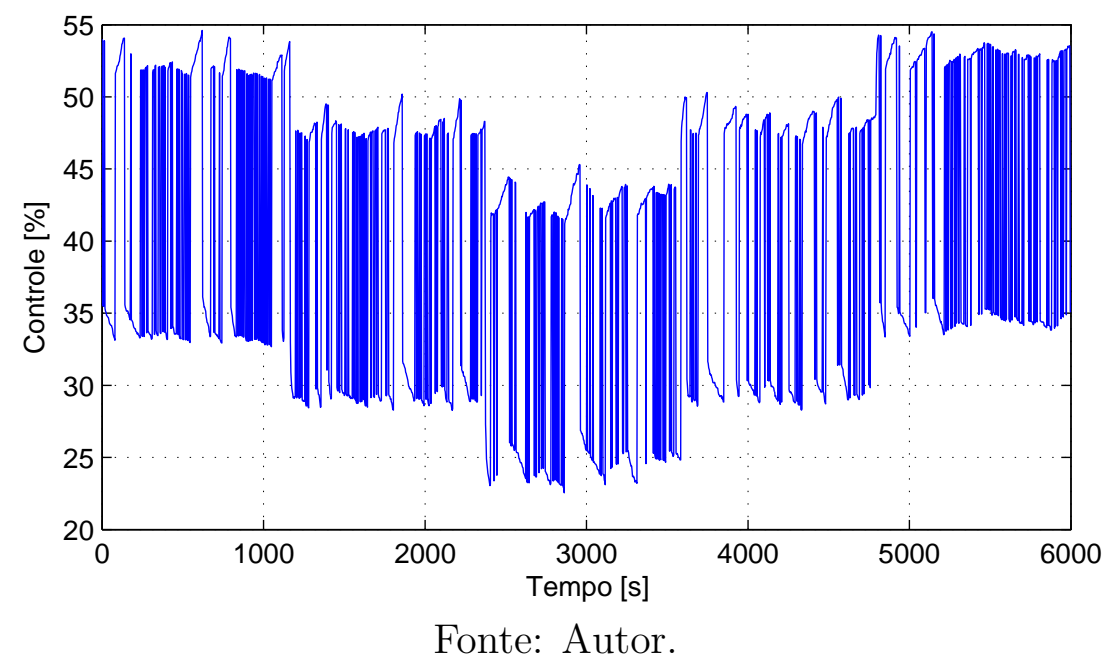

Figura 106: Posição da haste da válvula com o compensador CR2 ( $T=0,5 \mathrm{~s})$.

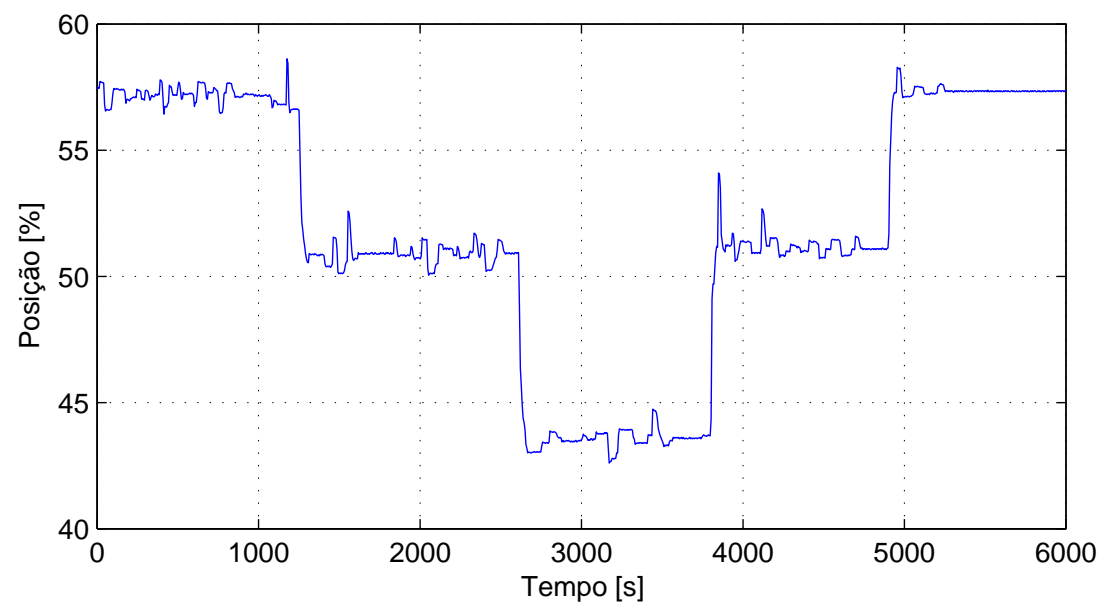

Fonte: Autor.

Nas Figuras 110 a 112 apresentam-se os resultados obtidos com o compensador Twomove. Neste caso é evidente que o período de amostragem afeta ainda mais o desempenho 
Figura 107: Vazão obtida para o compensador Knocker $(T=0,5$ s).

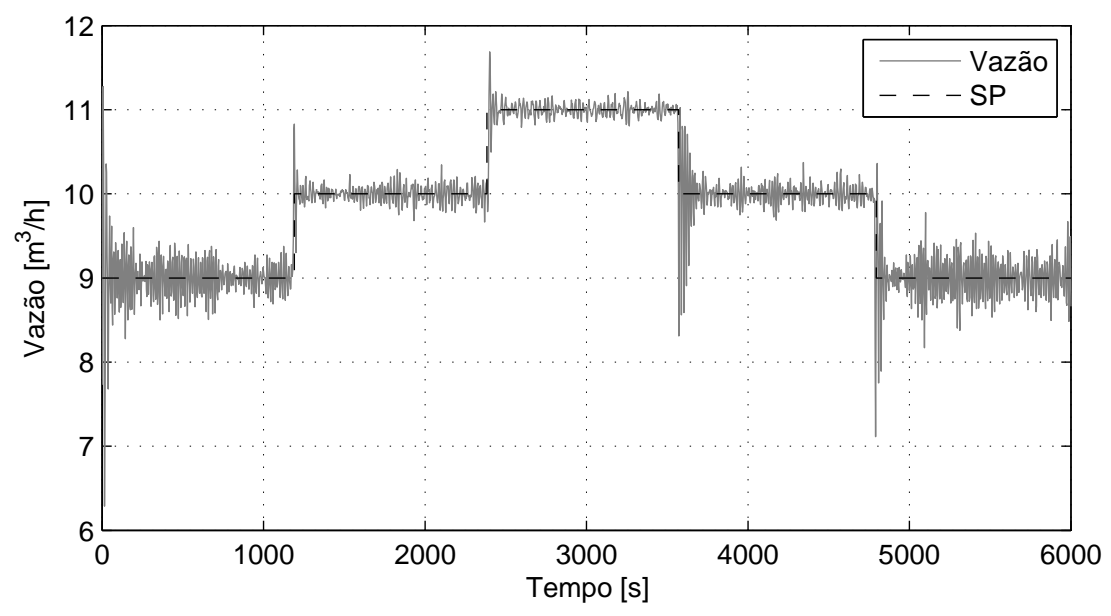

Fonte: Autor.

Figura 108: Sinal de controle do compensador Knocker $(T=0,5 \mathrm{~s})$.

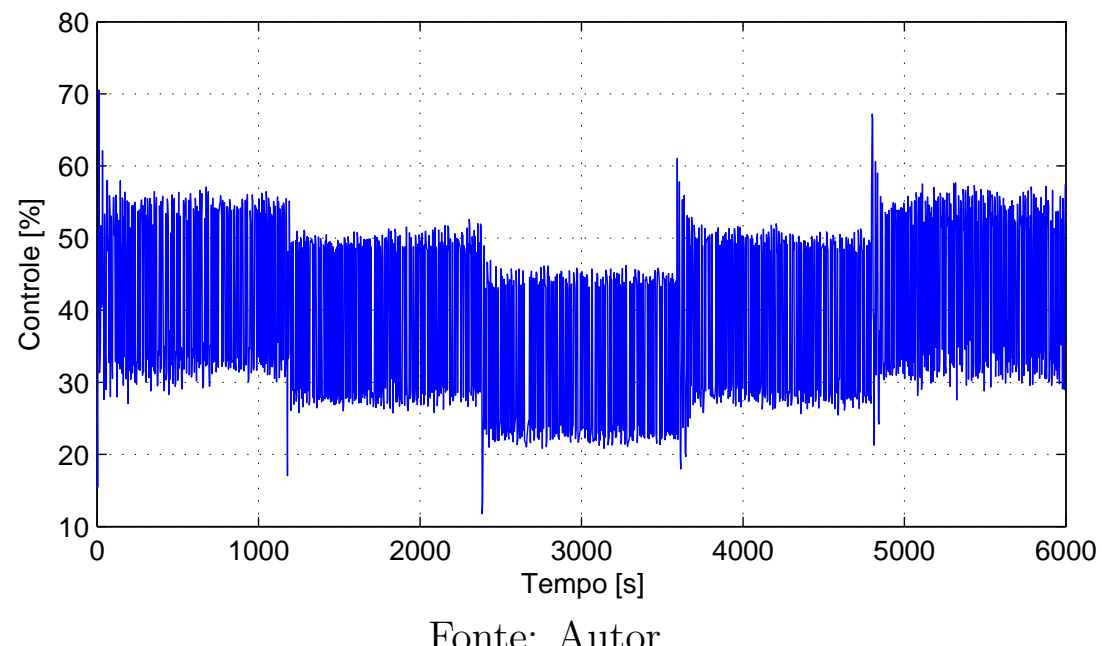

Figura 109: Posição da haste da válvula com o compensador Knocker ( $T=0,5 \mathrm{~s})$.

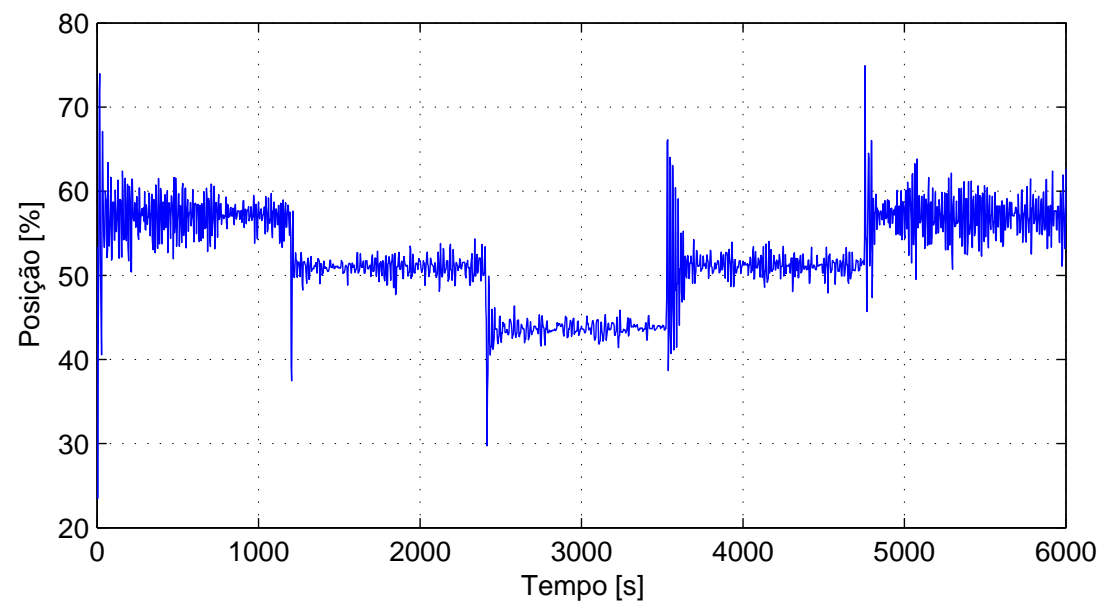

Fonte: Autor.

do compensador Two-move do que o compensador Knocker. Isto acontece porque o Twomove demora mais tempo em passar de um movimento a outro. Para uma melhor análise, 
Figura 110: Vazão obtida com o compensador Two-move $(T=0,5 \mathrm{~s})$.

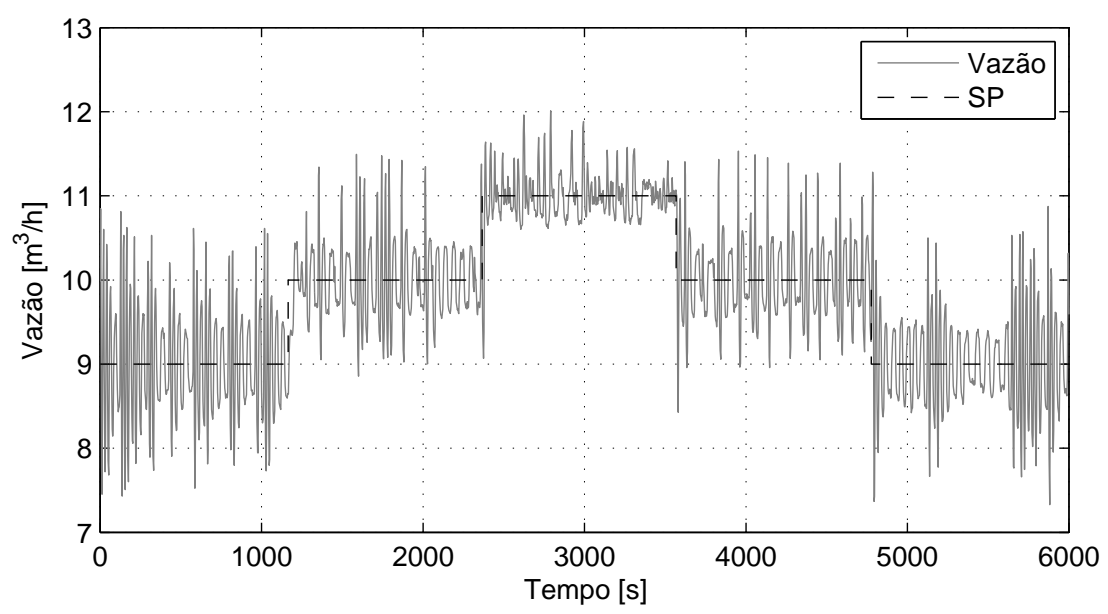

Fonte: Autor.

Figura 111: Sinal de controle com compensador Two-move $(T=0,5 \mathrm{~s})$.

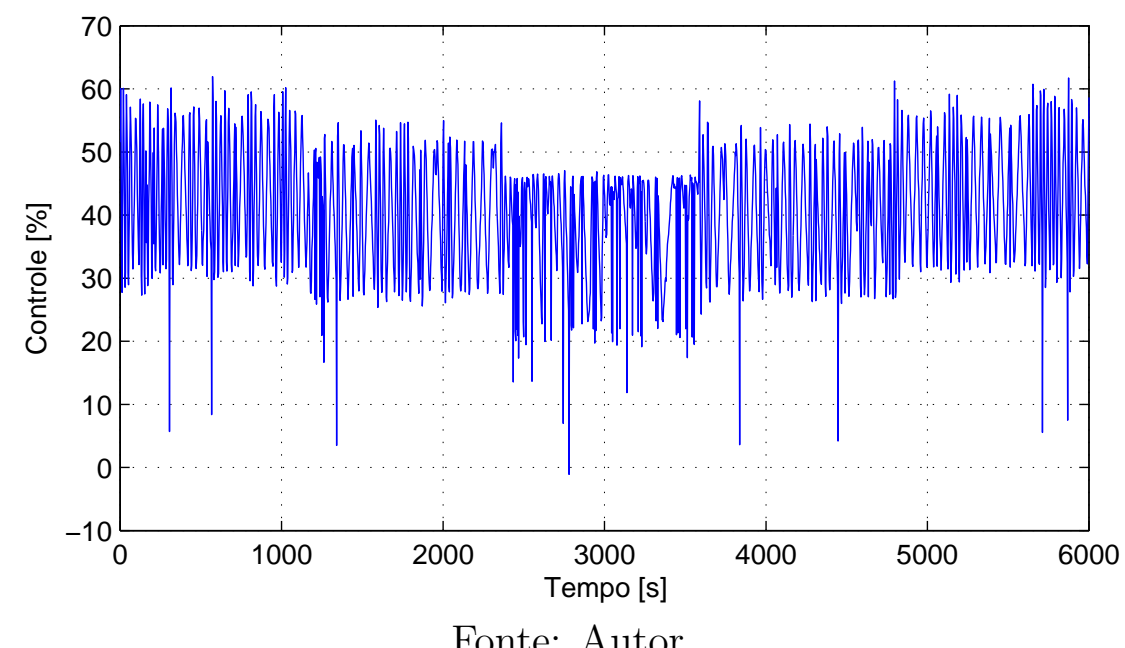

Fonte: Autor.

Figura 112: Posição da haste da válvula com o compensador Two-move ( $T=0,5 \mathrm{~s})$.

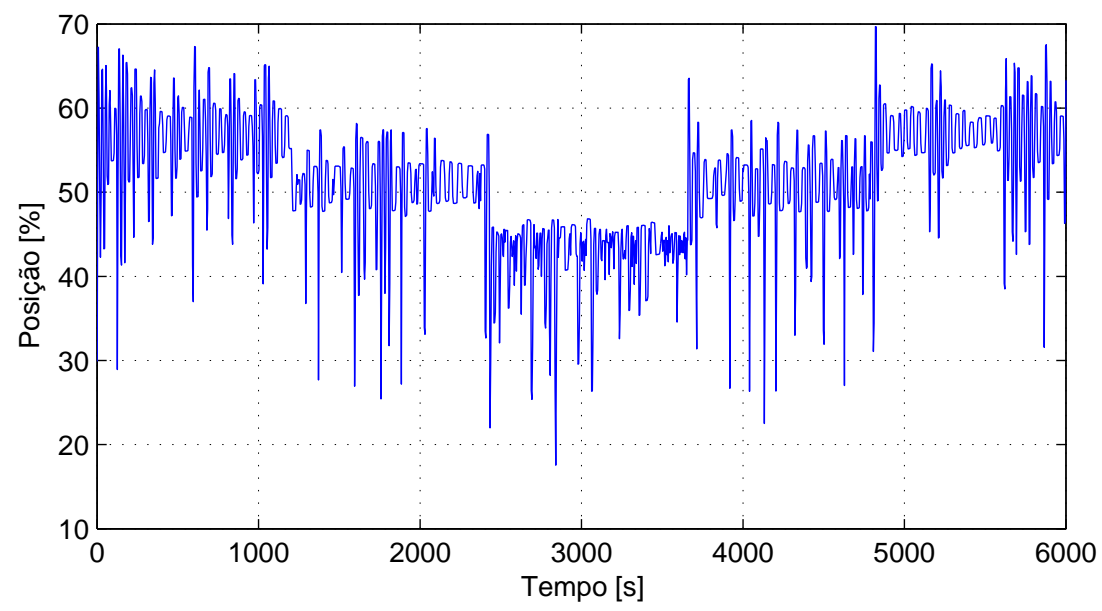

Fonte: Autor.

na Tabela 18 se apresentam os índices de desempenho para os compensadores CR1, CR2, Knocker e Two-move. 
Tabela 18: Índices de desempenho dos compensadores de atrito para o período de amostragem de $0,5 \mathrm{~s}$.

\begin{tabular}{ccccc}
\hline Ensaio & ITAE [\%] & IAE [\%] & $D_{v}[\%]$ & $T_{s}[\mathrm{~s}]$ \\
\hline PI com sintonia original & 156,9031 & 316,8347 & 239,4659 & 11,1275 \\
CR1 & 44,1645 & 84,7067 & 172,0772 & 39,17 \\
CR2 & 45,0985 & 95,9490 & 118,9867 & 32,28 \\
Knocker & 128,0122 & 259,8466 & 2961,9 & 5,965 \\
Two-Move & 390,7669 & 813,2347 & 4349,7 & 7,575 \\
\hline
\end{tabular}

Segundo os índices de desempenho, os compensadores CR1 e CR2 apresentaram melhoras consideráveis nos índices ITAE e IAE. Também conseguiram diminuir o desgaste na válvula conforme sugere o índice $D_{v}$. O compensador Knocker também conseguiu melhorar os índices ITAE e IAE, porém aumentou o desgaste na válvula. O compensador Two-move não conseguiu melhorar nenhum índice de desempenho, portanto foi o compensador mais afetado pelo período de amostragem.

\subsubsection{Controle por modos deslizantes}

Nas Figura 113 a 128 se apresentam os resultados obtidos com os controladores por modos deslizantes e modos deslizantes integrador utilizando a sintonia do PI apresentada na Tabela 3 e os parâmetros apresentados nas Tabelas 8 e 9.

Figura 113: Vazão para o controlador por modos deslizantes com chattering $(T=0,5 \mathrm{~s})$.

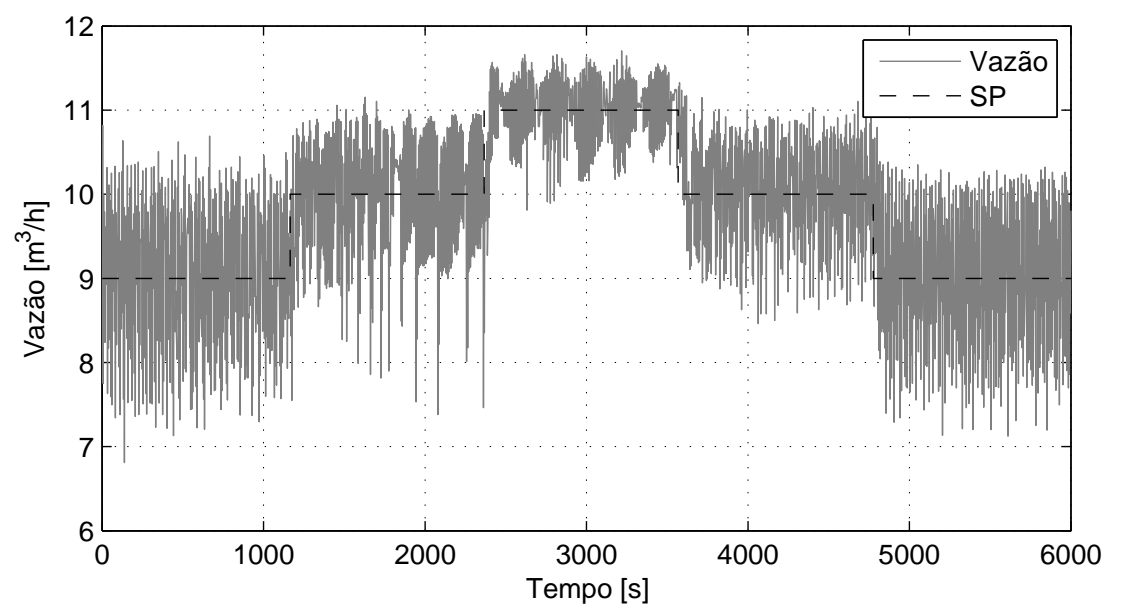

Fonte: Autor.

Depois de analisar todos os resultados obtidos, pode-se dizer que mesmo que a superfície de escorregamento esteja ao redor de zero, que é o esperado, os controladores por modos deslizantes com período de amostragem alto não têm um bom desempenho, não melhorando nenhum índice e o desgaste da válvula é enorme. 
Figura 114: Sinal de controle do controlador por modos deslizantes com chattering $(T=$ $0,5 \mathrm{~s})$.

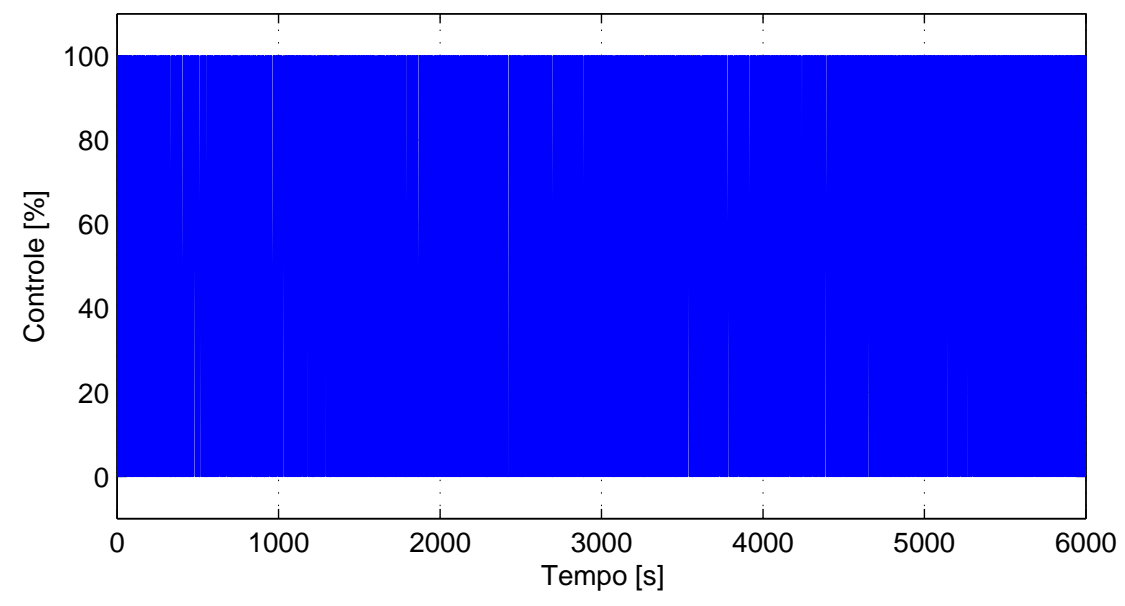

Fonte: Autor.

Figura 115: Posição da haste da válvula para o controlador por modos deslizantes com chattering $(T=0,5 \mathrm{~s})$.

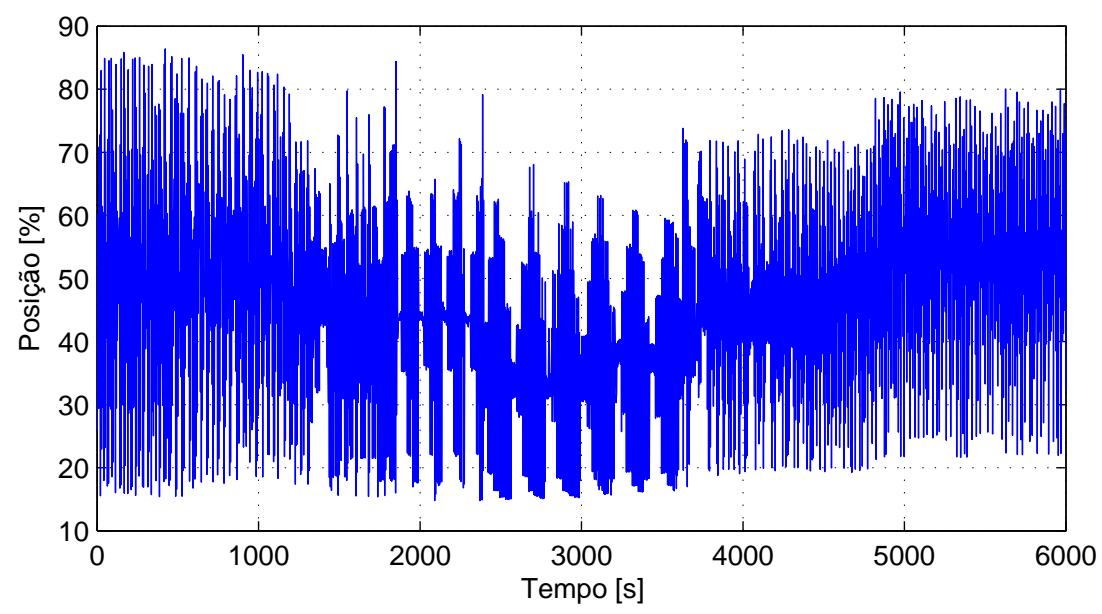

Fonte: Autor.

A Tabela 19 apresenta os índices de desempenho para estes controladores.

Tabela 19: Índices de desempenho dos controladores por modos deslizantes e modos deslizantes integrador para o período de amostragem de $0,5 \mathrm{~s}$.

\begin{tabular}{cccc}
\hline Ensaio & ITAE [\%] & IAE [\%] & $D_{v}[\%]$ \\
\hline PI com sintonia original & 156,9031 & 316,8347 & 239,4659 \\
MDC & 634,5931 & 1310 & 58825 \\
MDS & 790,5184 & 1562,8 & 49696 \\
MDIC & 2082,9 & 4080 & 56682 \\
MDIS & 2217,7 & 4394 & 56227 \\
\hline
\end{tabular}

Segundo os índices de desempenho, é evidente que os controladores por modos deslizantes e modos deslizantes integrador não conseguem ter um bom desempenho. Para o caso dos controladores por modos deslizantes, o processo tenta seguir a referência. 
Figura 116: Superficie de escorregamento para o controlador por modos deslizantes com chattering $(T=0,5 \mathrm{~s})$.

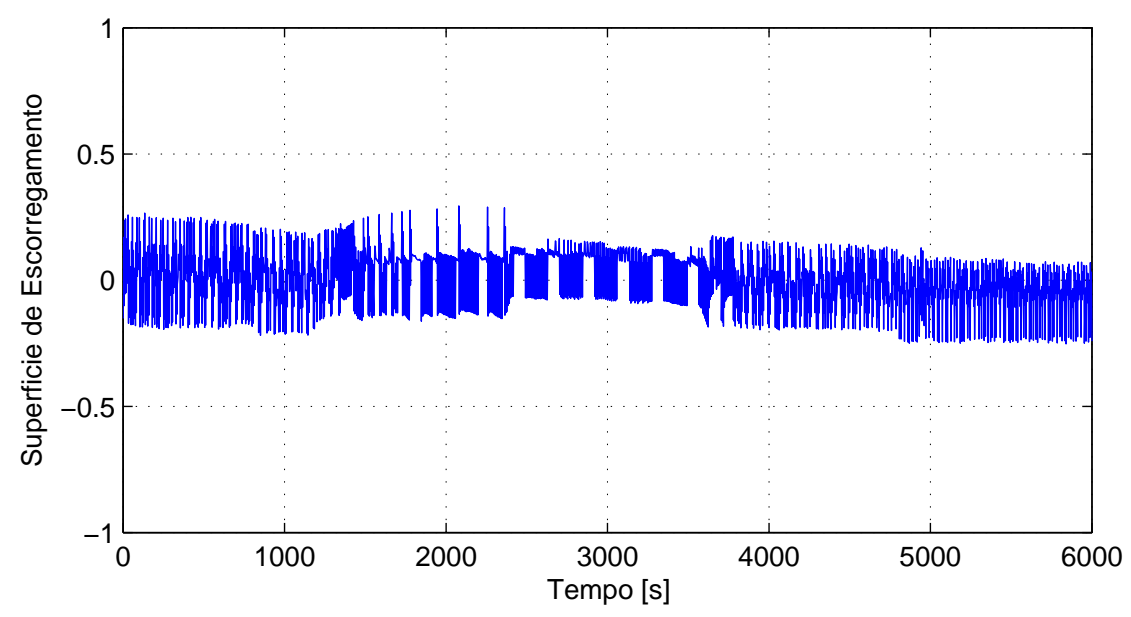

Fonte: Autor.

Figura 117: Vazão para o controlador por modos deslizantes sem chattering $(T=0,5 \mathrm{~s})$.

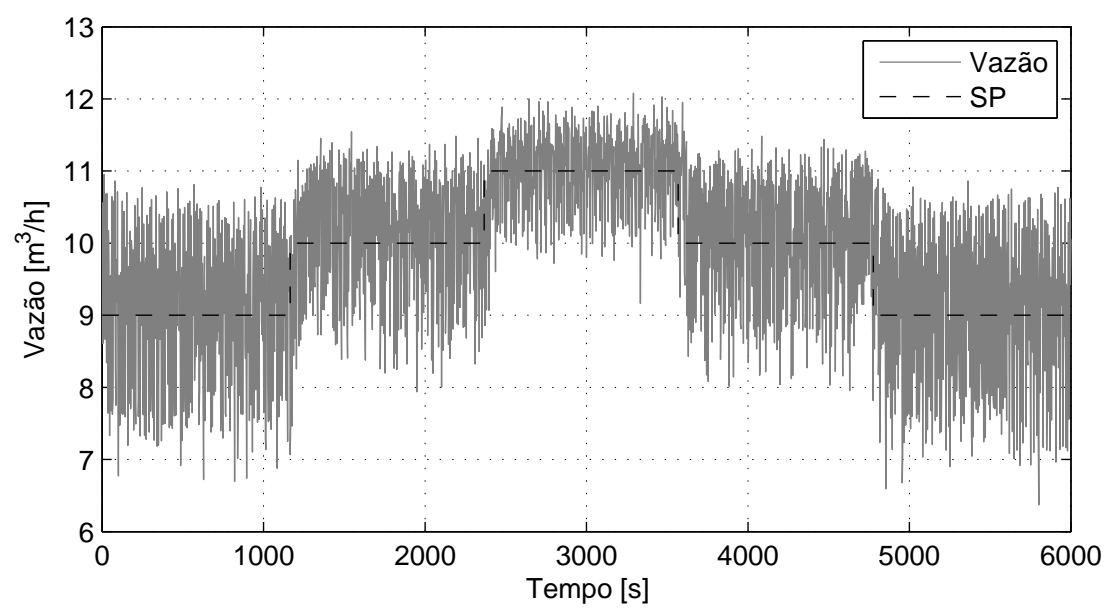

Fonte: Autor.

Figura 118: Sinal de controle do controlador por modos deslizantes sem chattering $(T=$ $0,5 \mathrm{~s})$.

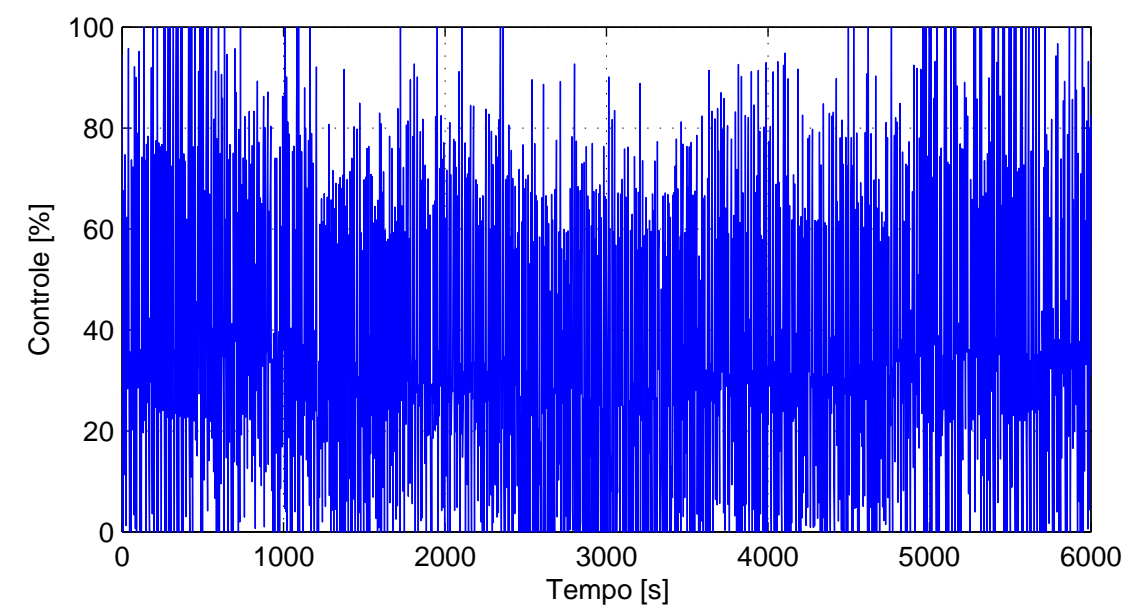

Fonte: Autor. 
Figura 119: Posição da haste da válvula para o controlador por modos deslizantes sem chattering $(T=0,5 \mathrm{~s})$.

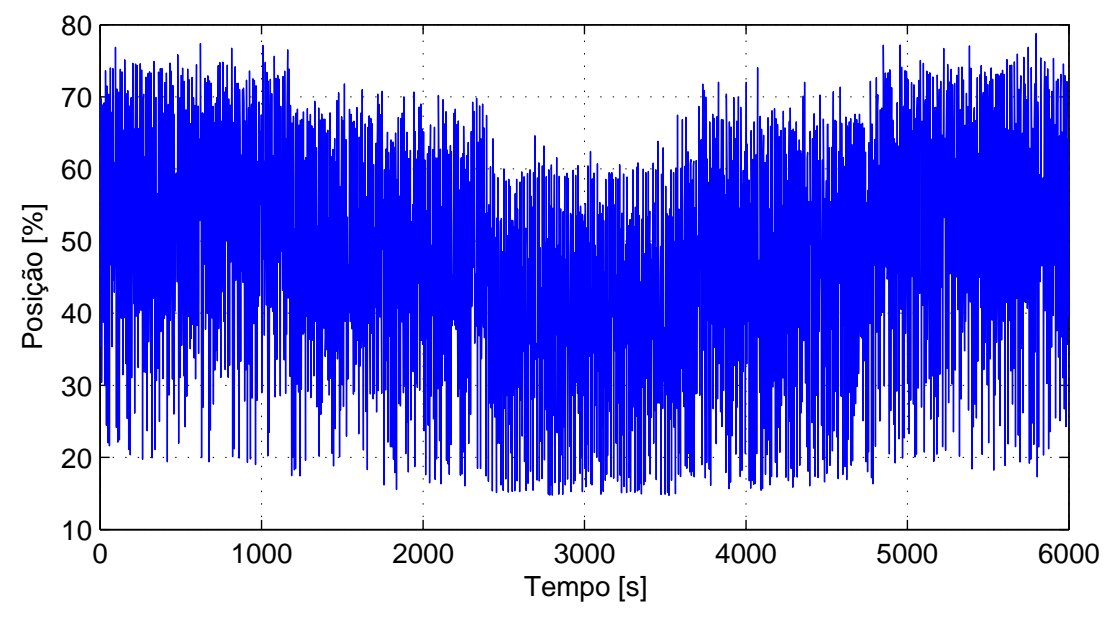

Fonte: Autor.

Figura 120: Superficie de escorregamento para o controlador por modos deslizantes sem chattering $(T=0,5 \mathrm{~s})$.

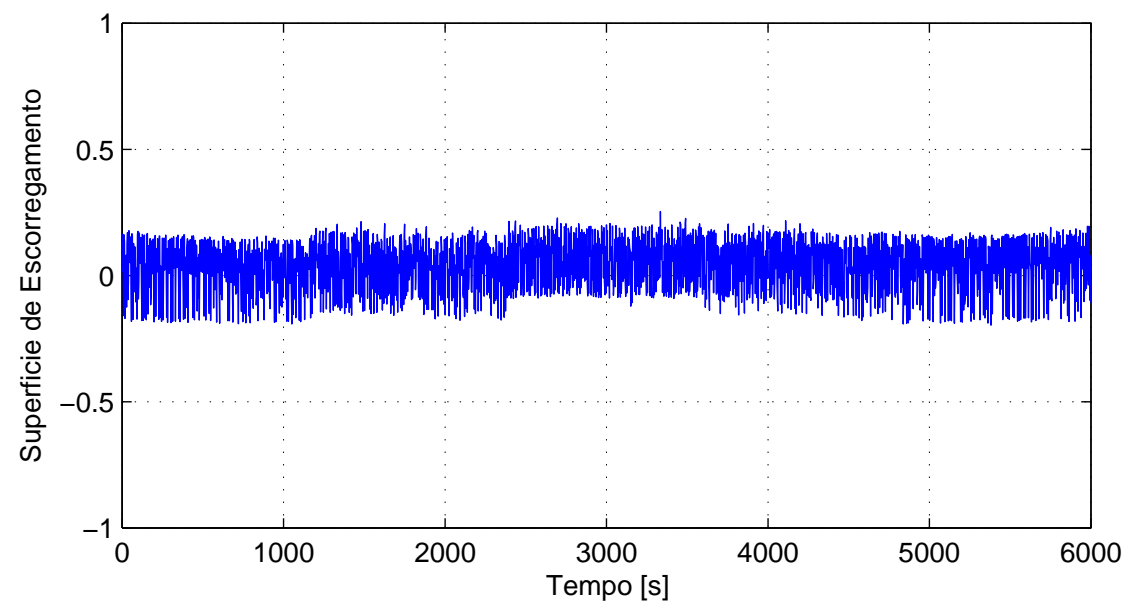

Fonte: Autor.

Para os controladores por modos deslizantes integrador, o processo não consegue seguir a referência, portanto este compensador é o mais afetado pelo aumento do período de amostragem. Com estes controladores, foi obtido o maior desgaste na válvula, portanto, para este processo industrial não é conveniente a sua utilização.

Na Tabela 20 são apresentados todos os índices obtidos nos resultados práticos da Planta de Vazão para o período de amostragem de 0,5 s. Assim como nos resultados anteriores, pode-se ver que também os compensadores CR1 e CR2 mostraram os melhores resultados, conseguindo compensar o atrito em uma válvula de controle, diminuindo as oscilações da variável controlada e reduzindo o desgaste da válvula, conforme indica o índice $D_{v}$. Com respeito aos controladores por modos deslizantes, eles foram projetados para períodos de amostragem pequenos, portanto, fica evidente que ao aumentar o período de amostragem, a resposta deles não é a esperada. 
Figura 121: Vazão para o controlador por modos deslizantes integrador com chattering $(T=0,5 \mathrm{~s})$.

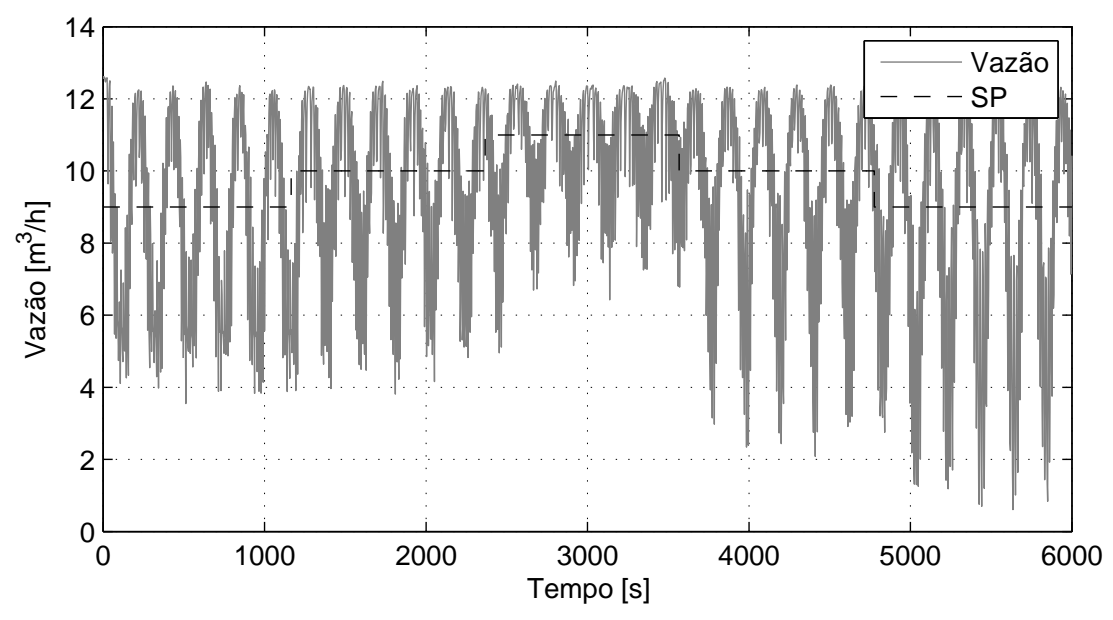

Fonte: Autor.

Figura 122: Sinal de controle para o controlador por modos deslizantes integrador com chattering $(T=0,5 \mathrm{~s})$.

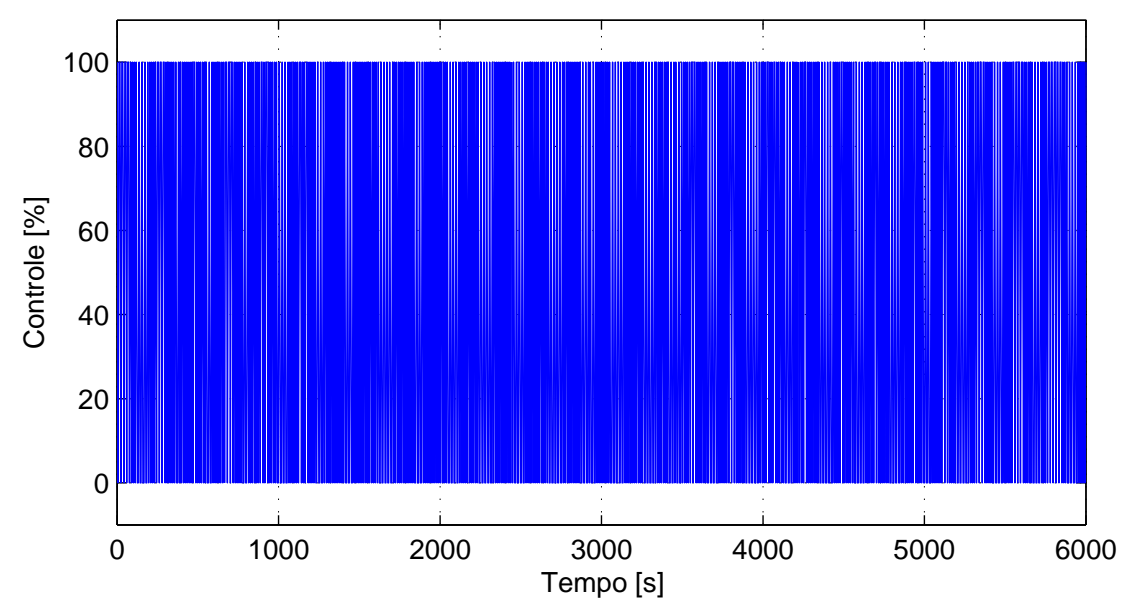

Fonte: Autor.

\subsection{Ensaios no modo Regulatório}

Os ensaios apresentados a seguir foram realizados para um período de amostragem $T$ de $10 \mathrm{~ms}$. O set-point de todos os ensaios é constante e igual a $9 \mathrm{~m}^{3} / \mathrm{h}$. As perturbações inseridas foram feitas modificando a rotação da bomba, nos primeiros 500 segundos a rotação da bomba foi de $80 \%$ da sua capacidade máxima, nos seguintes 500 segundos a rotação foi mudada para de $70 \%$ da sua capacidade máxima e finalmente para os últimos 500 segundos a rotação voltou a 80\%. A duração do ensaio é de 1500 s, com a finalidade de conseguir ver as oscilações na variável controlada.

As Figuras 129 a 137 mostram os resultados obtidos com as três sintonias do controlador PI. Analisando-se os resultados obtidos para as três sintonias do controlador PI, pode-se ver que as sintonias mais lentas não conseguem melhorar o ITAE nem o IAE e também não melhoram o desgaste da válvula, como indica o índice $D_{v}$. 
Figura 123: Posição da haste da válvula para o controlador por modos deslizantes integrador com chattering $(T=0,5 \mathrm{~s})$.

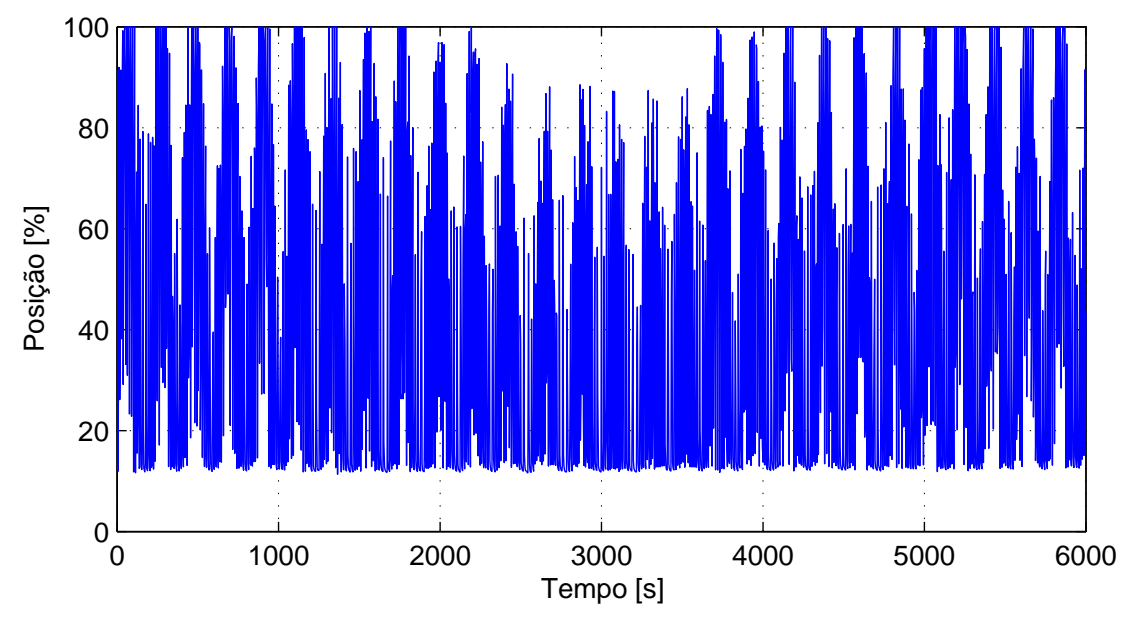

Fonte: Autor.

Figura 124: Superficie de escorregamento para o controlador por modos deslizantes integrador com chattering $(T=0,5 \mathrm{~s})$.

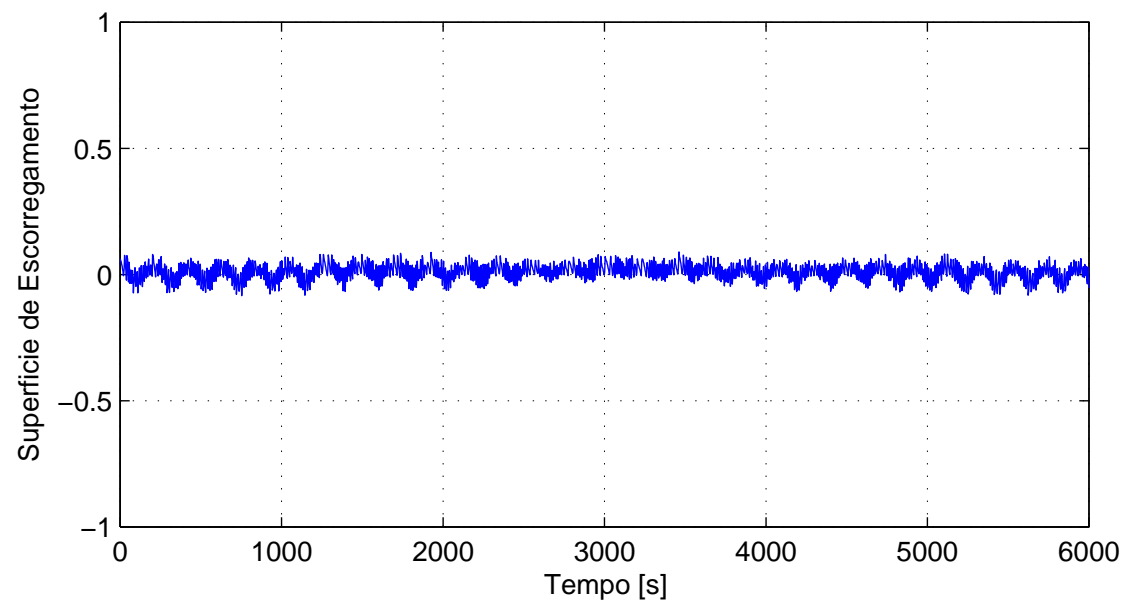

Fonte: Autor.

O compensador CR1 foi quem apresentou a melhor resposta em termos dos índices ITAE e IAE, mas também aumentou o desgaste da válvula, dado pelo índice $D_{v}$.

O compensador CR2 também conseguiu melhorar os índices de desempenho ITAE e IAE e o desgaste da válvula apresentou uma melhora. Os resultados obtidos deses compensadores podem ser vistos nas Figuras 138 a 143.

Segundo os índices de desempenho, o compensador Knocker também apresentou uma boa resposta. Ele consegue melhorar os índices ITAE e IAE, mas aumentou o índice de desgaste da válvula $D_{v}$ é considerável. Os resultados deste compensador são apresentados nas Figuras 144 a 146. 
Figura 125: Vazão para o controlador por modos deslizantes integrador sem chattering $(T=0,5 \mathrm{~s})$.

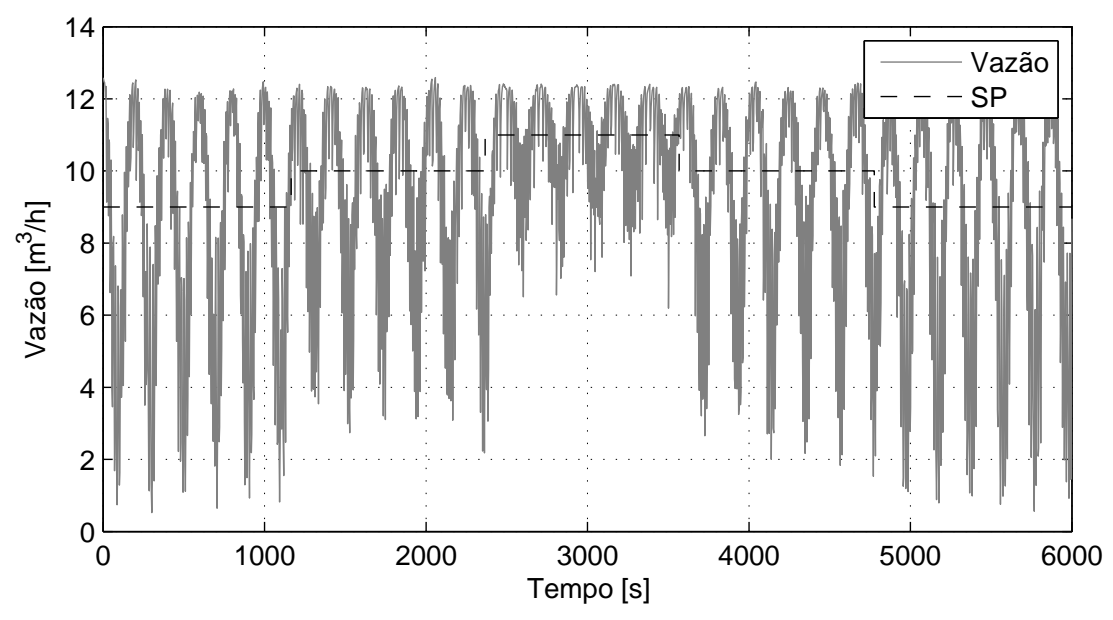

Fonte: Autor.

Figura 126: Sinal de controle para o controlador por modos deslizantes integrador sem chattering $(T=0,5 \mathrm{~s})$.

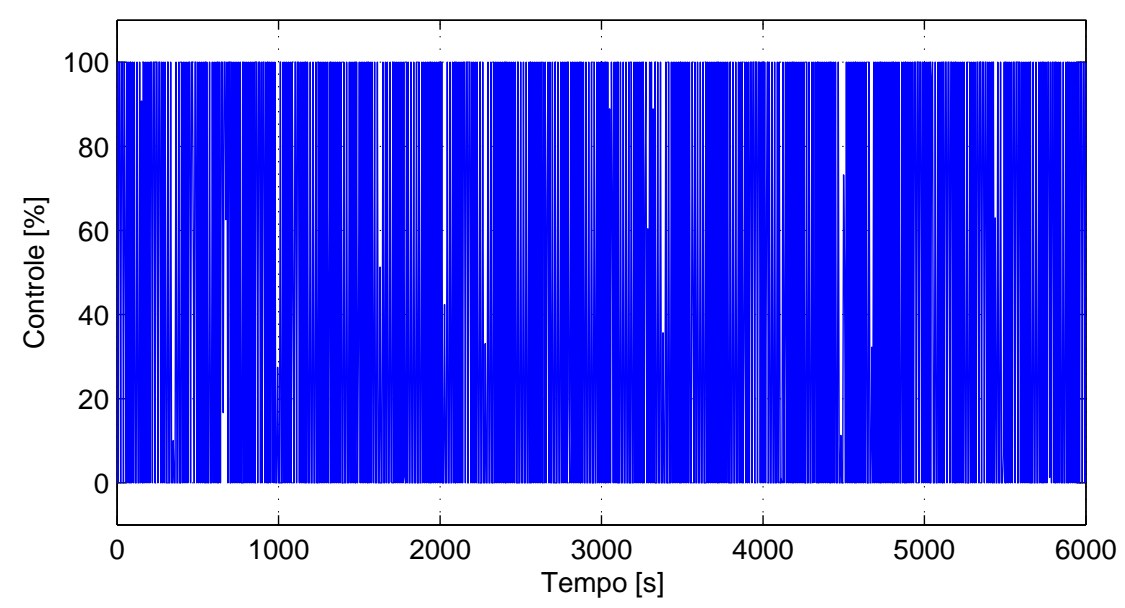

Fonte: Autor.

Analisando-se os resultados do compensador Two-move, os índices ITAE e IAE ficaram parecidos aos índices do controlador PI original. O desgaste da válvula é menor do que o desgaste gerado pelo compensador Knocker e CR1. Nas Figuras 147 a 149 se mostram os resultados deste compensador.

As Figuras 150 a 157 mostram os resultados obtidos com os controladores por modos deslizantes com chattering e sem chattering.

Ao analisar os resultados obtidos com os controladores por modos deslizantes, devido à oscilação da variável de processo, não é tão claro observar as duas perturbações inseridas no processo. Pode-se ver que entre 500 e 1000 segundos, devido à mudança na rotação da bomba, as oscilações diminuíram, isto acontece porque ao haver menos potência na bomba, é mais fácil controlar a vazão. 
Figura 127: Posição da haste da válvula para o controlador por modos deslizantes integrador sem chattering $(T=0,5 \mathrm{~s})$.

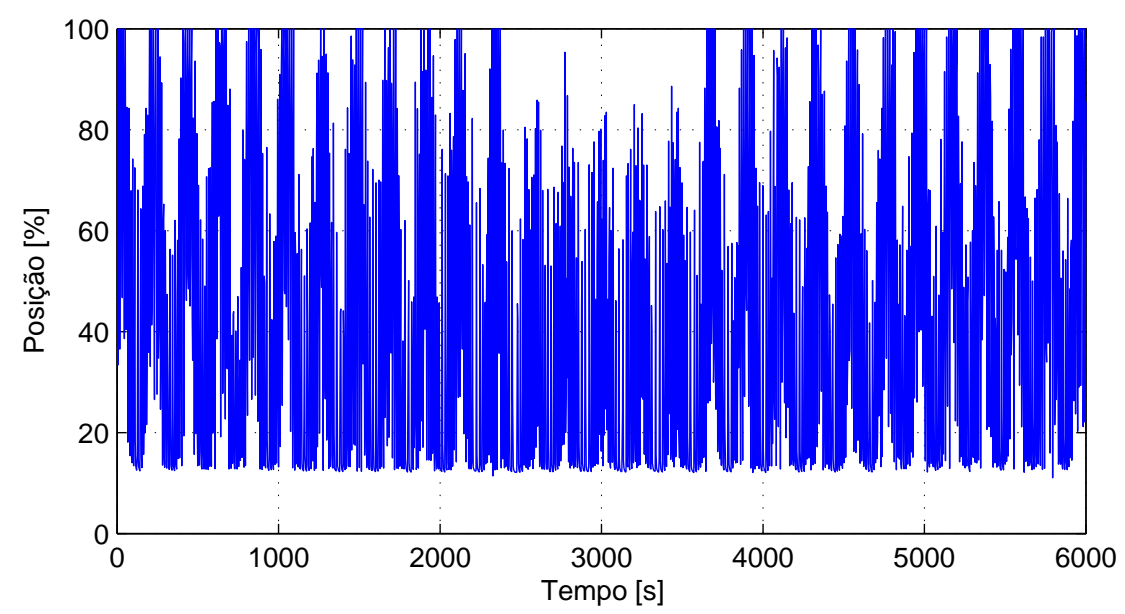

Fonte: Autor.

Figura 128: Superficie de escorregamento para o controlador por modos deslizantes integrador sem chattering $(T=0,5 \mathrm{~s})$.

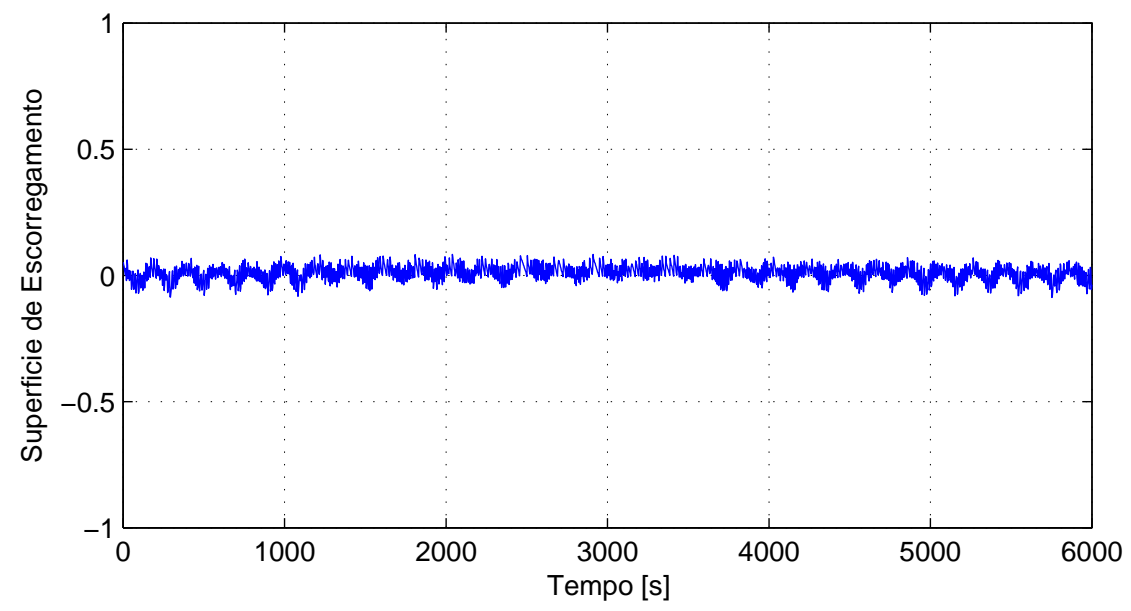

Fonte: Autor.

Figura 129: Vazão obtida com o controlador PI para o modo regulatório.

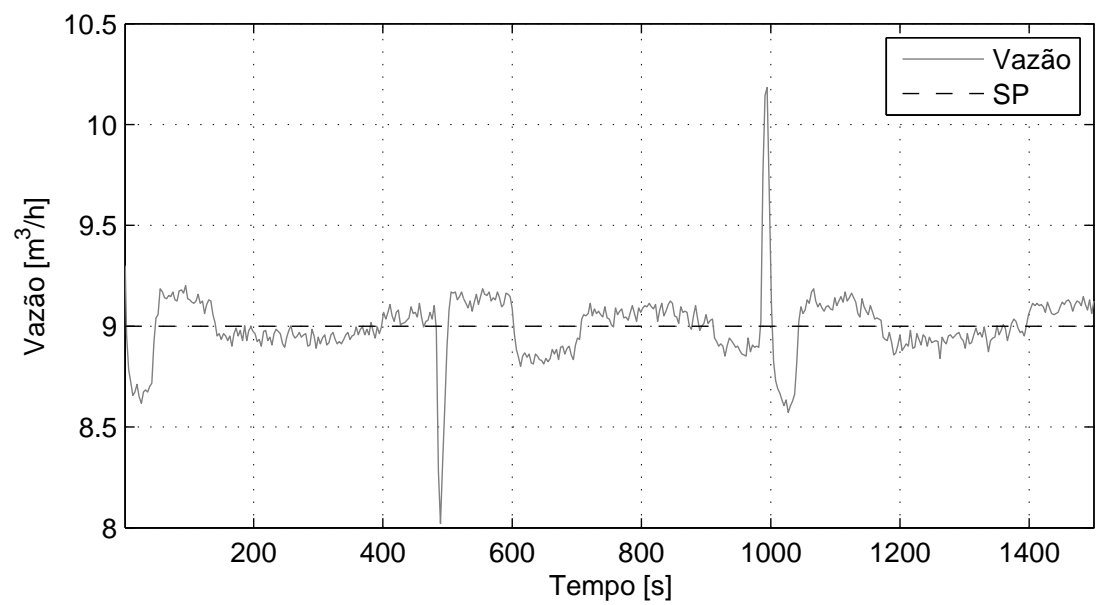

Fonte: Autor. 
Tabela 20: Índices de desempenho dos controladores e compensadores de atrito para o período de amostragem de $0,5 \mathrm{~s}$.

\begin{tabular}{ccccc}
\hline Ensaio & ITAE [\%] & IAE [\%] & $D_{v}[\%]$ & $T_{s}[\mathrm{~s}]$ \\
\hline PI com $T_{i}=2,54$ & 156,9031 & 316,8347 & 239,4659 & 11,1275 \\
PI com $T_{i}=12$ & 82,0028 & 180,9308 & 50,7913 & 74,5125 \\
PI com $T_{i}=16$ & 62,5120 & 124,3063 & 40,1128 & 97,5 \\
CR1 & 44,1645 & 84,7067 & 172,0772 & 39,17 \\
CR2 & 45,0985 & 95,9490 & 118,9867 & 32,28 \\
Knocker & 128,0122 & 259,8466 & 2961,9 & 5,965 \\
Two-Move & 390,7669 & 813,2347 & 4349,7 & 7,575 \\
MDC & 634,5931 & 1310 & 58825 & - \\
MDS & 790,5184 & 1562,8 & 49696 & - \\
MDIC & 2082,9 & 4080 & 56682 & - \\
MDIS & 2217,7 & 4394 & 56227 & - \\
\hline
\end{tabular}

Figura 130: Sinal de controle do controlador PI para o modo regulatório.

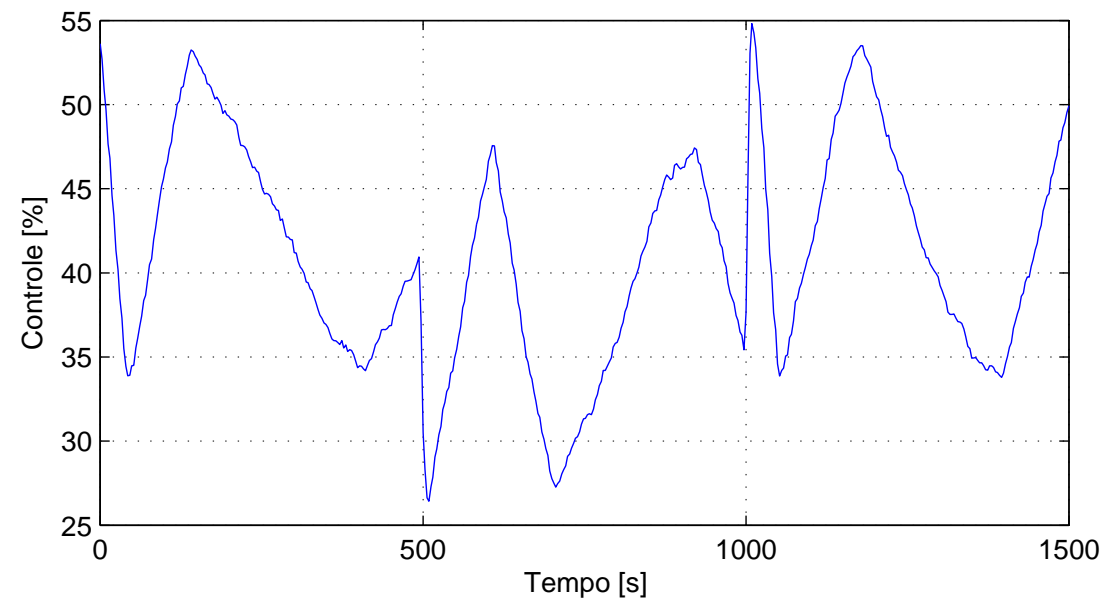

Fonte: Autor.

Figura 131: Posição da haste da válvula com o controlador PI para o modo regulatório.

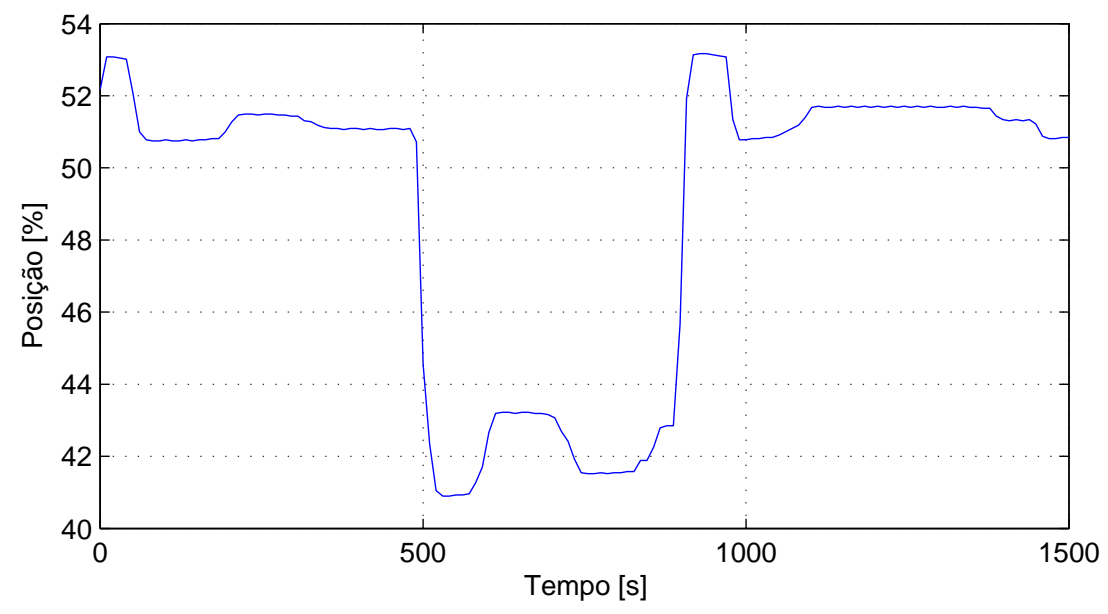

Fonte: Autor.

Segundo os índices obtidos, pode-se ver que nenhum dos controladores por modos des- 
Figura 132: Vazão obtida com o controlador PI para o modo regulatório.

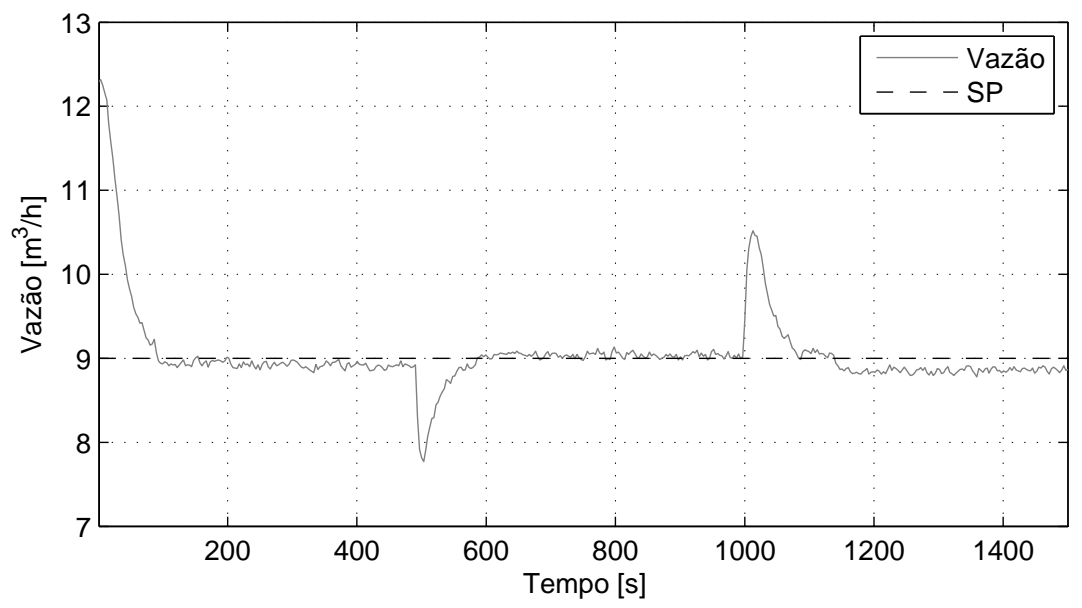

Fonte: Autor.

Figura 133: Sinal de controle do controlador PI para o modo regulatório.

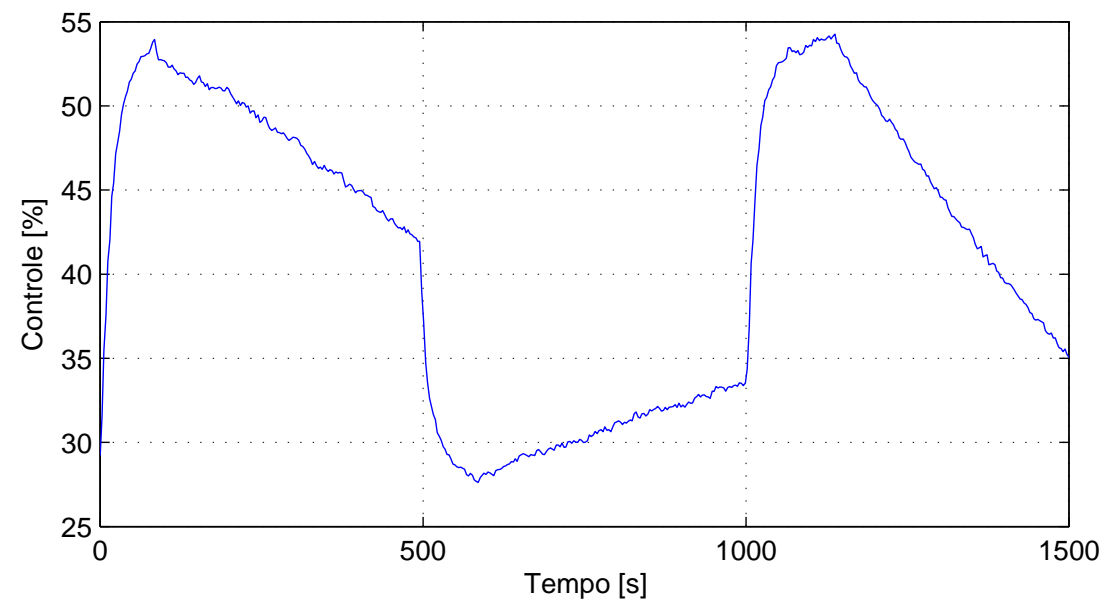

Fonte: Autor.

Figura 134: Posição da haste da válvula com o controlador PI para o modo regulatório.

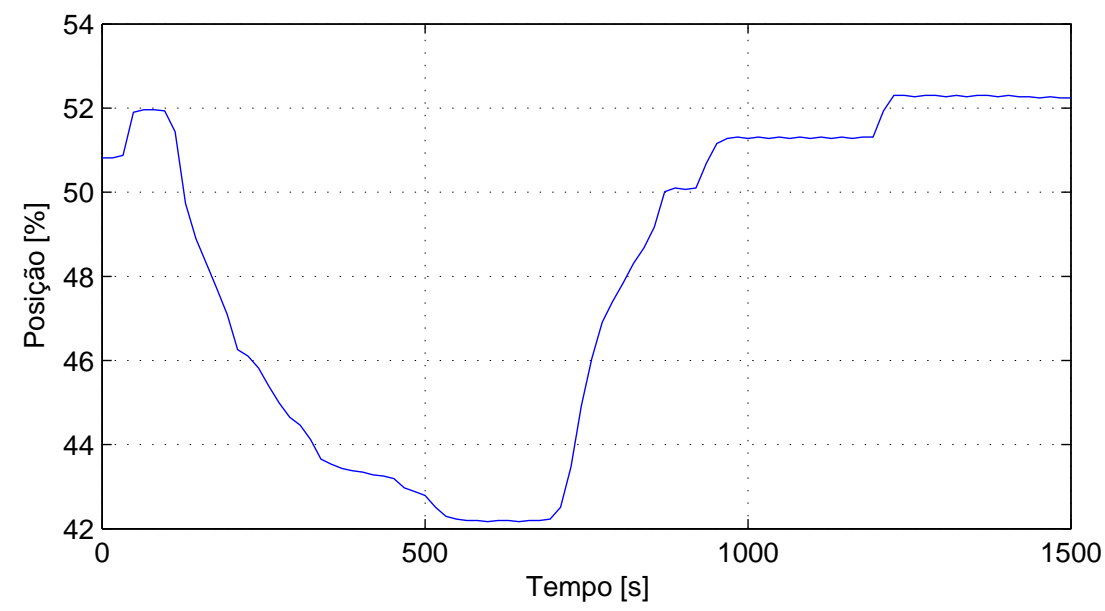

Fonte: Autor.

lizantes (com e sem chattering) consegue melhorar os índices ITAE e IAE. O controlador sem chattering apresentou melhores resultados. 
Figura 135: Vazão obtida com o controlador PI para o modo regulatório.

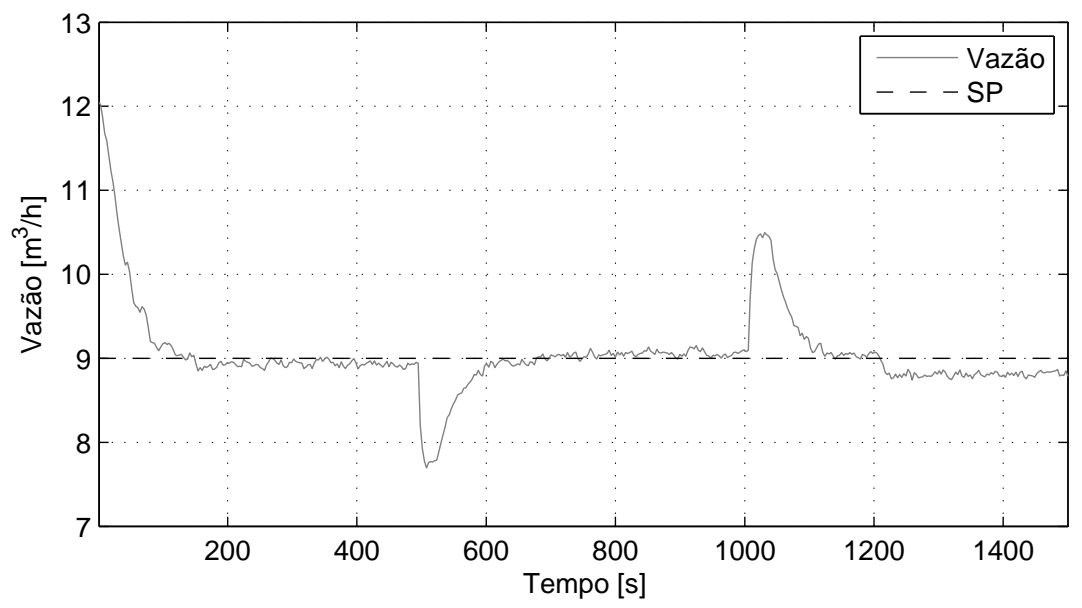

Fonte: Autor.

Figura 136: Sinal de controle do controlador PI para o modo regulatório.

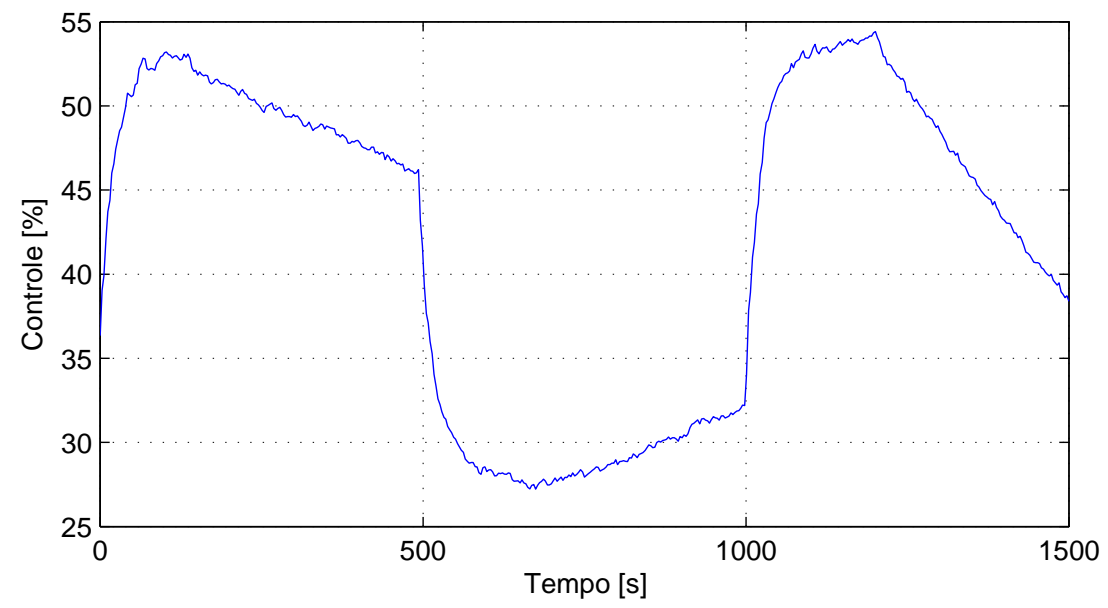

Fonte: Autor.

Figura 137: Posição da haste da válvula com o controlador PI para o modo regulatório.

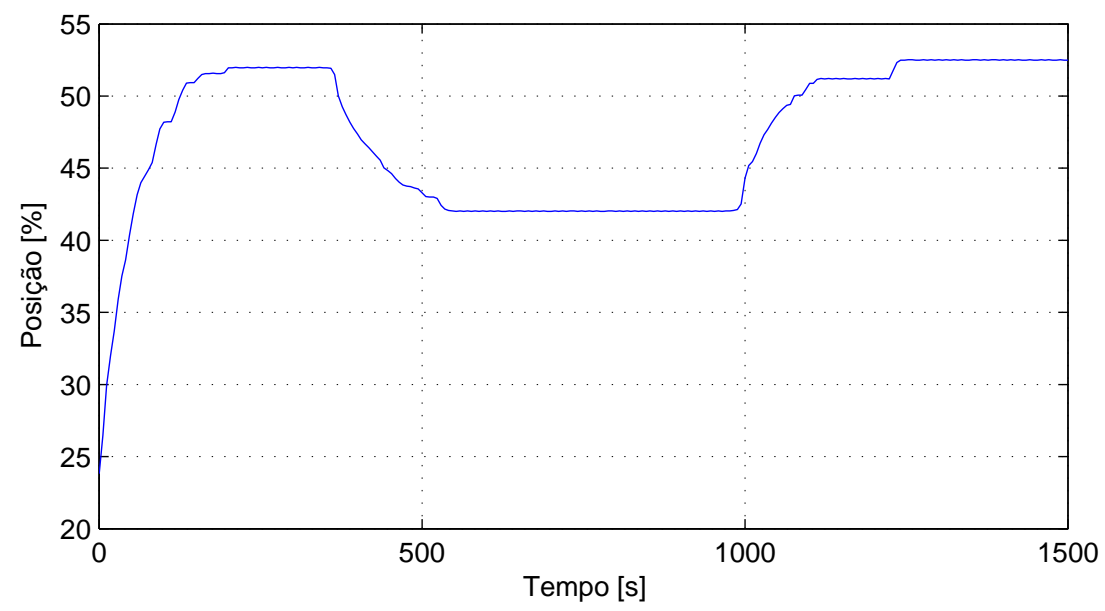

Fonte: Autor. 
Figura 138: Vazão obtida com o compensador CR1 para o modo regulatório.

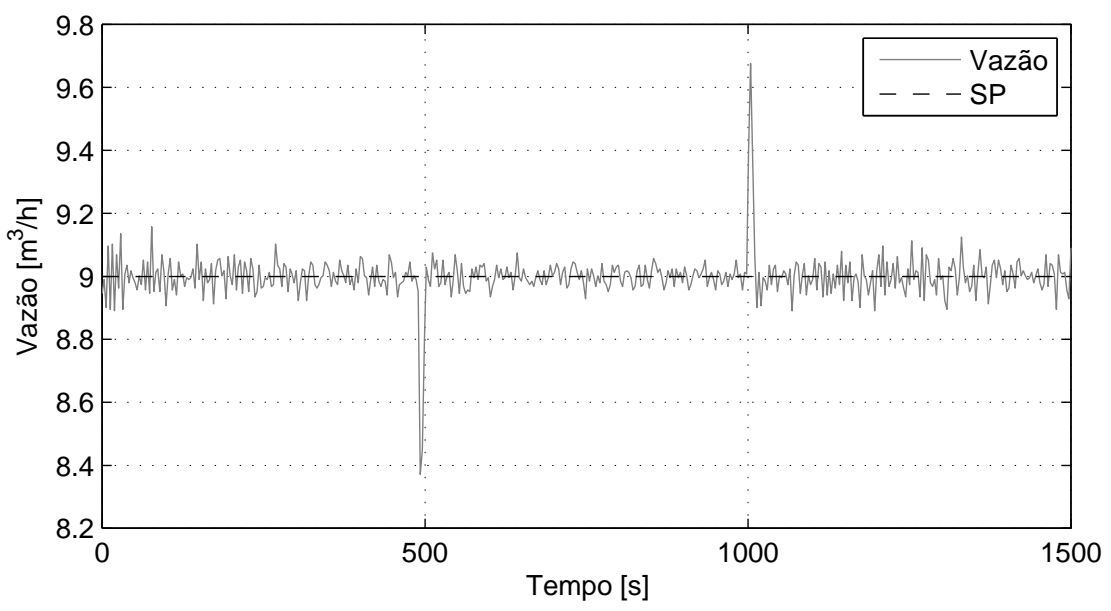

Fonte: Autor.

Figura 139: Sinal de controle do compensador CR1 para o modo regulatório.

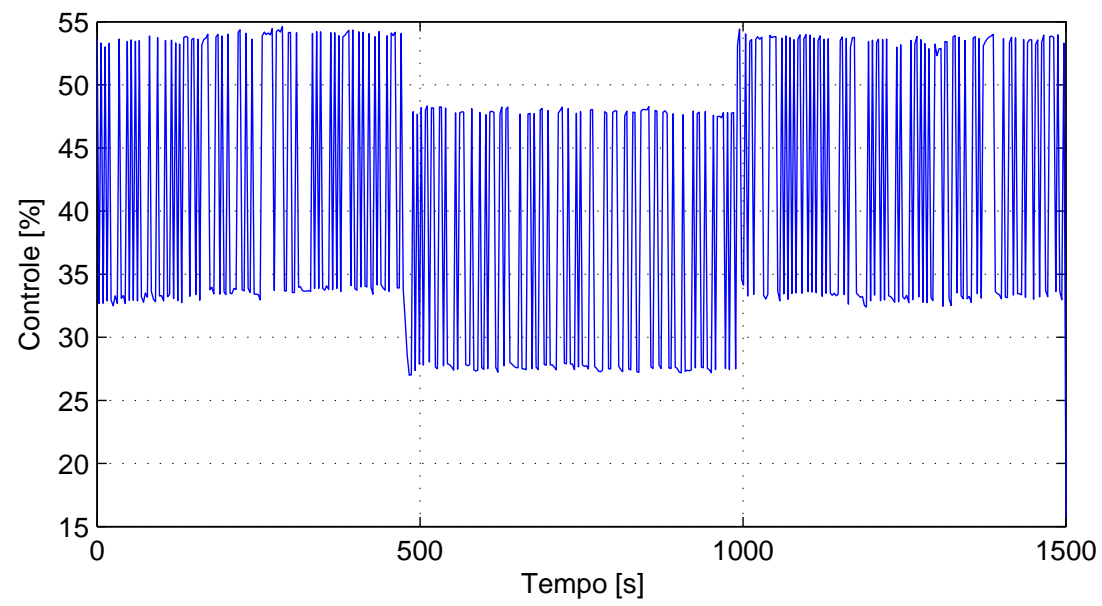

Fonte: Autor.

Figura 140: Posição da haste da válvula com o compensador CR1 para o modo regulatório.

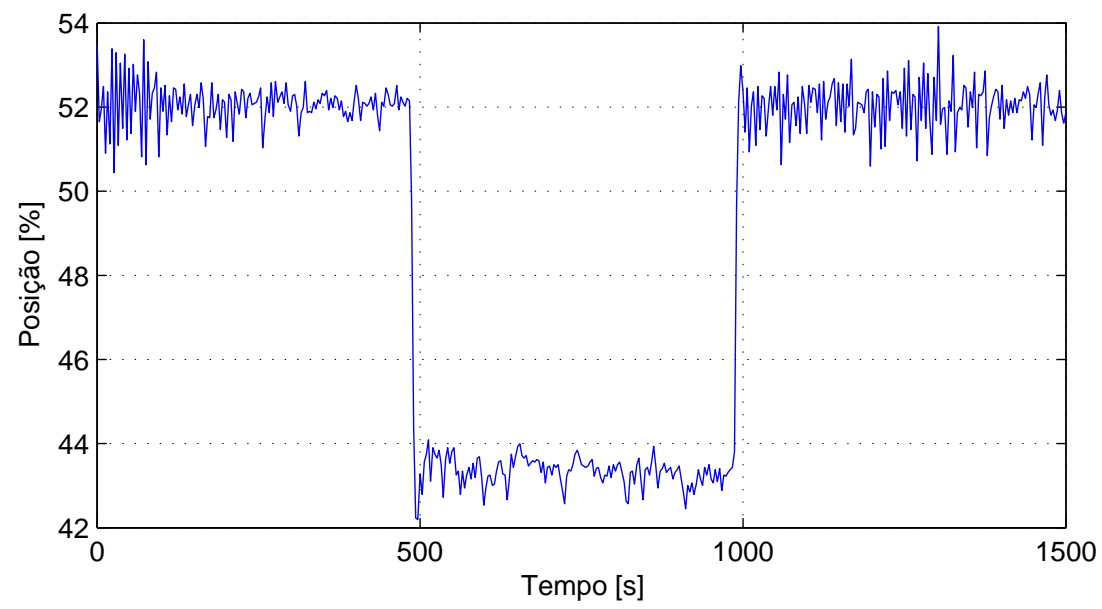

Fonte: Autor.

As Figuras 158 a 165 mostram os resultados obtidos com os controladores por modos deslizantes integrador com chattering e sem chattering. 
Figura 141: Vazão obtida com o compensador CR2 para o modo regulatório.

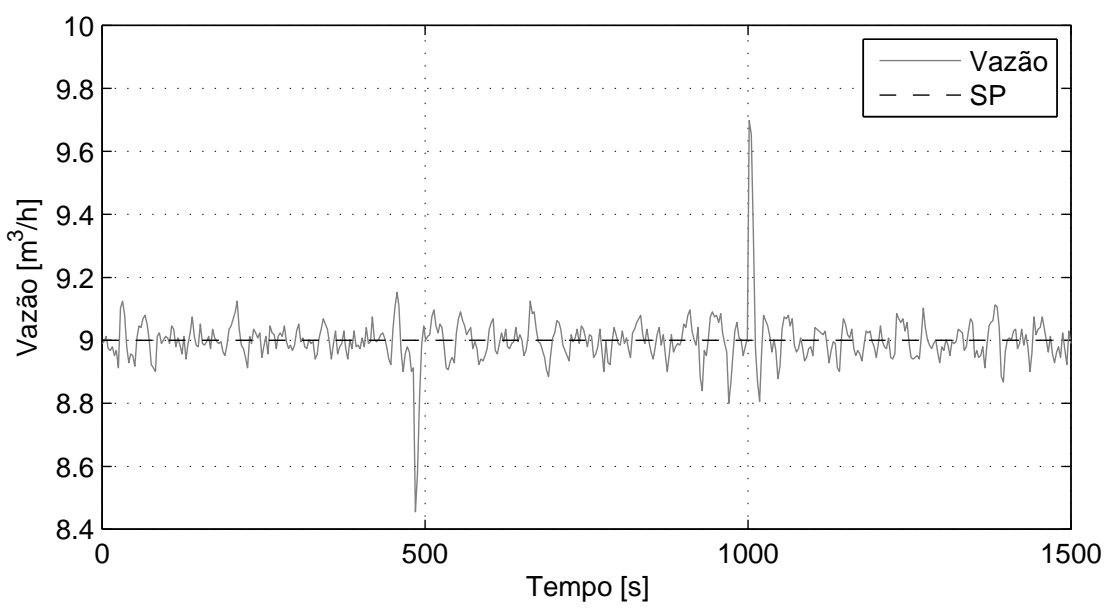

Fonte: Autor.

Figura 142: Sinal de controle do compensador CR2 para o modo regulatório.

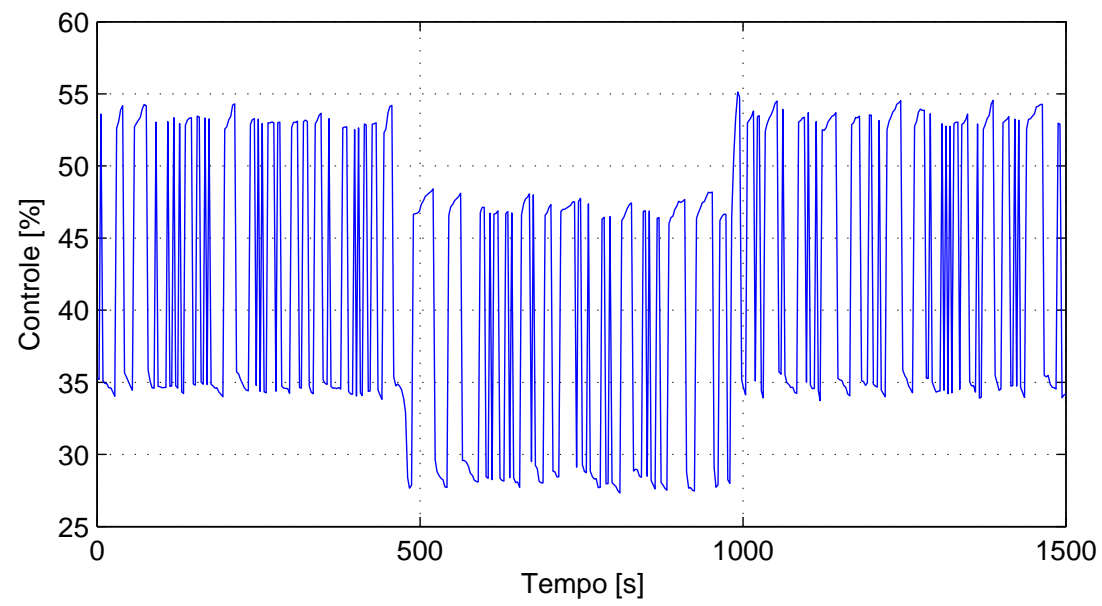

Fonte: Autor.

Figura 143: Posição da haste da válvula com o compensador CR2 para o modo regulatório.

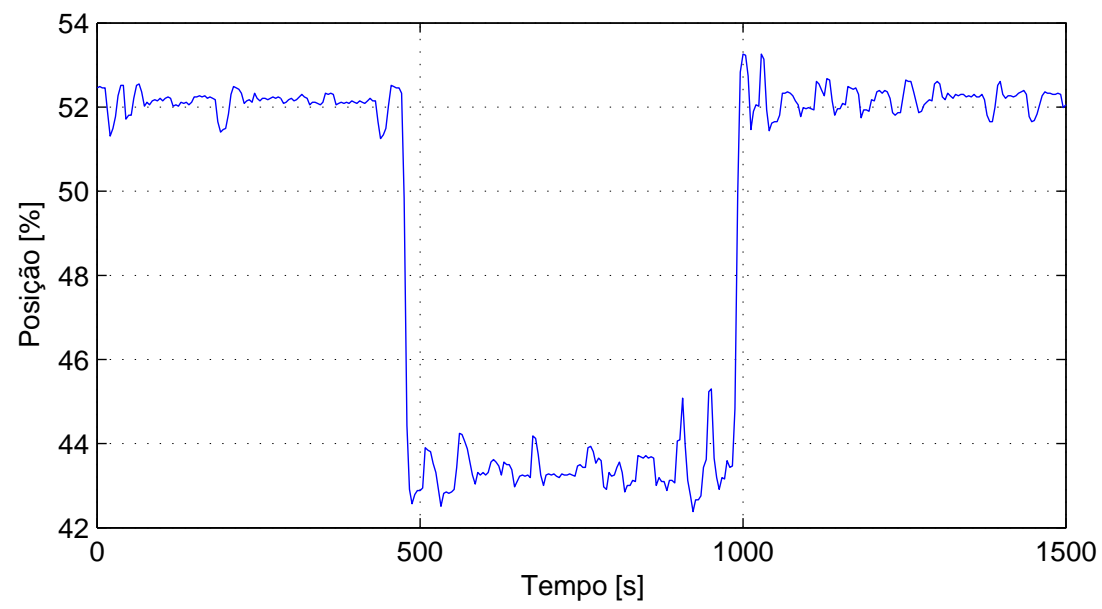

Fonte: Autor. 
Figura 144: Vazão obtida com o compensador Knocker para o modo regulatório.

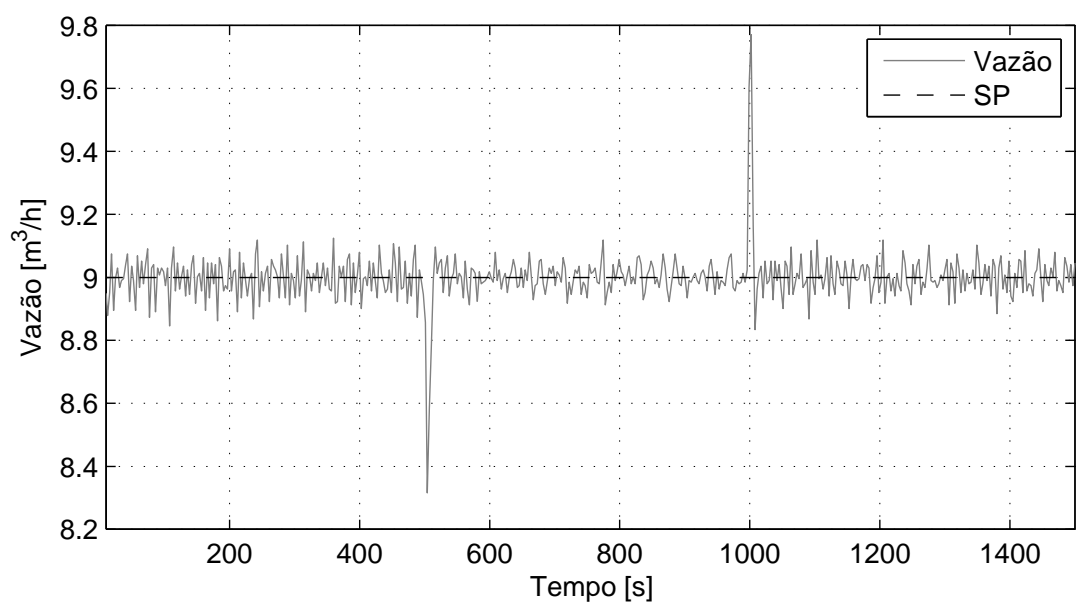

Fonte: Autor.

Figura 145: Sinal de controle do compensador Knocker para o modo regulatório.

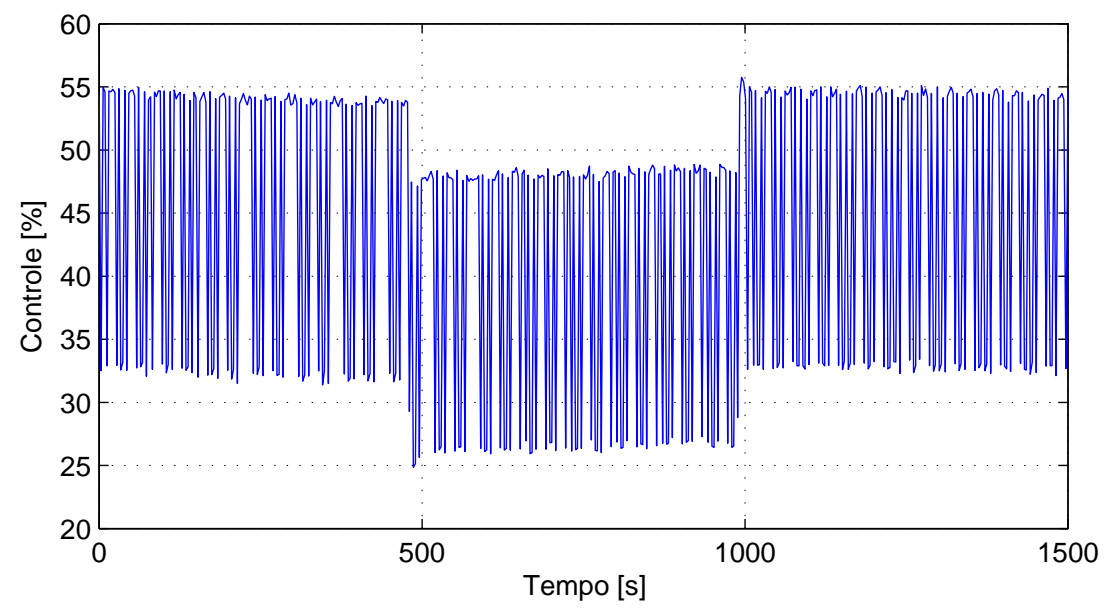

Fonte: Autor.

Figura 146: Posição da haste da válvula com o compensador Knocker para o modo regulatório.

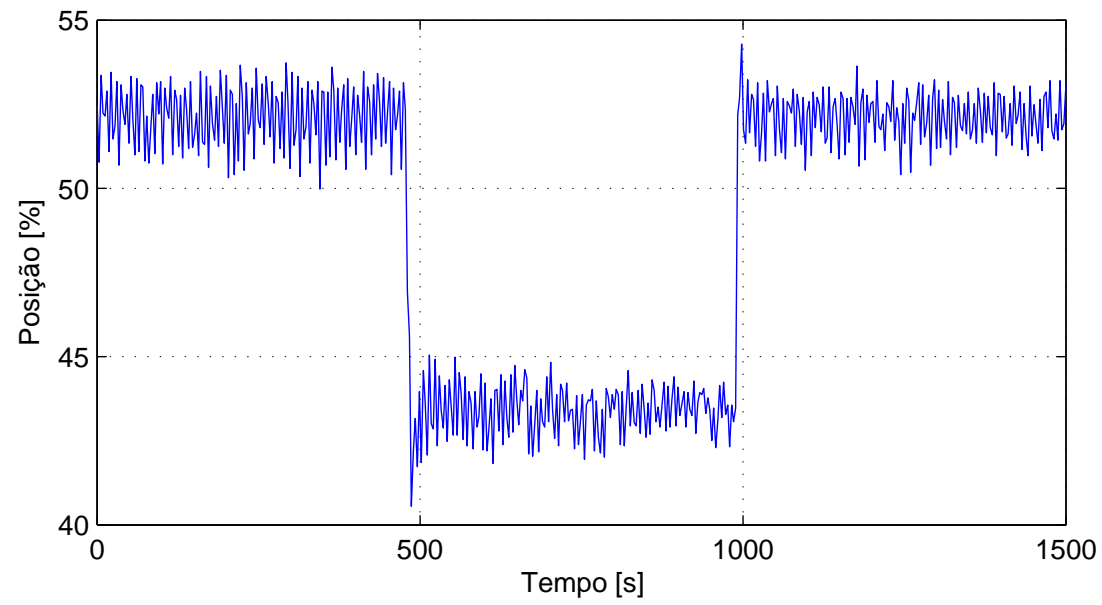

Fonte: Autor. 
Figura 147: Vazão obtida com o compensador Two-move para o modo regulatório.

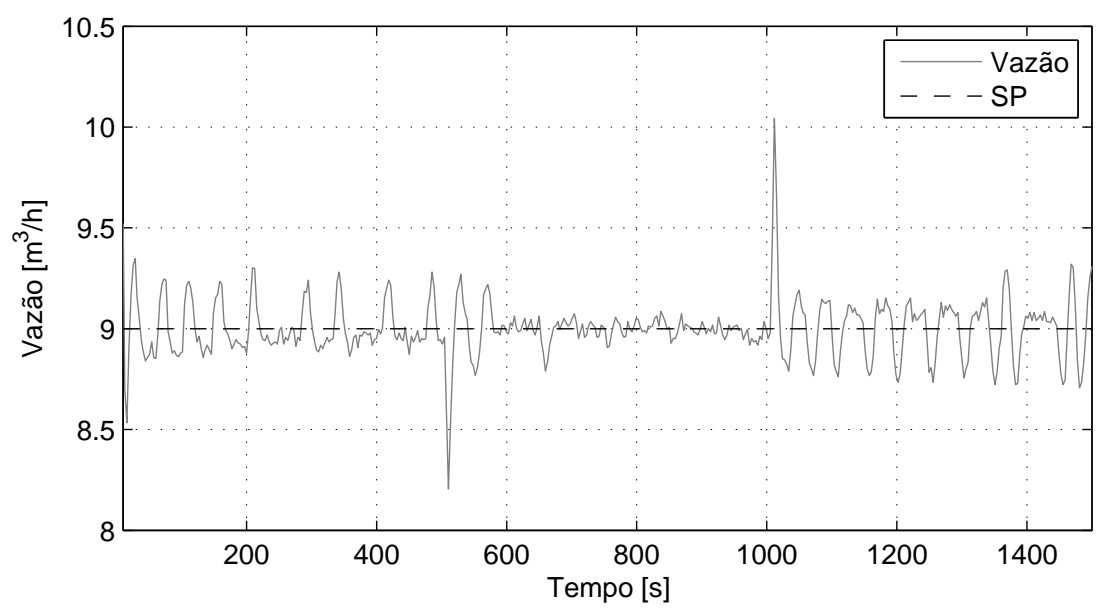

Fonte: Autor.

Figura 148: Sinal de controle do compensador Two-move para o modo regulatório.

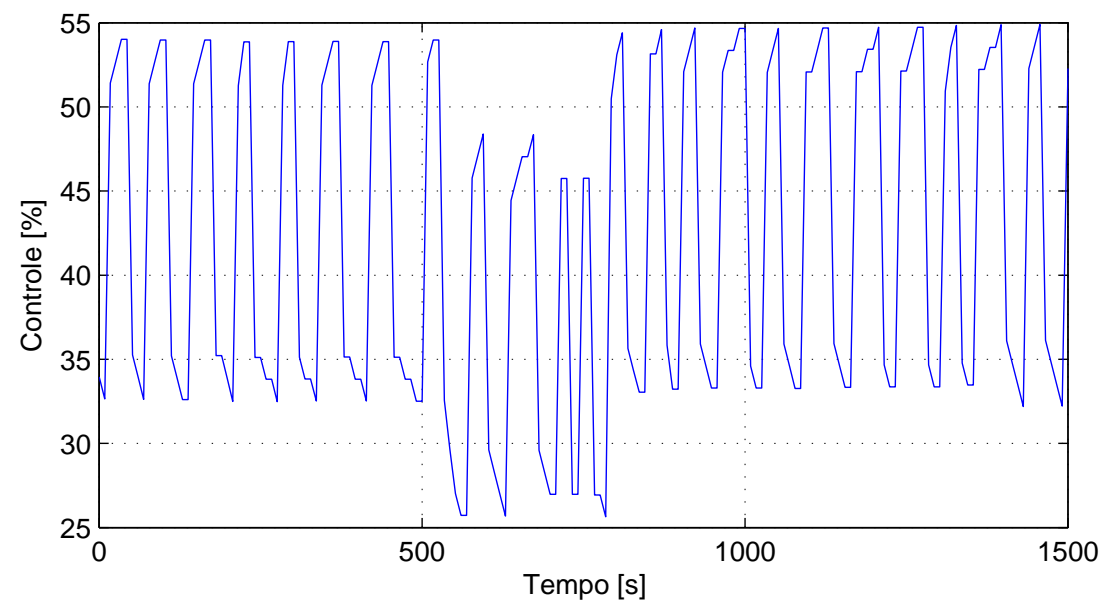

Fonte: Autor.

Figura 149: Posição da haste da válvula com o compensador Two-move para o modo regulatório.

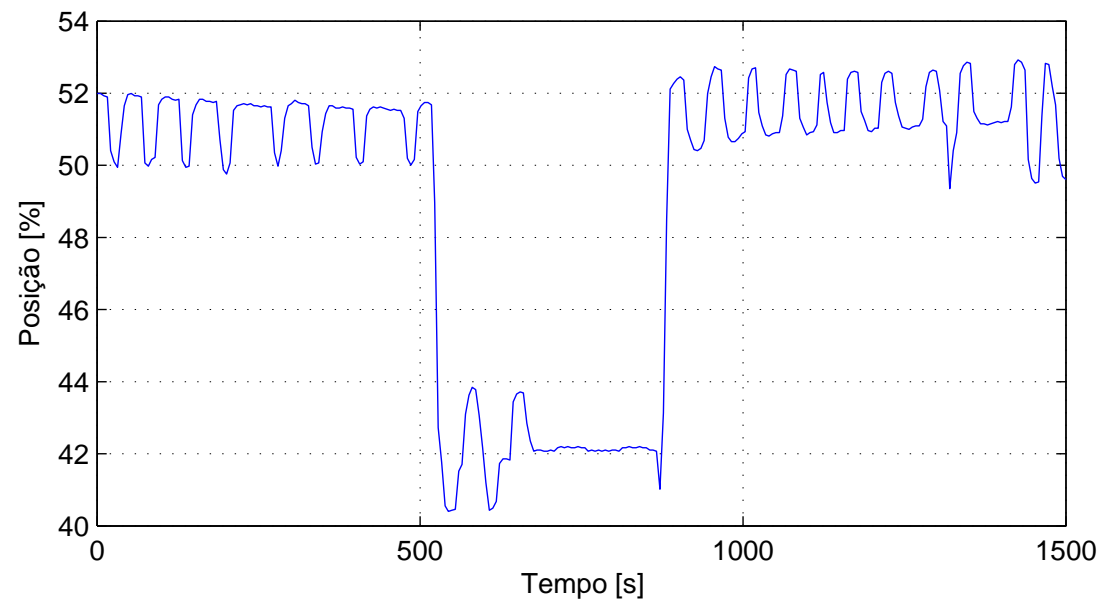

Fonte: Autor. 
Figura 150: Vazão com o controlador por modos deslizantes com chattering para o modo regulatório.

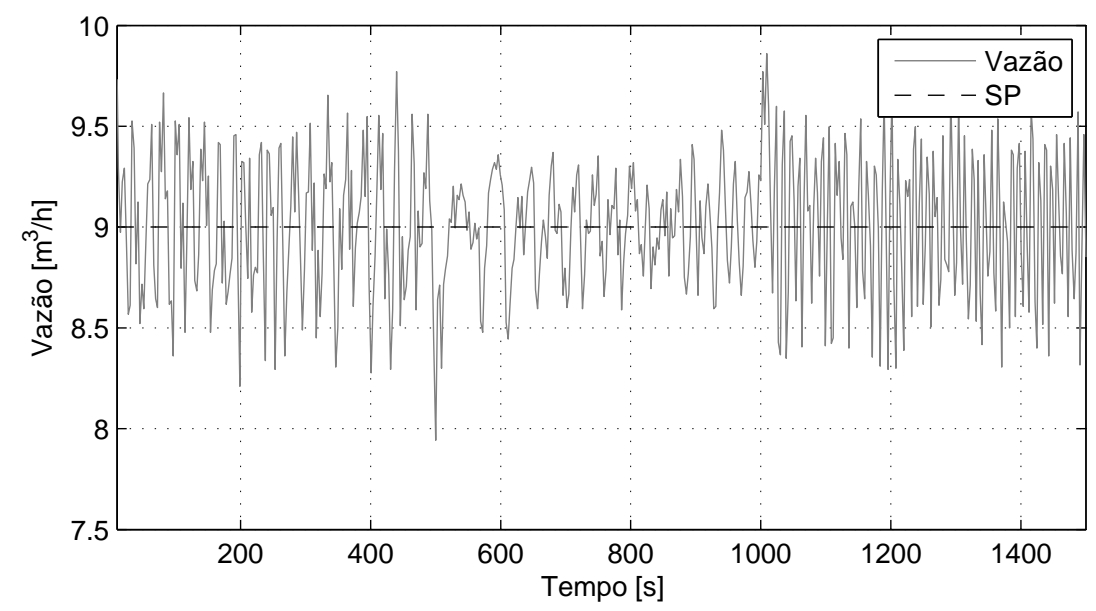

Fonte: Autor.

Figura 151: Sinal de controle do controlador por modos deslizantes com chattering para o modo regulatório.

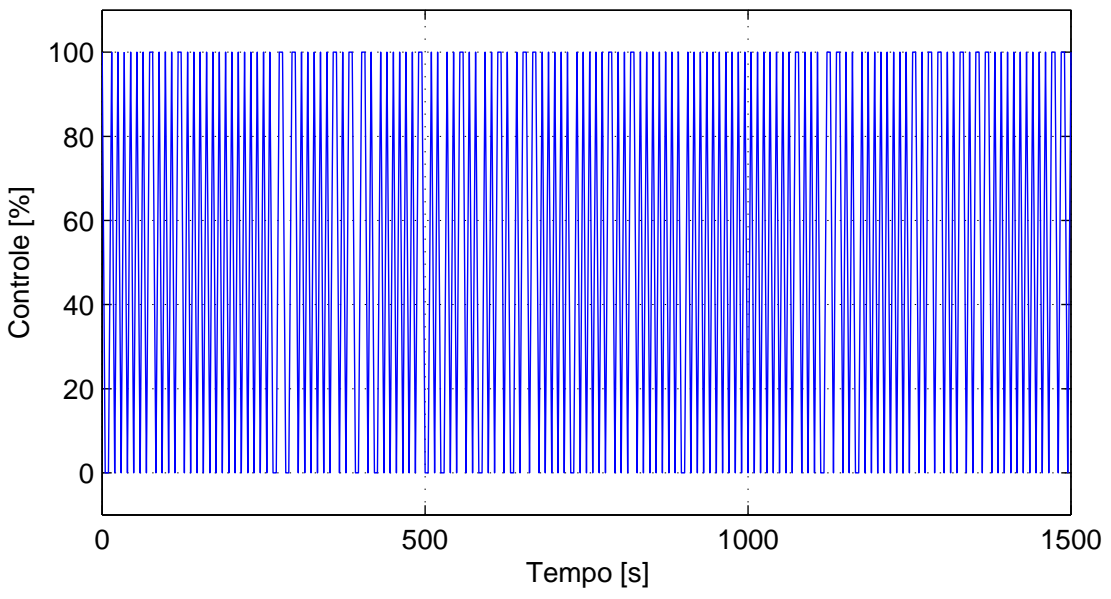

Fonte: Autor.

Os controladores por modos deslizantes integrador mostraram piores índices de desempenho do que os outros compensadores e um aumento no desgaste da válvula de controle. Todos os controladores por modos deslizantes conseguem levar a superfície de escorregamento ao redor do zero, porém, devido ao período de amostragem, o controlador não consegue ser suficientemente rápido para mudar o sinal de controle.

Na Tabela 21 pode-se ver todos os índices obtidos nos resultados práticos no modo regulatório da Planta de Vazão. Os compensador CR2 foi quem apresentao melhores resultados, conseguindo compensar o atrito na válvula de controle. Conseguiu melhorar os índices ITAE e IAE e diminuiu o desgaste gerado na válvula, conforme indica o índice $D_{v}$ ". 
Figura 152: Posição da haste da válvula com o controlador por modos deslizantes com chattering para o modo regulatório.

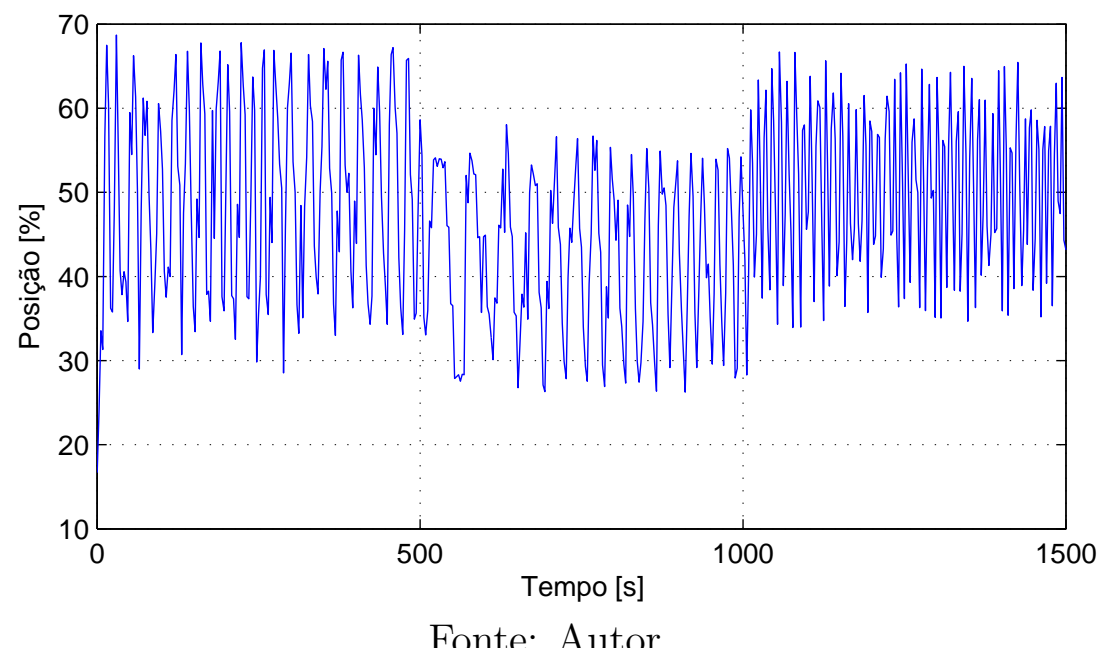

Figura 153: Superfície de escorregamento do controlador por modos deslizantes com chattering para o modo regulatório.

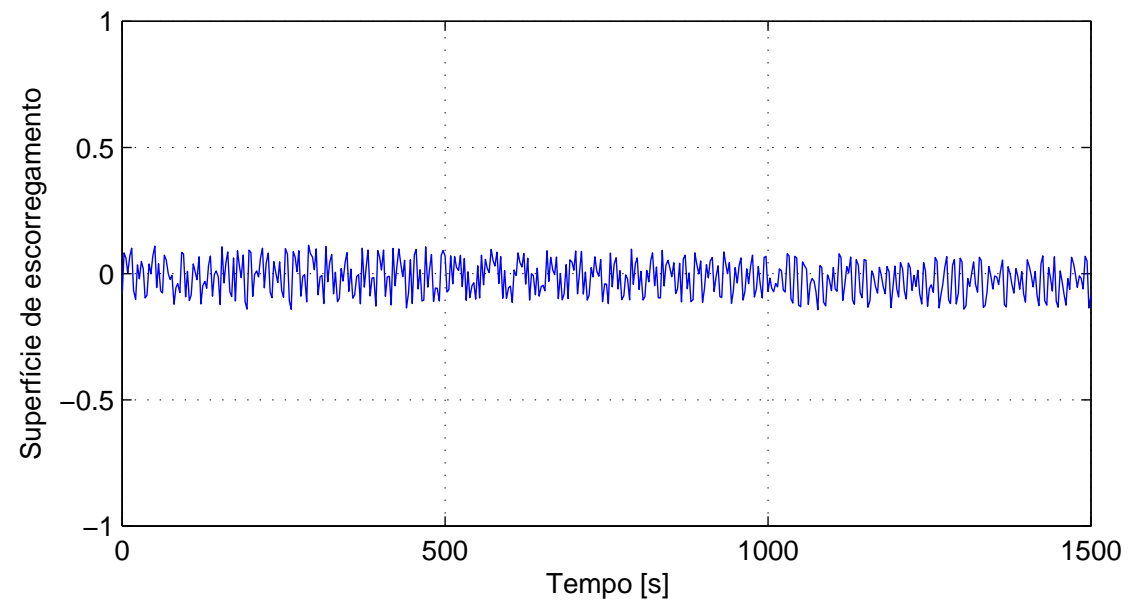

Fonte: Autor.

Figura 154: Vazão para o controlador por modos deslizantes sem chattering para o modo regulatório.

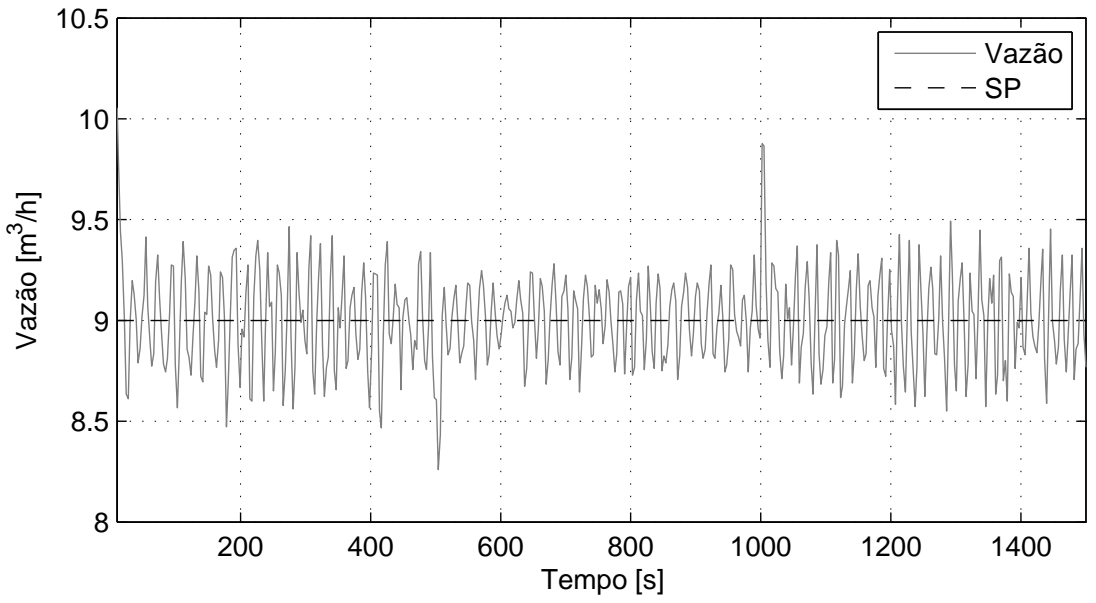

Fonte: Autor. 
Figura 155: Sinal de controle do controlador por modos deslizantes sem chattering para o modo regulatório.

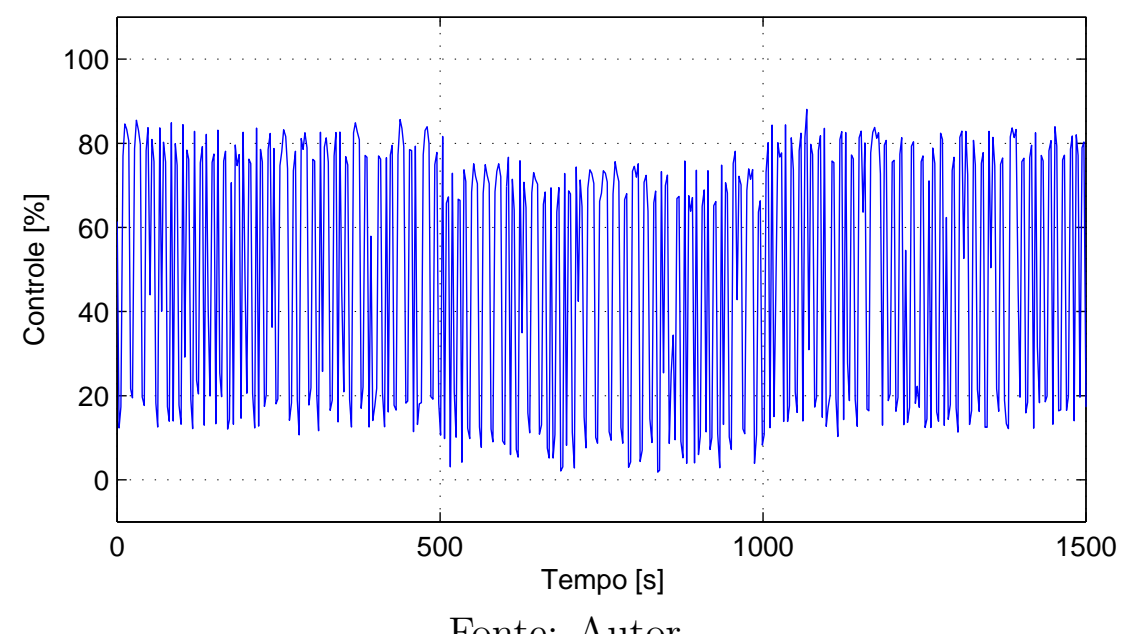

Fonte: Autor.

Figura 156: Posição da haste da válvula com o controlador por modos deslizantes sem chattering para o modo regulatório.

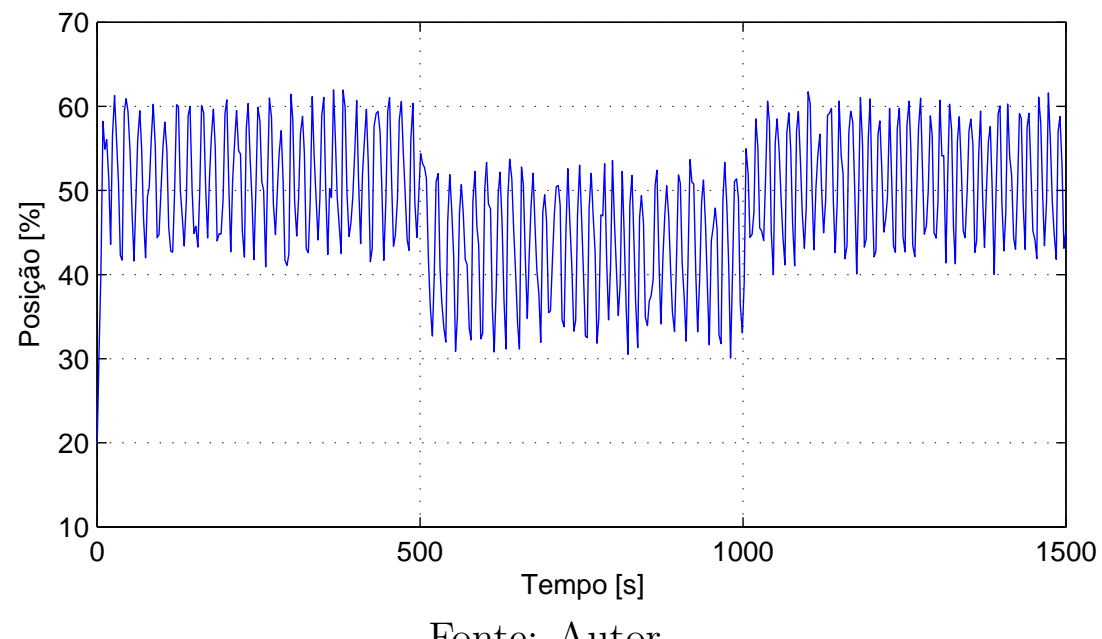

Fonte: Autor.

Figura 157: Superfície de escorregamento do controlador por modos deslizantes com chattering para o modo regulatório.

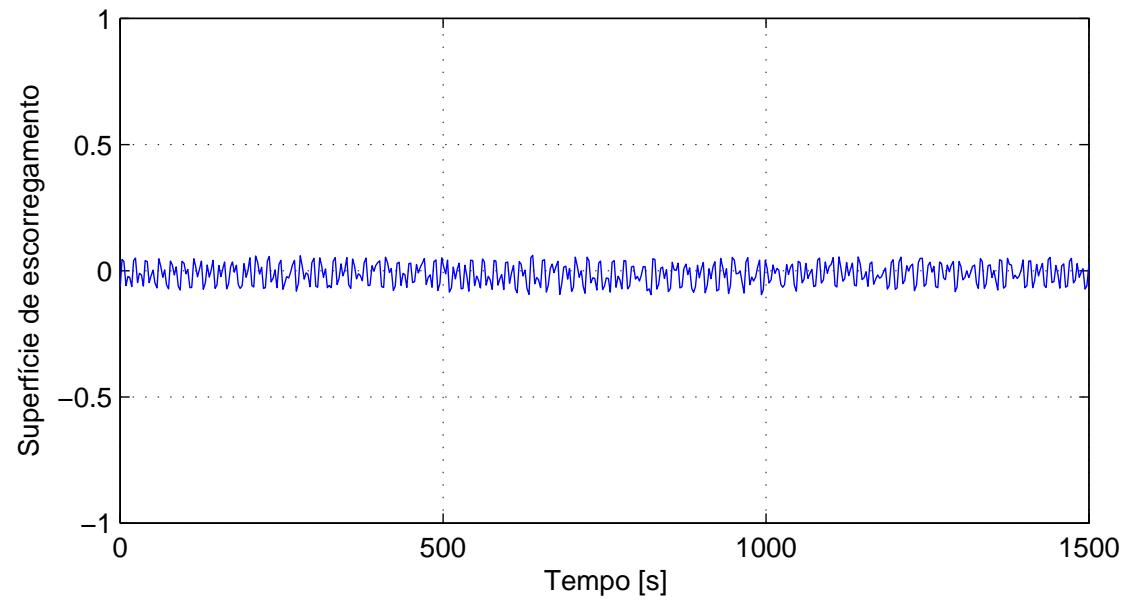

Fonte: Autor. 
Figura 158: Vazão com o controlador por modos deslizantes integrador com chattering para o modo regulatório.

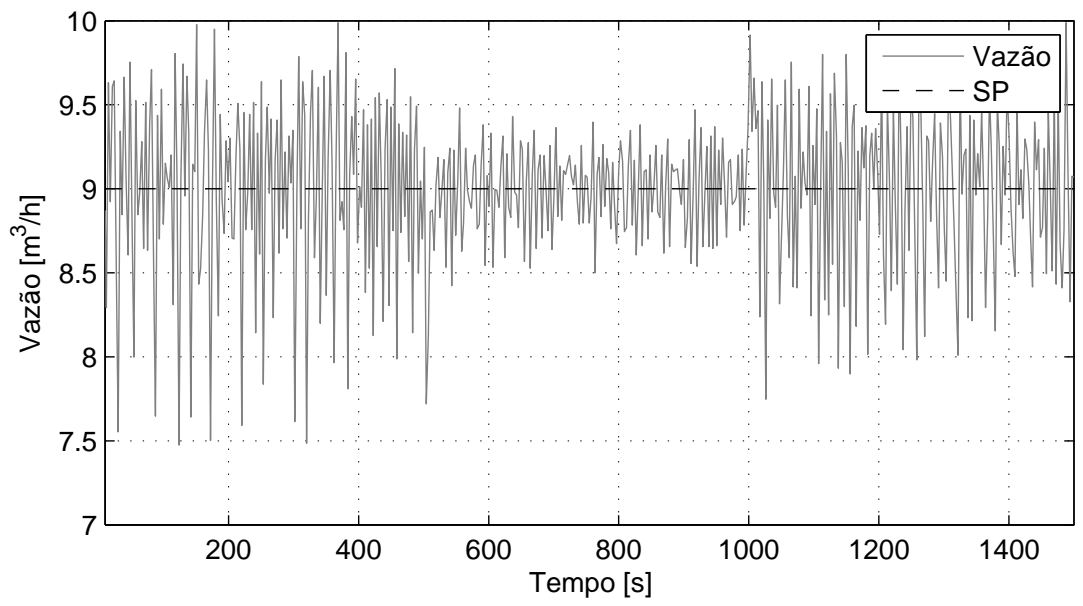

Fonte: Autor.

Figura 159: Sinal de controle com o controlador por modos deslizantes integrador com chattering para o modo regulatório.

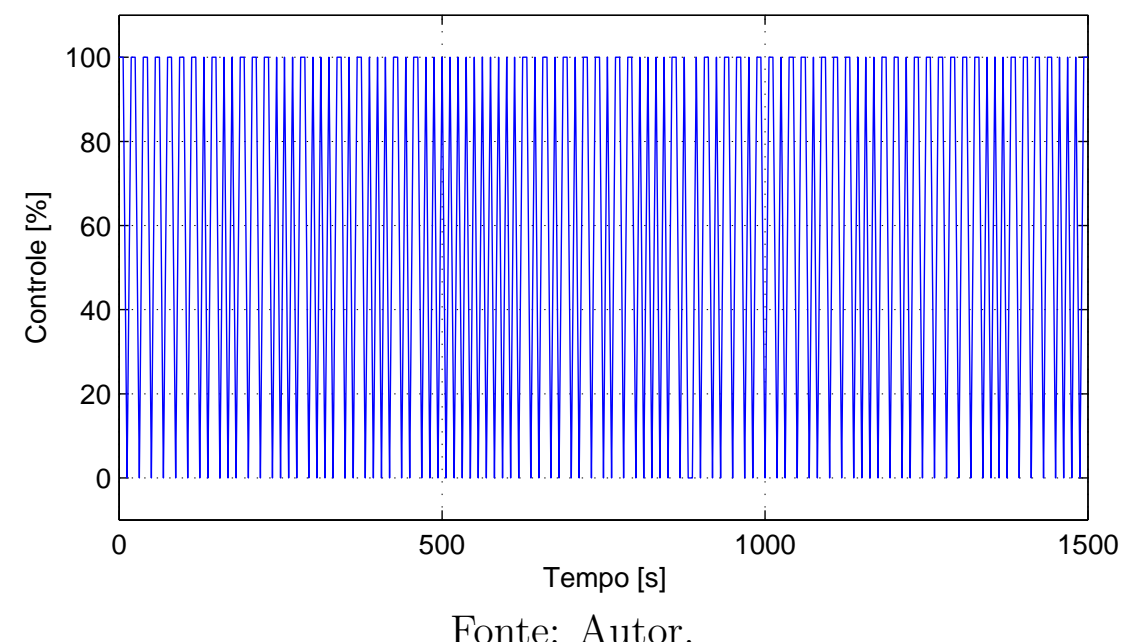

Figura 160: Posição da haste da válvula com o controlador por modos deslizantes integrador com chattering para o modo regulatório.

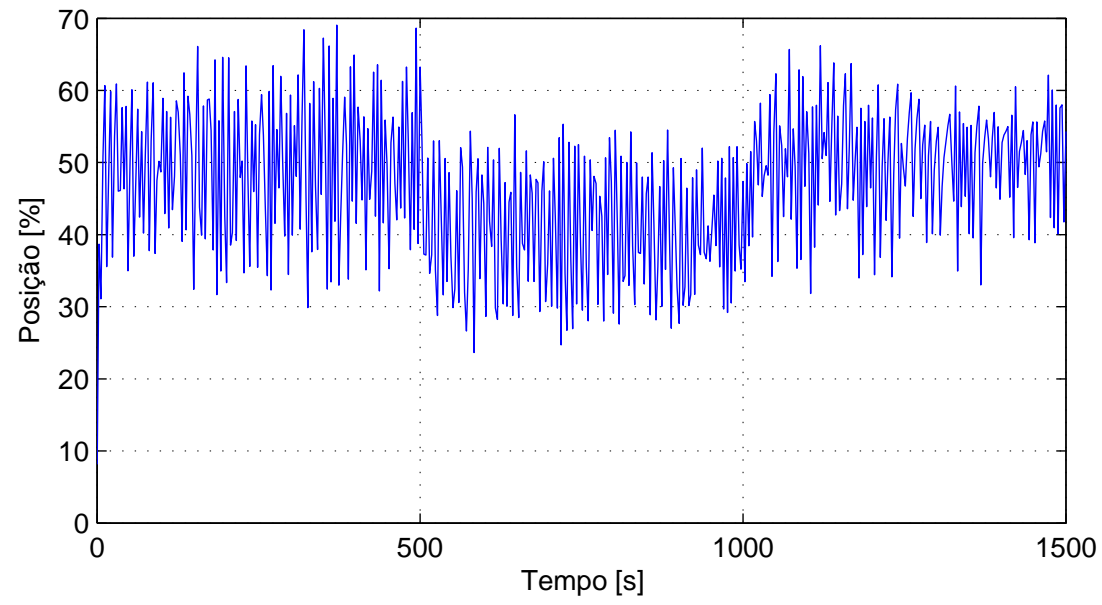

Fonte: Autor. 
Figura 161: Superfície de escorregamento com o controlador por modos deslizantes integrador com chattering para o modo regulatório.

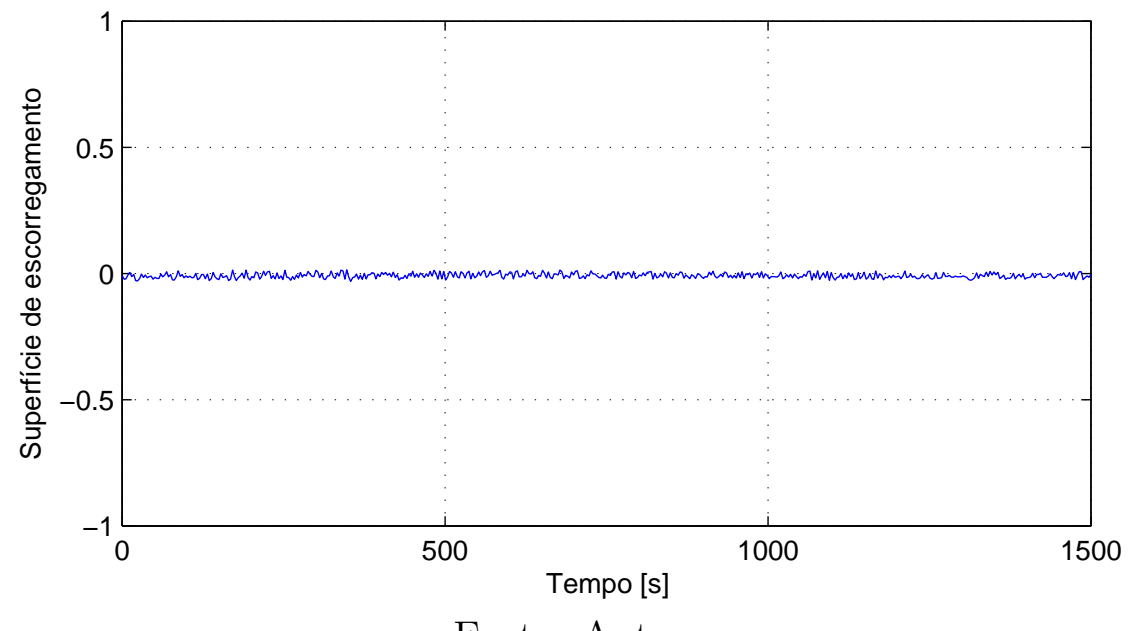

Figura 162: Vazão com o controlador por modos deslizantes integrador sem chattering para o modo regulatório.

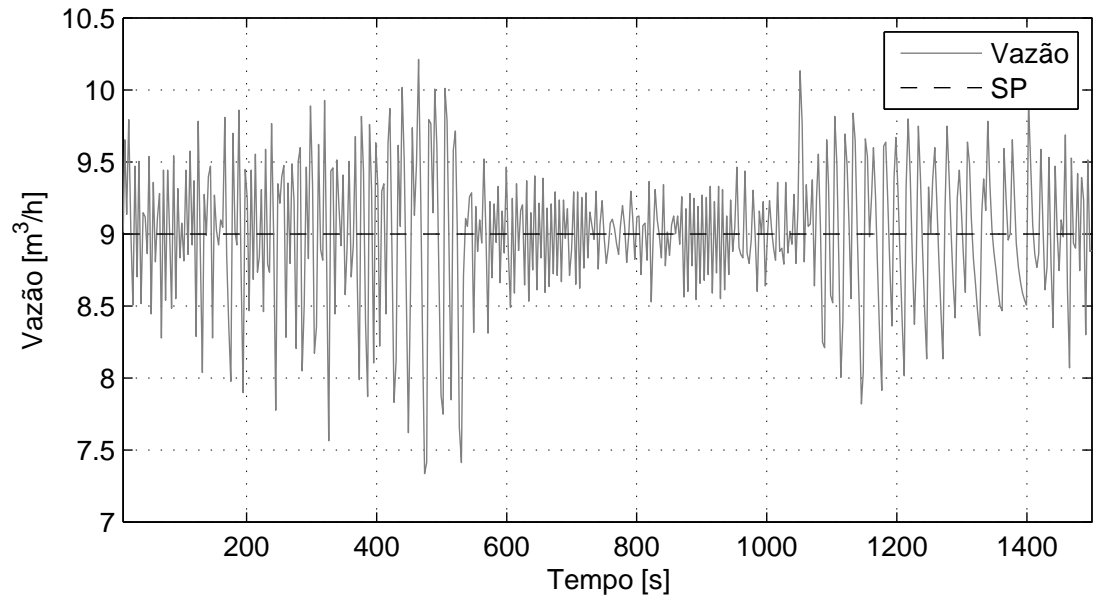

Fonte: Autor.

Figura 163: Sinal de controle com o controlador por modos deslizantes integrador sem chattering para o modo regulatório.

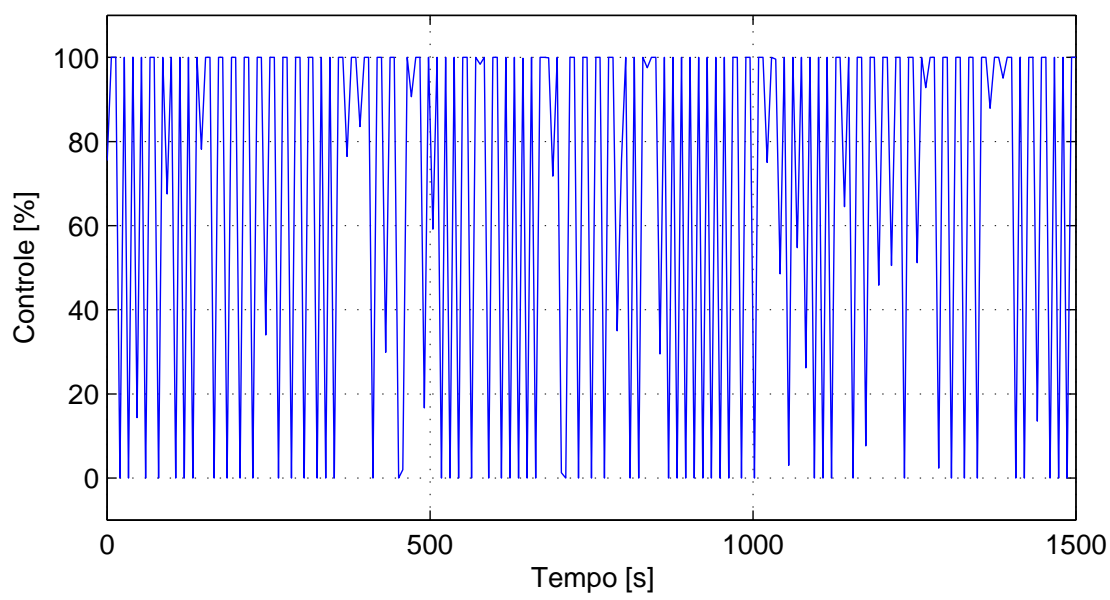

Fonte: Autor. 
Figura 164: Posição da haste da válvula com o controlador por modos deslizantes integrador sem chattering para o modo regulatório.

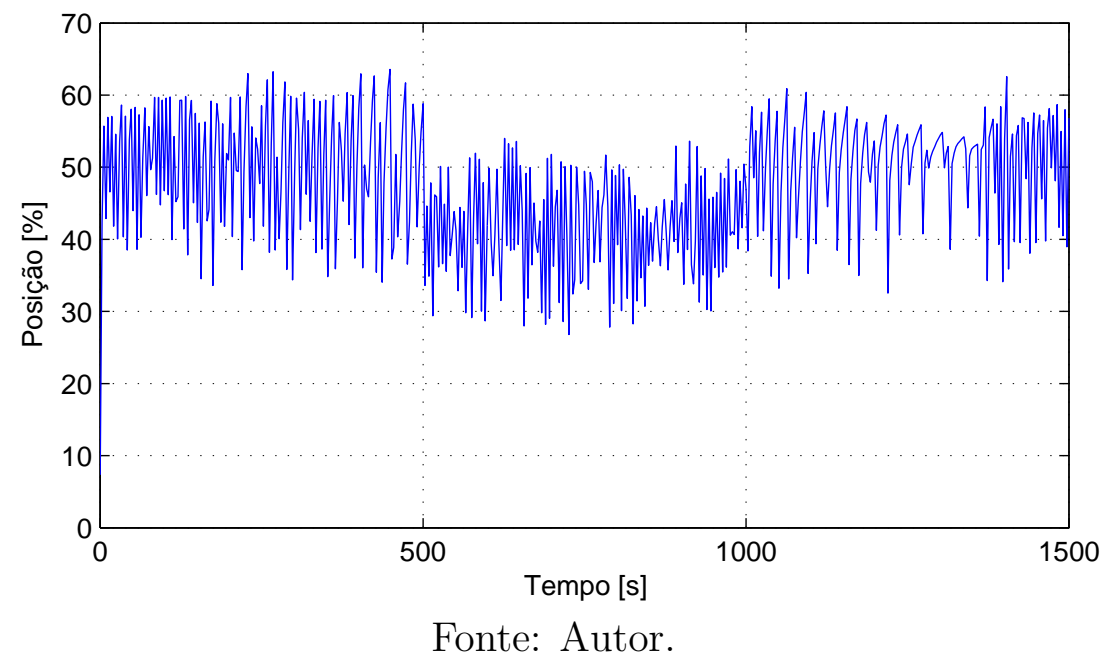

Figura 165: Superfície de escorregamento do controlador por modos deslizantes integrador sem chattering para o modo regulatório.

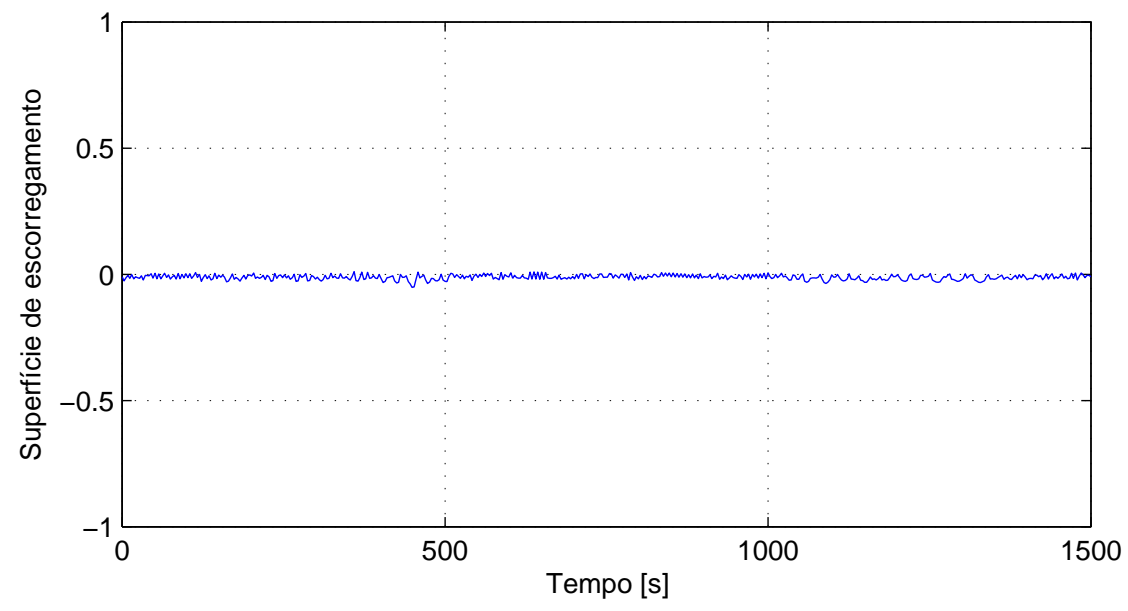

Fonte: Autor.

Tabela 21: Índices de desempenho dos compensadores e controladores de atrito para o modo regulatório.

\begin{tabular}{cccc}
\hline Ensaio & ITAE [\%] & IAE [\%] & $D_{v}[\%]$ \\
\hline PI com $T_{i}=2,5317 \mathrm{~s}$ & 23,95 & 49,7860 & 35,8129 \\
PI com $T_{i}=12 \mathrm{~s}$ & 68,4842 & 142,8988 & 58,4775 \\
PI com $T_{i}=16 \mathrm{~s}$ & 71,4831 & 155,9514 & 62,9296 \\
CR1 & 9,1280 & 26,7138 & 262,64 \\
CR2 & 11,2538 & 29,7724 & 29,7724 \\
Knocker & 10,9452 & 30,8463 & 643,5325 \\
Two-Move & 23,7294 & 54,8119 & 112,6497 \\
MDC & 70,4581 & 145,0543 & 4653,6 \\
MDS & 45,6975 & 101,2480 & 3080,1 \\
MDIC & 86,3786 & 186,1681 & 6634,4 \\
MDIS & 86,4337 & 188,8882 & 5045 \\
\hline
\end{tabular}


Figura 166: Diagrama de barras para o índice ITAE $(T=10 \mathrm{~ms})$.

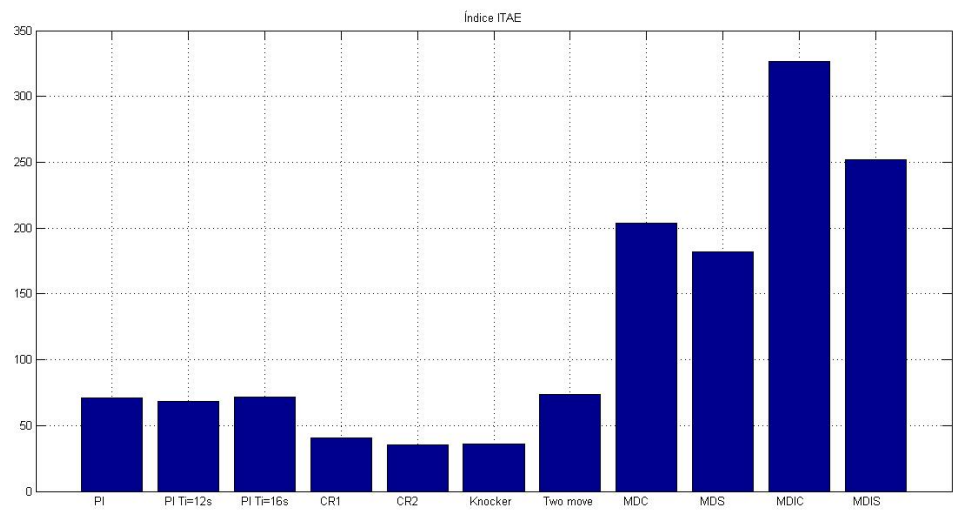

Fonte: Autor.

Figura 167: Diagrama de barras para o índice IAE ( $T=10 \mathrm{~ms})$.

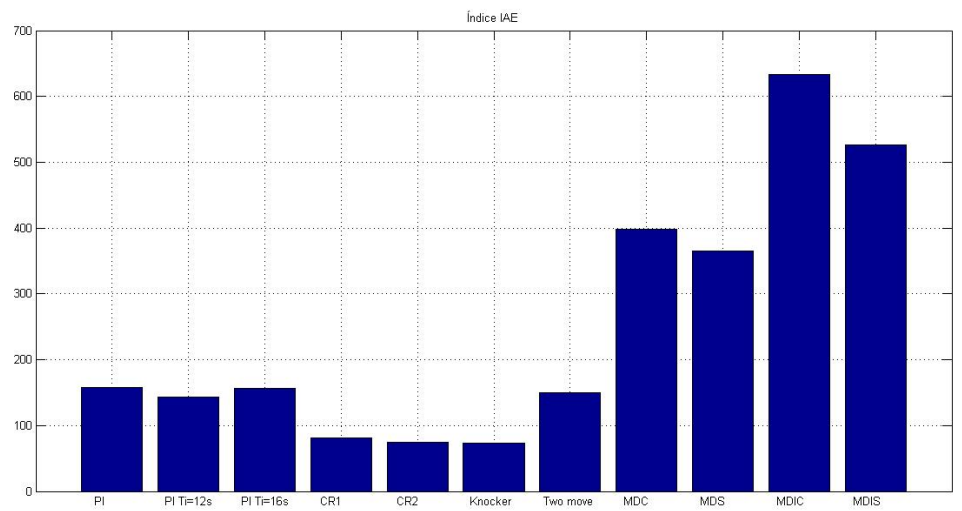

Fonte: Autor.

Figura 168: Diagrama de barras para o tempo de subida $(T=10 \mathrm{~ms})$.

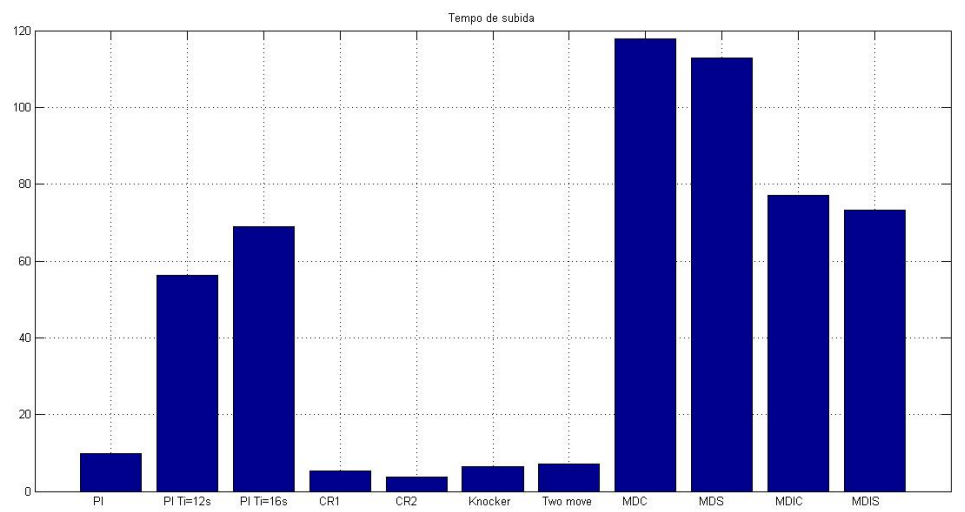

Fonte: Autor. 
Figura 169: Diagrama de barras para o índice $D_{v}(T=10 \mathrm{~ms})$.

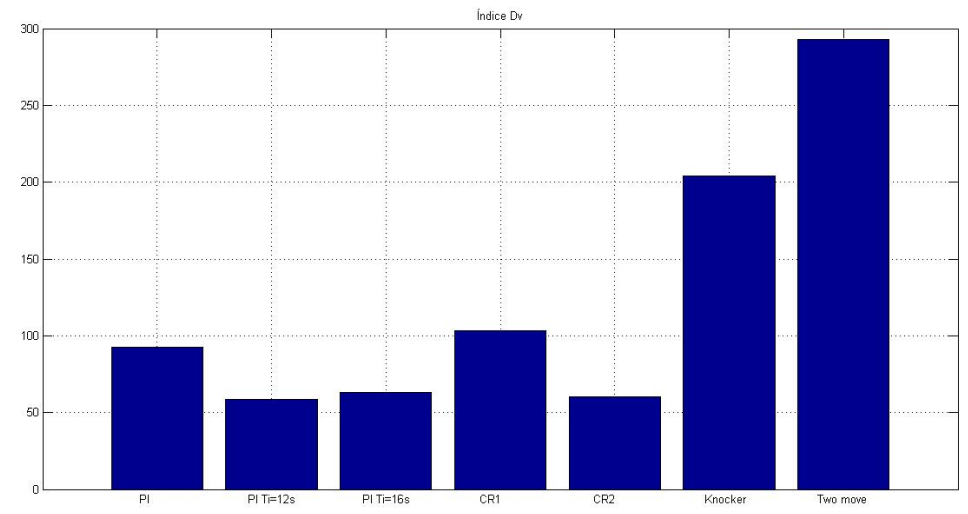

(a) Índice $D_{v}$ para os controladores PI e compensadores.

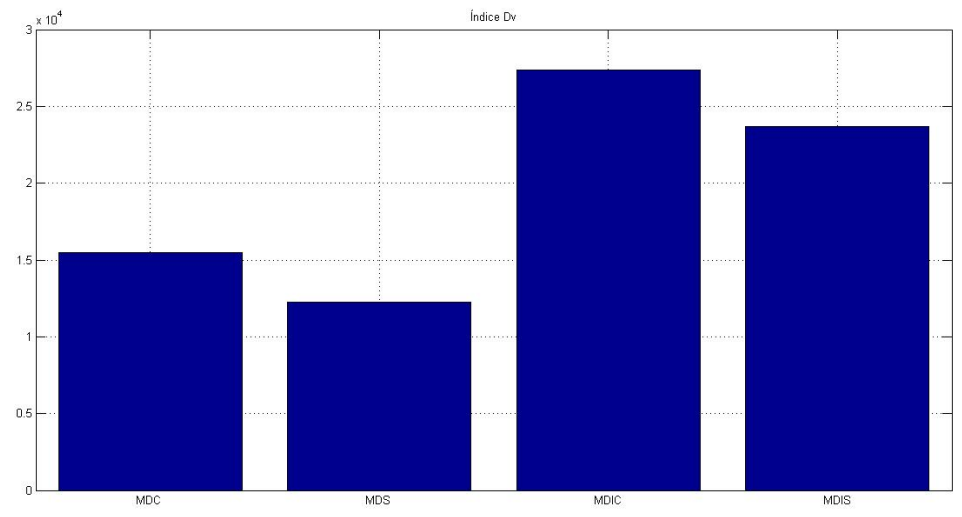

(b) Índice $D_{v}$ para os controladores por modos deslizantes.

Figura 170: Diagrama de barras para o índice ITAE $(T=0,5 \mathrm{~s})$.

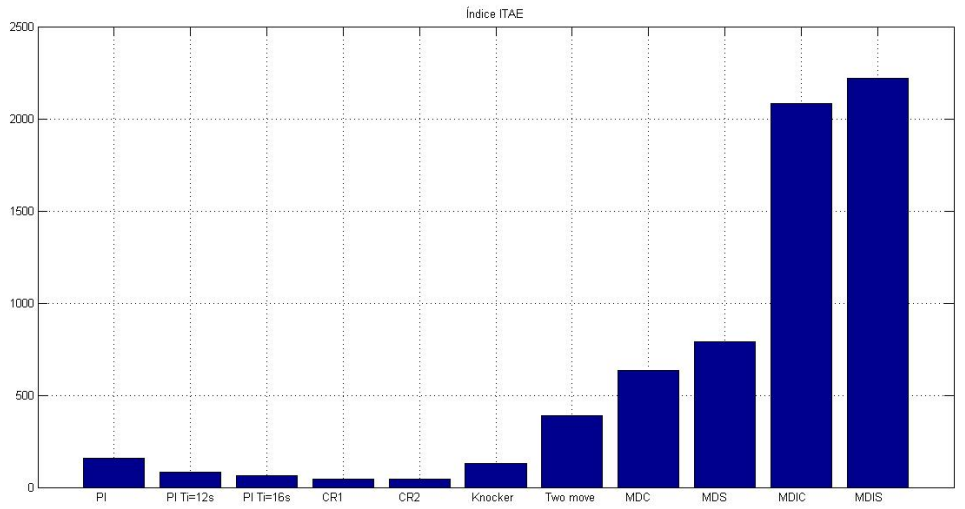

Fonte: Autor. 
Figura 171: Diagrama de barras para o índice IAE $(T=0,5 \mathrm{~s})$.

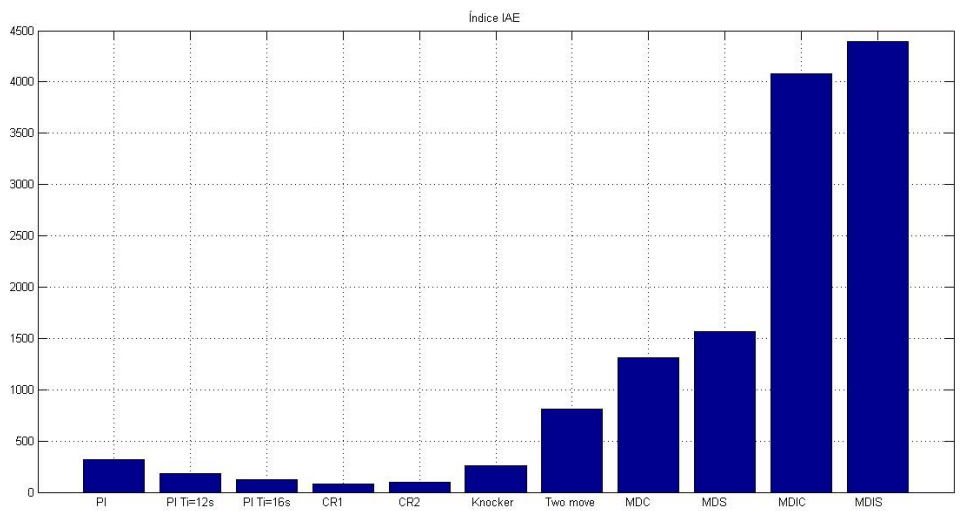

Fonte: Autor.

Figura 172: Diagrama de barras para o tempo de subida $(T=0,5 \mathrm{~s})$.

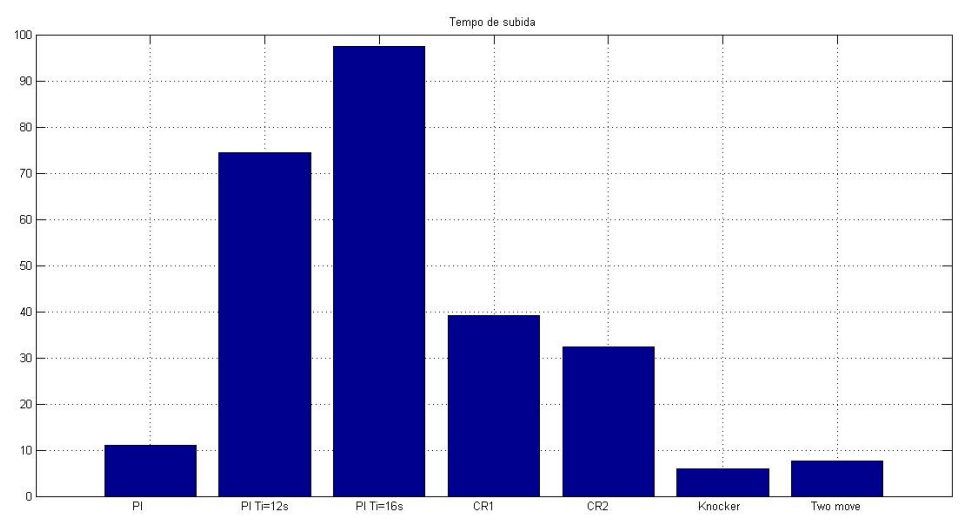

Fonte: Autor. 
Figura 173: Diagrama de barras para o índice $D_{v}(T=0,5 \mathrm{~s})$.

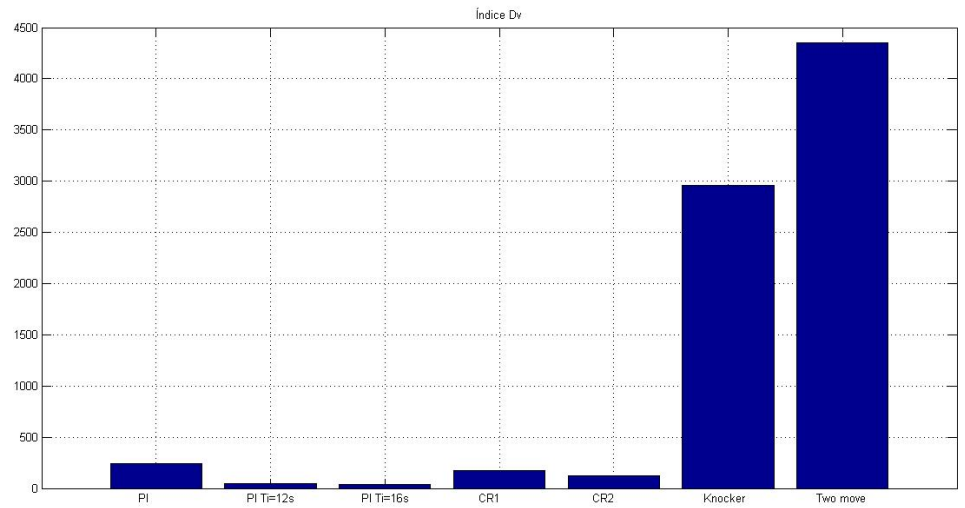

(a) Índice $D_{v}$ para os controladores PI e compensadores.

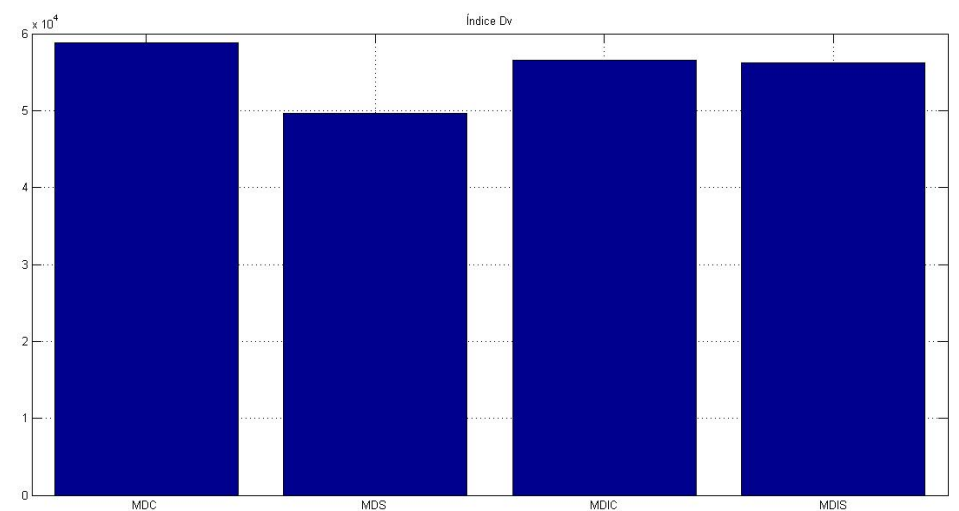

(b) Índice $D_{v}$ para os controladores por modos deslizantes. 


\section{Conclusões}

Este capítulo apresenta as conclusões de todos os resultados obtidos neste trabalho de Mestrado. Na primeira parte vai-se falar sobre os resultados obtidos com o modelo da válvula com gaxetas de grafite. A seguir são analisados os resultados práticos obtidos com os compensadores de atrito com o período de amostragem de $10 \mathrm{~ms}$ e 0,5 s. Também se apresentam conclusões referentes aos resultados práticos dos compensadores de atrito com o período de amostragem de $0,5 \mathrm{~s}$, tanto no modo servo como no modo regulatório. Finalmente, são apresentadas algumas sugestões para trabalhos futuros.

\subsection{Análise dos resultados para o modelo da válvula com gaxetas de grafite}

O trabalho apresentou as simulações de quatro compensadores de atrito: compensador CR1, compensador CR2, compensador Knocker e compensador Two-move. Também apresentou as simulações de dois controladores não lineares: Controlador por Modos Deslizantes e Controlador por Modos Deslizantes Integrador. Foi discutida a teoria de cada controlador com a finalidade de implementar cada técnica e avaliar o seu desempenho em uma válvula de controle real.

O principal objetivo das simulações é verificar o desempenho dos compensadores de atrito e verificar a coerência no momento da implementação na válvula real. Também foi a base para a sintonia e o projeto dos controladores na válvula de controle real.

Ao analisar os resultados dos controladores PI, as simulações indicam que ao aumentar o tempo integral, a frequência e a amplitude das oscilações na variável de processo geradas pelo alto índice de atrito na válvula de controle diminuem. Os índices de desempenho mostram que o controlador PI com $T_{i}=12 \mathrm{~s}$ foi a sintonia que apresentou melhor desempenho, diminuindo os índices ITAE e IAE, assim como também diminuiu o desgaste da válvula indicado pelo índice $D_{v}$.

Analisando-se os resultados obtidos nas simulações para os compensadores de atrito, pode-se ver que os compensadores conseguem reduzir as oscilações da variável de processo. Segundo os índices, só o compensador Knocker não conseguiu melhorar os índices ITAE e IAE. O compensador Two-move foi quem teve o melhor desempenho em termos dos índices ITAE e IAE. Nenhum dos compensadores melhorou o desgaste da válvula, eles 
aumentaram de forma dramática o desgaste gerado na válvula, como sugere o índice $D_{v}$.

As simulações para os controladores não lineares (Modos Deslizantes e Modos Deslizantes Integrador) mostraram que os controladores também conseguem eliminar as oscilações. A superfície de escorregamento permite analisar que os controladores estão trabalhando de forma certa, mas não conseguem reduzir a variabilidade da variável controlada, isto gera um aumento no movimento na posição da haste da válvula e, portanto aumenta o desgaste. Segundo os índices de desempenho, só o controlador por modos deslizantes com chattering não consegue melhorar o índice ITAE. Quanto ao índice IAE, os controladores por modos deslizantes integrador conseguem diminuir esse índice. Nenhum controlador conseguiu reduzir o desgaste na válvula de controle.

Ao finalizar as simulações se pode dizer que os compensadores e controladores tiveram uma boa resposta, portanto tomando como ponto de partida os compensadores e controladores projetados, foi possível continuar a implementação, mas agora no SDCD da ABB.

\subsection{Análise dos resultados para os compensadores de atrito}

No capítulo 6 se apresentaram os resultados para todos os compensadores e controladores da válvula de controle real com gaxetas de grafite, por meio do SDCD da ABB. A seguir se comentam os resultados obtidos para os períodos de amostragem de $10 \mathrm{~ms}$ e 0,5 s.

\subsubsection{Análise dos resultados para os compensadores de atrito para o período de amostragem de $10 \mathrm{~ms}$}

Para o controlador PI e a suas diferentes $\operatorname{sintonias}\left(T_{i}=2,5317 \mathrm{~s}, T_{i}=12 \mathrm{~s}\right.$ e $T_{i}=16$ s), obtiveram-se resultados muito semelhantes aos obtidos nas simulações. Neste caso, também ao aumentar o tempo integral, consegue-se diminuir a frequência das oscilações da variável de processo. Analisando-se os índices de desempenho, o ITAE foi muito parecido nos três casos, só a sintonia com tempo integral de $12 \mathrm{~s}$ conseguiu melhorar este índice. No caso do índice IAE, as duas sintonias $\left(T_{i}=12 \mathrm{~s}\right.$ e $\left.T_{i}=16 \mathrm{~s}\right)$ conseguiram melhorá-lo e o desgaste gerado na válvula de controle foi reduzido, conforme indica o índice $D_{v}$.

Observando-se os resultados obtidos para os compensadores de atrito, pode-se ver que conseguem eliminar as oscilações da variável de processo. Os compensadores CR1, CR2 e Knocker mostraram uma boa melhora ao reduzir os índices ITAE e IAE. Os compensadores CR1 e CR2 também conseguiram diminuir o desgaste gerado na válvula de controle dado pelo índice $D_{v}$, portanto, pode-se dizer que o compensador CR2 foi quem apresentou o melhor desempenho segundo os índices ITAE, IAE e $D_{v}$. 
Os controladores por Modos Deslizantes e Modos Deslizantes Integrador não conseguiram melhorar nenhum índice de desempenho. Além disso, o aumento no desgaste da válvula é drástico. Portanto, entre as sintonias PI, compensadores e controladores, foi o compensador CR2 quem apresentou o melhor desempenho.

\subsubsection{Análise dos resultados para os compensadores de atrito para o período de amostragem de $0,5 \mathrm{~s}$}

Para o controlador PI e a suas diferentes sintonias $\left(T_{i}=2,5317 \mathrm{~s}, T_{i}=12 \mathrm{~s}\right.$ e $T_{i}=16$ s), pode-se ver que ao aumentar o tempo integral, consegue-se diminuir a frequência das oscilações da variável de processo. As duas sintonia com tempo integral aumentado conseguiram melhorar todos os índice de desempenho. A sintonia com $T_{i}=16 \mathrm{~s}$ foi quem conseguiu o menor índice ITAE e IAE e quem mais melhorou o desgaste gerado na válvula de controle, dado pelo índice $D_{v}$.

Observando-se os resultados obtidos para os compensadores de atrito, assim como nos resultados obtidos para o período de amostragem de $10 \mathrm{~ms}$, pode-se ver que os compensadores CR1, CR2 e Knocker conseguiram reduzir os índices ITAE e IAE. Os compensadores CR1 e CR2 também conseguiram diminuir o desgaste gerado na válvula de controle, enquanto os compensadores Knocker e Two-move aumentaram dramaticamente o desgaste na válvula de controle, portanto, pode-se dizer que o controlador CR2 foi quem apresentou o melhor desempenho, com base nos índices ITAE, IAE e $D_{v}$.

Os controladores por Modos Deslizantes e Modos Deslizantes Integrador mostraram o pior desempenho para este período de amostragem. Não conseguiram melhorar nenhum índice de desempenho. Além disso, o aumento do desgaste na válvula foi o maior obtido neste trabalho. Então pode-se afirmar, que para processos industrias, os quais trabalham com períodos de amostragem na faixa de 0,5 a $1 \mathrm{~s}$, não é aconselhável usar estes controladores.

Portanto, depois de observar todos os resultados obtidos, pode-se concluir que os compensadores CR1 e CR2 oferecem um bom desempenho tanto para períodos de amostragem pequenos como para períodos de amostragem grandes e portanto são uma boa escolha para tentar compensar o atrito estático existente em válvulas de controle.

\subsubsection{Sugestões para trabalhos futuros}

Algumas propostas apresentadas para trabalhos futuros são:

- Implementar, junto com os compensadores, algoritmos de desabilitação de controle com a finalidade de tentar diminuir o desgaste gerado na válvula de controle, conforme sugerido em (CUADROS, 2012). 
- Implementar as demais técnicas de controladores não-lineares utilizadas em (BAEZA, 2013) no SDCD da ABB.

- Estudar e pesquisar novas possibilidades de projeto para os controladores por modos deslizantes e modos deslizantes integrador, como por exemplo, o uso de modos deslizantes de ordem superior. 


\section{Referências Bibliográficas}

AGOSTINHO, A. C. Controle por modos deslizantes aplicado a sistema de posicionamento dinâmico. Dissertação (Mestrado) — Escola Politécnica da USP. Departamento de Engenharia de Telecomunicações e Controle, 2009.

BAEZA, J. R. Controle não linear aplicado a malhas de controle com válvulas de alto atrito. Dissertação (Mestrado) — Escola Politécnica da USP. Departamento de Engenharia de Telecomunicações e Controle, 2013.

CHOUDhURY, M. A. A. S.; THORNHILL, N. F.; SHAH, S. L. A data-driven model for valve stiction. Proc IFAC Symposium on Advanced Control of Chemical Processes (ADCHEM), Hong Kong, 2004.

CHOUDHURY, M. A. A. S.; THORNHILL, N. F.; SHAH, S. L. Modelling valve stiction. Control Engineering Practice, v. 13, p. 641-658, 2005.

CUADROS, M. A. S. L. Novel model-free approach for stiction compensation in control valves. Industrial \& Chemical Research, v. 51, p. 8465-8476, 2012.

DANESHWAR, M. A.; NOH, N. M. Identification of a process with control valve stiction using a fuzzy system: A data-driven approach. Journal of Process Control, v. 24, p. 249-260, 2014.

EDWARDS, C.; SPURGEON, S. K. Sliding Mode Control: Theory and applications. 1. ed. [S.l.]: Taylor \& Francis, 1998.

ELY, V. E.; LONGHI, L. G. S. Desenvolvimento e implementação de um compensador de agarramento para válvulas de controle. Congresso Internacional de Automação, Sistemas e Instrumentação, São Paulo, 2011.

GARCIA, C. Comparison of friction models applied to a control valve. Control Engineering Practice, v. 16, p. 1231-1243, 2008.

HÄGGLUND, T. A friction compensator for pneumatic control valves. Journal of Process Control, v. 12, p. 897-904, 2002.

HÄGGLUND, T. Automatic on-line estimation of backlash in control loops. Journal of Process Control, v. 17, p. 489-499, 2007.

HÄGGLUND, T. A shape-analysis approach for diagnosis of stiction in control valves. Control Engineering Practice, v. 19, p. 782-789, 2011.

HIDALGO, M. C. Compensação de atrito em válvulas de controle: Técnicas usuais e inovações. Dissertação (Mestrado) - Escola Politécnica da USP. Departamento de Engenharia de Telecomunicações e Controle, 2015. 
ISA. Test procedures for control valve response measurement from step inputs. [S.1.], 2000. Technical Report ANSI/ISA-752501-2000.

ISA. Control valve diagnostic data acquistion and reporting. [S.1.], 2006. Technical Report ANSI/ISA-752601-2006.

ISIDORI, A. Nonlinear control systems an introduction. [S.l.]: Springer, 1988.

IVAN, L. Z. X.; LAKSHMINARAYANAN, S. A new unified approach to valve stiction quantification and compensation. Industrial and Engineering Chemistry Research, v. 48, p. 3474-3483, 2009.

KANO, M. et al. Pratical model and detection algorithm for valve stiction. In: 7th IFAC DYCOPS. Yokohama: [s.n.], 2004.

KAYIHAN, A.; DOYLE, F. J. Friction compensation for a process control valve. Control Engineering Practice, v. 8, p. 799-812, 2000.

KHALIL, H. K. Nonlinear systems. [S.l.]: Prentice Hall, 2002.

KVAM, A. Detection of stiction in Control Valves. Dissertação (Mestrado) - Norwegian University of Science and Technology, 2009.

MOHAMMAD, M. A.; HUANG, B. Compensation of control valve stiction through controller tuning. Journal of Process Control, v. 22-9, p. 1800-1819, 2012.

MOHIEDDINE, J.; HUANG, B. Detection and diagnosis of stiction in control loops. [S.l.]: Springer-Verlag, 2010.

MORA, J. A. Modelagem e simulação de uma planta piloto de vazão. Dissertação (Mestrado) - Escola Politécnica da USP. Departamento de Engenharia de Telecomunicações e Controle, 2014.

ROMANO, R. A. Identificação de processos não-lineares e quantificação de atrito em vávulas de controle. Tese (Doutorado) - Escola Politécnica da USP. Departamento de Engenharia de Telecomunicações e Controle, 2009.

ROMANO, R. A.; GARCIA, C. Karnopp friction model identification for a real control valve. $17^{\text {th }}$ IFAC World Congress of the International Federation of Automatic Control, Seul, p. 14906-14911, 2008.

SILVA, B. C. Avaliação da eficiência de compensadores de atrito aplicados a válvulas de controle. Dissertação (Mestrado) - Escola Politécnica da USP. Departamento de Engenharia de Telecomunicações e Controle, 2013.

SKILLSÄTER, C. Evaluation and Configuration of a Control Asset Monitoring Tool. Dissertação (Mestrado) - Department of Electrical Engineering - Linköping Universitet, 2011.

SLOTINE, J. J. E.; LI, W. Applied nonlinear control. [S.l.]: Prentice Hall, New Jersey, 1991. 
SRINIVASAN, R.; RENGASWAMY, R. Stiction compensation in process control loops: A framework for integrating stiction measure and compensation. Industrial and Engineering Chemistry Research, v. 44, p. 9164-9174, 2005.

SRINIVASAN, R.; RENGASWAMY, R. Approaches for efficient stiction compensation in process control valves. Computers \&f Chemical Engineering, v. 32, p. 218-229, 2008.

STENMAN, A.; GUSTAFSSON, F.; FORSMAN, K. A segmentation-based method for detection os stiction in control valves. International Journal of Adaptative Control and Signal Processing, v. 17, p. 625-634, 2003.

STRIBECK, R. Die wesentlichen eigenschaften der gleit und rollenlager - the key qualities of sliding and roller bearings. Zeitschrift des Vereines Seutscher Ingenieure, v. 46(38,39), p. 1342-48, 1432-37, 1902.

TAN L.; RAJA AHMAD, R. K.; IBRAHIM, M. N.; TAIP, F. S. Relationship of lamda and overshoot of the step response for a direct synthesis pi controller. Brazilian Journal of Chemical Engineering, v. 29, p. 537-547, 2011.

XIE, L.; CONG, Y.; HORCH, A. An improved valve stiction simulation model based on ISA standard tests. Control Engineering Practice, v. 21, p. 1359-1368, 2013. 